Universidade de São Paulo

Instituto de Astronomia, Geofísica e Ciências Atmosféricas

Departamento de Astronomia

Luiz Alberto de Paula

\title{
Estudo da formação e migração de um núcleo sólido planetário
}

"Versão Corrigida. O original encontra-se disponível na Unidade."

São Paulo 

Luiz Alberto de Paula

\section{Estudo da formação e migração de um núcleo sólido planetário}

"Versão Corrigida. O original encontra-se disponível na Unidade."

Dissertação apresentada ao Departamento de Astronomia do Instituto de Astronomia, Geofísica e Ciências Atmosféricas da Universidade de São Paulo como requisito parcial para a obtenção do título de Mestre em Ciências.

Área de Concentração: Astronomia

Orientadora: Prof. ${ }^{a}$ Dr. ${ }^{\text {a }}$ Tatiana Alexandrovna Michtchenko

São Paulo 

Aos meus pais, José e Sônia, pelo esforço e a dedicação em todos os momentos. Espero que tenham compreendido minha ausência durante a realização desta caminhada.

À minha mulher, Maristela, pelo apoio e a paciência, que não foi pouca, em todos os instantes desta importante etapa em minha vida.

Dedico também este trabalho a você leitor, pois espero, sinceramente, que ele possa saciar sua sede em vez da fome das traças da biblioteca. 



\section{Agradecimentos}

Escrever uma dissertação é uma experiência extremamente enriquecedora. No entanto, é uma tarefa árdua, cujos obstáculos se tornam transponíveis apenas com muito esforço e com a ajuda de muitas pessoas que participam, direta ou indiretamente, e que, muitas vezes, nem se dão conta da enorme contribuição que deram. Meus agradecimentos são direcionados a essas pessoas.

Primeiramente, gostaria de agradecer toda minha familía, principalmente meus pais, José Carlos e Sônia dos Anjos, que mesmo diante de todas as adversidades puderam me dar a estrutura necessária, sem a qual este trabalho não existiria. Saibam que meu agradecimento é infinito e que nunca poderei recompensá-los à altura.

À minha esposa, Maristela Gonçalves Machado, pela paciência e o apoio nos momentos difíceis.

À minha orientadora e professora, Tatiana A. Michtchenko, por ter me dado a oportunidade que muitos outros negaram, pelas horas de leitura e revisão desta dissertação, ao incentivo dado quando eu parecia perdido e desnorteado e, principalmente, por ter exigido maiores aperfeiçoamentos quando necessários. Aos professores, Ramachrisna Teixeira, Iberê Luiz Caldas e Sylvio Ferraz-Mello, pelas valiosas aulas durante estes dois anos.

Aos colegas do grupo de Astronomia Dinâmica: Adrian Rodriguez Colucci, Alan Jorge Alves do Carmo, Eduardo Andrade Inês, Hugo Alberto Folonier, Jorge Alfredo Correa Otto, Levy Scalise Maciel, Marcos Tadeu dos Santos e Natasha Fioretto Aguero, por todas as dicas e contribuições para o desenvolvimento deste trabalho.

A Marilu Maranho Tassetto e Silvana Cobucci, pelos apontamentos e as dicas preciosas da língua portuguesa, que melhoraram muito esta dissertação.

Aos colegas Juliane Matsubara Barroso, Fábio Martins de Leonardo e Ana Paula Nani, 
que compreenderam a importância deste momento da minha vida. Só eles sabem quanto contribuíram para a construção deste sonho.

A toda a equipe do Laboratório de Astroinformática, que além de ajudar na manutenção e instalação de todo aparato técnico, se dispuseram a esclarecer todas as dúvidas, sem essa contribuição esta dissertação não teria sido realizada.

À FAPESP, pelo apoio financeiro, com o projeto noํ: 2012/01369-5, que possibilitou que eu me dedicasse à pesquisa e à escrita desta dissertação. Estendo este agradecimento a todos os funcionários do programa de Pós-graduação do Instituto de Astronomia, Geofísica e Ciências Atmosférias da Universidade de São Paulo (IAG-USP), que sempre estiveram à disposição para ajudar nos processos burocráticos que envolvem um curso de mestrado em Ciências. 
"Não vá aonde o caminho o leva; vá aonde não há caminho e deixe seu rastro" Ralph Waldo Emerson (1803-1882), poeta norte-americano

"Não existem ideias originais, apenas pessoas originais" Barbara Grizzuti Harrison (1934-2002), jornalista norte-americana 



\section{Resumo}

Este trabalho tem como objetivo abordar a modelagem da formação e migração de um núcleo sólido planetário . Para isso, foi utilizado um modelo de acreção de planetesimais, baseado no trabalho de Inaba et al. (2000), no qual a taxa de acreção média depende da inclinação e excentricidade dos planetesimais, obtidas através da situação de equilíbrio entre a interação com o protoplaneta e o arrasto do gás (Fortier et al., 2013).

Para complementar esse cenário, foi incluída a migração de tipo I, que ocorre devido à interação do planeta com o disco de gás. O modelo analítico que descreve essa migração teve como base o trabalho de Tanaka et al. (2002).

O perfil de densidade de gás e sólidos foi obtido com base em três modelos diferentes para o disco. O primeiro é o modelo clássico da Nebulosa Solar, no qual o perfil de densidade decai com $r^{-3 / 2}$; o segundo é um modelo híbrido, que utiliza medidas observacionais da densidade superficial do gás (Andrews e Williams, 2005) e uma estimativa analítica para a densidade volumêtrica do gás; por fim, o terceiro modelo é um disco de acreção que utiliza a parametrização de Shakura e Sunyaev (1973) com $\alpha$ constante.

Com o uso desses três perfis diferentes para o disco, foi possível explorar a variação dos parâmetros livres do modelo e a possibilidade de formação de núcleos sólidos, da ordem de $10 \mathrm{M}_{\text {Terra }}$, num tempo menor que o tempo de vida do disco, estimado como menor que $10 \times 10^{6}$ anos.

Em geral, a migração de tipo I é muito rápida, de modo que o protoplaneta cai na estrela antes mesmo de adquirir massa suficiente para iniciar a acreção de gás. No entanto, a análise revelou, para o disco híbrido, a possibilidade de se obter massas próximas de $10 \mathrm{M}_{\text {Terra }}$, num tempo da ordem de $2 \times 10^{6}$ anos, em distâncias de até 3.5 UA.

Conclui-se, então, que modelos de acreção mais completos, assim como a obtenção de 
perfis de densidade de gás e sólidos dos discos protoplanetários mais coerentes, podem explicar a formação de núcleos sólidos num tempo hábil para a formação de planetas gigantes, sem a necessidade de fatores numéricos que reduzam a taxa de migração de tipo I. 


\section{Abstract}

The aim of this paper is to model the planetary formation and migration of a solid core. Therefore, it was used a model of planetesimal accretion, based on the paper of Inaba et al. (2000), in which the average accretion tax depends on the inclination and eccentricity of that planetesimals. These parameters were obtained through the balance situation between the interaction with the protoplanet and gas draft (Fortier et al. 2013$)$.

In order to complete this scenario, the migration type I, which occurs due to an interaction of the planet with the gas disc, was included. The analytical model that describes this migration has its basis on (Tanaka et al., 2002).

The density of solids and gas profile was based on three different models for the disc. The first one is a classical of Nebulosa Solar, in which the density profile varies $r^{-3 / 2}$, the second is a hybrid model that uses observational measures of the gas superficial density (Andrews et al., 2010) and an analytical formula for the gas volumetric density; at last, the third model is an accretion disc which uses the parameterization of (Shakura e Sunyaev, 1973 ) with $\alpha$ constant.

Using these three different disc profiles, it was possible to explore the variation of the model free parameters and the possibility of the solid cores formation with $10 \mathrm{M}_{\text {Earth }}$ within time smaller than $10 \times 10^{6}$ years, which is the estimated limit lifetime of the disc.

In general, migration type I is very fast, so that the protoplanet falls on the star before acquiring enough mass to begin the gas accretion. However, the analysis has revealed, for the hybrid disc, the possibility to obtain masses up to $10 \mathrm{M}_{\text {Earth }}$ within time $2 \times 10^{6}$, for distance up to $3.5 \mathrm{AU}$.

In conclusion, more complete models of accretion as well as the more coherent density gas and solid profiles of the protoplanet obtained may explain the formation of solid cores 
within a useful time for the giant planets formation, not using numerical factors that reduce the migration type I tax. 


\section{Lista de Figuras}

1.1 Imagem no óptico de Fomalhaut b com o uso do telescópio espacial Hubble. 26

1.2 A curva de 51 Pegasi, medida pelo grupo de M. Mayor no Haute Provence

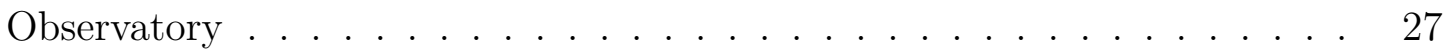

1.3 Órbita da estrela em torno do centro de massa do sistema estrela-exoplaneta 28

1.4 Representação do efeito de microlentes gravitacionais. . . . . . . . . . . . . 33

1.5 Geometria e curva de luz de um exoplaneta gigante. . . . . . . . . . . . . . 34

1.6 Histograma da distribuição de massa mínima para estrelas, companheiras subestelares e exoplanetas. . . . . . . . . . . . . . . 36

1.7 Massa mínima versus período dos exoplanetas . . . . . . . . . . . . . . 38

1.8 Distribuição do período dos planetas para diferentes regimes de massa . . . 40

1.9 Distribuição da metalicidade em estrelas com exoplanetas . . . . . . . . . . 42

1.10 Massa mínima versus metalicidade de estrelas com exoplaneta . . . . . . . 44

1.11 Gráfico do período do exoplaneta versus metalicidade . . . . . . . . . 46

2.1 Modelo de Kalnajs. . . . . . . . . . . . . . . . . . . . . . . . . 50

2.2 Esboço do gráfico do potencial gravitacional efetivo. . . . . . . . . . . 51

2.3 Composição do movimento orbital com o movimento epicicloidal. . . . . . 53

2.4 Desenvolvimento de ondas espirais em simulações hidrodinâmicas devido a perturbação do planeta no disco fluido. . . . . . . . . . . 555

2.5 Representação de um fluido ocupando um volume $V$. . . . . . . . . . . 56

3.1 Classificação empírica de objetos estelares jovens (YSOs) . . . . . . . . . 66

3.2 Geometria para o cálculo do perfil de temperatura de um disco plano. . . . 70 
3.3 Geometria para o cálculo do perfil de temperatura de um disco em formato

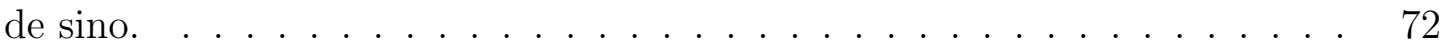

3.4 Fração de discos protoplanetários em aglomerados jovens em função da estimativa de idade do aglomerado. . . . . . . . . . . . . . 74

3.5 a) $h / r$, b) $\Sigma$ em g/ $\mathrm{cm}^{2}$ e c) $T_{\mathrm{m}}$ em $\mathrm{K}$ em função do raio em U.A. usando escala $\operatorname{logarítmica.~.~.~.~.~.~.~.~.~.~.~.~.~.~.~.~.~.~.~.~.~} 80$

3.6 Idem Figura 3.5 para $\alpha=10^{-3} \ldots \ldots \ldots$. . . . . . . . . . . . 81

4.1 Sedimentação e coagulação de uma partícula de poeira num disco não turbulento ............................... 89

4.2 Gráfico da velocidade radial das partículas no plano médio do disco em função do tempo de parada . . . . . . . . . . . . . . . . . . . . . . 93

4.3 Gráfico do tempo de descolamento de uma partícula com velocidade máxima em função do raio do disco . . . . . . . . . . . . . . . . . . . . . 94

4.4 Seção de choque durante um encontro gravitacional . . . . . . . . . . . . 96

4.5 Enxame de planetesimais . . . . . . . . . . . . . . . . . 999

4.6 Trajetória de partículas em órbitas circulares próximas de um protoplaneta considerando o problema de três corpos . . . . . . . . . . . . . . 101

4.7 Uma visão de perfil mostrando o fluxo de planetesimais dentro da esfera de Hill do protoplaneta no regime de três corpos . . . . . . . . . . . . 102

4.8 Dependência do foco gravitacional em função da razão da velocidade de escape e da velocidade de dispersão dos planetesimais . . . . . . . . . 103

4.9 Densidade superficial do gás e de sólidos em função do raio para Nebulosa Solar Mínima . . . . . . . . . . . . . . . . . . . . . . . . . 110

4.10 Densidade superficial do gás e de sólidos em função do raio para as medidas observacionais de Andrews et al. $(2010)$. . . . . . . . . . . . . . 111

4.11 Ajuste de uma curva exponencial para a densidade superficial do gás em função do raio num disco de acreção em equilíbrio . . . . . . . . . . . . . . 112

4.12 Ajuste de uma curva exponencial para a densidade volumétrica do gás em função do raio num disco de acreção em equilíbrio . . . . . . . . . . . . 112

4.13 Gráfico do crescimento da massa de um protoplaneta de $0.01 \mathrm{M}_{\text {Terra }}$ até $1 \mathrm{M}_{\text {Terra }}$ para diferentes perfis de disco protoplanetário . . . . . . . . . . 115 
5.1 Simulação computacional obtida com o programa FARGO mostrando braços espirais gerados pela pertubação do planeta no disco protoplanetário . . . . 120

5.2 Simulação computacional obtida com o programa FARGO mostrando a abertura de um gap no disco protoplanetário . . . . . . . . . . . . . . . . 121

5.3 Simulação computacional obtida com o programa FARGO mostrando a abertura de um gap parcial no disco protoplanetário . . . . . . . . . . . . 122

5.4 Interação entre o elemento de fluido e o planeta . . . . . . . . . . . . . . 123

5.5 Gráfico do deslocamento da ressonância devido a inclusão de uma perturbação imaginária . . . . . . . . . . . . . . . . . . . . . 132

5.6 Torque interno e externo no disco protoplanetário . . . . . . . . . . . . 134

5.7 Gráfico do crescimento da massa de um protoplaneta com migração . . . . 137

5.8 Gráfico do crescimento de um planeta obtido por Armitage (2010) . . . . . 138

5.9 Possíveis valores para a configuração final do planeta (ou núcleo sólido) para o modelo da Nebulosa Solar . . . . . . . . . . . . . . . . . . . . . . 141

5.10 Possíveis valores para a configuração final do planeta (ou núcleo sólido) para o modelo híbrido . . . . . . . . . . . . . . . . . . . . . . 143

5.11 Possíveis valores para a configuração final do planeta (ou núcleo sólido) para o modelo de disco de acreção em equilíbrio . . . . . . . . . . . . . . . . 145

A.1 Dedução parâmetros de Oorst's . . . . . . . . . . . . . . . . 163

A.2 Dedução parâmetros de Oorst's . . . . . . . . . . . . . . . . . . . . 164 



\section{Lista de Tabelas}

3.1 Comparação das propriedades da região interna de uma nuvem molecular e de uma estrela similar ao Sol . . . . . . . . . . . . . . . . . . . . . 64 64

3.2 Parâmetros para a opacidade analítica média de Rosseland. . . . . . . . . . 78

4.1 Medidas observacionais de Andrews et al. $(2010)$. . . . . . . . . . . 110

4.2 Resumo de dados para cada perfil do disco . . . . . . . . . . . . . . . . 113

5.1 Ajuste do modelo híbrido . . . . . . . . . . . . . . . . . . 136 



\section{Sumário}

1. Introdução . . . . . . . . . . . . . . . . . . . . . . . 23

1.1 Métodos de detecção dos exoplanetas . . . . . . . . . . . . . . 24 24

1.1.1 Método por imagem direta . . . . . . . . . . 25

1.1.2 Método de velocidade radial . . . . . . . . . . . . . . 26

1.1.3 Método de timing . . . . . . . . . . . . . . . . . . . . . 30

1.1.4 Método de astrometria . . . . . . . . . . . . . 31

1.1.5 Método de microlentes gravitacionais . . . . . . . . . 32

1.1.6 Método de trânsito . . . . . . . . . . . . . . . . . . . 34

1.2 Distribuição dos parâmetros orbitais dos exoplanetas: uma conexão com o processo de migração . . . . . . . . . . . . . . . . . . . 35

1.2.1 Influência da massa no processo de migração . . . . . . . . . . . . 36

1.2.2 Metalicidade da estrela . . . . . . . . . . . . . . . . 41

1.3 Sumário . . . . . . . . . . . . . . . . . . . . . . . 47

2. Fundamentos teóricos . . . . . . . . . . . . . . . . . . . . . . 49

2.1 Ondas de densidade espirais . . . . . . . . . . . . . . . . . . . 49

2.2 Equações da Hidrodinâmica . . . . . . . . . . . . . . . . . . . . 55

2.2.1 Equação de continuidade . . . . . . . . . . . . 55

2.2.2 Equação de Euler . . . . . . . . . . . . . . . . . . . 57

2.3 Potencial gravitacional do planeta . . . . . . . . . . . . . 59

3. Disco protoplanetário . . . . . . . . . . . . . . . . . . . 61

3.1 Introdução . . . . . . . . . . . . . . . . . . . . . . 61

3.2 Nuvens moleculares e a formação estelar . . . . . . . . . . . . . . . . . . . 62 
3.3 Formação do disco protoplanetário . . . . . . . . . . . . . . . . . 64

3.4 Estimativa do raio de um disco protoplanetário . . . . . . . . . 66 66

3.5 Estrutura vertical . . . . . . . . . . . . . . . . 67

3.6 Discos passivos . . . . . . . . . . . . . . . . . . 69

3.6 .1 Disco plano . . . . . . . . . . . . . . . 70

3.6 .2 Disco em formato de sino . . . . . . . . . . . . 71

3.7 Discos de acreção . . . . . . . . . . . . . . . . . . . . 73

3.7.1 Modelo computacional para o disco de acreção . . . . . . . . . . 75

3.8 Sumário . . . . . . . . . . . . . . . . . . . . . . . . . . . . . . . . . . . . . 82

4. Formação planetária . . . . . . . . . . . . . . . . . 85

4.1 Introdução . . . . . . . . . . . . . . . . . . . . 85

4.2 Formação de planetesimais . . . . . . . . . . . . . . . . 866

4.2.1 Distribuição vertical de partículas sólidas . . . . . . . . . . 88

4.2.2 Distribuição radial de partículas sólidas . . . . . . . . . . . . . . 90

4.3 Formação de planetas terrestres . . . . . . . . . . . . . . . . . 95

4.3.1 Crescimento do planeta no regime de dois $\operatorname{corpos}\left(\sigma>v_{\mathrm{H}}\right) \ldots 98$

4.3.2 Crescimento do planeta no regime de três corpos $\left(\sigma<v_{\mathrm{H}}\right) \quad \ldots . .100$

4.4 Modelo computacional para formação de um núcleo sólido . . . . . . . . . 104

4.4.1 Modelos de discos protoplanetários usados no modelo computacional da formação planetária . . . . . . . . . . . . . . . . . . . . . . . . 108

4.4 .2 Resultados obtidos . . . . . . . . . . . . . . . 113

4.5 Sumário . . . . . . . . . . . . . . . . . . . . 116

5. Migração planetária devido à interação com o disco de gás . . . . . . . . . . . . 119

5.1 Introdução . . . . . . . . . . . . . . . . . . . . . . . . . . . . . . . 119

5.2 Derivação do torque pelo método de aproximação impulsiva . . . . . . . . 123

5.3 Derivação do torque via ressonâncias de Lindblad . . . . . . . . . . . . . 126

5.4 Modelo computacional para formação planetária com a migração devido à interação com o disco . . . . . . . . . . . . . . . . . . 135

5.5 Sumário . . . . . . . . . . . . . . . . . . . . . 146

6. Conclusão e perspectivas . . . . . . . . . . . . . . . . . . . . . 149 


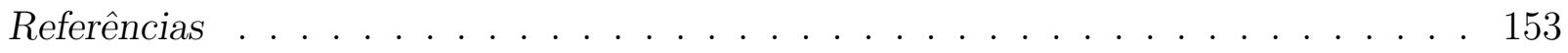

Apêndice 161

A. Dedução dos parâmetros de Oorst's . . . . . . . . . . . . . . . . . . . . . . . 163

B. Condições de fronteira para a estrutura vertical do disco protoplanetário . . . . 167 

Capítulo 1

\section{Introdução}

Os estudos dos processos de migração planetária ajudam a compreender melhor a formação e a evolução dos sistemas planetários. De fato, os dados observacionais indicam que tais processos possuem um papel significativo na evolução desses sistemas, uma vez que, por meio deles, um planeta gigante formado muito além da linha de gelo pode ser encontrado em regiões próximas da estrela.

A migração planetária pode ser provocada pela interação com o disco de gás e poeira, por efeito de maré decorrente da atração gravitacional da estrela, pela interação com o disco de planetesimais ou com outros exoplanetas e até mesmo pela presença de uma estrela próxima. Nesta dissertação, vamos concentrar nosso estudo na migração produzida pelos torques gravitacionais entre o protoplaneta e o disco protoplanetário. Assim, ao ser empregado no singular, o termo processo de migração designa exclusivamente a interação com o disco de gás.

No Capítulo 1 fazemos uma breve descrição dos métodos de detecção dos exoplanetas, enfatizando algumas peculiaridades que ajudarão a compreender os resultados de uma análise estatística dos parâmetros orbitais encontrados. Veremos como essas estatísticas corroboram os processos de migração planetária.

A compreensão da interação do planeta com o disco protoplanetário exige alguns requisitos teóricos que abrangem desde as equações que regem o movimento planetário até equações fundamentais da Hidrodinâmica. No Capítulo 2, apresentamos uma breve introdução a alguns desses conceitos, ressaltando sobretudo as limitações e aproximações teóricas envolvidas.

No Capítulo 3, focalizamos algumas propriedades físicas do disco protoplanetário, assim como sua formação e evolução, que resulta num modelo computacional para um disco 
de acreção, que é essencial à obtenção de alguns parâmetros utilizados no processo de migração. Tais parâmetros também serão utilizados no estudo da formação planetária, abordada no Capítulo 4, num modelo computacional para acreção de sólidos que complementa o cenário de migração do planeta, já que os dois processos ocorrem conjuntamente. Nesta dissertação, trabalhamos com a formação do core planetário sólido, enquanto a acreção de gás, que resulta nos planetas gasosos, será abordada em trabalhos futuros.

Por fim, o Capítulo 5 abrange a migração do planeta provocada pela interação com o disco protoplanetário, abordando os modelos analíticos existentes e suas limitações.

\subsection{Métodos de detecção dos exoplanetas}

Nos dias de hoje, apesar de todo o avanço tecnológico, a detecção de um exoplaneta através de uma imagem direta ainda é uma tarefa bastante laboriosa, principalmente em virtude do contraste de brilho entre o exoplaneta e a estrela hospedeira e a baixíssima separação angular entre ambos. Essas dificuldades podem ser ainda maiores caso essas observações sejam feitas na superfície da Terra, onde os efeitos da atmosfera terrestre atrapalham as medições. Isso levou à criação de métodos indiretos para comprovar a existência de exoplanetas e obter os principais parâmetros necessários ao seu estudo.

Atualmente foram confirmados 763 exoplanetas 1 , detectados por diferentes métodos desenvolvidos ao longo das últimas décadas. Podemos dividir os métodos de detecção com base no tipo de efeito analisado: o primeiro está relacionado com o efeito dinâmico sobre a estrela, causado pela interação gravitacional com o exoplaneta, que pode ser medido com o método de velocidade radial através do deslocamento das linhas espectrais da atmosfera estelar, do qual se obtêm a curva de velocidade da estrela; com o método de timing, que possibilita medir a variação do tempo de chegada de um sinal periódico de um pulsar sob influência gravitacional do exoplaneta e com o método de astrometria, por meio das medidas astrométricas do movimento da estrela.

O segundo tipo está associado com a deflexão do raio de luz de uma fonte distante pelo campo gravitacional do exoplaneta e de sua estrela hospedeira, trata-se do método de microlentes gravitacionais.

Finalmente, o terceiro tipo está associado com medidas fotométricas da estrela. Nele são

\footnotetext{
${ }^{1}$ Dado obtido em: < http://exoplanets.org/>. Acesso em: 20 jan. de 2014.
} 
medidas variações do brilho da estrela durante o trânsito do exoplaneta em órbita, por isso denominado método de trânsito. Nessa categoria, incluem-se as medidas fotométricas do exoplaneta na detecção por imagem direta.

A seguir, apresentamos uma breve descrição desses métodos e suas limitações, salientando alguns pontos importantes para compreender como são obtidos os parâmetros dos exoplanetas.

\subsubsection{Método por imagem direta}

Esse método busca encontrar a imagem de um exoplaneta através da luz da estrela central nele refletida. Além disso, também permite medir a emissão térmica emitida pelo exoplaneta na região do infravermelho. No entanto, em ambos os casos, a tarefa é árdua, pois o forte brilho da estrela com relação ao exoplaneta e a baixa separação angular entre os dois fazem com que sua imagem fique completamente envolvida pela da estrela.

Para ter uma ideia das dificuldades mencionadas, imaginemos o sistema Júpiter-Sol a uma distância de 10 pc. Sabendo que a distância entre os dois é de 5.2 UA, deveríamos medir uma separação angular de apenas 0.5 arcseg. Ademais, a razão entre a luminosidade de Júpiter e do Sol, no óptico, é de aproximadamente $10^{-9}$. Em geral, para os exoplanetas, a razão de luminosidade em relação à estrela é da ordem de $10^{-5}$ no infravermelho e $10^{-10}$ no óptico (Perryman, 2011).

Embora a razão do fluxo no infravermelho configure uma vantagem, esta é ofuscada pela necessidade de grandes telescópios para sua detecção. Por exemplo, uma resolução espacial de 0.5 UA numa distância de 5 pc corresponde a uma resolução angular de 0.1 arcseg. Para um exoplaneta similar à Terra ao redor de uma estrela de tipo solar, o melhor contraste no infravermelho, que seria da ordem de $10^{-6}$, ocorre para $\lambda=20 \mu \mathrm{m}$, o que implica a necessidade de um telescópio de $50 \mathrm{~m}$ de diâmetro (Armitage, 2010).

Em 2008, Paul Kalas, da Universidade de Berkeley, anunciou a primeira detecção de um exoplaneta (Fomalhaut b) através de um telescópio óptico (Kalas et al., 2008). A técnica consistiu no uso de um coronógrafo no qual se obstrui a luz da estrela hospedeira, facilitando a obtenção da imagem do exoplaneta. Atualmente, porém, são empregadas técnicas complementares baseadas em interferometria. A Figura 1.1 mostra a imagem de Fomalhaut b obtida com o uso do telescópio espacial Hubble. 


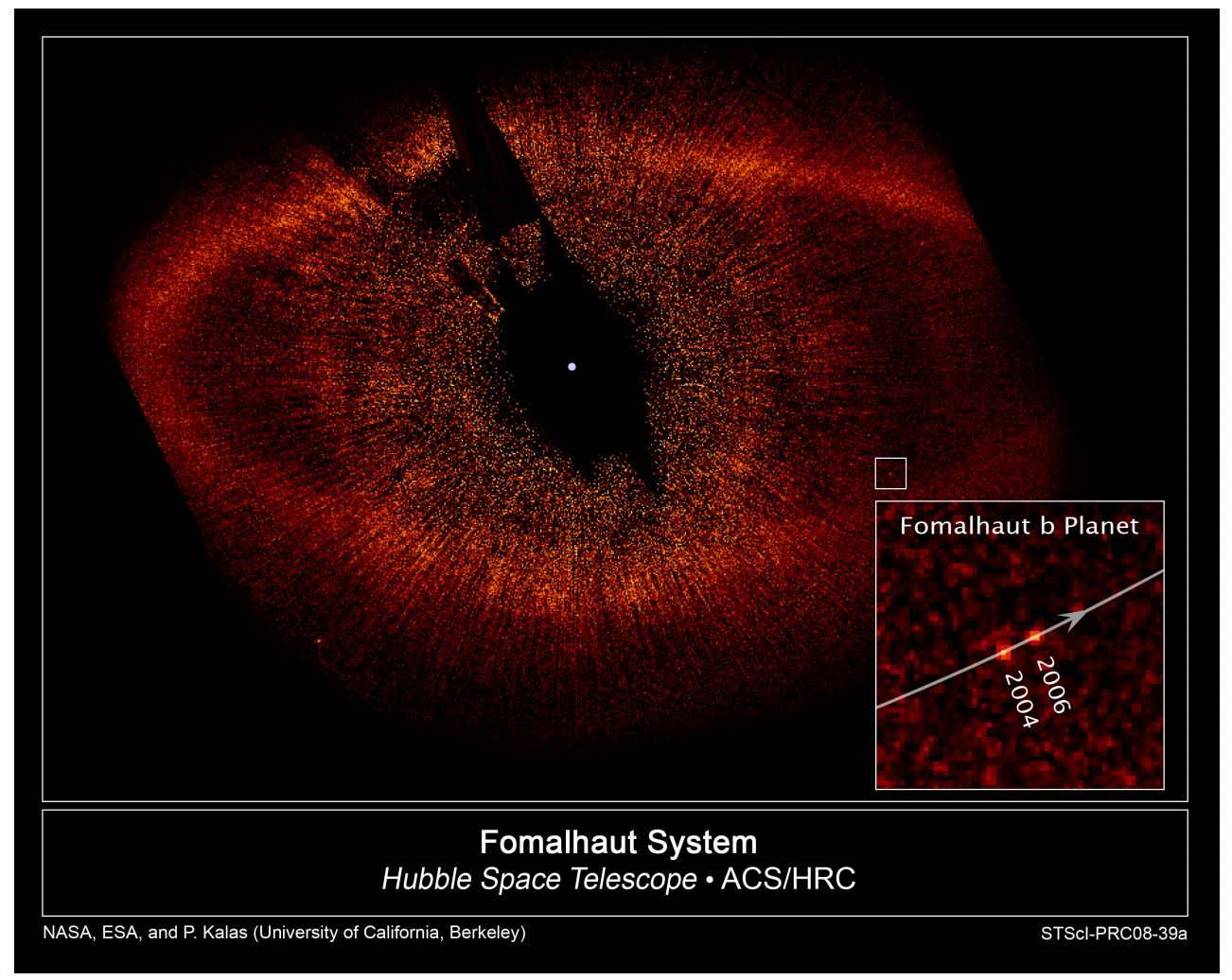

Figura 1.1: Imagem no óptico de Fomalhaut b com o uso do telescópio espacial Hubble. Crédito: NASA, ESA, P. Kalas, J. Graham, E. Chiang, and E. Kite (University of California, Berkeley), M. Clampin (NASA Goddard Space Flight Center, Greenbelt, Md.), M. Fitzgerald (Lawrence Livermore National Laboratory, Livermore, Calif.), and K. Stapelfeldt and J. Krist (NASA Jet Propulsion Laboratory, Pasadena, California). Figura obtida em: $<$ http://www.nasa.gov/missionpages/hubble/science/fomalhaut.html $>$.

Devido às dificuldades relatadas, apenas oito exoplanetas confirmados ${ }^{1}$ possuem imagens diretas. No futuro, espera-se que o desenvolvimento desse método possa contribuir para o estudo das atmosferas exoplanetárias. Alguns projetos para equipar telescópios com o intuito de obter essas imagens são o Gemini Planet Imager (GPI), Spectro-Polarimetric High-contrast Exoplanet REsearch (SPHERE) e o Palomar 1640.

\subsubsection{Método de velocidade radial}

O método de velocidade radial (V.R.) surgiu como uma tentativa de descobrir estrelas de baixa massa de sistemas binários, como no trabalho de Campbell et al. (1988a), que identificou, o que acreditava ser, um objeto subestelar ao redor de $\gamma$ Cep com um período de aproximadamente 2.5 anos e massa de $\approx 1.7 \mathrm{M}_{\mathrm{J}}$, depois confirmado como exoplaneta

\footnotetext{
${ }^{1}$ Dado obtido em: <http://exoplanets.org/>. Acesso em: 24 jan. 2014.
} 
por Hatzes et al. (2003). Esse fato também ocorreu para HD 114762, no qual se identificou uma companheira de período de aproximadamente 84 dias e massa de $\approx 11 \mathrm{M}_{\mathrm{J}}$ (Latham et al. 1989), posteriormente confirmado um exoplaneta por Cochran et al. (1991).

O primeiro exoplaneta descoberto nas proximidades de uma estrela da sequência principal foi detectado usando o método de velocidade radial por Mayor e Queloz (1995) e confirmado pelo Observatório de Lick, orbitando a estrela 51 Peg, com um período de 349.3 dias e massa de $\approx 0.472 \mathrm{M}_{\mathrm{J}}$ (Figura 1.2 ). Essa descoberta contribuiu muito para aumentar as pesquisas sobre exoplanetas e, nos tempos atuais, o método V.R. continua sendo o mais utilizado para obtenção dos parâmetros orbitais dos exoplanetas.

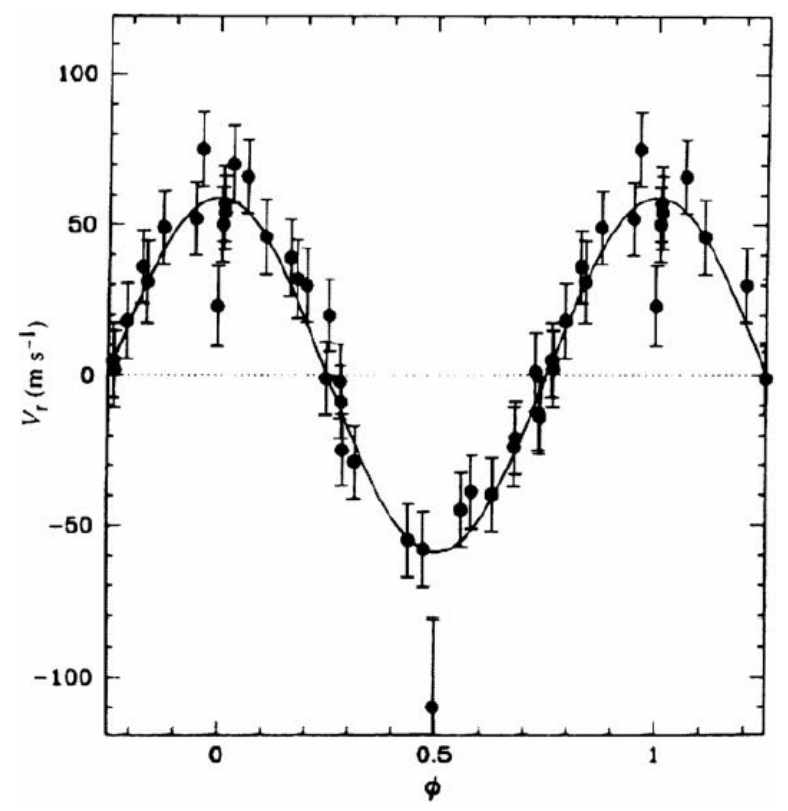

Figura 1.2: A curva de 51 Pegasi, medida pelo grupo de M. Mayor no Haute Provence Observatory. Figura obtida em: Mayor e Queloz (1995).

Devido à atração gravitacional do planeta sobre a estrela, ocorre um movimento dessa última em torno do baricentro do sistema (exoplaneta-estrela). Portanto, o método consiste na detecção do exoplaneta através da análise do movimento orbital dessa estrela.

Para especificar a órbita em três dimensões, necessitamos de seis parâmetros $a, e, t_{\mathrm{p}}, i$, $\Omega, \omega$. Os dois primeiros, $a$ e $e$, são respectivamente o semieixo maior e a excentricidade, e especificam o tamanho e a elipsidade da órbita, enquanto $t_{\mathrm{p}}$ está relacionado com a posição do objeto ao longo da órbita a partir de uma referência, normalmente escolhida como a passagem pericêntrica. Os três ângulos $i, \Omega, \omega$ representam a projeção da órbita verdadeira em uma órbita aparente e dependem da posição do observador em relação a essa órbita. 
O ângulo $i$ especifica a inclinação da órbita com relação ao plano de referência e o ângulo $\Omega$ representa a longitude do nodo ascendente, ou seja, o ângulo entre a direção do nodo ascendente e a direção de referência ao longo do plano de referência, no sentido do movimento do corpo. Já o ângulo $\omega$ é o argumento do pericentro, que é a medida angular entre a direção do pericentro e o nodo ascendente, ao longo do plano orbital, também medido no sentido de movimento do corpo. Definidos os elementos orbitais, obtemos a órbita representada na Figura 1.3

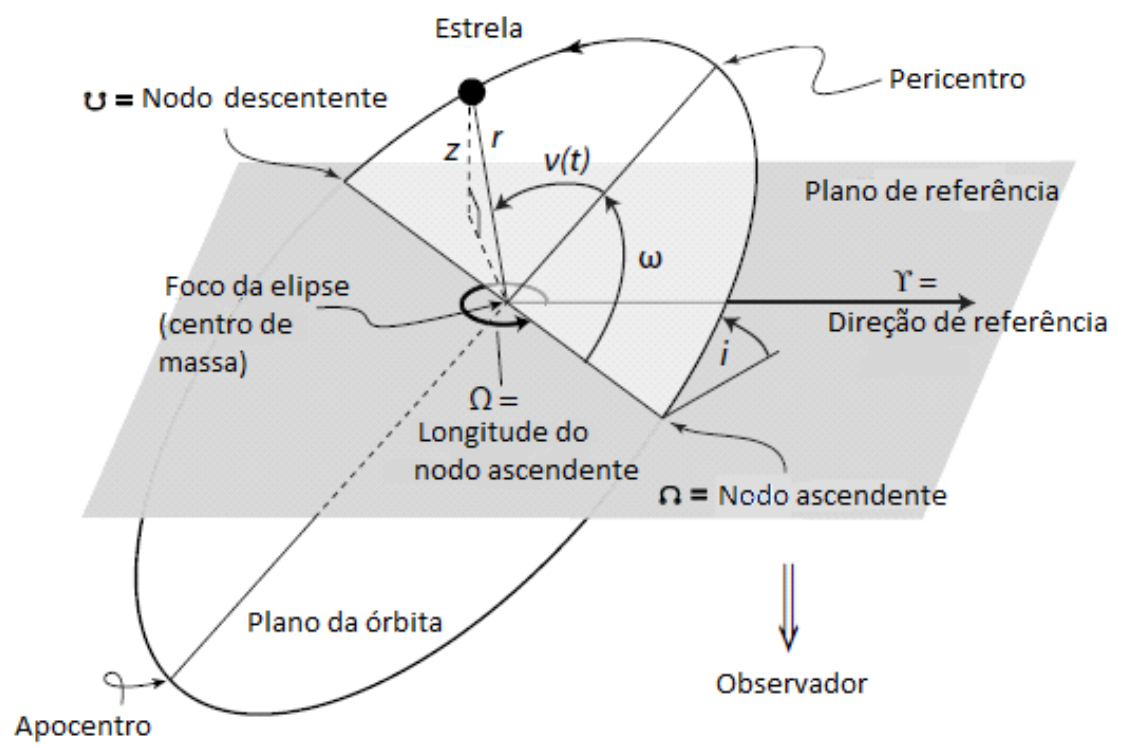

Figura 1.3: Órbita da estrela em torno do centro de massa do sistema estrela-exoplaneta. Figura obtida em: Perryman (2011).

Com base na primeira lei de Kepler, sabemos que a estrela descreverá uma órbita elíptica em torno do baricentro do sistema (estrela-exoplaneta). Nele fixamos o sistema de coordenadas $x^{\prime}, y^{\prime}$ e $z^{\prime}$, onde o eixo $x^{\prime}$ aponta na direção do pericentro e, juntamente com o eixo ortogonal $y^{\prime}$, define o plano da órbita. Desse modo, o eixo $z^{\prime}$ será perpendicular a esse plano.

A equação que descreve a trajetória da estrela ao redor de seu baricentro em coordenadas polares é

$$
r=\frac{a_{\star}\left(1-e^{2}\right)}{1+e \cos v}
$$

onde $v$ é a anomalia verdadeira (ângulo entre o raio vetor e a direção do pericentro), $e$ a excentricidade da órbita, e $a_{\star}$ é o semieixo maior da órbita da estrela em relação ao 
baricentro.

Derivando a Equação 1.1, obtemos a velocidade da estrela ao redor do baricentro. Antes disso, porém, vamos utilizar outro sistema de coordenadas $x, y$, z, também centrando no baricentro, no qual os eixos $x, y$ definem o plano de referência e o eixo $z$ aponta na direção do observador. Essa escolha não é arbitrária e deve-se ao fato de, na prática, só termos acesso à medida da velocidade da estrela na direção do observador. Da Figura 1.3, obtemos, por meio da trigonometria, o deslocamento da estrela ao longo da direção do observador (direção z)

$$
z=r \sin i \sin (\omega+v)
$$

cuja derivada nos fornece a velocidade da estrela nessa direção

$$
\dot{z}=\sin i[\dot{r} \sin (\omega+v)+r \dot{v} \cos (\omega+v)] .
$$

Substituindo a derivada da Equação 1.1 na relação acima, obtemos

$$
\dot{z}=\frac{r \dot{v} \sin i}{1+e \cos v}[e \cos \omega+\cos (\omega+v)]
$$

Da dinâmica de dois corpos (Murray e Dermott, 1999), sabemos que o momento angular específico $l$ é dado por $l=r^{2} \dot{v}=n a_{\star}{ }^{2} \sqrt{1-e^{2}}$, onde $n=\frac{2 \pi}{P}$. Isso permite escrever

$$
\dot{v}=\frac{2 \pi a_{\star}^{2}}{P r^{2}} \sqrt{1-e^{2}}
$$

no qual $P$ é o período do planeta.

Logo, a Equação 1.4 pode ser escrita na forma

$$
\dot{z}=K[\cos (\omega+v)+e \cos \omega]
$$

onde

$$
K=\frac{2 \pi}{P} \frac{a_{\star} \sin i}{\left(1-e^{2}\right)^{1 / 2}} .
$$

Não podemos esquecer que o baricentro do sistema pode estar em movimento em relação ao referencial que for adotado para a medição da velocidade. Considerando uma velocidade $V_{0}$ do centro de massa na direção do observador, temos

$$
\dot{z}=V_{0}+K[\cos (\omega+v)+e \cos \omega] .
$$


Por mínimos quadrados e outras ferramentas estatísticas, podemos encontrar os valores dos elementos orbitais que melhor ajustam a Equação 1.8 aos dados observacionais. A velocidade $\dot{z}$ é função de $a_{\star}, P, e, \omega, i, v$ e $V_{0}$, e podemos eliminar alguns desses termos usando algumas relações. Podemos, por exemplo, usar a terceira lei de Kepler para eliminar o semieixo maior da órbita da estrela ao redor do baricentro, assim

$$
P^{2}=\frac{4 \pi^{2}}{G M^{\prime}} a_{\star}^{3}
$$

onde

$$
M^{\prime}=\frac{M_{\mathrm{p}}^{3}}{\left(M_{\star}+M_{\mathrm{p}}\right)^{2}} .
$$

Substituindo ambas as relações acima na Equação 1.7, obtemos

$$
K=\left(\frac{2 \pi G}{P}\right)^{1 / 3} \frac{M_{\mathrm{p}} \sin i}{\left(M_{\star}+M_{\mathrm{p}}\right)^{2 / 3}} \frac{1}{\left(1-e^{2}\right)^{1 / 2}},
$$

que pode ser posto na forma

$$
\frac{M_{\mathrm{p}} \sin i}{\mathrm{M}_{\mathrm{J}}} \approx 4.9 \times 10^{-3}\left(\frac{K}{\mathrm{~m} / \mathrm{s}}\right)\left(1-e^{2}\right)^{1 / 2}\left(\frac{P}{\operatorname{dias}}\right)^{1 / 3}\left(\frac{M_{\star}+M_{\mathrm{p}}}{\mathrm{M}_{\odot}}\right)^{2 / 3} .
$$

Embora a massa da estrela $\left(M_{\star}\right)$ possa ser inferida por parâmetros astrofísicos bem conhecidos, não é possível obter o parâmetro $i$, a inclinação da órbita, uma vez que só temos a medida da velocidade na direção do observador. Isso implica que a massa do planeta $M_{\mathrm{p}}$ ficará em função de sin $i$, ou seja, só podemos determinar a massa mínima do planeta.

\subsubsection{Método de timing}

Um pulsar é uma estrela de nêutrons muito pequena e extremamente densa que emite ondas de rádio regulares enquanto executa seu movimento de rotação. Em decorrência dessa regularidade, é possível detectar a presença de um planeta através das pequenas anomalias observadas nos sinais periódicos. Assim como no método V.R., a perturbação gravitacional de um objeto próximo, como por exemplo um planeta, causa o movimento do pulsar ao longo de uma pequena órbita em torno do centro de massa do sistema. Cálculos 
baseados na alteração da frequência dos pulsos de rádio permitem revelar os parâmetros orbitais do perturbador.

Originalmente, o método não foi usado para detecção de exoplanetas, até porque os principais modelos de formação planetária aliados à evolução estelar não preveem a existência de um planeta em torno de um pulsar. No entanto, a precisão do método permite detectar objetos da ordem da massa terrestre e até mesmo sistemas planetários (Perryman, 2011).

Em 1992, com o uso desse método Wolszczan e Frail (1992), detectaram exoplanetas ao redor do pulsar PSR 1257+12. Essa descoberta foi rapidamente confirmada e tornou-se a primeira detecção de um planeta fora do Sistema Solar. Atualmente, já foram detectados 61 exoplanetas ${ }^{1}$ com o uso desse método.

\subsubsection{Método de astrometria}

A detecção por astrometria visa medir o deslocamento da estrela (seu fotocentro) a partir do centro de massa estrela-exoplaneta. Num problema simples de dois corpos, separados por $a$, sabemos que o semieixo maior da estrela em relação ao baricentro $\left(a_{\star}\right)$, pela definição de centro de massa, é dado por

$$
a_{\star}=\left(\frac{M_{\mathrm{p}}}{M_{\mathrm{p}}+M_{\star}}\right) a \approx\left(\frac{M_{\mathrm{p}}}{M_{\star}}\right) a,
$$

assim, para uma estrela a uma distância $d$ da Terra, o deslocamento angular do fotocentro ao longo da sua órbita tem uma escala de

$$
\theta \approx \frac{a_{\star}}{d} \approx\left(\frac{M_{\mathrm{p}}}{M_{\star}}\right) \frac{a}{d}
$$

É interessante notar que, ao contrário do método de detecção por velocidade radial, o método astrométrico é mais sensível para semieixos maiores do planeta. A principal vantagem do método é a possibilidade de medir a velocidade tangencial da estrela que, juntamente com velocidade radial, permite obter $\sin i$, que aparece na formulação do método V.R.

A principal dificuldade na implantação do método é que a medida astrométrica requer uma precisão extrema só passível de ser obtida no espaço com o uso de interferometria, o

\footnotetext{
${ }^{1}$ Dado obtido em: <http://exoplanets.org/>. Acesso em: 20 jan. 2014.
} 
que aumenta a complexidade técnica e o custo operacional. Além disso, esse método só pode ser utilizado para estrelas relativamente próximas, uma vez que o movimento aparente de uma estrela em torno do baricentro de seu sistema planetário descreve no céu um ângulo que é inversamente proporcional à sua distância. Para ter uma ideia, um exoplaneta de $10 \mathrm{M}_{\text {Terra }}$ distante de $1 \mathrm{UA}$ de sua estrela hospedeira causaria uma assinatura astrométrica de $\approx 3 \mu$ arcseg para uma estrela situada a 10 pc do observador.

Em princípio, os obstáculos são de caráter tecnológico e espera-se que, com a missão Gaia em funcionamento, seja possível obter precisões da ordem de $10 \mu$ arcseg para estrelas com magnitude $m_{\mathrm{V}} \leq 15$. No entanto, com a Space Interferometry Mission (SIM), da NASA, com lançamento previsto para depois de 2015, seria possível uma precisão de $1 \mu \operatorname{arcseg}$ (Olliver et al., 2009).

Atualmente, o catálogo disponível no sítio <http://exoplanets.org/>11 não registra nenhum exoplaneta detectado com o uso apenas desse método.

\subsubsection{Método de microlentes gravitacionais}

O efeito conhecido por microlentes gravitacionais ocorre quando os campos gravitacionais do exoplaneta e de sua estrela hospedeira curvam o raio de luz de uma fonte distante amplificando seu sinal.

Um fóton que passa pela estrela de massa $M_{\star}$ com parâmetro de impacto $b$, que corresponde à distância de menor aproximação entre o raio de luz e o corpo defletor, sofre uma deflexão cujo ângulo é dado por

$$
\alpha=\frac{4 G M_{\star}}{b c^{2}} .
$$

Se a estrela que hospeda o exoplaneta e a fonte de luz permanecem na mesma linha de visada, a imagem da fonte é distorcida na forma de um "anel", conhecido como anel de Einstein. Seja $d_{\mathrm{L}}$ a distância entre o observador e a lente (estrela-planeta), $d_{\mathrm{F}}$ entre observador e a fonte e $d_{\mathrm{LF}}$ entre a lente e a fonte, o raio angular do chamado anel de Einstein é dado por

$$
\theta_{\mathrm{E}}=\frac{2}{c} \sqrt{\frac{G M_{\star} d_{\mathrm{LF}}}{d_{\mathrm{L}} d_{\mathrm{F}}}}
$$

\footnotetext{
${ }^{1}$ Acesso em: 20 jan. 2014.
} 
A intensidade da fonte se mantém constante durante o alinhamento, mas muda-se a distribuição de sua área, aumentando-a, o que provoca um fluxo maior de luz na presença da lente gravitacional. Através da curva de magnificação da luz, à medida que o alinhamento entre a fonte e a lente varia, é possível detectar o exoplaneta, como mostra a Figura 1.4 .

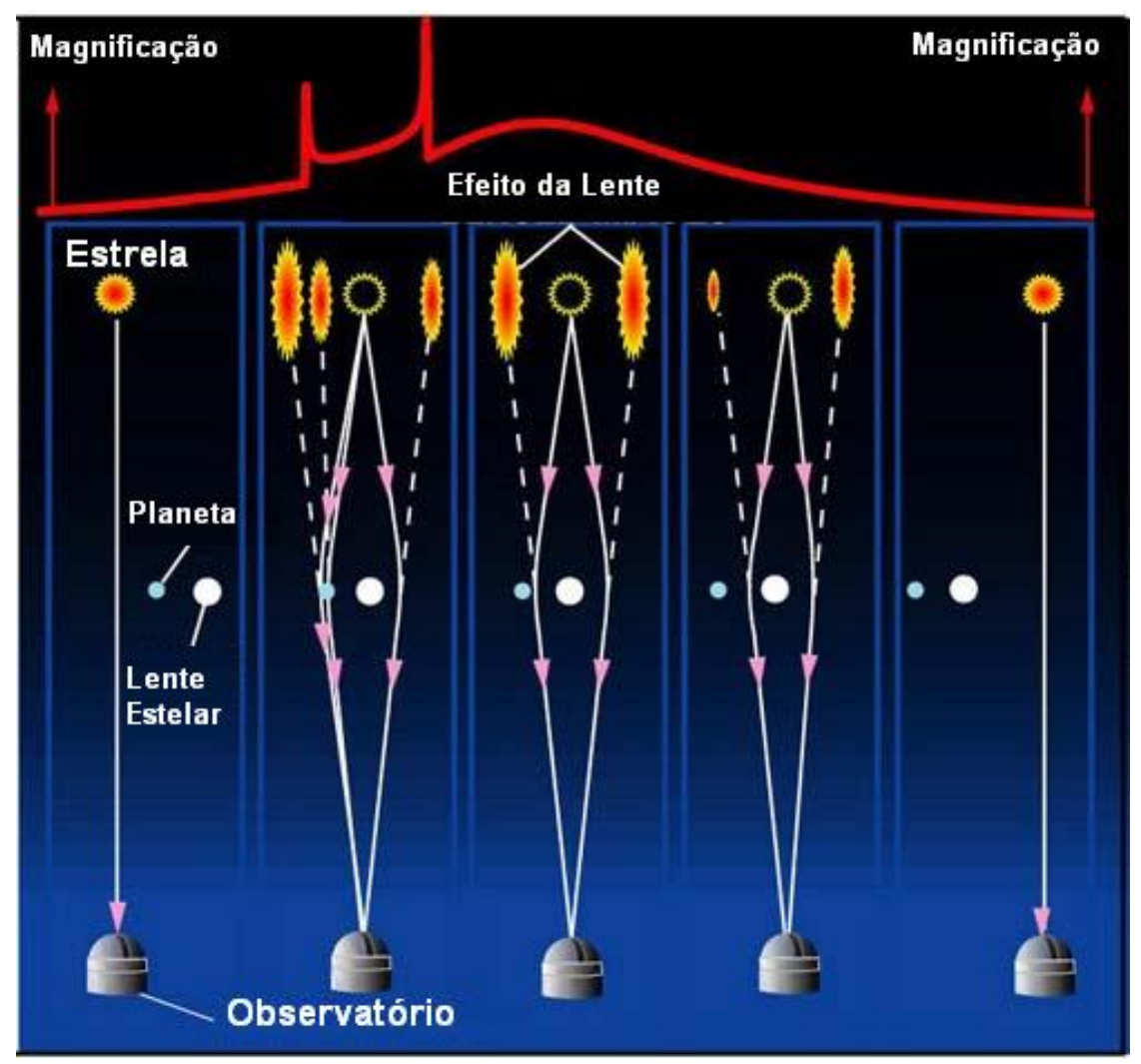

Figura 1.4: Representação do efeito de microlentes gravitacionais provocado por uma estrela acompanhada de um planeta. O brilho da estrela distante é representado pela linha vermelha no topo do diagrama. Figura obtida em: Giannini e Lunine (2013).

Devido a essa necessidade geométrica, esse método é empregado tendo como pano de fundo uma região densa de estrelas, normalmente, na direção do bulbo galáctico. São, portanto, eventos de curta duração, que não podem ser repetidos em decorrência da dinâmica das estrelas em torno da galáxia. Sua vantagem reside no fato de permitir a detecção de exoplanetas a distâncias maiores que no método V.R. e com massas menores. O tempo de duração do evento varia de um dia para exoplanetas da ordem da massa de Jupiter até algumas horas para os da massa da Terra (Perryman, 2011).

Atualmente, foram confirmados apenas 18 exoplanetas ${ }^{1}$ detectados com o uso desse método. No entanto, programas como Optical Gravitacional Lensing Experiment (OGLE),

\footnotetext{
${ }^{1}$ Dado obtido em: <http://exoplanets.org/>. Acesso em: 20 jan. 2014.
} 
financiado pela NASA e pela NSF, e o grupo Microlensing Observation in Astrophysics (MOA) buscam aperfeiçoar essa técnica.

\subsubsection{Método de trânsito}

Quando um exoplaneta orbita a estrela de modo que seu ângulo de inclinação é próximo de zero, ocorre um trânsito, ou eclipse, que pode ser detectado através do monitoramento das depressões geradas nas medidas do fluxo estelar. Como a diminuição do fluxo é bem pequena (Figura 1.5) e as medidas na Terra são limitadas em virtude da atmosfera, esse método vem sendo empregado em satélites como o CoRoT e o Kepler e o número de exoplanetas detectados confirmados já chega a 299 1

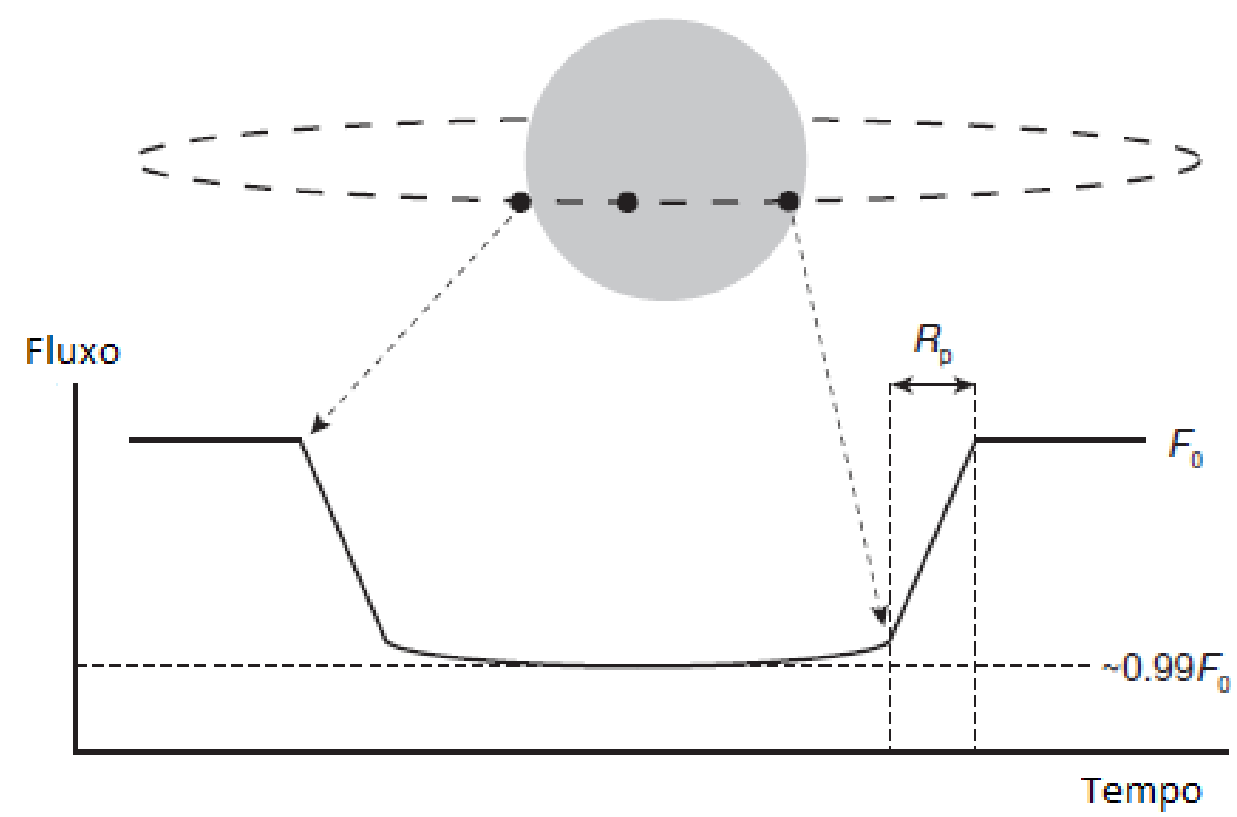

Figura 1.5: Geometria e curva de luz de um exoplaneta gigante. O fluxo detectado da estrela $F_{0}$ tem uma redução de aproximadamente $1 \%$ durante a passagem do planeta. Figura obtida em: Armitage (2010).

A necessidade de uma geometria particular é uma das limitações do método, assim, um planeta de raio $R_{\mathrm{p}}$ em órbita circular, de raio a e inclinação $i$ (medida entre o eixo de rotação da estrela e o plano da órbita do planeta), em torno de uma estrela de raio $R_{\star}$, só é passível de detecção caso a condição $\cos i \leq \frac{R_{\star}+R_{\mathrm{p}}}{a}$ seja respeitada.

Uma dificuldade do método de trânsito é a atividade estelar, que pode gerar variações de fluxos de tamanho suficiente, de modo a camuflar a detecção de exoplanetas menores.

\footnotetext{
${ }^{1}$ Dado obtido em: <http://exoplanets.org/>. Acesso em: 22 jan. 2014.
} 
Além disso, o método não permite detectar diretamente a massa do exoplaneta, exigindo o uso de métodos complementares.

Uma vez detectado o exoplaneta pelo método de trânsito, a medição do atraso de seu período pode inferir a presença dinâmica de outro exoplaneta em ressonância, mesmo que não se observe o trânsito do segundo planeta (Agol et al., 2005). Além disso, o uso combinado do método de trânsito com o método de velocidade radial permite observar o efeito Rossiter-MacLaughlin (Rossiter, 1924). Devido ao movimento de rotação da estrela, a parte da fotoesfera que se afasta possui espectro deslocado para o vermelho e a parte que se aproxima deslocado para o azul, o efeito Rossiter-MacLaughlin ocorre quando o exoplaneta orbita próximo do plano equatorial da estrela cobrindo alternadamente essas regiões da fotoesfera que se aproximam e se afastam do observador, o que muda a composição espectral da estrela. Isso permite a medição do desalinhamento entre o plano orbital e equatorial da estrela que é útil para testar explanações teóricas como, por exemplo, a ressonância Kozai.

\subsection{Distribuição dos parâmetros orbitais dos exoplanetas: uma conexão com o processo de migração}

O número de exoplanetas detectados até hoje (763, dos quais 625 possuem uma medida da massa mínima) $)_{1}^{1}$ permite fazer uma análise estatística de algumas propriedades relativas a seus parâmetros orbitais. Vimos que o método de detecção V.R. continua sendo o mais utilizado para obter a massa de exoplanetas, apesar de estar em função da inclinação da órbita $(M \sin i)$. Vamos analisar agora a distribuição e relação de alguns parâmetros em busca de vínculos para os processos migratórios.

A maioria dos gráficos utilizados foram obtidos com base nas medidas disponíveis na página <http://exoplanets.org/>, mantida por Jason Wright, Geoff Marcy e pelo California Planet Survey. Uma descrição desse trabalho pode ser encontrada em Wright et al. (2011). Evidentemente, o cenário estatístico apresentado aqui é influenciado pelo método de detecção, principalmente devido ao fato de o método V.R. ser mais sensível a exoplanetas massivos e próximos da estrela.

Adotando procedimentos similares aos de Udry et al. (2003), que utilizaram aproxima-

\footnotetext{
${ }^{1}$ Dado obtido em: <http://exoplanets.org/>. Acesso em: 24 jan. 2014.
} 
damente 100 exoplanetas com as massas mínimas disponíveis na época, discutimos se as abordagens estatísticas que evidenciam o processo de migração continuam válidas com os parâmetros atuais, dando maior sustentação à análise dos processos de migração.

\subsubsection{Influência da massa no processo de migração}

O método de detecção por velocidade radial pode ser empregado para descobrir qualquer tipo de corpo massivo orbitando uma estrela, como um planeta, uma anã marrom ou uma companheira estelar. Analisando a distribuição da massa mínima ( $M \sin i)$ para algumas centenas de objetos (Figura 1.6), percebe-se nitidamente uma distribuição bimodal da massa na qual planetas estão à esquerda $\left(M<0.01 \mathrm{M}_{\odot}\right)$ e estrelas à direita $\left(M>0.08 \mathrm{M}_{\odot}\right)$, separados por uma região vazia conhecida como "deserto de anãs marrons". Esse fato já havia sido evidenciado por Campbell et al. (1988b) e Marcy e Benitz (1989).

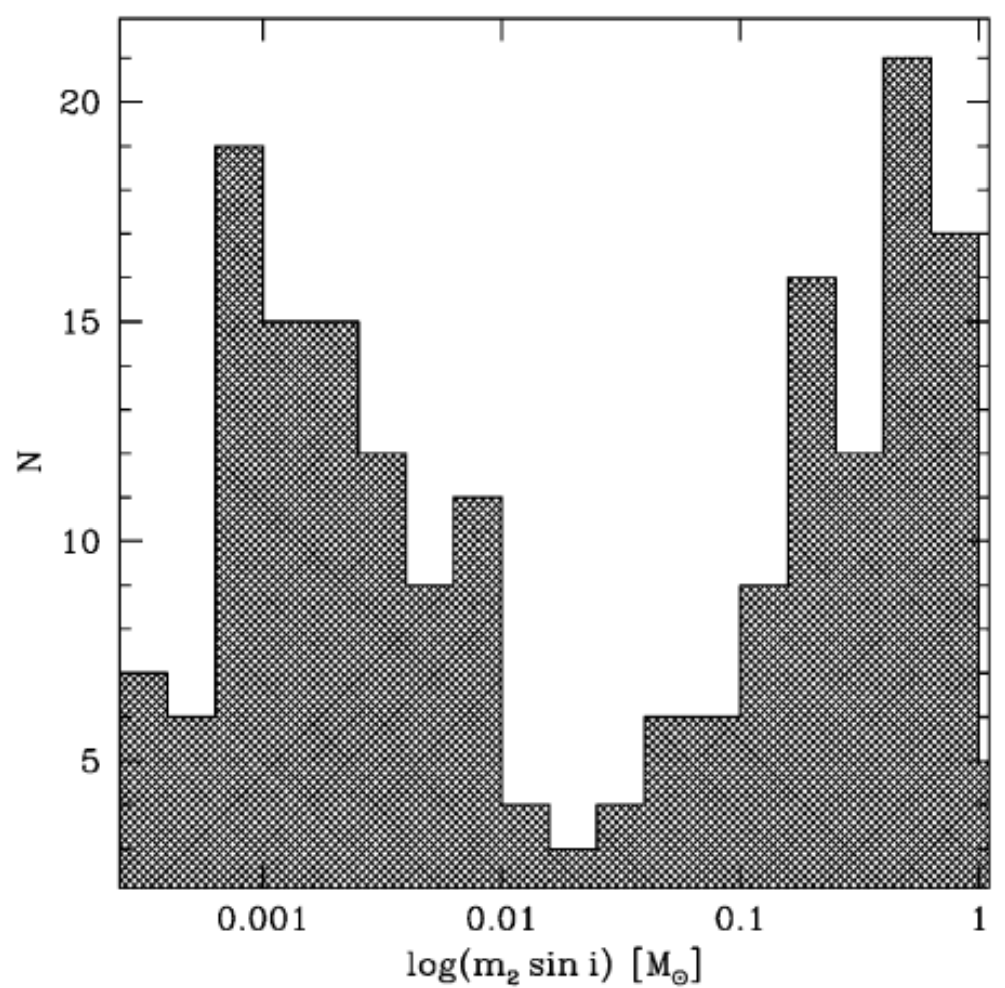

Figura 1.6: Histograma da distribuição de massa mínima para estrelas, companheiras subestelares e exoplanetas. Percebe-se uma distribuição com dois picos com planetas a esquerda $\left(M<0.01 \mathrm{M}_{\odot}\right)$ e estrelas a direita $\left(M>0.08 \mathrm{M}_{\odot}\right)$. A pouca quantidade de corpos no intervalo entre $0.01 \mathrm{M}_{\odot}$ e $0.08 \mathrm{M}_{\odot}$ da distribuição é conhecida como "deserto de anãs marrons". Figura obtida em: Santos et al. (2002).

Por causa das dificuldades observacionais, essa região deve ser analisada com mais 
cuidado, como indicam Grether e Lineweaver (2006) e Raghavan et al. (2010), assim, a região desértica de anãs marrons é ainda questão em debate. No entanto, alguns autores sugerem que ela pode ser compreendida levando em conta a diferença do paradigma atual no processo de formação de uma estrela e de um planeta. Como veremos no Capítulo 3, as estrelas se formam do colapso gravitacional do gás, enquanto os planetas são o resultado de um núcleo embrionário no qual ocorre acreção de matériạ. A diferença física dos dois processos, o início da formação e a migração podem explicar a distribuição bimodal encontrada, mais detalhes podem ser encontrados em Armitage e Bonnell (2002) e Ma e Ge 2013).

Focando na formação planetária, o modelo de acreção exige que os planetas gasosos se formem em regiões externas do disco protoplanetário, onde há disponibilidade de material. Mas, o fato de serem encontrados em regiões mais internas leva ao estudo dos modelos de migração. O gráfico de distribuição de massa em função do período (Figura 1.7) ajuda a compreender algumas características desse processo.

Na Figura 1.7A, obtida por Udry et al. (2003), podemos notar uma região vazia acima de $M \sin i>2 \mathrm{M}_{\mathrm{J}}$ para exoplanetas que não excedem $P=100$ dias, indicando uma falta de exoplanetas massivos em curtos períodos. Nessa figura, Udry et al. (2003) excluíram as estrelas binárias devido às diferenças no processo de formação e de evolução, que permitiriam a formação de exoplanetas em regiões mais próximas de uma das estrelas, como indicam Zucker e Mazeh (2002). Essa exclusão levou ao completo esvaziamento dessa região, com exceção do ponto ligado por uma linha tracejada referente a HD 168443, anteriormente considerado um sistema de anãs marrons e hoje reconhecido como um exoplaneta e uma anã marrom.

Na Figura 1.7B, mais atual, essa característica se mantém, apresentando um baixo número de exoplanetas massivos dentro dessa região. Inseriu-se também a indicação para binárias, para mostrar que sua exclusão não deixaria a região mais vazia, como ocorreu na Figura 1.7A.

Essa falta de exoplanetas massivos em períodos curtos é uma característica marcante, visto que o método de V.R. é mais sensível a planetas massivos mais próximos da estrela, como mostra a Equação 1.6, indicando que não se trata de um bias experimental.

\footnotetext{
${ }^{1}$ Um contraponto desse modelo, que não será discutido neste trabalho, é a formação de planetas gasosos via instabilidade do disco de gás protoplanetário (Boss, 1997).
} 

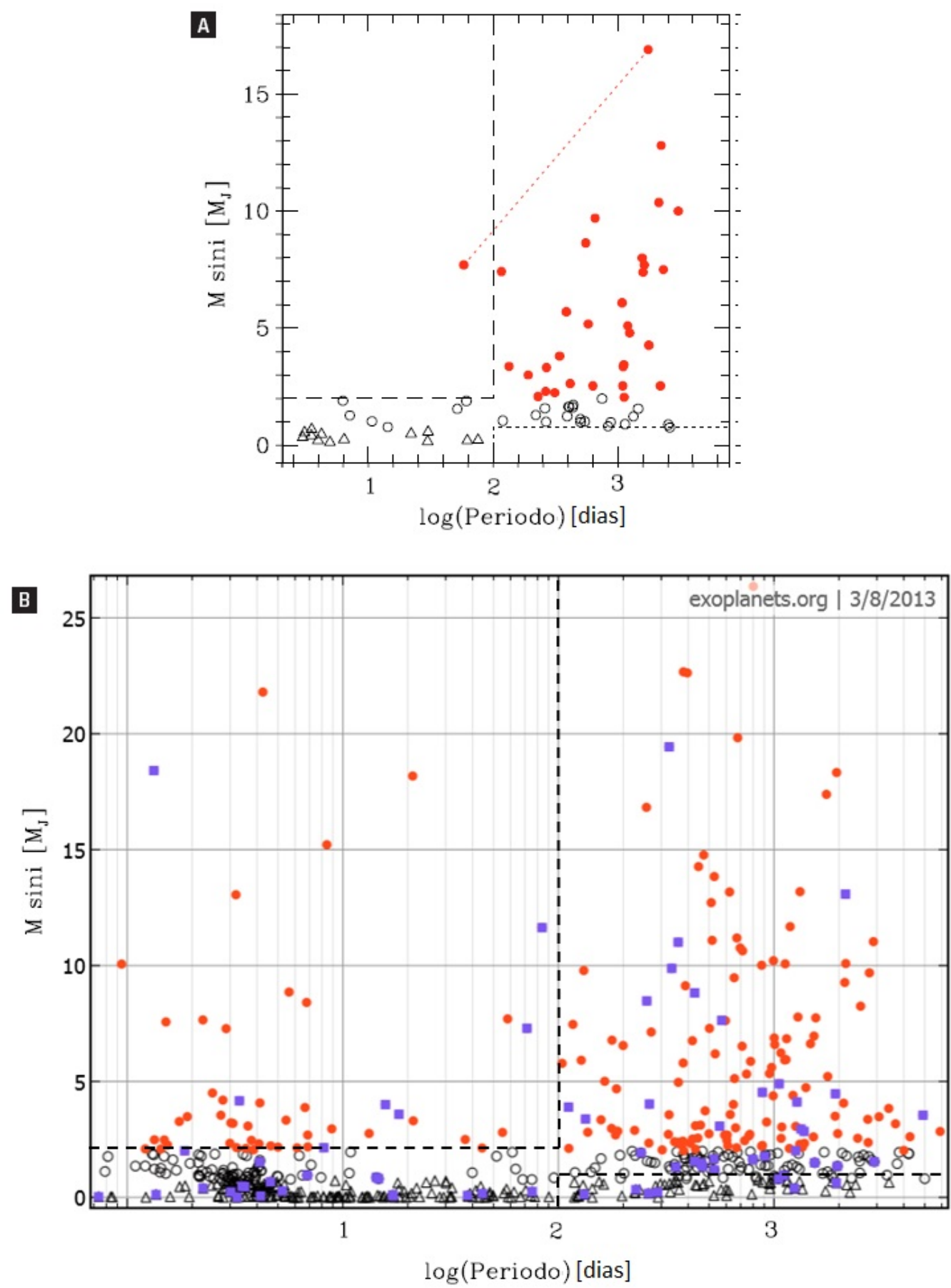

Figura 1.7: Massa mínima versus período dos exoplanetas. Seguindo o gráfico original (Udry et al. 2003), usa-se a diferença de cor e de símbolos para diferenciar a massa: os mais massivos $\left(M \sin i>2 \mathrm{M}_{\mathrm{J}}\right)$ são círculos preenchidos; os de massas intermediárias $\left(0.75 \mathrm{M}_{\mathrm{J}}<M \sin i<\right.$ $\left.2 \mathrm{M}_{\mathrm{J}}\right)$ são círculos sem preenchimento e os menos massivos $\left(M \sin i<0.75 \mathrm{M}_{\mathrm{J}}\right)$ são triângulos sem preenchimento. A linha horizontal mais acima indica um limitador para $M=2 \mathrm{M}_{\mathrm{J}}$; a linha vertical para $P=100$ dias e a linha horizontal mais abaixo para $M=0.75 \mathrm{M}_{\mathrm{J}}$. (A) Foram plotados apenas exoplanetas ao redor de estrelas que não são binárias. Figura obtida em: Udry et al. (2003). (B) Gráfico atualizado, em que estrelas binárias são indicadas por um quadrado preenchido. Figura obtida em: <http://exoplanets.org/>. Acesso em: 03 ago. 2013. 
Entre os diversos processos que visam explicar a falta de planetas massivos na região abaixo de $P=100$ dias, destacam-se três:

- os processos de migração do tipo II devido a interação com o disco de gás (que abrem um gap no disco) que ocorrem para exoplanetas massivos são menos efetivos que o tipo I, o que faz com que permaneçam mais próximos da região de formação (Benítez-Llambay et al., 2011);

- ao alcançar regiões próximas à estrela, a atração gravitacional poderia ser suficiente para o planeta perder seu envelope, ou até mesmo "cair" na estrela central (Davis e Wheatley, 2009);

- possibilidade de os exoplanetas, ao interagir com outros, migrarem para as regiões mais internas ou até mesmo externas, num processo de migração decorrente da interação planetária (Beaugé e Nesvorný, 2012). 11

Para o primeiro processo, de fato, simulações computacionais mostram que o processo de migração do tipo I é mais eficiente que o de tipo II, como indicam Crida et al. (2006).

Outra característica interessante, que podemos notar na Figura 1.7A, é a segunda região vazia para $P>100$ dias e $M \sin i<0.75 \mathrm{M}_{\mathrm{J}}$, que não mostra a mesma correlação na Figura 1.7B. Essa região deve ser vista com cuidado, primeiramente em virtude da dificuldade de detectar exoplanetas com esses parâmetros. Udry et al. (2003) destacam a possibilidade de essa região vazia ser produzida pelo efeito do torque co-orbital em disco massivo, no qual um exoplaneta, numa determinada faixa de massa, sofre uma migração runaway ou tipo III, como revelam os estudos de Masset e Papaloizou (2003). Apesar do aumento das detecções nessa região, a hipótese não pode ser descartada, pois as condições que envolvem esse tipo de migração exigem algumas características para o disco e só funcionam num regime de massa planetária específico.

Podemos realizar uma análise complementar comparando um histograma atual para a distribuição do período em função de uma faixa de massa particular (Figura 1.8) com o histograma obtido por Udry et al. (2003).

\footnotetext{
${ }^{1}$ Alguns autores não consideram esse processo como associado a migração cuja classificação depende da definição utilizada. Aqui estamos interessados nos efeitos que podem gerar mudanças nos elementos orbitais.
} 

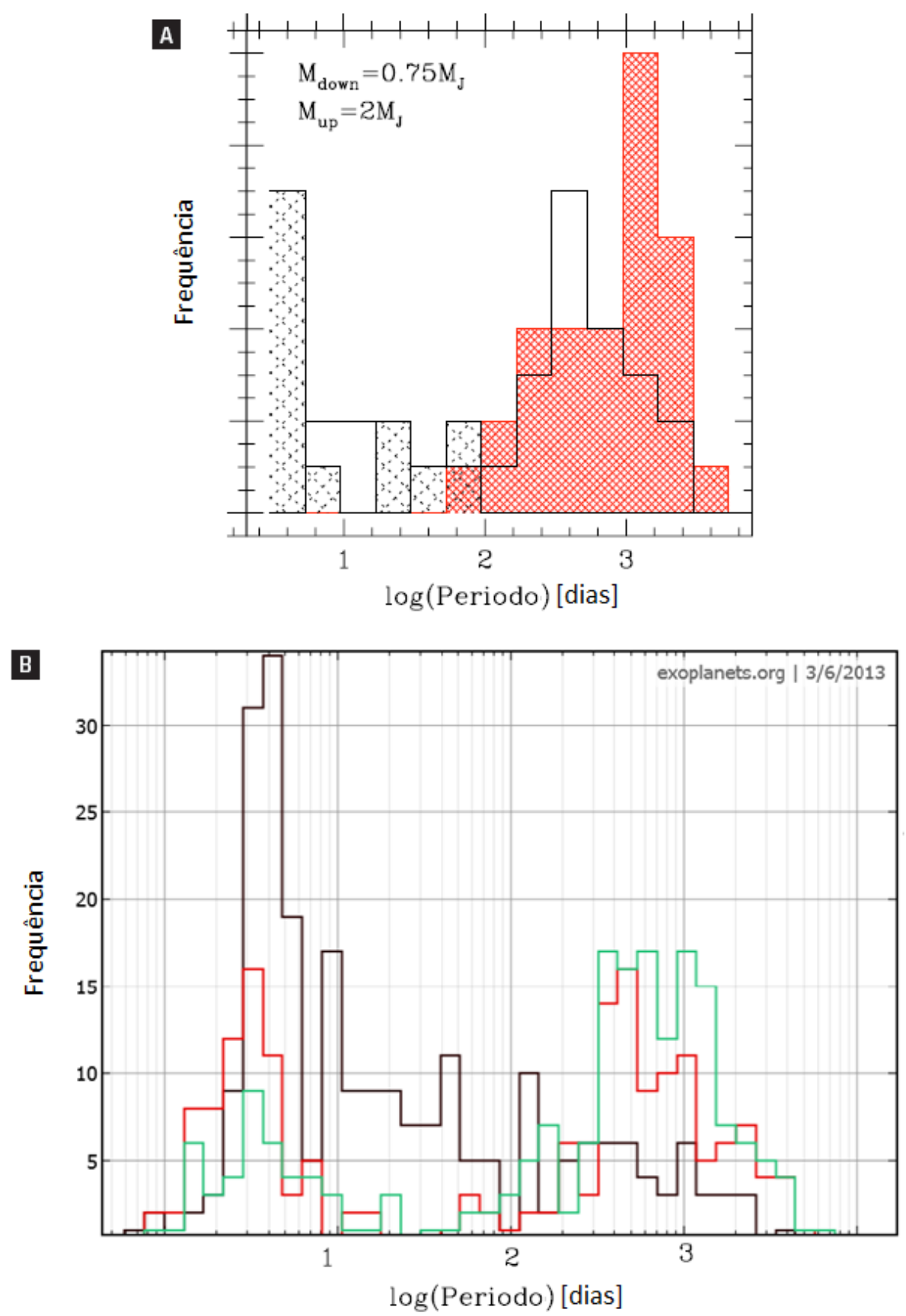

Figura 1.8: Distribuição do período dos planetas para diferentes regimes de massa. (A) Os histogramas pontilhados representam os planetas menos massivos $\left(M \sin i<0.75 \mathrm{M}_{\mathrm{J}}\right)$; os sem preenchimento têm massas intermediárias $\left(0.75 \mathrm{M}_{\mathrm{J}}<M \sin i<2 \mathrm{M}_{\mathrm{J}}\right)$; os preenchidos na cor escura são os massivos $\left(M \sin i>2 \mathrm{M}_{\mathrm{J}}\right)$. Foram excluídas as estrelas binárias ou múltiplas. Figura obtida em: Udry et al. (2003). (B) Os histogramas de linha preta representam os planetas menos massivos $\left(M \sin i<0.75 \mathrm{M}_{\mathrm{J}}\right)$; os de linha vermelha são massas intermediárias $\left(0.75 \mathrm{M}_{\mathrm{J}}<M \sin i<2 \mathrm{M}_{\mathrm{J}}\right)$; os de linha verde são os massivos $\left(M \sin i>2 \mathrm{M}_{\mathrm{J}}\right)$. Neste caso, não foram excluídas as binárias. Figura obtida em: <http://exoplanets.org/>. Acesso em: 03 jun. 2013. 
Com base nessa comparação, podemos perceber uma presença dominante de exoplanetas menos massivos em regiões de período mais curto. Em períodos mais longos, a relação se inverte e o número de exoplanetas massivos é maior que os dotados de menor massa. Não podemos esquecer, porém, a dificuldade de detecção de exoplanetas de baixa massa em periodos mais longos. Outro fato interesssante que podemos visualizar no histograma A é a queda acentuada de exoplanetas entre 10 e 100 dias. No histograma B, por sua vez, esse fato não ocorre para os exoplanetas de menor massa.

A presença do pico de exoplanetas menos massivos na região de curto período e a distribuição bimodal para os massivos e de massa intermediária não parecem ser decorrentes do bias observacional. O pico de exoplanetas menos massivos pode indicar a eficiência do processo de migração tipo I em distribuir esses exoplanetas em regiões mais próximas. O vale detectado entre a distribuição bimodal dos massivos e de massa intermediária, por sua vez, parece indicar uma região de transição entre categorias de exoplanetas que sofrem diferentes processos de migração. Trata-se, no caso, da migração tipo II, que faz com os exoplanetas mais massivos e de massa intermediária permaneçam mais afastados da estrela central.

\subsubsection{Metalicidade da estrela}

Diante da abundância de elementos no Universo, os astrônomos costumam trabalhar com uma distribuição de elementos que leva em conta a abundância relativa de hidrogênio $[X]$, hélio $[Y]$ e outros elementos, denominados "metais" $[Z]$, em que, por definição: $[X]+$ $[Y]+[Z]=1$.

Define-se, portanto, a metalicidade de uma estrela $[\mathrm{Fe} / \mathrm{H}]$ como o logaritmo da abundância de ferro na estrela relativo à abundância de ferro no Sol, que embora não seja o elemento mais predominante, é o mais fácil de medir, logo

$$
[\mathrm{Fe} / \mathrm{H}]=\log \left(\frac{N_{\mathrm{Fe}}}{N_{\mathrm{H}}}\right)_{\text {estrela }}-\log \left(\frac{N_{\mathrm{Fe}}}{N_{\mathrm{H}}}\right)_{\mathrm{Sol}},
$$

onde $N_{\mathrm{Fe}}$ e $N_{\mathrm{H}}$ são, respectivamente, o número de átomos de ferro e hidrogênio por unidade de volume.

Essa relação é positiva para estrelas com maior metalicidade que o Sol, zero para estrelas com a mesma metalicidade e negativo quando a metalicidade é menor. 
O estudo das estrelas que hospedam exoplanetas tem revelado que elas são mais ricas em metais que as estrelas anãs. Além disso, a presença de exoplanetas gigantes parece ter uma relação forte com o aumento da metalicidade, como indicam Johnson et al. (2010). Essa observação não parece resultar da forma de detecção, mas uma característica do processo de formação planetária. A Figura 1.9 faz uma comparação entre os dados obtidos por Santos et al. (2003) e os dados atuais com relação à metalicidade de estrelas que possuem exoplanetas.

A
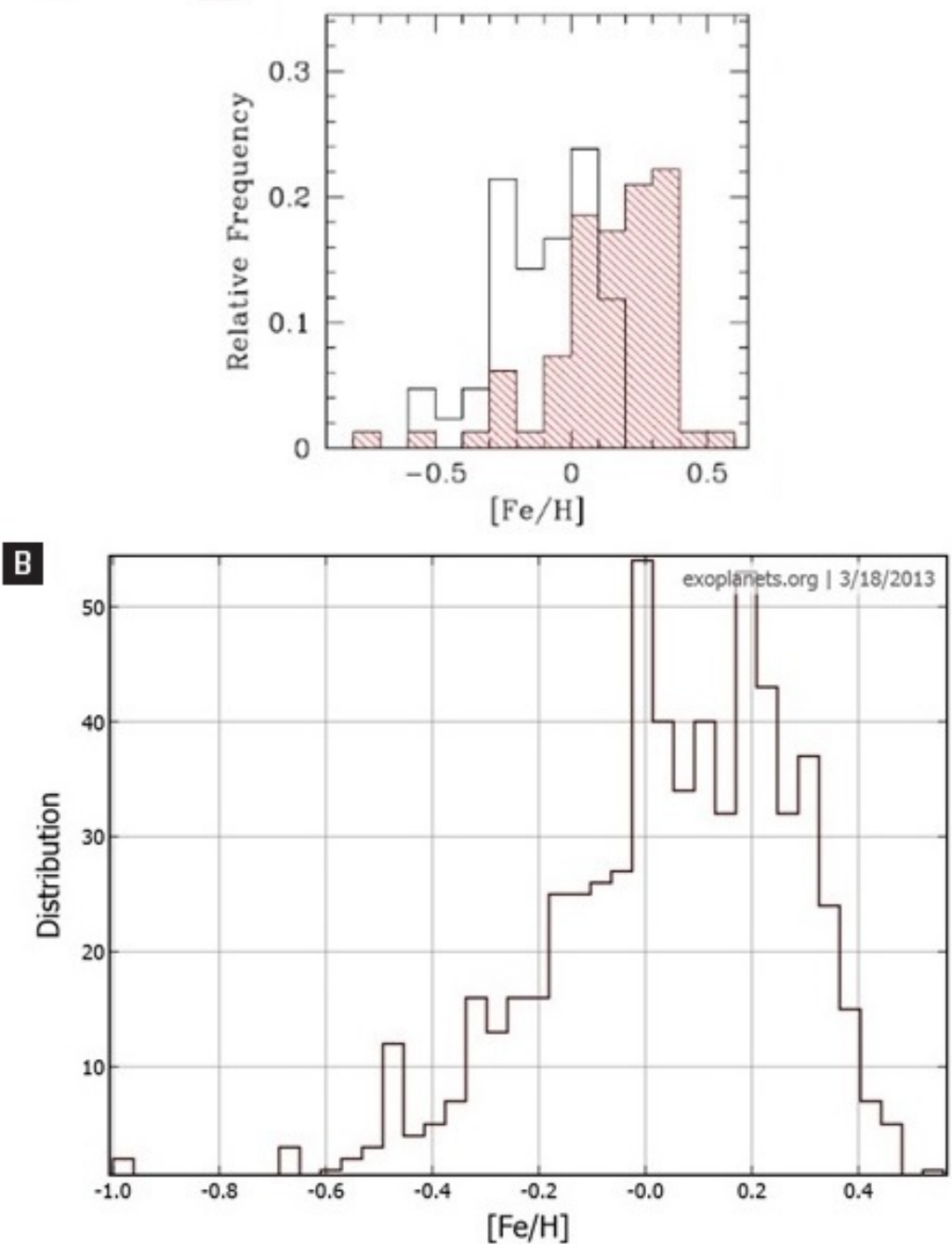

Figura 1.9: (A) Distribuição da metalicidade em estrelas com exoplanetas (histograma hachurado) comparada com a mesma distribuição em um grupo de anãs sem exoplanetas (histograma vazio). Figura obtida em: Santos et al. (2003). (B) Distribuição atual da metalicidade em estrelas com exoplanetas. Figura obtida em: <http://exoplanets.org/>. Acesso em: 18 mar. 2013. 
Comparando os dois gráficos, percebemos que houve um aumento de estrelas de metalicidade similar à do Sol que possuem exoplanetas. No entanto, nota-se também maior distribuição de estrelas com maior metalicidade. Considerando a distribuição da metalicidade das estrelas anãs obtida na Figura $1.9 \mathrm{~A}$, observamos que as estrelas com exoplanetas efetivamente indicam maior metalicidade. Assim, a probabilidade de encontrar um exoplaneta gigante parece ter forte relação com a metalicidade da estrela. É importante destacar que o fato de o excesso de metalicidade aumentar a probabilidade de encontrar um exoplaneta não significa que este não possa se formar em regiões de baixa metalicidade como destacam Santos et al. (2003).

É importante ressaltar que a Figura 1.9A, obtida utilizando aproximadamente 89 estrelas com exoplanetas, contou com uma análise espectroscópica e um tratamento de dados mais pontual, como pode ser visto em Santos et al. (2003), ao passo que a Figura $1.9 \mathrm{~B}$ contou com uma análise estatística das medidas disponíveis no domínio <http://exoplanets.org/>, sugerindo que alguns pontos individuais podem divergir. Além disso, a busca de exoplanetas envolve estrelas com determinada temperatura efetiva, portanto, um vínculo experimental. Embora esse fato não interfira na amostra, constitui um ponto de dificuldade nos estudos dos parâmetros estelares e sua relação com a formação planetária.

Estudos indicam que esse excesso de metalicidade envolve uma origem primordial, na qual o teor de metal da nuvem formadora do sistema é o principal parâmetro para o nascimento de planetas gigantes, embora esse vínculo não seja encontrado para planetas de tipo terrestre, como indicam Buchhave et al. (2012). De fato, simulações revelam que, quanto maior a metalicidade do disco protoplanetário, maior a possibilidade da formação dos núcleos planetários que levarão à formação dos exoplanetas gigantes como indicam Pollack et al. (1996). Vale destacar, que apesar de ser um vínculo forte em favor do modelo de acreção para formação planetária, esse fato não descarta a possibilidade da formação através do modelo de instabilidade do disco (Boss, 1997).

É interessante analisar alguns parâmetros planetários em função da metalicidade da estrela hospedeira. A Figura 1.10 apresenta a relação da metalicidade com a massa mínima. 

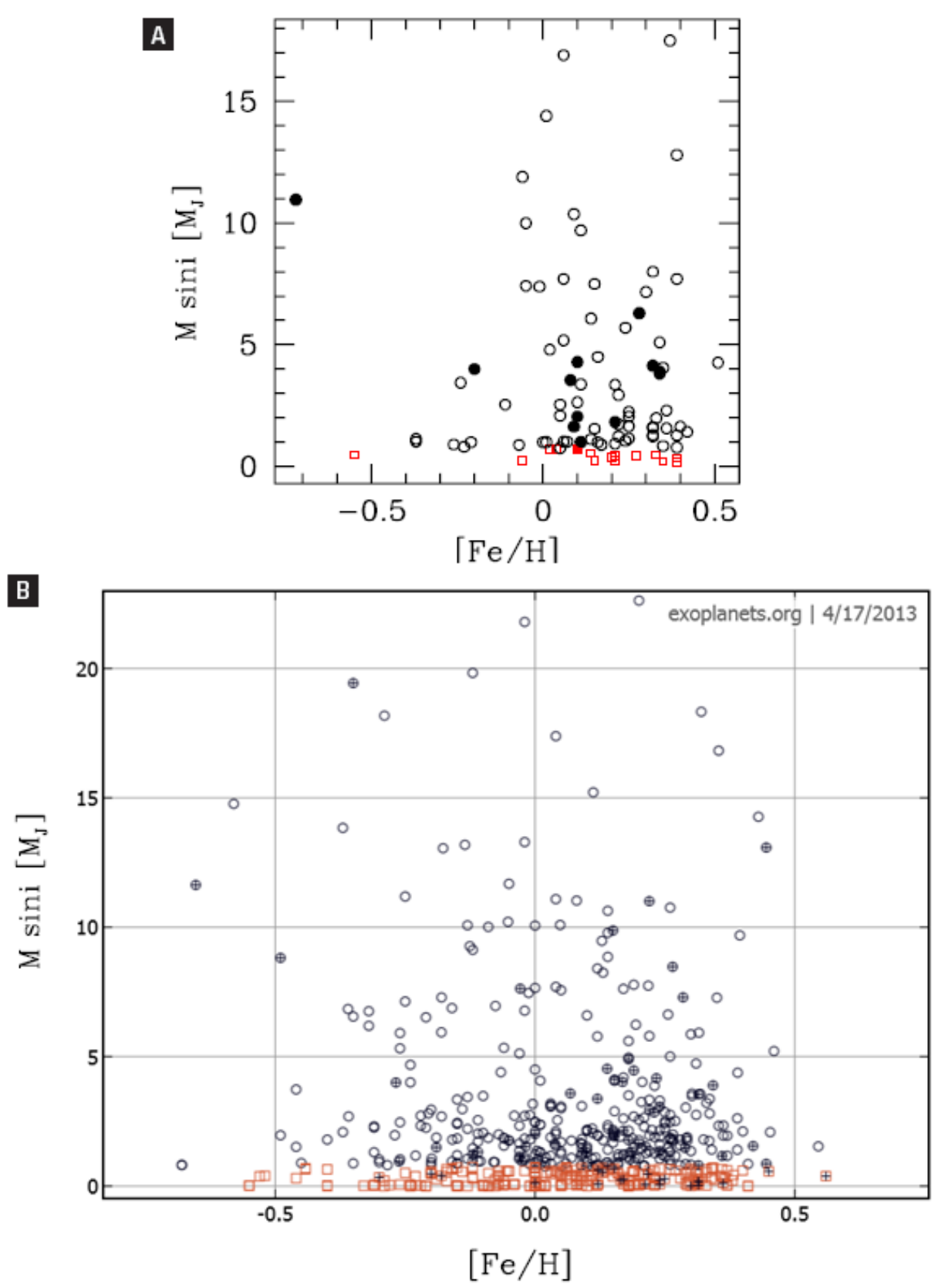

Figura 1.10: (A) O gráfico da massa do exoplaneta versus metalicidade da estrela hospedeira parecia indicar que os exoplanetas mais massivos são formados em estrelas com excesso de metalicidade (os quadrados vermelhos representam uma massa mínima menor que $0.75 \mathrm{M}_{\mathrm{J}}$, ao passo que os círculos indicam massas maiores; círculos ou quadrados preenchidos correspondem a sistemas estelares múltiplos). Figura obtida em: Santos et al. (2003). (B) Os dados atuais mostram uma distribuição mais homogênea tanto para planetas mais massivos quanto para os menos massivos. Na figura, a cruz dentro do quadrado ou do círculo representa sistemas estelares múltiplos. Figura obtida em: <http://exoplanets.org/>. Acesso em: 17 abr. 2013. 
A Figura 1.10A parecia indicar que haveria uma falta de planetas massivos em estrelas de baixa metalicidade. No entanto, Santos et al. (2003) observaram que a análise estatística não aponta para esse fato e, como notamos na Figura $1.10 \mathrm{~B}$, mais atual, esse vínculo realmente não existe.

Os dois gráficos também não parecem indicar nenhuma relação entre massa mínima e metalicidade para a formação nos sistemas estelares múltiplos.

Já a Figura 1.11 permite analisar a distribuição do período do exoplaneta em função da metalicidade da estrela. A Figura 1.11A parecia indicar maior presença de planetas de curto período em estrelas mais ricas em metais, fato usado como um vínculo do excesso de metalicidade na estrela em virtude da migração da poeira e dos exoplanetas, que poderiam ter poluído seu envelope convectivo. A análise estatística de Santos et al. (2003) revelou que esse vínculo não era tão forte. De fato, na Figura $1.11 \mathrm{~B}$, mais atual, podemos ver uma distribuição bem mais homogênea do período.

Além disso, também não se encontra nenhuma relação entre período e metalicidade da estrela para sistemas estelares múltiplos.

A ausência de uma relação clara entre o período orbital e a metalicidade indica que o mecanismo de migração parece ser independente da metalicidade do disco. No entanto, esse fato deve ser visto com cuidado, uma vez que, apesar de não existir essa dependência direta, o excesso de metalicidade, ao que tudo indica, aumenta a taxa de acreção de materiais para formação do planeta, como o processo de migração depende da massa planetária, há uma dependência indireta com a metalicidade.

Outra característica interessante é que, se em estrelas de baixa metalicidade, só se formam planetas de baixa massa, estrelas pobres em metais deveriam ter preferenciavelmente planetas em curto período, já que os planetas menos massivos migram mais rapidamente que os massivos. No entanto, esse vínculo é difícil de detectar e requer uma análise mais cuidadosa, pois o método de velocidade radial favorece a detecção de exoplanetas massivos em curtos períodos. 

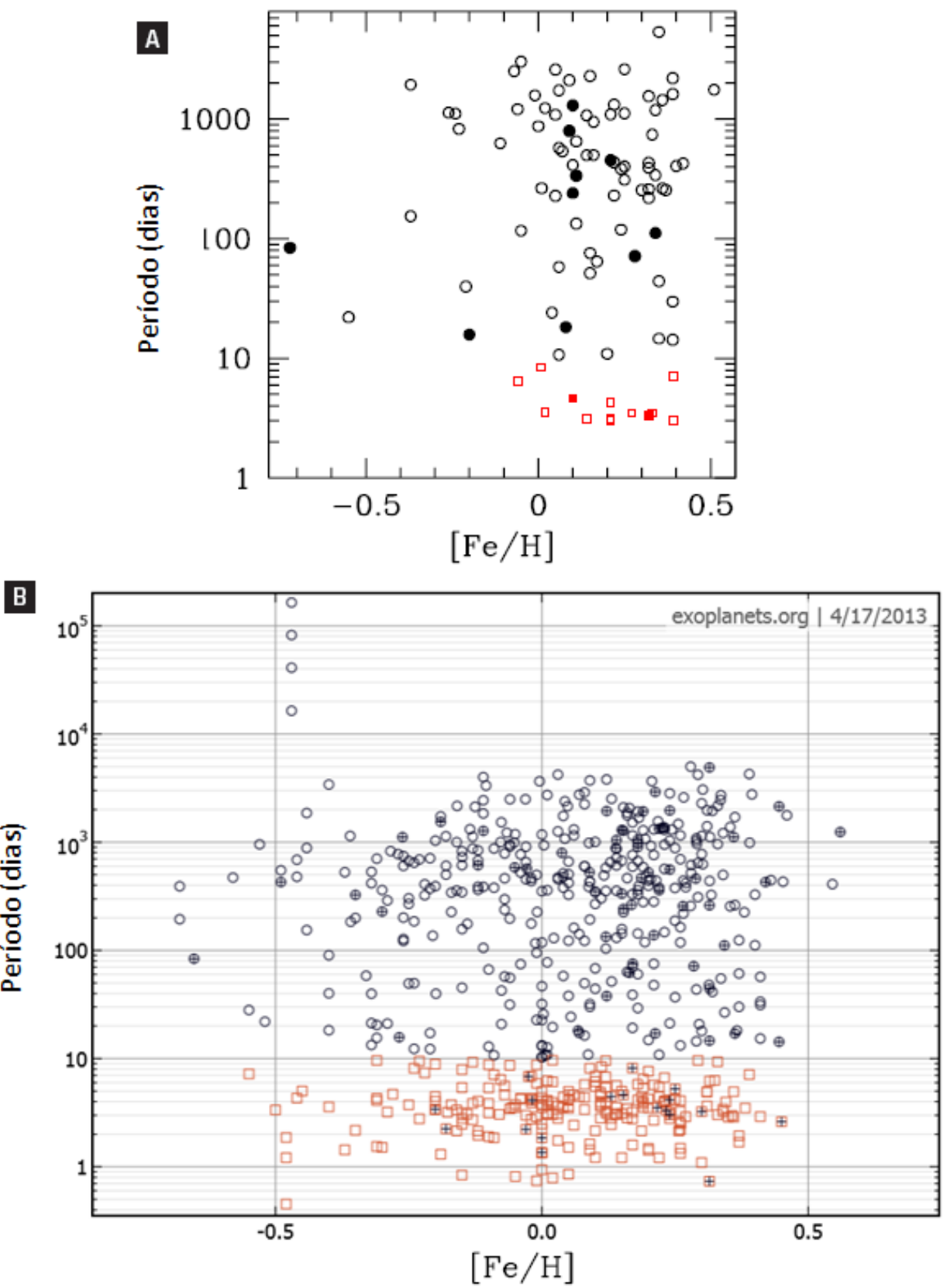

Figura 1.11: (A) O gráfico do período do exoplaneta versus metalicidade da estrela parecia indicar maior presença de planetas de curto período em estrelas mais ricas em metais (os quadrados vermelhos indicam um período menor que 10 dias; os círculos, períodos maiores; círculos ou quadrados preenchidos representam sistemas estelares múltiplos). Figura obtida em: Santos et al. (2003). (B) Os dados atuais não mostram a mesma correlação encontrada na Figura (A); ocorre uma distribuição homogênea tanto para exoplanetas de longo ou curto período (na figura, a cruz dentro do quadrado ou do círculo corresponde a sistemas estelares múltiplos). Figura obtida em: <http://exoplanets.org/>. Acesso em: 17 abr. 2013. 


\subsection{Sumário}

A breve descrição dos métodos de detecção dos exoplanetas permitiu verificar que o método de velocidade radial (V.R.) ainda é o mais comumente usado para obter os parâmetros orbitais do exoplaneta.

A análise desse parâmetros orbitais revelou a presença de exoplanetas gasosos em regiões muito mais próximas da estrela do que os gasosos de nosso Sistema Solar. É justamente esse fato que leva ao estudo dos processos de migração planetária que podem ser provocados por forças de maré, pela interação planeta-planeta ou pela interação com o disco protoplanetário. Esta dissertação tem como objeto precisamente este último. Assim, com base nos parâmetros orbitais obtidos através do método V.R. (disponíveis no sítio $<$ http://exoplanets.org/>), realizamos algumas análises estatísticas com o objetivo de obter vínculos capazes de contribuir para o estudo desse processo de migração.

O primeiro vínculo que encontramos, baseado na Figura 1.7, é a influência da massa planetária no processo de migração. Em períodos menores que 100 dias, percebe-se uma falta de exoplanetas massivos (acima de $2 \mathrm{M}_{\mathrm{J}}$ ). Esse dado é interessante visto que o método V.R. é muito mais sensível a exoplanetas massivos próximos da estrela, constituindo, portanto, um forte indicativo de que a taxa de migração é maior para os menos massivos $\left(M<0.75 \mathrm{M}_{\mathrm{J}}\right)$. Uma análise mais cuidadosa com base no histograma da Figura $1.8 \mathrm{~B}$ reforça esse vínculo e mostra que, de fato, há um vale entre os períodos de 10 a 100 dias para exoplanetas acima de $0.75 \mathrm{M}_{\mathrm{J}}$, indicando uma região de transição entre processos migratórios diferentes. Além da migração devido ao disco de gás, outras hipóteses são sugeridas, como a evaporação e/ou queda do envelope planetário na estrela, que poderiam reduzir a massa dos exoplanetas mais próximos, também há a possibilidade de a interação entre um sistema de exoplanetas favorecer esse cenário. No entanto, simulações numéricas hidrodinâmicas, baseadas na interação disco-planeta, mostram que os menos massivos sofrem um processo migratório tipo I e, à medida que capturam material do disco (planetesimais e gás), adquirem massa o suficiente para abrir um gap no disco, que os leva a um processo migratório diferente, de tipo II. Esse processo, mais lento que o anterior, faz com que permaneçam mais afastados da estrela.

Outro aspecto a ser investigado são os exoplanetas com massa inferior a $0.75 \mathrm{M}_{\mathrm{J}}$ em períodos maiores que 100 dias. Podemos notar na Figura $1.8 \mathrm{~B}$ um relativo esvaziamento 
dessa região. Simulações numéricas, usando interação disco-planeta, revelam que certa faixa de massas planetárias em um disco razoavelmente massivo sofrem uma migração tipo III ou runaway, que poderia ser a causa desse esvaziamento. Esse fator deve ser analisado criteriosamente, em virtude da dificuldade de detecção de exoplanetas de baixa massa em longos períodos.

A dependência da massa leva a outros estudos como, por exemplo, a formação planetária, já que o processo migratório devido à interação com o disco ocorre conjuntamente com ela.

O estudo da metalicidade das estrelas que possuem exoplanetas revela uma metalicidade maior em comparação com o nosso Sol, como mostra a Figura 1.9. Atribuía-se vínculo ao processo de migração que poderia contaminar o envelope estelar, mas as referências mostram que essa poluição não é suficiente para comprovar o desvio apresentado. Além disso, esse fato levaria a uma presença maior de exoplanetas de curto período em estrelas de maior metalicidade. No entanto, como revela a Figura 1.11B, esse vínculo não ocorre. Sugere-se então uma origem primordial, ou seja, um disco protoplanetário mais rico em metais que facilita a acreção de matéria e a criação de um núcleo sólido que, por sua vez, acretaria gás rapidamente até que ocorresse a dissipação do disco. Esse modelo para a formação planetária, conhecido como modelo de acreção, será o utilizado nesta dissertação. Todavia, se discos com maior metalicidade favorecem a formação planetária, era de esperar uma presença maior de exoplanetas massivos em estrelas de maior metalicidade, mas, como mostra a Figura $1.10 B$, isso não ocorre. A dificuldade de encontrar exoplanetas em regiões mais afastadas da estrela, com o uso do método V.R., pode servir de justificativa para esse fato. No entanto, vale destacar que trabalhos mais atuais, como Buchhave et al. (2012), que utiliza dados obtidos por trânsito, apontam para uma relação da presença de exoplanetas gigantes com a alta metalicidade. 
Capítulo 2

\section{Fundamentos teóricos}

\subsection{Ondas de densidade espirais}

Esta seção tem como objetivo fornecer algumas considerações teóricas sobre o desenvolvimento de ondas de densidade no disco protoplanetário, que ocorrem por causa da perturbação gerada pelo planeta, e são comumentemente vistas em simulações numéricas hidrodinâmicas. O tratamento é similar àquele encontrado no estudo de discos galácticos, e irá fornecer as ideias básicas para entender o desenvolvimento das equações da migração planetária do Capítulo 5.

Antes de começar uma análise formal, faremos uma descrição didática do desenvolvimento dessas ondas de densidade.

Vamos considerar o disco protoplanetário ao redor da estrela como um fluido, de modo que, seu menor elemento de volume tenha suas propriedades médias (pressão, densidade e temperatura) variando de forma contínua. Vamos nos preocupar com a região próxima do planeta. Ignorando o movimento randômico do elemento de fluido, podemos considerar sua órbita não perturbada, como se fosse um círculo perfeito ao redor do planeta. Mas, ao sofrer uma pequena perturbação, esse elemento sofre um deslocamento de sua posição de equilíbrio. Esses deslocamentos serão maiores para elementos de fluidos próximos de qualquer situação de ressonância. Como o deslocamento na situação de ressonância é maior que o deslocamento imediatamente ao lado, ocorrem regiões de compressão e rarefação do material ao longo do disco.

Imaginemos que essa pequena perturbação leve os elementos de fluido a realizar uma órbita elíptica, vista do referencial do planeta. Em alguns lugares, essas órbitas ficam mais próximas, ao passo que, em outros, a distância entre elas é maior, criando regiões mais 
e menos densas. O modelo de Kalnajs ajuda a visualizar como o espaçamento entre as órbitas pode produzir uma onda de densidade espiral (Figura 2.1). Embora essa estrutura seja fixa no espaço, há uma velocidade de deslocamento em relação ao elemento de fluido que compõe o disco, o que permite afirmar que se trata de uma onda.

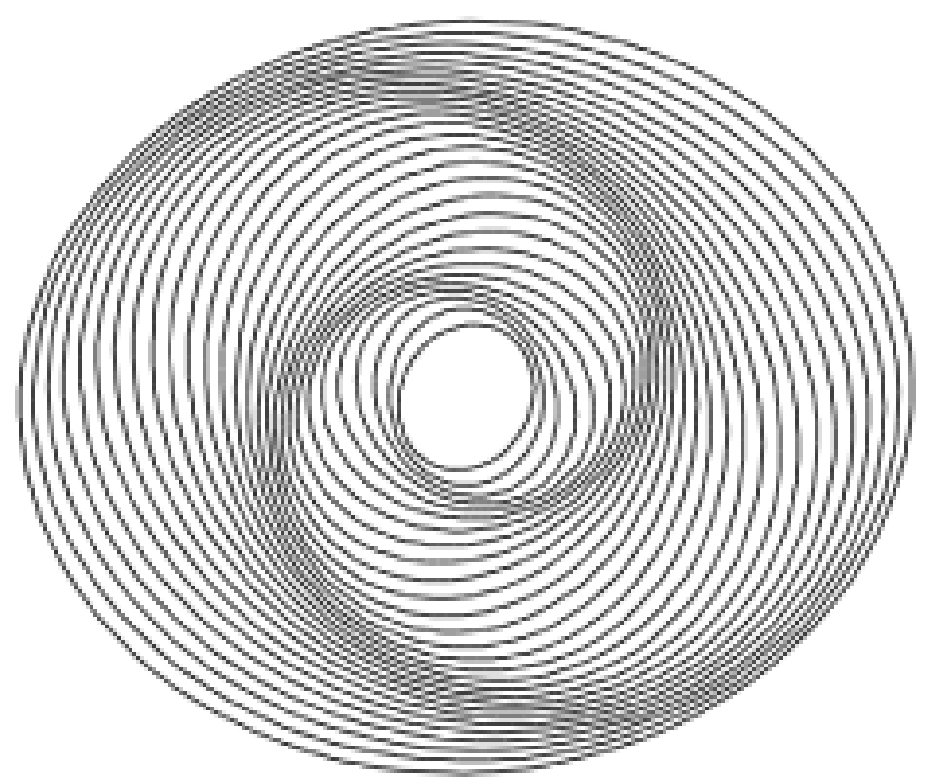

Figura 2.1: No modelo de Kalnajs podemos visualizar que nas regiões na qual as órbitas se aproximam ocorre naturalmente uma densidade maior, gerando uma estrutura espiral. Figura obtida em: $<$ http://www.astro.virginia.edu/class/whittle/astr553/Topic06/Lecture_6.html>. Acesso em: 22 jan. 2014.

Entretanto, temos que verificar até que ponto estamos próximos da realidade e se essas órbitas poderiam ou não acontecer e até mesmo se manter.

Vamos, então, analisar matematicamente o que ocorre quando esse elemento de fluido sofre uma pequena perturbação radial na vizinhança do planeta, ou seja, vamos desprezar os efeitos da estrela central.

Considerando um elemento de fluido que gira com velocidade angular constante $\Omega>0$ ao redor do planeta, podemos descrevê-lo por meio de um sistema de coordenadas cilindricas $(r, \theta, z)$ centrado no planeta, cujo potencial, com simetria azimutal, é descrito pela função $\Phi(r, z)$ de modo que ocorre a conservação do momento angular. Ademais, considere um disco bidimensional, o que permite escrever

$$
\ddot{\vec{r}}=-\vec{\nabla} \Phi(r) \quad \text { e } \quad l_{z}=r^{2} \dot{\theta}=\text { cte }
$$


Logo, na direção radial, temos

$$
\ddot{r}-r \dot{\theta}^{2}=-\frac{\partial \Phi}{\partial r} \Rightarrow \ddot{r}=r \dot{\theta}^{2}-\frac{\partial \Phi}{\partial r} .
$$

Usando a relação $l_{z}=r^{2} \dot{\theta}$, podemos escrever a aceleração radial em termos de um potencial efetivo, assim

$$
\ddot{r}=-\frac{\partial \Phi_{\mathrm{eff}}}{\partial r}
$$

onde

$$
\Phi_{\mathrm{eff}}=\Phi(r)+\frac{l_{z}^{2}}{2 r^{2}}
$$

A Figura 2.2 mostra um esboço do gráfico do potencial efetivo em função de $r$. Observe que ele possui um mínimo em $r=R_{\mathrm{g}}$, correspondente à menor energia da órbita.

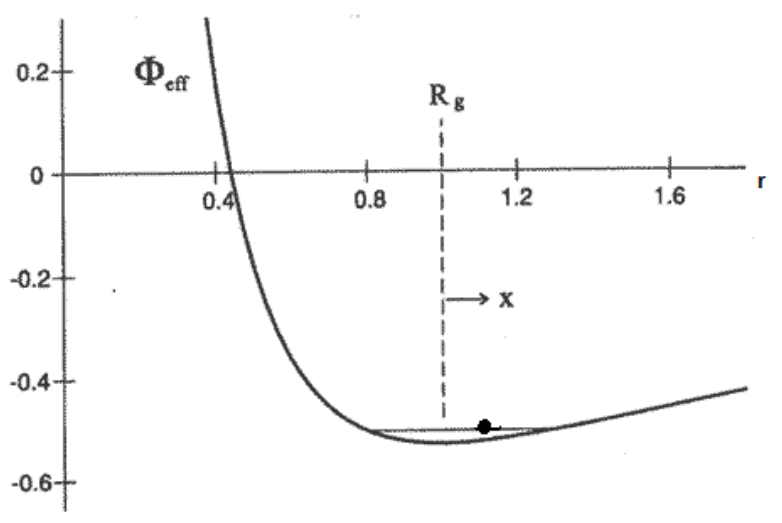

Figura 2.2: Esboço do gráfico do potencial gravitacional efetivo $\Phi_{\text {eff }}$ que possui um mínimo correspondente à menor energia da órbita. Figura obtida em: <http://www.astro.virginia.edu/class/whittle/astr553/Topic06/Lecture_6.html>. Acesso em: 22 jan. 2014.

O cálculo a seguir, por meio do qual se obtém a aceleração centrípeta, revela que essa energia mínima corresponde a uma órbita circular

$$
\left(\frac{\partial \Phi_{\mathrm{eff}}}{\partial r}\right)_{R_{\mathrm{g}}}=0 \Rightarrow\left(\frac{\partial \Phi}{\partial r}\right)_{R_{\mathrm{g}}}-R_{\mathrm{g}} \dot{\theta}^{2}=0 \Rightarrow\left(\frac{\partial \Phi}{\partial r}\right)_{R_{\mathrm{g}}}=\frac{V_{c}^{2}}{R_{\mathrm{g}}}
$$

Expandindo o potencial em $r=R_{\mathrm{g}}+x$, tal que $x \ll R_{\mathrm{g}}$, obtemos

$$
\ddot{r}=\ddot{x}=-\left(\frac{\partial \Phi_{\mathrm{eff}}}{\partial r}\right)_{R_{\mathrm{g}}}-x\left(\frac{\partial^{2} \Phi_{\mathrm{eff}}}{\partial r^{2}}\right)_{R_{\mathrm{g}}}=-x\left(\frac{\partial^{2} \Phi_{\mathrm{eff}}}{\partial r^{2}}\right)_{R_{\mathrm{g}}}=-\kappa^{2} x .
$$


Portanto, ao sofrer uma pequena perturbação na direção radial, uma partícula nesse potencial realiza uma oscilação harmônica simples na mesma direção, cuja equação de movimento é

$$
\ddot{x}+\kappa^{2} x=0
$$

A solução da equação acima é da forma

$$
x(t)=X \cos (\kappa t+\psi),
$$

onde $\psi$ é a fase determinada pelas condições iniciais e $\kappa$ a frequência, conhecida como frequência epicíclica, definida por

$$
\kappa^{2}=\left(\frac{\partial^{2} \Phi_{\mathrm{eff}}}{\partial r^{2}}\right)_{R_{g}}=\left(\frac{\partial}{\partial r}\left(\frac{\partial \Phi}{\partial r}\right)\right)_{R_{\mathrm{g}}}+\frac{3 l_{z}{ }^{2}}{R_{\mathrm{g}}{ }^{4}}=\left(r \frac{d \Omega^{2}}{d r}+4 \Omega^{2}\right)_{R_{\mathrm{g}}},
$$

que também pode ser escrita como

$$
\kappa^{2}=\left(\frac{1}{r^{3}} \frac{d}{d r}\left[r^{2} \Omega(r)\right]^{2}\right)_{R_{\mathrm{g}}} .
$$

Agora, vamos analisar o que acontece na direção $\theta$ devido à oscilação radial. Usando a definição de momento angular $\left(l_{\mathrm{z}}=R_{\mathrm{g}}^{2} \Omega\right)$, encontramos, para $x \ll R_{\mathrm{g}}$

$$
\dot{\theta}=\frac{l_{z}}{r^{2}}=\frac{l_{z}}{\left(R_{\mathrm{g}}+x\right)^{2}} \simeq \Omega\left(1-\frac{2 x}{R_{\mathrm{g}}}\right)
$$

cuja integral nos fornece

$$
\theta(t)=\Omega t+\theta_{0}-\frac{2 \Omega}{\kappa R_{\mathrm{g}}} X \sin (\kappa t+\psi) .
$$

É comum definir a distância $y$ como a distância ao longo da órbita principal não perturbada na direção angular. Desse modo, num referencial girante, temos

$$
y \equiv R_{\mathrm{g}}\left(\theta-\theta_{\mathrm{g}}\right)=-\frac{2 \Omega}{\kappa} X \sin (\kappa t+\psi)=Y \sin (\kappa t+\psi)
$$

Com base nas Equações 2.4 e 2.8, percebemos que ambas as coordenadas executam uma oscilação harmônica com mesma frequência, mostrando que os epiciclos são, no referencial girante, elipses com razão $\frac{X}{Y}=\frac{\kappa}{2 \Omega}$. 
A interpretação física para a frequência epicíclica pode ser obtida levando em consideração o referencial adotado. A órbita de uma partícula de massa $m$ no referencial não inercial do planeta sofre uma aceleração centrífuga e uma força de Coriolis, que é responsável pelo movimento no epiciclo. Portanto, temos uma órbita circular de referência em torno do planeta, à qual daremos o nome de deferente, e um movimento elíptico ao redor de um ponto que se encontra no deferente. A composição desses movimentos descreve a órbita vista do referencial adotado.

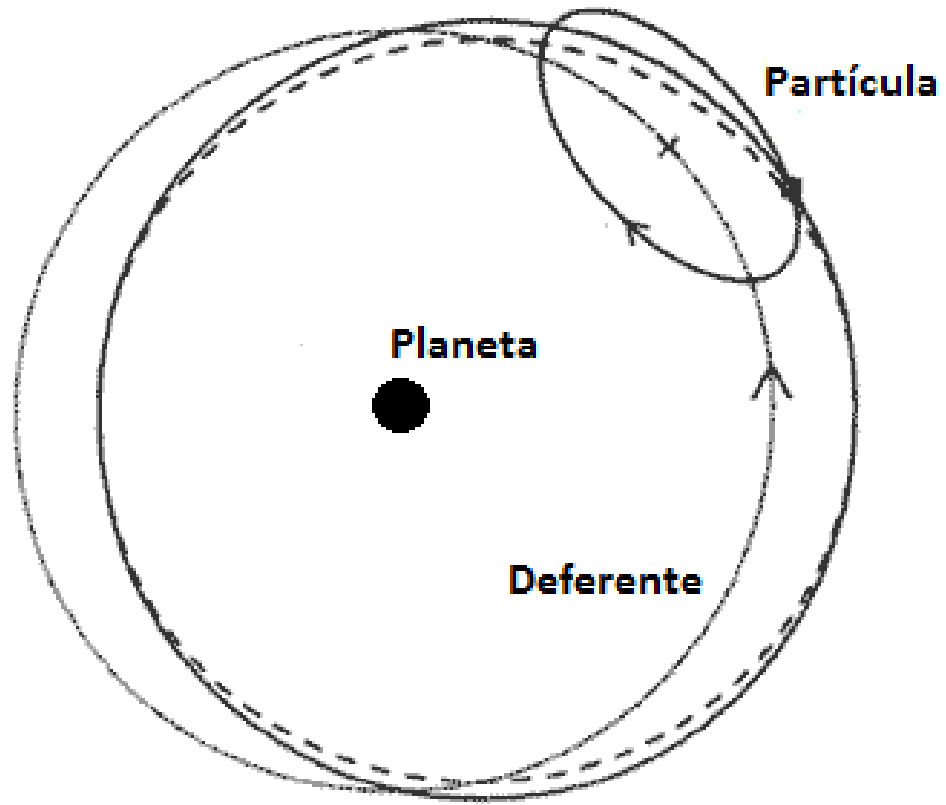

Figura 2.3: Órbita elíptica (curva pontilhada) gerada pela superposição do movimento retrógrado de frequência $\kappa$ ao longo de uma pequena elipse cujos eixos possuem razão $\frac{1}{2}$, e do movimento progressivo do centro da elipse com frequência $\Omega$ ao longo de um círculo. Figura obtida em: $<$ http://www.astro.virginia.edu/class/whittle/astr553/Topic06/Lecture_6.html>. Acesso em: 22 jan. 2014.

É possível construir órbitas fechadas através da composição do movimento orbital e epicicloidal. Para isso, basta que, ao realizar uma órbita completa, haja oscilações epicíclicas inteiras. Um caso interessante ocorre quando $\Omega=\kappa / 2$, cuja solução final é uma órbita fechada com aspecto de elipse, como mostra a curva pontilhada da Figura 2.3 .

É comum na literatura encontrar a frequência epicíclica e orbital em termos dos parâmetros de Oort's deduzidos no Apêndice A (Equações A.4 e A.5), logo

$$
\kappa^{2}=-4 B(A-B)
$$


e

$$
\Omega=A-B
$$

onde $A$ está relacionado com o movimento rotacional diferencial do disco ao redor da planeta e $B$ com o gradiente do momento angular na vizinhança, ou seja, a vorticidade.

No caso de $\Omega \sim \kappa / 2$, teríamos uma órbita ligeiramente aberta. Note, no entanto, que uma órbita aberta pode ser considerada uma órbita fechada que possui rotação. A essência da ideia é que as órbitas da Figura 2.1, não são fechadas, mas, sim, órbitas ligeiramente abertas que se tornam fechadas ao ser observadas num referencial em rotação. A velocidade de rotação do referencial para fechar a órbita é a velocidade de "precessão" da órbita. Isso significa, que o observador num referencial externo visualizará a onda espiral de densidade em rotação.

Desse modo, é possível que os braços espirais persistam mesmo em condições de órbitas abertas, bastanto aplicar uma "precessão" com frequência $\Omega_{\mathrm{p}}=\Omega-\kappa / 2$.

No entanto, como $\kappa$ e $\Omega$ variam com o raio, a "precessão" da órbita também deve variar. A diferença $\Omega-\kappa / 2$, contudo, deve ser constante para a onda de densidade manter seu formato. Caso isso não ocorra, verifica-se o enrolamento da onda de densidade espiral. Essa inconsistência é resolvida quando se consideram as alterações no potencial gravitacional devido à mudança de densidade superficial que ocorre no disco. Acrescentando esse potencial, podemos obter órbitas fechadas em algum referencial em rotação, o que permite a longa existência das ondas de densidade espirais (Amaral e Lepine, 1997).

No entanto, essa solução autoconsistente só é possível entre duas regiões ressonantes: na ressonância interna de Lindblad $\left(\Omega_{\mathrm{p}}=\Omega-\kappa / 2\right)$ e na ressonância externa de Lindblad $\left(\Omega_{\mathrm{p}}=\Omega+\kappa / 2\right)$. Como nossa análise toma como ponto de partida o referencial com rotação $\Omega_{\mathrm{p}}$, o sinal negativo deve-se ao fato de o elemento de fluido girar mais devagar que a onda espiral. Assim, no referencial com velocidade angular $\Omega_{\mathrm{p}}$, esse elemento é visto girando em sentido contrário. A ressonância co-orbital $\Omega_{\mathrm{p}}=\Omega$ também é um caso especial bastante explorado (Lépine, 2008).

A explanação acima é um recurso didático que ajuda a entender o desenvolvimento das ondas de densidade no disco protoplanetário, que, na literatura, é descrito não pela perturbação das órbitas do elemento de fluido, mas, sim, pelas perturbações nas equações da Hidrodinâmica. A Figura 2.4 mostra a visualização dessa onda de densidade espiral 
obtida através de simulações hidrodinâmicas.

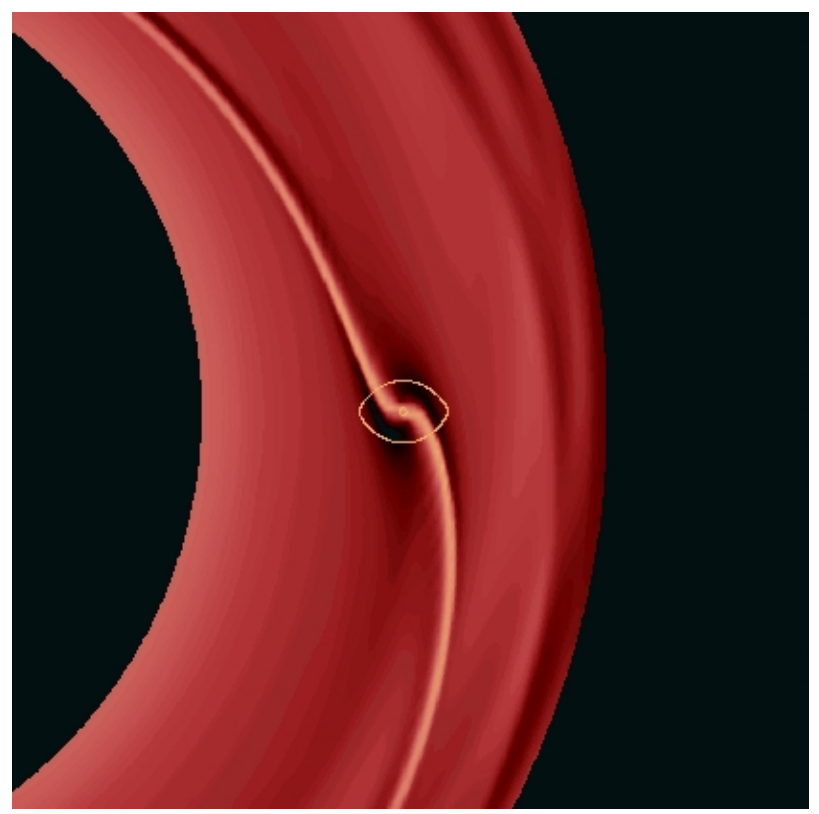

Figura 2.4: Desenvolvimento de ondas espirais em simulações hidrodinâmicas devido a perturbação do planeta no disco fluido. Figura obtida em: http://planets.utsc.utoronto.ca/ pawel/planets/results01.html. Acesso em: 22 jan. 2014.

Além disso, o desenvolvimento das ondas espirais nos discos protoplanetários devem levar em conta outras características físicas do disco, tornando a abordagem um pouco mais complicada, maiores detalhes podem ser obtidos em Goldreich e Tremaine (1980) e Tanaka et al. (2002).

\subsection{Equações da Hidrodinâmica}

Esta seção visa expor algumas relações hidrodinâmicas que serão usadas continuamente nos capítulos posteriores, e tem como principal objetivo fornecer um breve resumo de maneira a possibilitar uma leitura o mais linear possível. Esta explanação poderá ser complementada com a leitura de Maciel (2003) e Cattani (1990) que abordam o assunto de forma muito mais ampla.

\subsubsection{Equação de continuidade}

Considere um fluido isolado de volume $V$, cuja massa total é dada por 


$$
\int_{V} \rho d V
$$

Supondo um descréscimo de massa de fluido por unidade de tempo, podemos escrever

$$
\frac{d M}{d t}=-\frac{\delta}{\delta t} \int_{V} \rho d V
$$

Agora, vamos considerar a Figura 2.5, em que $d S$ é o elemento de superfície com o vetor $\vec{n}$ unitário e normal ao elemento. A quantidade de massa que atravessa esse elemento de área num determinado tempo será

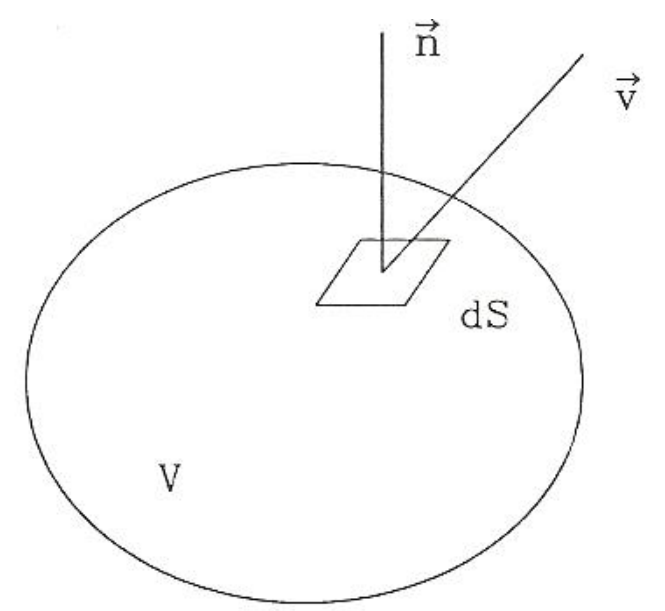

Figura 2.5: Representação de um fluido ocupando um volume $V$ e um elemento de superfície $d S$ com vetor unitário $\vec{n}$ normal ao elemento e dirigido para fora. Figura obtida em: Maciel (2003).

$$
\frac{d M}{d t}=\frac{\rho d V}{d t}=\rho \vec{v} \cdot \vec{n} d S
$$

cuja quantidade total pode ser obtida integrando sobre toda a área superficial. Assim

$$
\frac{d M}{d t}=\oint \rho \vec{v} \cdot \vec{n} d S
$$

Pela lei de conservação de massa, podemos igualar as Equações 2.12 e 2.14, obtendo

$$
-\frac{\delta}{\delta t} \int_{V} \rho d V=\oint \rho \vec{v} \cdot \vec{n} d S
$$

Usando o teorema do divergente na segunda integral, encontramos

$$
-\frac{\delta}{\delta t} \int_{V} \rho d V=\int_{V} \vec{\nabla} \cdot(\rho \vec{v}) d V
$$


Portanto,

$$
\int_{V}\left[\frac{\delta \rho}{\delta t}+\vec{\nabla} \cdot(\rho \vec{v})\right] d V=0
$$

Dessa forma, para qualquer volume, obtemos a relação

$$
\frac{\delta \rho}{\delta t}+\vec{\nabla} \cdot(\rho \vec{v})=0
$$

Essa equação é conhecida como equação de conservação de massa ou equação de continuidade e também pode ser escrita na forma aberta

$$
\frac{\delta \rho}{\delta t}+\rho \vec{\nabla} \cdot \vec{v}+\vec{v} \cdot \vec{\nabla} \rho .
$$

Em resumo, essa equação indica que a taxa de variação de massa dentro de certo volume é igual à taxa na qual a massa flui para dentro menos a taxa que flui para fora desse volume.

\subsubsection{Equação de Euler}

Considere um fluido ideal em equilíbrio, ou seja, em que não há forças tangenciais. A força resultante que atua num elemento $V$ do fluido, devido à interação com o restante do fluido, é obtida integrando sobre toda a área superficial. Desse modo, temos

$$
\vec{F}_{\text {res }}=-\oint P \vec{n} d S
$$

no qual o sinal $(-)$ indica que a força atua sobre o elemento $V$.

Aplicando o teorema do divergente, encontramos

$$
\vec{F}_{\mathrm{res}}=-\oint P \vec{n} d S=-\int_{V} \vec{\nabla} P d V
$$

Portanto, $-\vec{\nabla} P$ é a força por unidade de volume, ou seja

$$
\rho \vec{a}=-\vec{\nabla} P
$$

Como a velocidade do fluido é função da posição e do tempo $(\vec{v}=v(x, y, z, t))$, temos

$$
d \vec{v}=\frac{\delta \vec{v}}{\delta t} d t+(d \vec{r} \cdot \vec{\nabla}) \vec{v} .
$$

Assim, a aceleração pode ser escrita como 


$$
\vec{a}=\frac{d \vec{v}}{d t}=\frac{\delta \vec{v}}{\delta t}+(\vec{v} \cdot \vec{\nabla}) \vec{v}
$$

que substituída na Equação 2.22, fornece

$$
\rho\left[\frac{\delta \vec{v}}{\delta t}+(\vec{v} \cdot \vec{\nabla}) \vec{v}\right]=-\vec{\nabla} P .
$$

Essa relação é conhecida como equação de Euler. O caso mais geral ocorre na presença de forças externas. Assim, supondo uma força $\vec{F}$ atuando num volume unitário, podemos generalizar a equação de Euler na forma

$$
\frac{\delta \vec{v}}{\delta t}+(\vec{v} \cdot \vec{\nabla}) \vec{v}=-\frac{1}{\rho} \vec{\nabla} P+\frac{1}{\rho} \vec{F} .
$$

Um caso de interesse nos trabalhos de migração é o caso isentrópico, ou seja, quando a entropia do sistema permanece constante. Da primeira lei da Termodinâmica, sabemos que

$$
d Q=T d S=d U+P d V
$$

onde $d Q$ é a quantidade de calor absorvida em um processo infinitesimal, $d U$ é a variação da energia interna, $P d V$ é o trabalho realizado pelo sistema, $T$ a temperatura e $d S$ a variação de entropia.

Da definição de entalpia, temos

$$
H=U+P V
$$

$\log \mathrm{O}$

$$
d H=d U+P d V+V d P=T d S+V d P .
$$

Como o processo é isentrópico $d S=0$ e $d H=V d P$, dividindo ambos os lados pela massa, podemos escrever essa relação em termos da entalpia específica $(h)$. Assim

$$
\nabla h=\frac{1}{\rho} \nabla P
$$

Portanto, a equação de Euler para o caso isentrópico é escrita na forma 


$$
\frac{\delta \vec{v}}{\delta t}+(\vec{v} \cdot \vec{\nabla}) \vec{v}=-\nabla h+\frac{1}{\rho} \vec{F} .
$$

Essa relação costuma ser usada em fluidos barotrópicos, nos quais a temperatura é constante ou a diferença de temperatura entre as camadas é pequena, de modo que a pressão depende apenas da densidade.

\subsection{Potencial gravitacional do planeta}

Considere um planeta de massa $M_{\mathrm{p}}$ numa órbita aproximadamente circular ao redor de uma estrela, tal que o plano de inclinação da órbita seja nula com relação a um plano de referência. Sendo $\left(r_{\mathrm{p}}, \theta_{\mathrm{p}}\right)$ a posição em coordenadas polares do planeta, seu potencial gravitacional (parte direta) em um ponto $(r, \theta)$ é descrito por

$$
\Phi_{\mathrm{p}}=-G M_{\mathrm{p}}\left[r_{\mathrm{p}}^{2}+r^{2}-2 r_{\mathrm{p}} r \cos \left(\theta_{\mathrm{p}}-\theta\right)\right]^{-1 / 2}
$$

Similarmente ao que foi discutido na primeira seção, pequenos desvios da órbita circular de raio $a_{\mathrm{p}}$ produzem as equações

$$
R_{\mathrm{p}}=r_{\mathrm{p}}-a_{\mathrm{p}}=-e_{\mathrm{p}} a_{\mathrm{p}} \cos \left[\kappa_{\mathrm{p}}\left(t-t_{0}\right)\right]
$$

e

$$
\Theta_{\mathrm{p}}=\theta_{\mathrm{p}}-\Omega_{\mathrm{p}} t=e_{\mathrm{p}} \frac{2 \Omega_{\mathrm{p}}}{\kappa_{\mathrm{p}}} \sin \left[\kappa_{\mathrm{p}}\left(t-t_{0}\right)\right],
$$

onde $\kappa_{\mathrm{p}}$ é a frequência epicíclica e $e_{\mathrm{p}}$ a excentricidade do planeta, que é supostamente pequena (Henon e Petit, 1986).

Considerando $t=t_{0}$ como o instante em que o planeta passa pelo periapse, a expansão em primeira ordem das Equações 2.33 e 2.34 fornece

$$
-\frac{G M_{\mathrm{p}}}{\Delta^{1 / 2}}+\frac{G M_{\mathrm{p}}}{\Delta^{3 / 2}}\left\{R_{\mathrm{p}}\left[a_{\mathrm{p}}-r \cos \left(\Omega_{\mathrm{p}}-\theta\right)+\Theta_{\mathrm{p}} a_{\mathrm{p}} r \sin \left(\Omega_{\mathrm{p}}-\theta\right)\right]\right\}
$$

onde define-se

$$
\Delta \equiv a_{\mathrm{p}}^{2}+r^{2}-2 a_{\mathrm{p}} r \cos \left(\Omega_{\mathrm{p}}-\theta\right)
$$


Como $\Delta^{-1 / 2}$ e $\Delta^{-3 / 2}$ são funções periódicas pares de $\left(\Omega_{\mathrm{p}}-\theta\right)$, elas pode ser analisadas através de séries de cossenos de Fourier desta variável, portanto

$$
\begin{aligned}
\frac{a_{\mathrm{p}}}{\Delta^{1 / 2}} & =\frac{1}{2} b_{1 / 2}^{(0)}+\sum_{m=1}^{\infty} b_{1 / 2}^{(m)} \cos \left[m\left(\Omega_{\mathrm{p}}-\theta\right)\right] \\
\frac{a_{\mathrm{p}}^{3}}{\Delta^{3 / 2}} & =\frac{1}{2} b_{3 / 2}^{(0)}+\sum_{m=1}^{\infty} b_{3 / 2}^{(m)} \cos \left[m\left(\Omega_{\mathrm{p}}-\theta\right)\right]
\end{aligned}
$$

nas quais os $b s$, conhecidos como coeficientes de Laplace, são definidos pela integral

$$
b_{\gamma}^{(m)}(\beta) \equiv \frac{2}{\pi} \int_{0}^{\pi} \Gamma^{-\gamma} \cos (m \theta) d \theta \quad m=0,1,2,3 .
$$

onde

$$
\beta \equiv \frac{r}{a_{\mathrm{p}}}
$$

$\mathrm{e}$

$$
\Gamma \equiv 1+\beta^{2}-2 \beta \cos \theta
$$

As equações acima, junto com as Equações 2.33, 2.34 e 2.35, permitem que o potencial do planeta seja escrito em termos uma série na forma

$$
\Phi_{\mathrm{p}}(r, \theta, t)=\operatorname{Re} \sum_{m=-\infty}^{m=+\infty} \Phi_{m}(t) e^{i m\left(\theta-\omega_{\mathrm{p}} t\right)}
$$

O desenvolvimento completo dos cálculos acima pode ser visto em Shu (1984). 
Capítulo 3

\section{Disco protoplanetário}

\subsection{Introdução}

As observações de aglomerados de estrelas jovens em regiões ricas em gás e poeira são um indicativo de que sua formação se deve ao colapso de nuvens moleculares. No entanto, devido à conservação do momento angular, parte dessa nuvem não cai diretamente sobre a protoestrela, resultando em um disco de acreção denominado disco protoestelar.

Como resultado da viscosidade, boa parte da matéria do disco protoestelar espirala em direção à estrela, caindo sobre ela. Aproximadamente $10^{5}$ anos depois, com uma grande quantidade da matéria já acretada, temos como resultado um disco remanescente, ainda com acreção ativa, com uma massa bem menor que a da estrela $\left(M_{\text {disco }}<<M_{\star}\right)$. É nesse disco, cujo tempo de vida é da ordem de 10 milhões de anos, que ocorrem as condições para a formação planetária. Por esse motivo, ele é denominado disco protoplanetário.

Muitas observações vêm sendo feitas para extrair o máximo de informações sobre os discos protoplanetários encontrados ao redor de estrelas jovens (T-tauri e Herbig Ae/Be). No entanto, a "baixa" temperatura torna esses discos relativamente ricos em poeira e opticamente espessos para a maioria dos comprimentos de onda. Com isso, a maior parte das informações observacionais referem-se às camadas superficiais do disco e às regiões mais afastadas da estrela, nas quais o disco é opticamente fino para comprimentos de onda milimétricos (Armitage, 2010).

Diante dessa dificuldade, além de outras, como a alta resolução angular necessária para sua observação, ainda não é possível obter a estrutura dos discos protoplanetários apenas através de vínculos observacionais, sendo necessária, portanto, a criação de modelos teóricos. A obtenção de um modelo teórico para o disco protoplanetário capaz de servir 
para o estudo dos processos de formação e migração planetária é justamente o objetivo deste capítulo.

De início, faremos uma breve descrição da formação dos discos protoplanetários desde a composição das nuvens moleculares até sua detecção em estrelas jovens. Em seguida, analisaremos a estrutura vertical de um disco protoplanetário, bem como sua dependência com a distribuição de temperatura, discutindo também os mecanismos responsáveis pelo seu aquecimento. Por fim, segue uma descrição de um modelo computacional simplificado para um disco de acreção e uma análise de suas limitações.

Este capítulo visa sobretudo fazer um estudo inicial de discos protoplanetários que possa servir como base para trabalhos futuros mais complexos, haja vista a existência de modelos mais avançados que levam em conta a mudança de viscosidade ao longo do raio, convecção, efeitos de magneto-hidrodinâmica etc.

\subsection{Nuvens moleculares e a formação estelar}

A teoria de colapso para a formação de embriões estelares requer uma matéria interestelar preexistente. Em virtude de sua baixa temperatura (supondo uma região distante de estrelas) e constituição, essa matéria quase sempre é visualizada na região do infravermelho, requerendo assim o uso de radiotelescópios. Esse material constitui parte do denominado meio interestelar.

As observações das regiões de formação estelar evidenciam essa relação. No espectro visível, observam-se as nebulosas de reflexão, nas quais o gás e a poeira brilham devido ao espalhamento da luz estelar em sua vizinhança, como acontece no aglomerado Plêiades. Observa-se também a presença das denominadas nebulosas escuras que, graças à concentração de poeira, se apresentam como regiões vazias no céu, e das nebulosas de emissão, cujo brilho é proveniente da energia fornecida por estrelas próximas, normalmente uma estrela $\mathrm{O}$ ou $\mathrm{B}$ recém-formadas, que ionizam o gás através da radiação U.V.

O gás encontrado nessas nebulosas possui densidade média de $10^{6}$ átomos por $\mathrm{m}^{3}$, sendo a poeira interestelar ainda mais rarefeita. No entanto, são objetos extremamente extensos. A presença de uma fonte estelar ionizante, como nas nebulosas de emissão e reflexão, facilita o estudo de sua composição com espectroscopia óptica. Pode-se também recorrer à emissão em rádio do átomo de hidrogênio, na linha de $21 \mathrm{~cm}$, que permite o estudo das 
propriedades de todas as nebulosas, entre outras características do meio interestelar.

Essas nebulosas geralmente são encontradas em regiões ainda maiores, denominadas nuvens moleculares, que possuem temperaturas extremamente baixas $(10-20 \mathrm{~K})$ e densidade que pode atingir $10^{12}$ partículas por $\mathrm{m}^{3}$ (Lequeux, 2005). A análise espectral dessas nuvens revela principalmente a presença de $\mathrm{H}_{2}$ e CO. Entretanto, a detecção do hidrogênio é uma tarefa árdua, pois este não emite nem absorve ondas de rádio, mas, sim, ultravioleta de comprimento de onda curto. Além disso, a linha de $21 \mathrm{~cm}$ não é emitida, pois o hidrogênio está presente apenas na forma molecular. Assim, normalmente utiliza-se o monóxido de carbono (ou amônia), já para medir a quantidade de hidrogênio utiliza-se uma estimativa baseada no padrão de abundância conhecida para esses elementos.

Os estudos das nuvens moleculares revelaram estruturas cuja extensão chega até 50 pc, contendo gás suficiente para formar milhões de estrelas como o Sol, encontrando-se também pequenos núcleos de nuvens de várias massas solares que se formam através do colapso gravitacional (Kepler, 2004).

Os processos que podem ser responsáveis pelo colapso dessas nuvens são, entre outros:

- ventos de algumas estrelas próximas que comprimem o gás e a poeira;

- força explosiva de uma supernova que também comprime a nuvem;

- colisão entre nuvens moleculares;

- irradiação de calor de forma suficiente para a nuvem esfriar e condensar sem ajuda externa.

É nessas regiões complexas, normalmente responsáveis pela formação de aglomerados estelares ou sistemas múltiplos, que o disco protoplanetário herda características como sua massa inicial, tamanho e composição química. Além disso, o disco também pode ser afetado pelo ambiente no qual foi formado através da radiação de estrelas vizinhas ou de perturbações gravitacionais. Evidentemente, trabalhamos aqui com a hipótese de um disco isolado ou, pelo menos, formado num aglomerado com baixa densidade de estrelas.

Uma abordagem mais completa do meio interestelar e dos processos de formação estelar encontra-se em Lequeux (2005). 


\subsection{Formação do disco protoplanetário}

Quando o fragmento da nuvem molecular se torna suficientemente denso, a atração gravitacional leva a nuvem a colapsar, formando os denominados glóbulos de Bok. Essas regiões apresentam alta densidade de poeira, sendo escuras no espectro visível. No entanto, algumas observações no infravermelho conseguem revelar a presença de uma protoestrela em seu interior.

Observações mostram que as nuvens moleculares não são homogêneas e exibem movimento turbulento (McKee e Ostriker, 2007). Assim, qualquer colapso possui momento angular diferente de zero, fator que será fundamental para a formação de um disco (ou uma companheira binária). Goodman et al. (1993), por exemplo, estimaram a razão entre a energia rotacional e gravitacional de núcleos de nuvens moleculares, encontrando um valor médio de

$$
\beta \equiv \frac{E_{\text {rot }}}{E_{\text {grav }}} \sim 0.02
$$

Esse valor, aparentemente pequeno, mostra que essas estruturas possuem, em razão de sua grande extensão, uma grande reserva de momento angular.

Para compreender como o colapso da nuvem e a formação de uma protoestrela levam à formação do disco protoplanetário, vamos analisar a Tabela 3.1 que fornece as propriedades médias de alguns núcleos das nuvens moleculares e de uma estrela similar ao Sol (Kepler 2004).

Tabela 3.1 - Comparação das propriedades da região interna de uma nuvem molecular e de uma estrela similar ao Sol

\begin{tabular}{lcc}
\hline \hline & Nuvem molecular & Estrela \\
\hline Densidade média & $10^{4} \mathrm{~cm}^{-3}$ & $10^{24} \mathrm{~cm}^{-3}$ \\
Temperatura média & $10^{-30} \mathrm{~K}$ & $10^{7} \mathrm{~K}$ \\
Campo magnético médio & $20-30 \mu \mathrm{G}$ & $1 \mathrm{G}$ \\
Razão de gás ionizado & $10^{-7}$ & 1 \\
Tamanho & $10^{17} \mathrm{~cm}$ & $10^{11} \mathrm{~cm}$ \\
Velocidade angular & $10^{-14} \mathrm{rad} / \mathrm{s}$ & $10^{-6} \mathrm{rad} / \mathrm{s}$ \\
\hline \hline
\end{tabular}


Podemos observar duas características importantes na formação estelar: o raio diminuiu de um fator $10^{6}$ e a densidade aumentou em $10^{20}$. Com base nessas características, podemos fazer duas observações imediatas:

- há grande aumento do momento angular, pois a velocidade angular aumenta da ordem de $10^{13}$

- há grande aumento do fluxo magnético, pois o campo magnético também aumenta da ordem de $10^{13}$.

Esses dois fatores são as principais características que levam à formação de um disco de acreção, pois, pela conservação do momento angular, parte da massa é acelerada para a parte externa. Além disso, o campo magnético permite que as regiões centrais comecem a colapsar antes das partes mais externas. Esse tipo de colapso cria uma região rarefeita entre o núcleo denso e a borda interna do envelope de gás, que continua caindo para o centro. O campo magnético também é responsável pela expulsão da matéria por ejeção magnetocentrífuga, na forma de jatos bipolares (Kepler, 2004).

Um vínculo observacional de todo esse processo (Figura 3.1) é obtido com base na medida de distribuição de energia espectral (SED, Spectral Energy Distribution) na região do infravermelho de objetos estelares jovens (YSOs, Young Stellar Objects) de baixa massa Lada e Wilking, 1984; Andre e Montmerle, 1994).

Costuma-se dividir os YSOs em quatro classes que, embora empíricas, possuem relação teórica com uma sequência evolutiva (Adams et al., 1987), como descrito abaixo:

- Classe 0: o pico da SED encontra-se no infravermelho longínquo ou na parte milimétrica. Esses objetos estão no primeiro estágio da formação estelar e a protoestrela está profundamente coberta por gás e poeira, tornando-se invisível até mesmo no infravermelho próximo.

- Classe I: temos um pico mais reto entre o infravermelho próximo e o médio ou uma reta levemente decrescente. Esses objetos ainda estão envoltos por um envelope de gás e poeira que caem sobre a estrela, causando a emissão em comprimento de ondas mais longos. Além disso, verifica-se a presença de jatos que lançam material estelar no espaço. 


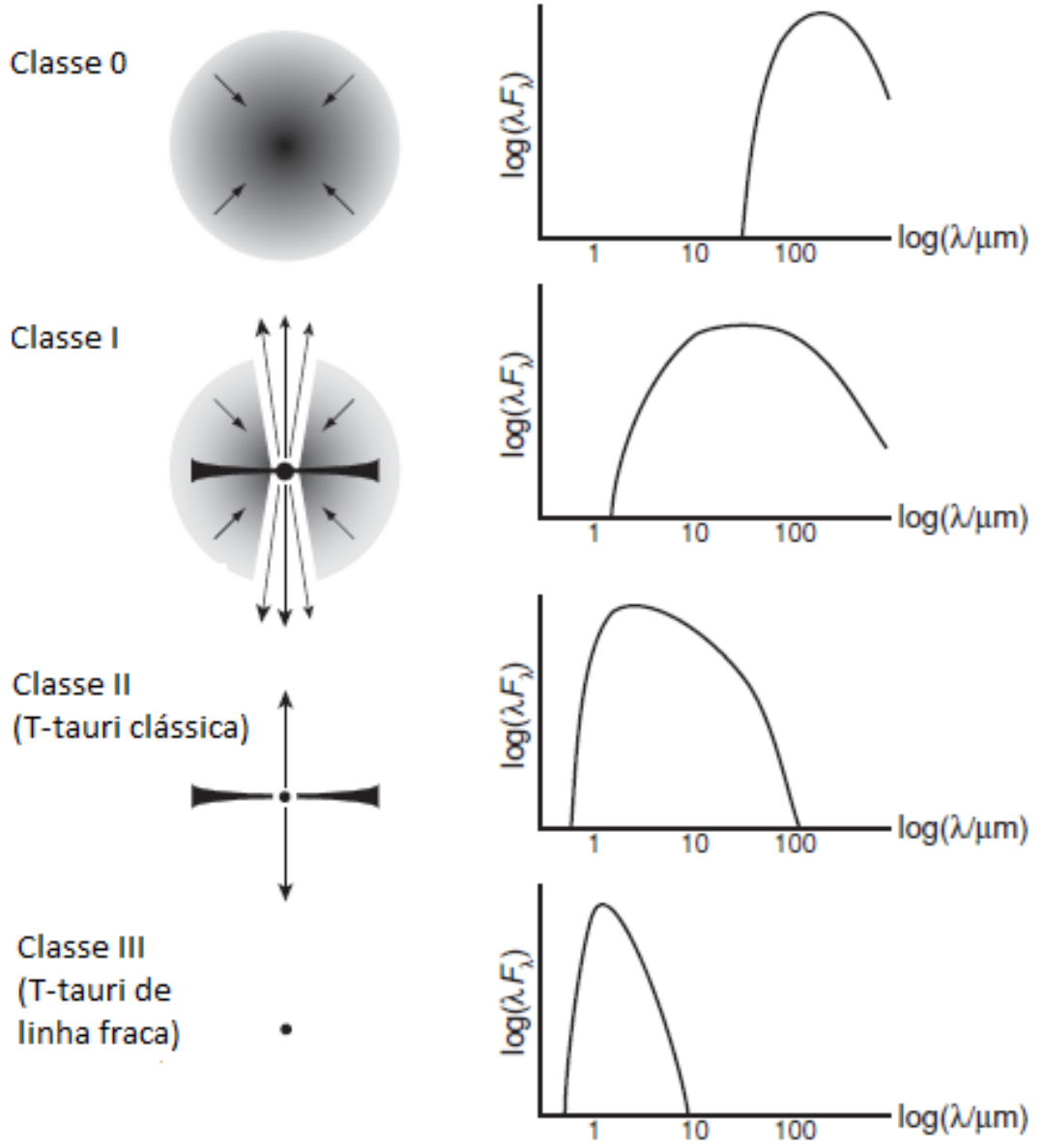

Figura 3.1: Classificação empírica de objetos estelares jovens (YSOs) com base na medida de distribuição de energia espectral (SED). Figura obtida em: Armitage (2010).

- Classe II: o SED cai nitidamente entre o infravermelho próximo e o médio. O envelope já foi acretado e sua emissão é a soma da emissão da estrela com a do disco que se forma ao redor dela. Esses objetos são conhecidos como estrelas T-tauri clássicas.

- Classe III: o SED é essencialmente o infravermelho de uma fotosfera estelar. Aqui, já temos uma completa dissipação do disco e um objeto já na pré-sequência principal. Alguns autores usam a denominação T-tauri de linha fraca.

O foco desta dissertação são os objetos de classe II, nos quais supostamente ocorrem a formação e a evolução dos sistemas planetários.

\subsection{Estimativa do raio de um disco protoplanetário}

Apenas de forma elucidativa, podemos fazer uma estimativa bem rudimentar do raio de 
um disco protoplanetário levando em conta a conservação do momento angular durante sua formação. Considere um glóbulo de Bok como um núcleo esférico de densidade uniforme, massa de $1 \mathrm{M}_{\odot}$ e raio de $r_{\mathrm{n}}=0.05 \mathrm{pc}$, usando a Equação 3.1, encontramos um momento angular específico para o núcleo $\left(j_{\mathrm{n}}\right)$ de aproximadamente $4.5 \times 10^{16} \mathrm{~m}^{2} \mathrm{~s}^{-1}$. Sendo $\Omega_{\mathrm{n}}$ a velocidade angular do núcleo homogêneo da nuvem, podemos escrever

$$
j_{\mathrm{n}} \propto \Omega_{\mathrm{n}} r_{\mathrm{n}}^{2} \sim 4.5 \times 10^{16} \frac{\mathrm{m}^{2}}{\mathrm{~s}} .
$$

Esse valor é muito maior que o momento angular típico de uma estrela como o Sol, o que indica que a maior parte do momento angular será distribuído ao longo do disco. Assim, considerando $\Omega_{\mathrm{d}}$ e $r_{\mathrm{d}}$, respectivamente, a velocidade angular e o raio do disco, pela conservação do momento angular, temos

$$
\Omega_{\mathrm{d}} r_{\mathrm{d}}^{2} \approx \Omega_{\mathrm{n}} r_{\mathrm{n}}^{2} \sim 4.5 \times 10^{16} \frac{\mathrm{m}^{2}}{\mathrm{~s}} .
$$

Assumindo que a massa do disco é bem menor que a da estrela $M_{\star}$, temos na periferia do disco uma velocidade angular $\Omega_{\mathrm{d}}^{2}=\frac{G M_{\star}}{r_{\mathrm{d}}^{3}}$, que, ao ser empregado na equação acima, fornece

$$
\frac{G M_{\star}}{r_{\mathrm{d}}^{3}}=\left(\frac{4.5 \times 10^{16}}{r_{\mathrm{d}}^{2}}\right)^{2}
$$

Isolando $r_{\mathrm{d}}$ e utilizando $G \approx 6.67 \times 10^{-11} \mathrm{~m}^{3} \mathrm{~kg}^{-1} \mathrm{~s}^{-2}$ e $1 \mathrm{UA} \approx 1.5 \times 10^{11} \mathrm{~m}$, encontramos

$$
r_{\mathrm{d}} \sim\left(\frac{2 \times 10^{32} \mathrm{~kg}}{M_{\star}}\right) \mathrm{UA}
$$

Supondo a massa da estrela central próxima da solar, obtemos um disco cujo raio é da ordem de 100 UA. Embora a relação seja rudimentar, os discos observados costumam ter um tamanho coerente com o valor encontrado. Assim, a formação de disco com tamanhos maiores ou comparáveis aos do nosso Sistema Solar parece ser uma consequência inevitável do alto valor do momento angular dos núcleos embrionários.

\subsection{Estrutura vertical}

É comum nos trabalhos de formação e migração planetária o uso de modelos de discos protoplanetários com escalas de altura $(h / r)$ da ordem de 0.05 ou menores. O estudo 
da estrutura vertical a seguir revela que a escala de altura depende da distribuição de temperatura ao longo do disco, o que leva à análise dos processos de aquecimento e resfriamento responsáveis por essa distribuição. Além disso, a distribuição de temperatura é fator primordial para obtenção do perfil de densidade superficial de gás e sólidos, parâmetros essenciais nos modelos de formação e migração planetária.

Para inferir a espessura do disco protoplanetário, vamos trabalhar com o conceito de equilíbrio hidrostático na vertical, raciocínio análogo ao empregado por Armitage (2010). Considere um sistema de coordenadas cilíndricas fixo no centro do disco, no qual a coordenada $r$ se encontra em seu plano e cujo eixo $z$ é perpendicular e aponta na direção do eixo de rotação, a equação de equilíbrio hidrostático na direção vertical será

$$
\frac{d P}{d z}=-g_{z} \rho
$$

na qual $g_{z}$ é a aceleração gravitacional na direção vertical, $P$ é a pressão do gás e $\rho$ sua densidade volumétrica.

Vamos considerar a massa do disco bem menor que a da estrela $\left(M_{\text {disco }} \ll M_{\star}\right)$, dessa forma, podemos negligenciar a atração gravitacional do disco sobre si mesmo. Assim, o campo gravitacional numa distância $(r, z)$ é dado por

$$
g_{z}=\frac{G M_{\star}}{d^{2}} \sin \theta=\frac{G M_{\star} z}{d^{3}}=\frac{G M_{\star} z}{\left(r^{2}+z^{2}\right)^{3 / 2}},
$$

onde $d$ e $(r, z)$ são, respectivamente, a distância e as coordenadas da partícula em relação ao sistema de referência. Levando em conta que o disco possui uma grande área superficial, o que implica um resfriamento bastante eficiente, podemos considerar seu raio extremamente maior que sua espessura $(r \gg z)$. Logo, a Equação 3.7 pode ser escrita na forma

$$
g_{z} \approx \Omega_{\mathrm{disco}}^{2} z
$$

A pequena espessura do disco em relação a seu raio permite assumir um disco verticalmente isotérmico, de modo que a pressão do gás pode ser descrita pela relação $P=c_{s}^{2} \rho$, na qual $c_{s}$ é a velocidade do som que, por sua vez, é dada por

$$
c_{s}^{2}=\frac{k_{B} T}{\mu m_{\mathrm{p}}},
$$


onde $k_{B}$ é a constante de Boltzmann e $\mu$ é a constante molecular média em unidades de massa do próton $m_{\mathrm{p}}$.

Assim, a Equação de equilíbrio 3.6 torna-se

$$
c_{s}^{2} \frac{d \rho}{d z}=-\Omega_{\mathrm{disco}}^{2} \rho z .
$$

A equação acima é uma equação diferencial de primeira ordem, cuja solução é

$$
\rho=\rho_{0} e^{-z^{2} / 2 h^{2}}
$$

na qual $h \equiv \frac{c_{s}}{\Omega_{\text {disco }}}$. Observe que, usando $\Omega_{\text {disco }}=\frac{v_{\varphi}}{r}$, onde $v_{\varphi}$ é a velocidade tangencial kepleriana do gás, podemos inferir

$$
\frac{h}{r} \sim \frac{c_{s}}{v_{\varphi}}
$$

Note também que $v_{\varphi}=r \Omega_{\text {disco }} \sim r^{-1 / 2}$, assim $h \sim \frac{c_{s} r}{\Omega_{\text {disco }}} \sim c_{s} \frac{r}{r^{-1 / 2}} \sim c_{s} r^{3 / 2}$, ou seja, $h$ aumenta com $r$. No entanto, a velocidade do som $c_{s}$ depende da temperatura que, por sua vez, varia com a distância à estrela. Considerando a velocidade do som parametrizada na forma $c_{s} \propto r^{-\beta}$, podemos escrever

$$
\frac{h}{r} \propto r^{-\beta+1 / 2}
$$

A relação acima mostra que a espessura do disco obtido pela relação $\frac{h}{r}$ depende de $T(r)$, tornando importante estudar como ocorrem as trocas de energia dentro do disco, de modo obter a distribuição radial de temperatura.

\subsection{Discos passivos}

O disco possui duas fontes principais de aquecimento: a primeira se deve à absorção da radiação estelar (geralmente pela poeira), enquanto a segunda é decorrente da dissipação da energia potencial gravitacional durante a queda de matéria do disco na direção da estrela. Denomina-se passivo o disco cuja primeira fonte predomina sobre a segunda. Convém lembrar que a taxa de aquecimento dessas fontes pode variar de acordo com a evolução do disco (Armitage, 2010). 
O perfil de temperatura de um disco é obtido através de um balanço entre a taxa de aquecimento e a de resfriamento. Desprezando o aquecimento que pode acontecer em virtude da presença de outras fontes externas, como estrelas vizinhas, o perfil de temperatura para um disco passivo dependerá de como a radiação estelar é absorvida e reemitida pelo disco, bem como de seu formato, que influencia a distribuição da radiação estelar. Vamos inicialmente trabalhar com um disco opticamente fino, de modo que o aquecimento ocorra no plano do disco.

\subsubsection{Disco plano}

Considerando uma estrela como uma esfera de brilho constante $I_{\star}$ e raio $R_{\star}$ e um sistema de coordenadas esféricas centrado na estrela, o fluxo através da superfície do disco, como mostra a Figura 3.2, é obtido através da relação

$$
F=\int I_{\star} \sin \theta \cos \theta d \Omega
$$

onde $d \Omega=\sin \theta d \theta d \phi$ indica o elemento de ângulo sólido.

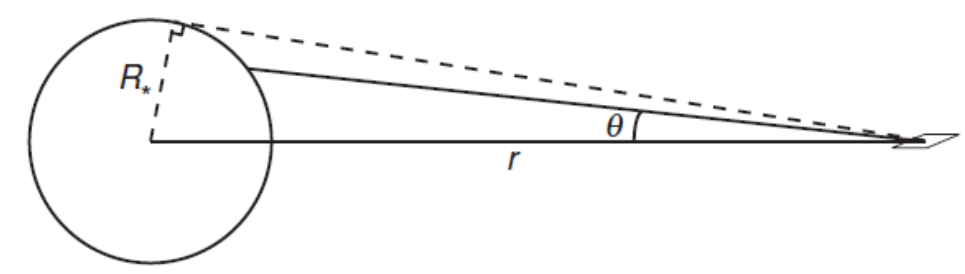

Figura 3.2: Geometria para o cálculo do perfil de temperatura de um disco plano. Figura obtida em: Armitage (2010).

Os limites de integração são $-\pi / 2<\phi<\pi / 2$ e $0<\theta<\sin ^{-1}\left(R_{\star} / r\right)$. Logo:

$$
F=I_{\star} \int_{-\pi / 2}^{\pi / 2} \cos \phi d \phi \int_{0}^{\sin ^{-1}\left(R_{\star} / r\right)} \sin ^{2} \theta d \theta=I_{\star}\left[\sin ^{-1}\left(\frac{R_{\star}}{r}\right)-\left(\frac{R_{\star}}{r}\right) \sqrt{1-\left(\frac{R_{\star}}{r}\right)^{2}}\right] .
$$

Dada a temperatura efetiva da estrela $T_{\star}$, seu brilho é calculado pela relação $I_{\star}=$ $(1 / \pi) \sigma T_{\star}^{4}$, onde $\sigma$ é a constante de Stefan-Boltzmann. Considerando que o disco emita como um corpo negro $\left(F=\sigma T_{\text {disco }}^{4}\right)$, determinamos, para um de seus lados, que o perfil de temperatura é da forma 


$$
\left(\frac{T_{\text {disco }}}{T_{\star}}\right)^{4}=\frac{1}{\pi}\left[\sin ^{-1}\left(\frac{R_{\star}}{r}\right)-\left(\frac{R_{\star}}{r}\right) \sqrt{1-\left(\frac{R_{\star}}{r}\right)^{2}}\right] .
$$

Expandindo o lado direito da Equação 3.16 numa série de Taylor no limite em que $\left(R_{\star} / r\right) \ll 1$, obtemos

$$
T_{\text {disco }} \propto r^{-3 / 4}
$$

Para um peso molecular $\mu$ fixo, isso significa que a velocidade do som (Equação 3.9) varia da forma $c_{s} \propto r^{-3 / 8}$. Assim, a Equação 3.13 para a escala de altura passa a ser

$$
\frac{h}{r} \propto r^{1 / 8}
$$

Observe, então, que, mesmo quando o aquecimento ocorre apenas no plano do disco, seu formato indica uma altura vertical alta em longas distâncias, o que implica uma captura maior de radiação estelar. Precisamos então considerar que a radiação atinja a superfície de um disco mais sinuoso para obter um perfil radial mais realista para a temperatura.

\subsubsection{Disco em formato de sino}

Considere um sistema de coordenadas cilíndricas e que, a uma distância $r$ da estrela, o disco absorva a radiação estelar numa altura $h_{\mathrm{p}}$ acima do plano, e que essa altura aumente com o raio. Essas condições implicam uma absorção maior da radiação estelar com relação ao disco plano e a mudança de seu perfil de temperatura.

O cálculo completo e exato pode ser encontrado em Kenyon e Hartmann (1987), aqui vamos usar os mesmos procedimentos do disco plano, recorrendo a algumas simplificações, como a distância radial bem maior que o raio estelar $\left(r \gg R_{\star}\right)$, que permite tratar a estrela como um objeto pontual. É interessante destacar que $h_{\mathrm{p}}$ não é necessariamente a altura vertical $h$ do disco, pois a absorção da radiação depende da densidade e da opacidade do material do disco aos fótons estelares. Da Figura 3.3, determinamos que o ângulo entre a radiação incidente e a superfície local é dado pela relação

$$
\alpha=\frac{d h_{\mathrm{p}}}{d r}-\frac{h_{\mathrm{p}}}{r} .
$$

Assim, a taxa de aquecimento por unidade de área do disco numa distância $r$, considerando os dois lados, pode ser calculada usando 


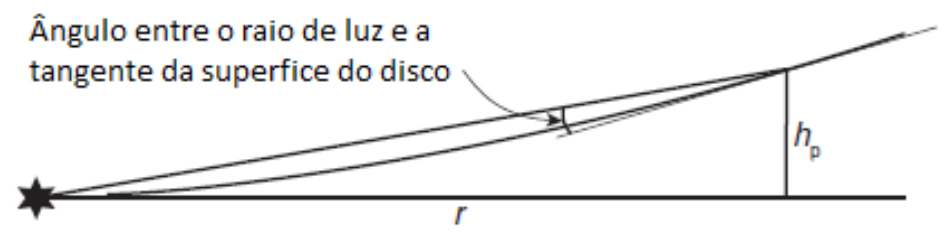

Figura 3.3: Geometria para o cálculo do perfil de temperatura de um disco em formato de sino. Figura obtida em: Armitage (2010).

$$
Q_{+}=2 \alpha\left(\frac{L_{\star}}{4 \pi r^{2}}\right)
$$

Considerando o esfriamento como num corpo negro $\left(Q_{-}=2 \sigma T_{\text {disco }}^{4}\right)$, e igualando as duas taxas, obtemos o perfil de temperatura na forma

$$
T_{\text {disco }}=\left(\frac{L_{\star}}{4 \pi \sigma}\right)^{1 / 4} \alpha^{1 / 4} r^{-1 / 2} .
$$

Como $L_{\star}=4 \pi R_{\star} \sigma T_{\star}^{4}$, podemos escrever

$$
T_{\text {disco }}=T_{\star}\left(\frac{R_{\star}}{r}\right)^{1 / 2} \alpha^{1 / 4} .
$$

Assumindo $h_{\mathrm{p}} \propto h$, plausível num disco opticamente fino, e também o disco verticalmente isotérmico, determinamos, com o uso da relação $h \equiv \frac{c_{\mathrm{s}}}{\Omega_{\text {disco }}}$, e as Equações $3.9,3.19$ e 3.22, o perfil de temperatura na forma

$$
T_{\text {disco }} \propto r^{-1 / 2}
$$

que é bem mais suave que o perfil para o disco plano (Equação 3.17).

Para um peso molecular $\mu$ fixo, isso significa que a velocidade do som (Equação 3.9) varia da forma $c_{s} \propto r^{-1 / 4}$. Assim, a Equação 3.13 passa a ser

$$
\frac{h}{r} \propto r^{1 / 4}
$$

É importante destacar que uma análise mais completa também deve levar em conta a emissividade, a distribuição de poeira, a opacidade, a ionização, a convecção, entre outros mecanismos, que podem mudar bastante o cálculo da temperatura radial do disco e, por fim, seu perfil. Aqui limitamo-nos apenas a fazer considerações mais simples, com o objetivo de mostrar como o perfil do disco é sensível a distribuição de temperatura. 
Para uma distância de 1 UA, por exemplo, e uma temperatura no plano médio do disco de $100 \mathrm{~K}(\mu=2.3)$, obtêm-se $h / r \approx 0.02$ e para $30 \mathrm{UA}$, obtém-se $h / r \approx 0.05$. Isso mostra que, pelas condições teóricas apresentadas, a suposição de um disco fino, dentro da região da formação planetária, é de fato bastante aceitável.

\subsection{Discos de acreção}

Até agora discutimos apenas o caso de um disco estático; no entanto, as observações mostram que os discos evoluem com o tempo. Essa evolução está intrinsecamente ligada ao transporte de momento angular no interior do disco, que leva o gás a espiralar e a ser acretado pela estrela. A compreensão dos mecanismos que permitem essa perda é a questão central nos discos de acreção.

O vínculo observacional mais forte para o estudo dos discos, como já discutido, é o excesso de infravermelho. Analisando a presença desse excesso em aglomerados estelares, é possível fazer uma estimativa do tempo de vida de um disco protoplanetário. A Figura 3.4 mostra a fração de estrelas jovens, em diferentes aglomerados, que possuem evidência da presença de discos protoplanetários. Essa fração é plotada junto com a idade estimada para esses aglomerados, obtidas da localização dessas estrelas no diagrama H-R, aliado a modelos de evolução. Podemos observar que a frequência de discos é quase de $100 \%$ para aglomerados com idade média inferior a 1 milhão de anos, caindo para aproximadamente $50 \%$ para aglomerados com 3 milhões de anos e chegando a $10 \%$ para idades médias próximas de 6 milhões de anos. Não há evidência de discos para aglomerados com mais de 10 milhões de anos. Portanto, podemos estimar o tempo de vida de um disco protoplanetário entre 6 e 10 milhões de anos.

Acredita-se que essas estrelas, devido à idade do aglomerado, são do tipo T-tauri, que possuem um disco primordial, não sendo estrelas mais velhas com disco de detritos cuja colisão poderia gerar a poeira responsável pelo excesso de infravermelho.

É importante mencionar também que as medidas do excesso de infravermelho são realizadas em regiões internas, próximas de $1 \mathrm{UA}$, o que nos leva a questionar o tempo de vida do restante do disco. No entanto, algumas evidências levam a acreditar que esse tempo é bastante plausível para todo o corpo do disco. A primeira é a medida espectroscópica que indica a acreção do gás, e que decai no tempo numa escala similar (Hartmann et al. 


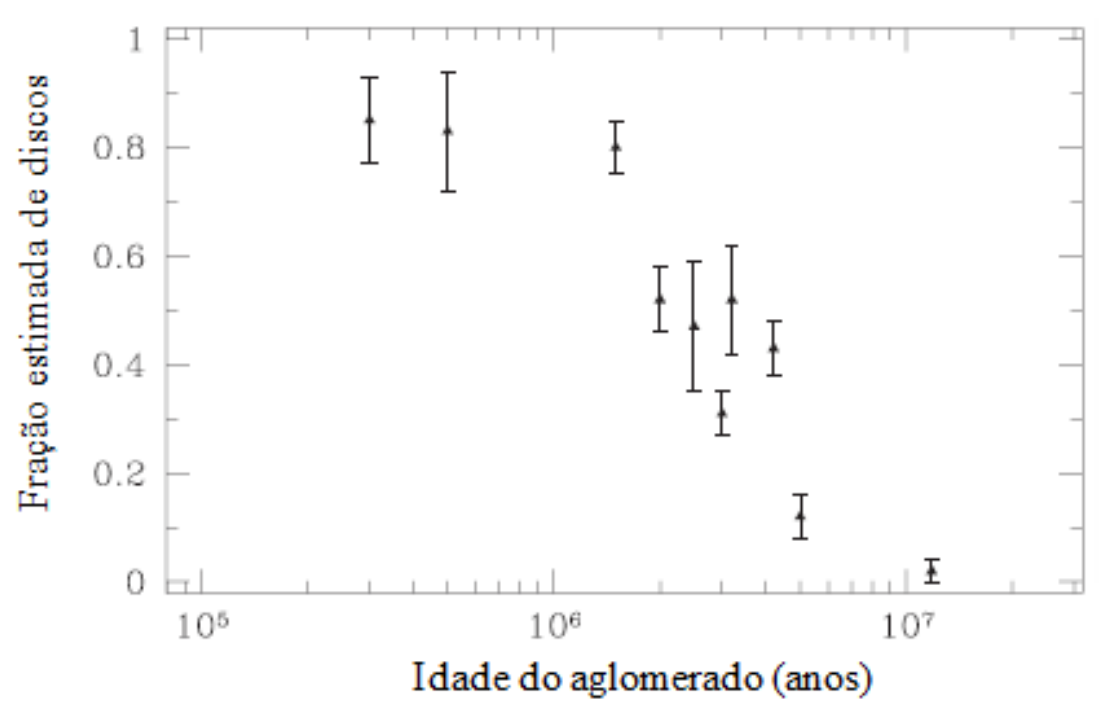

Figura 3.4: Fração de discos protoplanetários em aglomerados jovens em função da estimativa de idade do aglomerado. Os aglomerados plotados são NGC 2024, o Trapézio, NGC 2264, NGC 2362, NGC 133, $\sigma$-Ori, IC 348, Tr 37, NGC 7160 e Chamaeleon. Figura obtida em: Armitage (2010), onde também é possível encontrar as referências para cada aglomerado.

1998); a segunda é a presença de outros sinais, como o excesso na região millimétrica, em diferentes regiões. Estas observações indicam que os discos foram dispersados através de uma faixa de distância numa escala de tempo relativamente curta (Andrews e Williams, 2005).

Vamos considerar um disco protoplanetário cujo perfil de densidade superficial de gás seja dado por $\Sigma(r, t)$, no qual a velocidade radial do gás seja pequena e, conforme discutido no item acima, que o disco seja fino $(h / r \ll 1)$. Nesse caso, o efeito dominante é a atração gravitacional da estrela, o que implica um potencial gravitacional independente do tempo e, portanto, na conservação do momento angular. Na ausência de mecanismos de transporte desse momento angular, teríamos um disco estático e uma densidade superficial constante ao longo do tempo. Mas, a viscosidade faz com que uma parte do gás espirale em direção à estrela e, consequentemente, pela conservação do momento angular, outra parte espirale para fora. Outros mecanismos de transporte de momento angular são: a ação de fluxos magnéticos e a ação de ventos estelares, que não serão considerados neste trabalho.

A evolução de $\Sigma(r, t)$ pode ser deduzida considerando a equação de continuidade e a componente azimutal do momento angular, cujo cálculo completo pode ser obtido em Pringle (1981). A taxa de mudança de massa dentro de um anel de largura infinitesimal é 
dada por

$$
\frac{\delta}{\delta t}(2 \pi r \Delta r \Sigma)=2 \pi r \Sigma(r) v_{r}(r)-2 \pi(r+\Delta r) \Sigma(r+\Delta r) v_{r}(r+\Delta r)
$$

Como $\Sigma(r+\Delta r)=\Sigma(r)+\left(\frac{\delta \Sigma}{\delta r}\right) \Delta r$, fazendo $\Delta r \rightarrow 0$, encontramos

$$
r \frac{\delta \Sigma}{\delta t}+\frac{\delta}{\delta r}\left(r \Sigma v_{r}\right)=0
$$

A conservação do momento angular fornece

$$
r \frac{\delta}{\delta t}\left(r^{2} \Omega \Sigma\right)+\frac{\delta}{\delta r}\left(r^{2} \Omega r \Sigma v_{r}\right)=\frac{1}{2 \pi} \frac{\delta G}{\delta r}
$$

onde $G$ é o torque no anel gerado pelo produto do comprimento da circunferência, a força viscosa por unidade de comprimento e o braço de alavanca $r$, proporcional ao gradiente da velocidade angular, ou seja

$$
G=2 \pi r \nu \Sigma r \frac{d \Omega}{d r} r
$$

onde $\nu$ é a viscosidade cinemática (resultado da turbulência). Eliminando $v_{r}$ entre as Equações 3.26 e 3.27 , e especificando o potencial kepleriano $\left(\Omega \propto r^{-3 / 2}\right)$, obtém-se

$$
\frac{\delta \Sigma}{\delta t}=\frac{3}{r} \frac{\delta}{\delta r}\left[r^{1 / 2} \frac{\delta}{\delta r}\left(\nu \Sigma r^{1 / 2}\right)\right]
$$

que é a equação que rege a evolução da densidade superficial de um disco fino sob a ação do transporte de momento angular interno.

Contudo, a equação acima depende do conhecimento do perfil da densidade superficial do gás, cuja obtenção envolve um modelo computacional para o disco de acreção.

\subsubsection{Modelo computacional para o disco de acreção}

Nesta dissertação iremos implementar um código, utilizando o software MATHEMATICA, para um modelo de disco que tem como base o trabalho de Papaloizou e Terquem (1999). Esse modelo desconsidera o aquecimento devido à estrela. Outro, mais complexo, que inclui a radiação da estrela e o transporte de energia por convecção e condução, é encontrado em D'Alessio et al. (1998). A maioria dos modelos para discos de acreção baseiam-se 
na parametrização $\alpha$ de Shakura e Sunyaev (1973), em que a viscosidade anômala turbulenta que permite o transporte de momento angular para fora e, consequentemente, o espiralamento da matéria para dentro, aumenta com o tensor de pressão, que é simplesmente proporcional a pressão do gás. Vamos nos limitar ao caso de $\alpha$ constante, embora seja bem provável que o valor varie ao longo do disco. Apesar disso, esse modelo simples é bastante útil para nosso caso de interesse.

Consideremos um disco fino e as coordenadas cilíndricas fixas $(r, \phi, z)$ com origem na estrela central, tal que $z=0$ corresponda ao plano do disco. O modelo computacional utiliza três equações diferenciais fundamentais: a equação de equilíbrio vertical, a equação de energia e a equação de fluxo radioativo.

A equação de equilíbrio vertical, já descrita anteriormente, é

$$
\frac{1}{\rho} \frac{d P}{d z}=-\Omega^{2} z
$$

A equação de energia, que impõe que a taxa de energia perdida pela radiação seja balanceada pela taxa de energia produzida pela dissipação viscosa, é

$$
\frac{d F}{d z}=\frac{9}{4} \rho \nu \Omega^{2}
$$

na qual $F$ é o fluxo radioativo de energia através da superfície com z constante, dado por

$$
F=-\frac{16 \sigma T^{3}}{3 \kappa \rho} \frac{d T}{d z}
$$

onde $\rho$ é a densidade volumétrica, $P$ a pressão, $T$ a temperatura, $\Omega$ a velocidade angular, $\nu$ a viscosidade cinemática, $\kappa$ a opacidade que depende de $\rho$ e $T$ e $\sigma$ a constante de StefanBoltzmann.

Para um disco com massa desprezível, temos: $\Omega^{2}=\frac{G M_{\star}}{r^{3}}$, no qual $G$ é a constante gravitacional e $M_{\star}$ a massa da estrela.

A pressão, a densidade volumétrica e a temperatura estão relacionadas pela equação de um gás ideal

$$
P=\frac{\rho k T}{\mu m_{\mathrm{H}}},
$$

onde $k$ é a constante de Boltzmann, $\mu$ o peso molecular médio (usa-se $\mu=2$ ) e $m_{\mathrm{H}}$ a massa do átomo de hidrogênio. Consideremos o limite de temperatura como aproximamente 
$4 \times 10^{3} \mathrm{~K}$, que assegura o hidrogênio na forma molecular.

A adoção da parametrização de Shakura e Sunyaev (1973) permite escrever a viscosidade cinemática na forma

$$
\nu=\frac{\alpha c_{s}^{2}}{\Omega}
$$

em que $c_{\mathrm{s}}$ é a velocidade isotérmica do som $\left(c_{\mathrm{s}}^{2}=\frac{P}{\rho}\right)$.

Substituindo a equação acima na Equação 3.31, obtém-se

$$
\frac{d F}{d z}=\frac{9}{4} \alpha \Omega P .
$$

Agora, precisamos resolver as equações diferenciais 3.30, 3.32 e 3.35 em três variáveis $F, P$ e $T$ como função de $z$ para um dado valor de $r$. Para tanto, necessitamos de três condições de contorno.

A primeira condição de contorno é obtida integrando a Equação 3.30 de $h$ até o infinito, que fornece

$$
P_{\mathrm{s}}=\frac{\Omega^{2} h \tau_{a b}}{\kappa_{s}}
$$

no qual $\tau_{a b}$ é a densidade óptica acima do disco.

A segunda condição é obtida integrando a Equação 3.31 entre - $h$ e $h$, que resulta em

$$
F_{\mathrm{s}}=\frac{3 \dot{M}_{\mathrm{st}} \Omega^{2}}{8 \pi}
$$

no qual $\dot{M}_{\text {st }}$ mede a taxa de acreção do disco, ou seja, a quantidade de massa que é acretada pela estrela num determinado tempo, assumida constante ao longo do disco.

A terceira e última condição de contorno é uma expressão para temperatura na superfície

$$
2 \sigma\left(T_{\mathrm{s}}^{4}-T_{b}^{4}\right)-\frac{9 \alpha k T_{s} \Omega}{8 \mu m_{H} \kappa_{s}}-\frac{3}{8 \pi} \dot{M}_{\mathrm{st}} \Omega^{2}=0
$$

A temperatura de fundo é assumida como $T_{b}=10 \mathrm{~K}$ e a opacidade superficial $\kappa_{\mathrm{s}}$ depende de $T_{\mathrm{s}}$ e $\rho_{\mathrm{s}}$. A dedução das equações de contorno acima pode ser encontrada no Apêndice B.

Dado um raio $r$ e os valores de $\dot{M}_{\text {st }}$ e $\alpha$, podemos resolver as equações diferenciais com as condições de contorno, encontrando assim a dependência das variáveis de estado em 
função de $z$. A opacidade na superfície e abaixo do disco foi calculada usando a fórmula para opacidade analítica média de Rosseland $\left(\kappa=\kappa_{n} \rho^{\alpha} T^{\beta}\right)$, cujos parâmetros variam de acordo com a tabela abaixo.

Tabela 3.2 - Parâmetros para a opacidade analítica média de Rosseland (Bell et al. 1997).

\begin{tabular}{cccc}
\hline \hline$k_{n}$ & $\alpha$ & $\beta$ & Temp. máx. (K) \\
\hline $1.10^{-4}$ & 0 & 2.1 & 132 \\
$3.10^{0}$ & 0 & -0.01 & 170 \\
$1.10^{-2}$ & 0 & 1.1 & 375 \\
$5.10^{4}$ & 0 & -1.5 & 390 \\
$1.10^{-1}$ & 0 & 0.7 & 580 \\
$2.10^{15}$ & 0 & -5.2 & 680 \\
$2.10^{-2}$ & 0 & 0.8 & 960 \\
$2.10^{81}$ & 1 & -24 & 1570 \\
$1.10^{-8}$ & $2 / 3$ & 3 & 3730 \\
& & & \\
\hline \hline
\end{tabular}

Note que, para $T_{\mathrm{s}}$ menor que $960 \mathrm{~K}$, a opacidade $\kappa_{\mathrm{s}}$ na superfície do disco não depende de $\rho_{\mathrm{s}}$, ao passo que, para valores maiores, o segundo termo da Equação 3.38 que contém $\kappa_{\mathrm{S}}$ é desprezível comparado ao terceiro.

Para calcular o valor de $h$, vamos usar um modo iterativo. Começamos com um valor estimado, calculamos $P_{\mathrm{s}}$ e $T_{\mathrm{s}}$ e integramos as equações de $h$ até o plano médio do disco em $z=0$. Em geral, a condição $F=0 \mathrm{em} z=0$ não é satisfeita, e a iteração é feita ajustando o valor de $h$ até encontrar $F=0$ com certa acurácid 1 , À medida que ocorre o processo iterativo, o programa ajusta um valor de opacidade para a superfície e o restante da escala de altura com base nos cálculos da temperatura da superfície e do plano médio do disco. Considera-se, portanto, um disco fino de modo que a opacidade não sofra grandes alterações ao longo de sua altura.

\footnotetext{
${ }^{1}$ Devido ao valor de $F$ em $z=0$ ser extremamente sensível aos valores de $h$, o sistema foi integrado sobre uma faixa de valores de $h$, da qual se extraiu o valor minímo (dentro de certa precisão) obtido para $F(0)$ e o valor de $h$ correspondente.
} 
As Figuras 3.5 e 3.6 mostram os valores obtidos para a razão de altura $(h / r$, adimensional), densidade superficial no plano médio do disco $\left(\Sigma \mathrm{em} \mathrm{g} / \mathrm{cm}^{2}\right)$ e temperatura no plano médio do disco $\left(T_{m}\right.$ em $\left.\mathrm{K}\right)$ para, respectivamente, $\alpha=10^{-2}$ e $\alpha=10^{-3}$, comparando com os valores obtidos por Papaloizou e Terquem (1999).

A comparação indica uma certa discrepância para valores muito próximos da estrela, principalmente no que se refere à temperatura do plano médio do disco. Os dois principais motivos que levam a essa discordância são: a taxa de precisão para o valor do fluxo no plano médio do disco que deve ser próximo de zero, ou seja, valores mais precisos exigem passos menores para $h$ e, consequentemente, maior tempo computacional; e a atualização dos valores para a opacidade, para os quais foram utilizados valores diferentes dos usados no artigo.

De fato, a simulação numérica se mostrou bastante sensível aos valores iterados para $h$, principalmente para regiões próximas da estrela, onde a opacidade passa a depender da densidade superficial. Nesta dissertação, a região de interesse se encontra acima de 1 UA, cujos resultados mostraram uma excelente concordância com os obtidos por Papaloizou e Terquem (1999). Para regiões muito próximas da estrela, Souza (2008) adapta um algoritmo genético que reduz consideravelmente o enorme custo computacional, tornando possível aumentar a precisão do modelo e obter valores mais confiáveis para regiões próximas da estrela. 


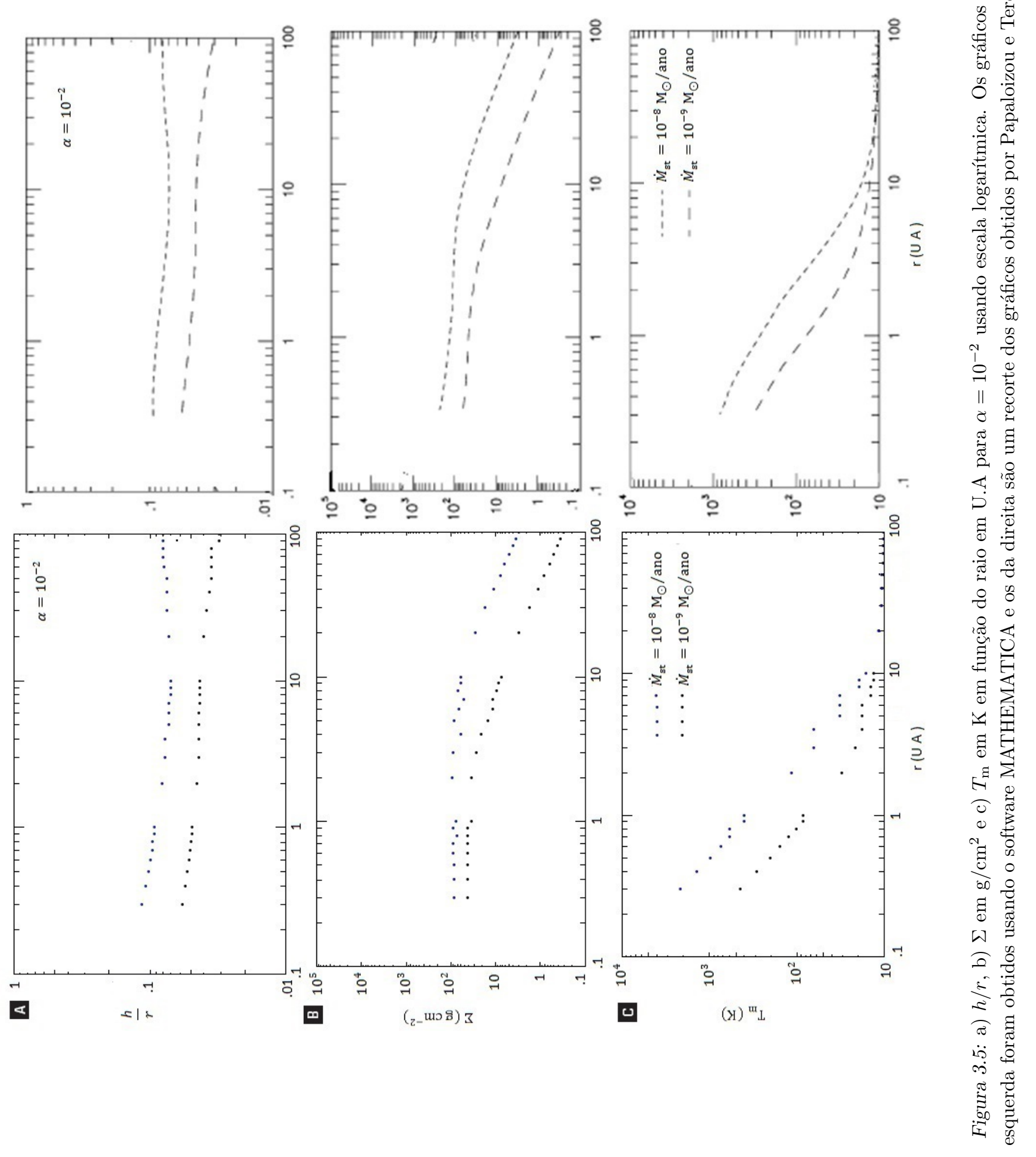



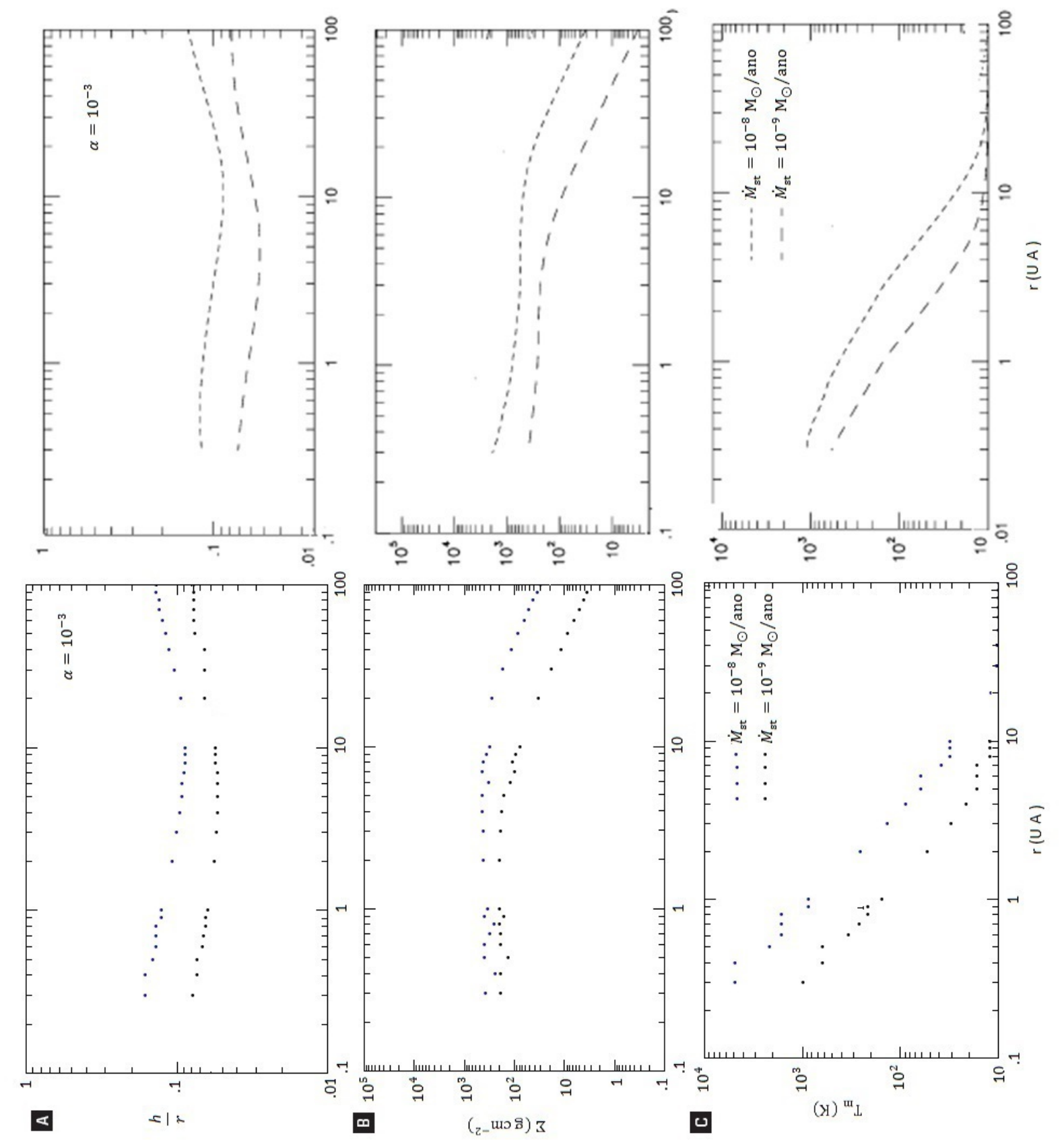

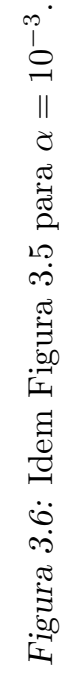




\subsection{Sumário}

Primeiramente, foi visto que a formação do disco protoplanetário é uma consequência direta da formação estelar, uma vez que o núcleo das nuvens moleculares possui grande quantidade de momento angular para colapsar, provocando a distribuição do material para regiões externas na forma de um disco protoestelar. Após um período de $10^{5}$ anos, no qual ocorre acreção de grande parte da massa desse disco pela estrela, ele passa a ter as condições necessárias à formação planetária, passando então a ser denominado disco protoplanetário.

A maior parte das medidas efetuadas relacionadas à formação estelar são encontradas na região do infravermelho em aglomerados de estrelas jovens. Essas observações permitem traçar um aspecto evolutivo desde o colapso até a formação do disco (Figura 3.1). Nesta dissertação, estamos mais interessados nos discos de acreção ao redor de estrelas jovens do tipo T-tauri.

A medida do momento angular específico médio dos núcleos de algumas nuvens moleculares, obtidas por Goodman et al. (1993), nos permitiu estimar o raio médio de um disco protoplanetário como próximo de 100 UA. Embora rudimentar, essa estimativa combina com os valores observacionais encontrados e sugere que discos protoplanetários da ordem do tamanho do nosso Sistema Solar são uma consequência direta da formação estelar.

Para o estudo da estrutura vertical dos discos protoplanetários, consideramos a situação de equilíbrio hidrostático com duas observações que simplificam os cálculos do problema. A primeira delas consistiu em desprezar o efeito gravitacional da massa do disco, que funciona bem quando $M_{\text {disco }}<0.1 M_{\star}$. Acima desse valor, efeitos de instabilidade devem ser levados em conta. A segunda considerou seu raio bem maior que sua espessura $(r \gg z)$, característica decorrente da grande área superficial do disco que permite um resfriamento eficiente. Com isso, foi possível obter a Equação 3.12 para um disco verticalmente isotérmico. Parametrizando a velocidade do som $\left(c_{\mathrm{S}} \propto r^{-\beta}\right)$, obtém-se a razão $h / r$ em função do parâmetro $\beta$, o que mostra a dependência entre o formato do disco e a distribuição de temperatura ao longo do raio (Equação 3.13).

Para obter a distribuição de temperatura do disco, foi necessário estudar os principais fatores de aquecimento, que são a radiação da estrela e a acreção de matéria. Além disso, é preciso compreender os mecanismos responsáveis pela troca de calor.

As Equações 3.18 e 3.24 mostram o perfil de temperatura radial para um disco, res- 
pectivamente, plano e outro em formato mais sinuoso, considerando apenas o aquecimento devido à radiação da estrela, ou seja, um disco passivo. Essas relações mostram que os modelos de discos costumeiramente usados em trabalhos de formação planetária possuem de fato uma escala de altura pequena dentro da região de interesse. No entanto, o perfil de densidade volumétrica e superficial do gás pode ser bastante afetado apenas levando em conta a radiação estelar. As propriedades físicas dos discos podem mudar radicalmente em função de outros mecanismos de transporte, como convecção, radiação e valores diferentes de opacidade, isso sem considerar os efeitos de magneto-hidronâmica.

Nesta dissertação, será utilizado um disco de acreção, do qual, foi obtido um valor de referência para seu tempo médio de vida (Figura 3.4) e, em seguida, seguindo o modelo de Pringle (1981), a Equação 3.29 que descreve a evolução temporal da densidade superficial do disco. Por fim, utilizando o trabalho de Papaloizou e Terquem (1999) e os valores de opacidade de Bell et al. (1997), construiu-se um modelo computacional para o disco de acreção, no qual se desconsiderou a radiação decorrente da estrela. Esse modelo, embora limitado, é adequado para um estudo inicial dos processos de formação e migração planetária.

É interessante destacar, que com base nesse modelo, podemos obter, para cada distância $r$ e taxa de acreção $\dot{M}_{\text {st }}$, a distribuição de temperatura $T\left(r, \dot{M}_{\text {st }}\right)$ e a densidade superficial $\Sigma\left(r, \dot{M}_{\text {st }}\right)$ e volumétrica do gás no plano médio do disco, bem como sua viscosidade $\nu\left(r, \dot{M}_{\mathrm{st}}\right)$. Seguindo Papaloizou e Terquem (1999), também é possível inverter essas relações e obter $T(r, \Sigma)$ e $\nu(r, \Sigma)$ para cada valor de $r$ que, junto com a Equação 3.29, nos permite computar a evolução do disco. Esse modelo para evolução do disco pode ser explorado em trabalhos futuros. 
Capítulo 4

\section{Formação planetária}

\subsection{Introdução}

Nas regiões internas do disco protoplanetário, o processo de aglomeração de poeira, rochas e planetesimais resulta nos planetas de tipo rochosos, já nas regiões mais externas, um dos modelos sugere a formação de um núcleo que acumula gravitacionalmente gás e gelo, resultando na formação de planetas gasosos gigantes. Esse modelo é conhecido como modelo de acreção. O grande desafio desse modelo é obter um tempo de formação para o núcleo sólido que seja compatível com o tempo de vida do disco, já que, o núcleo precisa se formar num tempo hábil, de modo que ainda sobre tempo para a acreção do gás remanescente do disco protoplanetário, que dará origem aos planetas gigantes.

A formação de um planeta gigante é costumeiramente dividida em três grandes estágios que apesar de serem, de certa forma, arbitrários, irão nos ajudar a compreender os diferentes fenômenos físicos envolvidos no processo (Armitage, 2010).

O primeiro estágio trata da formação dos planetesimais, definidos como corpos grandes o suficiente para que sua evolução orbital seja dominada por suas interações gravitacionais mútuas, em vez do arrasto aerodinâmico com o disco de gás. É justamente esse arrasto, agindo na evolução de partículas de poeira até pequenas rochas, que leva à sua formação. Nessa dissertação, trabalharemos com planetesimais cujo raio varia de 0.1 até $100 \mathrm{~km}$.

No segundo estágio, ocorre a acumulação de milhões de planetesimais durante um longo tempo, ocasionando a formação de planetas terrestres ou de núcleos de planetas gigantes.

No último estágio, além da acreção de planetesimais, ocorre novamente uma interação com o disco protoplanetário, todavia, dominada pela interação gravitacional em vez do arrastro aerodinâmico, que leva à captura do gás remanescente do disco e à formação dos 
planetas gigantes.

Neste estudo, iremos tratar apenas da formação de planetas terrestres e dos núcleos de planetas gigantes, ou seja, trabalharemos com os dois primeiros estágios, deixando o terceiro para ser explorado num trabalho futuro. Vale ressaltar que o tema é bastante abrangente e, portanto, este trabalho conta com modelos simplificados; porém, para um maior aprofundamento, sugestões bibliográficas serão fornecidas ao longo do capítulo.

\subsection{Formação de planetesimais}

Os principais modelos para a formação planetária consideram os planetesimais (entre 0.1 e $100 \mathrm{~km}$ ) já formados, isto é, trabalham exclusivamente com a segunda fase da formação, ou seja, a acreção desses planetesimais por um protoplaneta entre 0.01 e $0.1 \mathrm{M}_{\text {Terra. }}$. Isto se deve à consideração de que a formação de planetesimais ocorre de forma rápida em comparação com o processo completo de formação planetária. Nesta seção, vamos estudar os mecanismos que podem justificar essa assertiva.

As partículas de poeira presentes no disco protoplanetário estão sujeitas às forças gravitacionais, principalmente da estrela, e ao arrasto aerodinâmico por causa da interação com o gás, que será o principal mecanismo responsável pela distribuição vertical e radial de partículas no disco protoplanetário.

Considere um grão de poeira como uma partícula esférica de raio $s$ e densidade $\rho_{\mathrm{m}}$ movendo-se com velocidade $v$ relativa ao gás de densidade $\rho_{\mathrm{g}}$. O arrasto aerodinâmico $F_{\mathrm{A}}$, que age na direção oposta ao movimento, pode ocorrer em dois regimes físicos diferentes que dependem da relação entre o raio $s$ da partícula e de seu livre caminho médio $\lambda$. O primeiro ocorre quando $s<\lambda$, causado pelas colisões das partículas de gás com os grãos de poeira, conhecido como arrasto de Epstein. Nesse regime

$$
F_{\mathrm{A}}=-\frac{4 \pi}{3} \rho_{\mathrm{g}} s^{2} v v_{\mathrm{th}},
$$

onde $v_{\text {th }}$ é a velocidade térmica do gás.

O segundo regime ocorre para $s>\lambda$, nesse caso, o disco de gás é considerado um fluido obstruído pela presença da partícula cuja área frontal é $\pi s^{2}$, trata-se do arrasto de Stokes, no qual 


$$
F_{\mathrm{A}}=-\frac{1}{2} C_{\mathrm{A}} \pi s^{2} \rho_{\mathrm{g}} v^{2}
$$

onde $C_{\mathrm{A}}$ é o coeficiente de arrasto que depende do número de Reynolds $\left(\operatorname{Re}=\frac{2 s v}{\nu_{m}}, \nu\right.$ é a viscosidade do gás), para um esfera, experimentalmente, obtém-se

$$
\begin{aligned}
& C_{\mathrm{A}} \simeq 24 \operatorname{Re}^{-1} \quad(\operatorname{Re}<1) \\
& C_{\mathrm{A}} \simeq 24 \operatorname{Re}^{-0.6} \quad(1<\operatorname{Re}<800) \quad \mathrm{e} \\
& C_{\mathrm{A}} \simeq 0.44 \quad(\operatorname{Re}>800) .
\end{aligned}
$$

Os dois regimes são iguais para $s=\frac{9 \lambda}{4}$, que pode ser tomado como um valor de transição entre os dois casos. Nesta dissertação é adotado o regime de Epstein, pois consideramos um valor baixo para a densidade do gás o que implica num valor grande para o livre caminho médio.

Como consequência da força de arrasto, as partículas de poeira são rapidamente acopladas ao gás, fato que pode ser analisado através da definição da varíavel tempo de fricção

$$
t_{\text {fric }}=\frac{m v}{\left|F_{\mathrm{A}}\right|},
$$

que mede o tempo necessário para uma partícula de massa $m$ se acoplar ao gás, resultando numa velocidade relativa nula Armitage, 2010). Usando $m=\frac{4}{3} \pi s^{3} \rho_{\mathrm{m}}$ e a força de arrasto no regime de Epstein (Equação 4.1), encontramos

$$
t_{\text {fric }}=\frac{\rho_{\mathrm{m}}}{\rho_{\mathrm{g}}} \frac{s}{v_{\mathrm{th}}} .
$$

Valores típicos em $r=1$ UA onde $\rho_{\mathrm{g}}=10^{-9} \mathrm{~g} / \mathrm{cm}^{3}, \rho_{\mathrm{m}}=3 \mathrm{~g} / \mathrm{cm}^{3}$ e $v_{\text {th }}=10^{5} \mathrm{~cm} / \mathrm{s}$ fornecem, para um grão de poeira de $s=1 \mu \mathrm{m}$, um tempo de fricção de aproximadamente $3 \mathrm{~s}$, comprovando realmente esse ligeiro acoplamento que faz com que a poeira seja rapidamente varrida pelo gás.

O cenário para formação de planetesimais é bastante complexo e ainda tema de estudo, portanto, vamos inferir um tempo para essa formação com base no estudo da distribuição vertical e radial das partículas. Devido à atração gravitacional e ao arrasto com o gás, as partículas de poeira que se encontram numa determinada altura serão levadas ao plano médio do disco, processo denominado sedimentação; além disso, essas partículas de poeira também irão espiralar em direção à estrela até que caiam sobre ela, o que permite obter o tempo máximo para os planetesimais se formarem. 


\subsubsection{Distribuição vertical de partículas sólidas}

Considere uma partícula de poeira inicialmente em repouso que acelera devido a atração gravitacional da estrela e, que durante seu movimento, sofra um arrasto aerodinâmico no regime de Epstein. Igualando a aceleração gravitacional na vertical (Equação 3.8) com a aceleração devido ao arrasto (Equação 4.1), podemos obter a velocidade terminal da partícula, logo

$$
v_{\text {ter }}=\frac{\rho_{\mathrm{m}}}{\rho_{\mathrm{g}}} \frac{s}{v_{\mathrm{th}}} \Omega^{2} z
$$

Para completar a descrição acima, temos que levar em conta o processo de coagulação, no qual as partículas interagem umas com a outras e podem se aglutinar aumentando sua massa e seu raio e, consequentemente, a velocidade terminal.

Adota-se um modelo simples, no qual a partícula cresce em massa e tamanho numa taxa que reflete o volume varrido pela sua seção tranversal (Safronov, 1972), portanto

$$
\frac{d m}{d t}=\rho_{\mathrm{g}} \pi s^{2}\left|v_{\mathrm{ter}}\right| f
$$

onde $f$ é a razão da quantidade de gás e poeira no disco. Substituindo a Equação 4.5 e lembrando que $m=\frac{4}{3} \pi r^{3} \rho_{\mathrm{m}}$, podemos escrever

$$
\frac{d m}{d t}=\frac{3}{4} \frac{\Omega^{2} f}{v_{\mathrm{th}}} z m
$$

Como $z=z(t)$, esta equação não pode ser integrada imediatamente. Dado que o tempo de fricção é bem curto, ela pode ser resolvida em conjunto com a Equação 4.5, que pode ser escrita na forma

$$
\frac{d z}{d t}=-\frac{\rho_{\mathrm{m}}}{\rho_{\mathrm{g}}} \frac{s}{v_{\mathrm{th}}} \Omega^{2} z
$$

A Figura 4.1 mostra a solução numérica, obtida usando o sofware MATHEMATICA, para as Equações 4.7 e a 4.8, na qual foi plotado o raio da partícula em vez de sua massa, considerando sua densidade constante. A análise do gráfico mostra um tempo de sedimentação, com a inclusão da coagulação, da ordem de $1 \times 10^{3}$ anos e partículas alcançando um raio da ordem de $1 \times 10^{4} \mu \mathrm{m}$ ao atingir o plano médio do disco. É interessante notar que a partícula cresce mais rápido do que se sedimenta, implicando um aumento exponencial da massa com o tempo. 

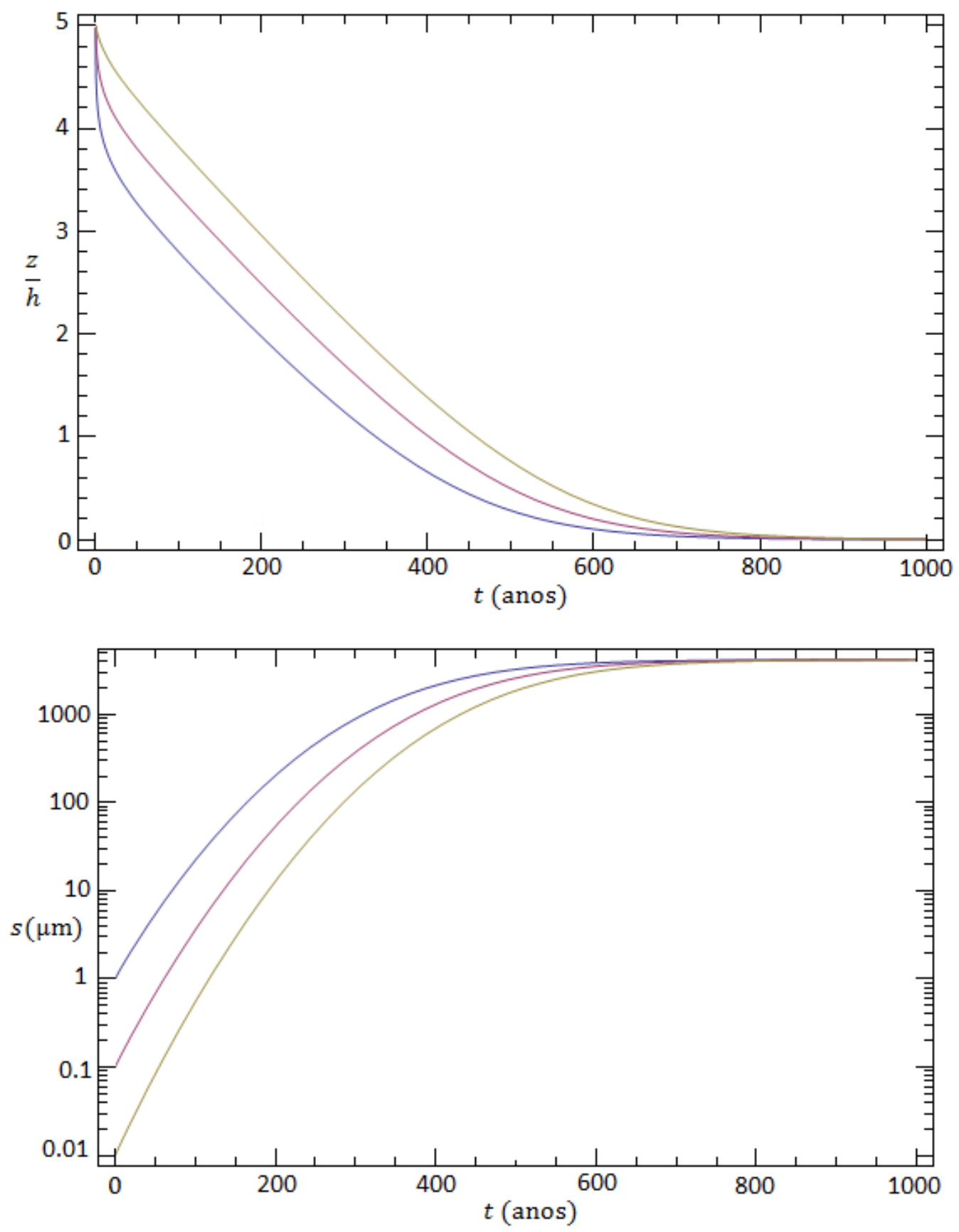

Figura 4.1: Sedimentação e coagulação de uma partícula de poeira num disco não turbulento. A linha azul corresponde a uma partícula inicialmente com raio $1 \mu \mathrm{m}$, a linha vermelha inicialmente com $0,1 \mu \mathrm{m}$ e a linha amarela com $0.01 \mu \mathrm{m}$. As figuras superior e inferior indicam, respectivamente, a altura da partícula em relação ao plano médio do disco e seu raio $s$ em função do tempo. Para a densidade do gás, foi usado o perfil de um disco isotérmico (Equação 3.11. Os parâmetros adotados para o disco foram: $r=1 \mathrm{UA}, h=3 \times 10^{11} \mathrm{~cm}$, $\Sigma=10^{3} \mathrm{~g} / \mathrm{cm}^{2}, f=10^{-2}, \rho_{\mathrm{m}}=3 \mathrm{~g} / \mathrm{cm}^{3}$ e $v_{\mathrm{th}}=10^{5} \mathrm{~cm} / \mathrm{s}$ Armitage, 2010). 
O escoamento turbulento, no qual as partículas se misturam de forma não linear, isto é, de forma caótica, pode aumentar o tempo de sedimentação; no entanto, nesta dissertação, trabalha-se apenas com discos laminares. Em geral, a inclusão da turbulência ainda mantém tempos bem pequenos em relação à evolução dinâmica do sistema.

Observações de discos protoplanetários têm mostrado uma população de grãos maior do que o esperado (Furlan et al., 2006). Entender como esses grãos sobreviveram nesse longo período de tempo ainda é um desafio. Uma possível explicação para isso é a fragmentação que pode ocorrer durante as colisões. Mas, isso exige colisões mais energéticas, com velocidades da ordem de $\mathrm{m} / \mathrm{s}$, porém as velocidades típicas encontradas nos modelos são da ordem de cm/s.

\subsubsection{Distribuição radial de partículas sólidas}

Após determinar que o tempo de sedimentação é muito curto, podemos analisar a distribuição radial das partículas e calcular o tempo para ela cair na estrela, para isso precisamos da velocidade orbital do gás, que pode ser obtida para um determinado perfil de densidade superficial e de temperatura através da equação de Euler (Equação 2.26), para um fluído não magnetizado e sem viscosidade, temos

$$
\frac{\delta \vec{v}}{\delta t}+(\vec{v} \cdot \vec{\nabla}) \vec{v}=-\frac{1}{\rho} \vec{\nabla} P+\vec{\nabla} \Phi
$$

onde $\vec{v}$ é a velocidade, $\rho$ é a densidade volumétrica do gás, $P$ é a pressão e $\Phi$ é o potencial gravitacional. Considerando que o potencial gravitacional da estrela seja o dominante, a componente radial da equação acima implica uma velocidade orbital $v_{\phi \text {,gas }}$ dada por

$$
\frac{v_{\phi, \text { gas }}^{2}}{r}=\frac{G M_{\star}}{r^{2}}+\frac{1}{\rho} \frac{d P}{d r} .
$$

Como a pressão decresce com o aumento de $r$, o segundo termo do lado direito é negativo, de modo que a velocidade orbital do gás é levemente menor que a velocidade kepleriana de uma partícula sólida no mesmo raio. Podemos quantificar essa diferença considerando uma lei de potência para a pressão na forma

$$
P=P_{0}\left(\frac{r}{r_{0}}\right)^{-n},
$$


num disco verticalmente isotérmico $P_{0}=\rho_{0} c_{\mathrm{s}}^{2}$, de maneira que a Equação 4.10 pode ser escrita na forma

$$
v_{\phi, \text { gas }}=v_{\mathrm{K}}\left(1-n \frac{c_{\mathrm{s}}^{2}}{v_{\mathrm{K}}^{2}}\right)^{1 / 2},
$$

onde $v_{\mathrm{K}}$ é a velocidade kepleriana.

Para um disco cuja razão de altura é $h / r=0.05$ e o perfil de densidade superfical do gás $\Sigma \propto r^{-1}$, obtém-se $n=3$ e

$$
v_{\phi, \mathrm{gas}} \simeq 0,996 v_{\mathrm{K}}
$$

Analisaremos, portanto, as consequências físicas da ação do arrasto aerodinâmico num disco cujo gás possui velocidade próxima da kepleriana.

Para uma partícula pequena, o acoplamento com o gás será muito forte $\left(\Omega t_{\text {fric }} \ll 1\right)$, o que faz com que a poeira seja varrida pelo gás igualando suas velocidades azimutais, como esta velocidade é um pouco menor que a kepleriana, a força centrífuga não consegue equilibrar a atração gravitacional da estrela e, portanto, a partícula espirala em direção à estrela.

Partículas grandes, nas quais o acoplamento não é forte $\left(\Omega t_{\text {fric }} \gg 1\right)$, também espiralam em direção à estrela, pois o arrasto aerodinâmico, devido à pequena diferença entre a velocidade do gás e da partícula, age como uma perturbação ao movimento orbital do corpo, levando a perda do momento angular.

É possível descrever a taxa com que ocorre esse deslocamento radial em função do tempo de fricção (Equação 4.3) das partículas no plano médio do disco. Um cálculo mais completo pode ser obtido em Takeuchi e Lin (2002). Considerando $v_{r}$ e $v_{\phi}$, respectivamente, a velocidade radial e azimutal da partícula, a equação de movimento será da forma

$$
\frac{d v_{r}}{d t}=\frac{v_{\phi}^{2}}{r}-\Omega_{\mathrm{K}}^{2} r-\frac{1}{t_{\text {fric }}}\left(v_{r}-v_{r, \text { gas }}\right),
$$

e

$$
\frac{d}{d t}\left(r v_{\phi}\right)=-\frac{r}{t_{\text {fric }}}\left(v_{\mathrm{EE}}-v_{\phi, \text { gas }}\right) .
$$

Levando em conta que o momento angular específico permanece próximo do kepleriano, podemos escrever 


$$
\frac{d}{d t}\left(r v_{\phi}\right) \approx v_{r} \frac{d}{d r}\left(r v_{\mathrm{k}}\right)=\frac{1}{2} v_{r} v_{\mathrm{K}}
$$

o que resulta em

$$
v_{\phi}-v_{\phi, \text { gas }} \approx-\frac{1}{2} \frac{t_{\text {fric }} v_{r} v_{\mathrm{K}}}{r}
$$

Isolando $\Omega_{\mathrm{K}}\left(v_{\mathrm{K}}=\Omega_{\mathrm{K}} r\right)$ da Equação 4.12 e substituindo na Equação 4.14, encontramos, neglegenciando os temos de ordem mais alta

$$
\frac{d v_{r}}{d t}=-\eta \frac{v_{\mathrm{K}}^{2}}{r}+\frac{2 v_{\mathrm{K}}}{r}\left(v_{\phi}-v_{\phi, \text { gas }}\right)-\frac{1}{t_{\text {fric }}}\left(v_{r}-v_{r, \text { gas }}\right)
$$

onde $\eta=n \frac{c_{\mathrm{s}^{2}}}{v_{\mathrm{K}^{2}}}$.

Desprezando $\frac{d v_{r}}{d t}$ e substituindo o termo $\left(v_{\phi}-v_{\phi \text {,gas }}\right)$ da Equação 4.17 na 4.18 , encontramos

$$
v_{r}=\frac{\left(r / v_{\mathrm{K}}\right) t_{\text {fric }}^{-1} v_{r, \text { gas }}-\eta v_{\mathrm{K}}}{\left(v_{\mathrm{K}} / r\right) t_{\text {fric }}+\left(r / v_{\mathrm{K}}\right) t_{\text {fric }}^{-1}} .
$$

É comum na literatura sobre formação de planetesimais, o uso da grandeza adimensional denominada tempo de parada $\left(\tau_{\mathrm{p}}\right)$, definida como

$$
\tau_{\mathrm{p}} \equiv t_{\text {fric }} \Omega_{\mathrm{K}}
$$

de modo que a Equação 4.19 pode ser escrita na forma

$$
v_{r}=\frac{\tau_{\mathrm{p}}^{-1} v_{r, \mathrm{gas}}-\eta v_{\mathrm{K}}}{\tau_{\mathrm{p}}+\tau_{\mathrm{p}}^{-1}} .
$$

A Figura 4.2 mostra a razão da velocidade radial pela velocidade kepleriana em função do tempo de parada para alguns parâmetros do disco num raio de 5 UA e um dado valor de $\eta$.

Podemos observar que, para partículas pequenas $\left(\tau_{\mathrm{p}} \approx 0.1\right)$, o deslocamento radial aumenta de forma aproximadamente linear com o tempo de parada, já para partículas grandes $\left(\tau_{\mathrm{p}} \approx 10\right)$, a velocidade radial decai linearmente com o tempo de parada. O pico do gráfico ocorre em $v_{r} \approx-\frac{1}{2} \eta v_{\mathrm{k}}$ e o tamanho correspondente a esse tempo de fricção pode ser obtido através da escolha do regime (Epstein ou Stokes). Para o regime de Epstein e 


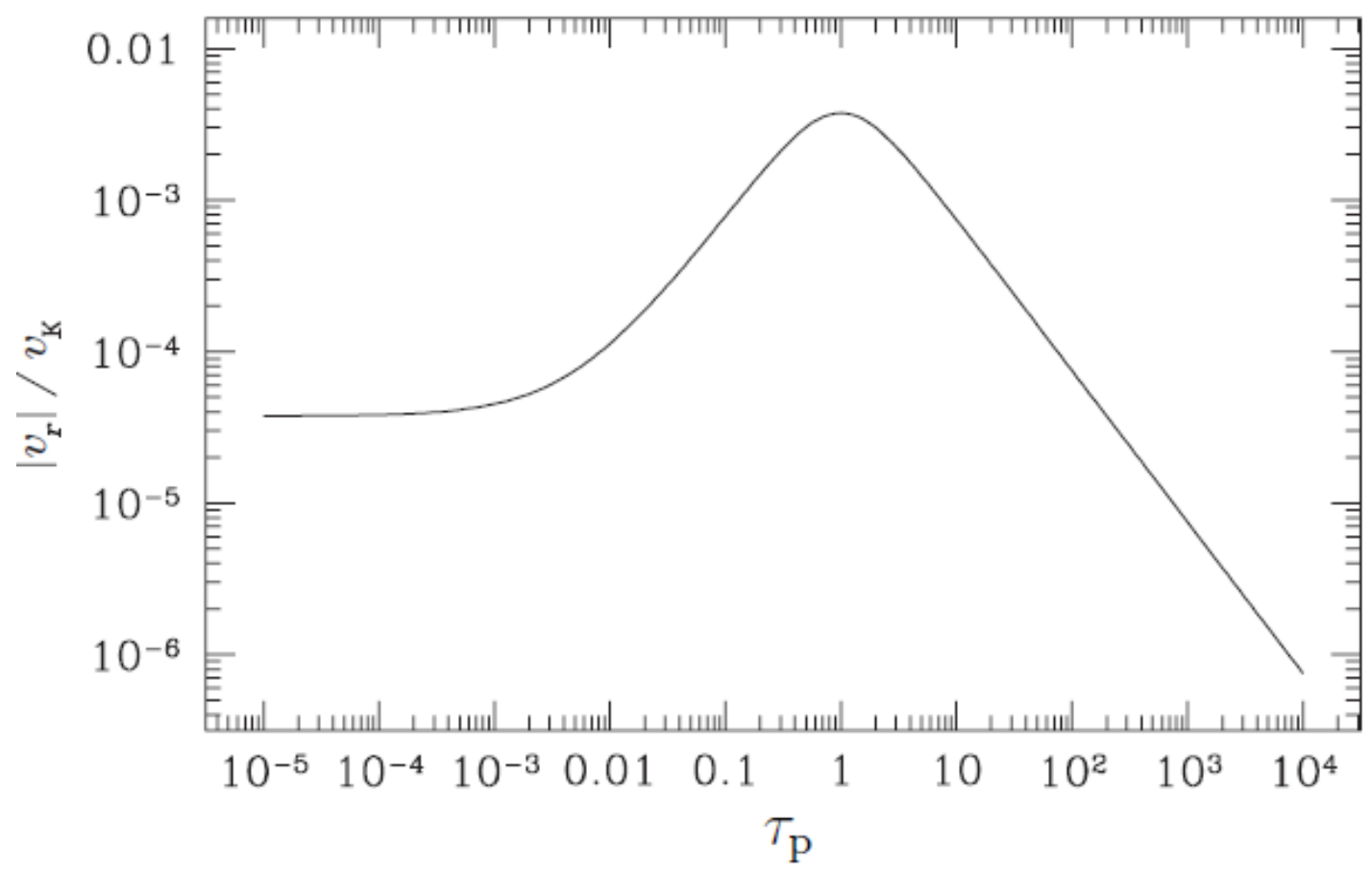

Figura 4.2: Gráfico da velocidade radial das partículas no plano médio do disco em função do tempo de parada. Foi adotado $\eta=7.5 \times 10^{-3}$ e $v_{r \text {,gas }} / v_{\mathrm{K}}=3.75 \times 10^{-5}$. Esses valores foram obtidos para um disco com $h / r=0.05$ e $\alpha=10^{-2}$ em 5 UA. Figura obtida em: Armitage (2010).

dados típicos do disco em 5 UA, verificou-se que o deslocamento mais rápido ocorre para $s \approx 20 \mathrm{~cm}$ (Armitage, 2010).

A Figura 4.3 mostra o tempo minímo $\left(t_{\min }\right)$, isto é, o tempo que uma partícula com velocidade máxima demora para cair na estrela, em função de sua posição radial inicial. Percemos que o tempo é extremamente curto - da ordem de $10^{3}$ anos para distâncias radiais próximas de 10 UA.

Podemos então destacar algumas características interessantes. A primeira delas é que a formação planetesimal precisa ser rápida, pois, se não fosse assim, as partículas mais leves iriam parar rapidamente nas regiões mais internas e seriam evaporadas pela estrela central. Outra conclusão é que ocorre uma distribuição de partículas ao longo do disco, havendo locais onde há um preenchimento de material e em outros seu esgotamento, dependendo sobretudo do tamanho das partículas.

O modelo acima não leva em consideração o crescimento da partícula durante seu deslocamento radial, portanto, o próximo passo é considerar a coagulação que ocorre em razão da diferenciação de velocidade entre as partículas de diversos tamanhos. Usando o 


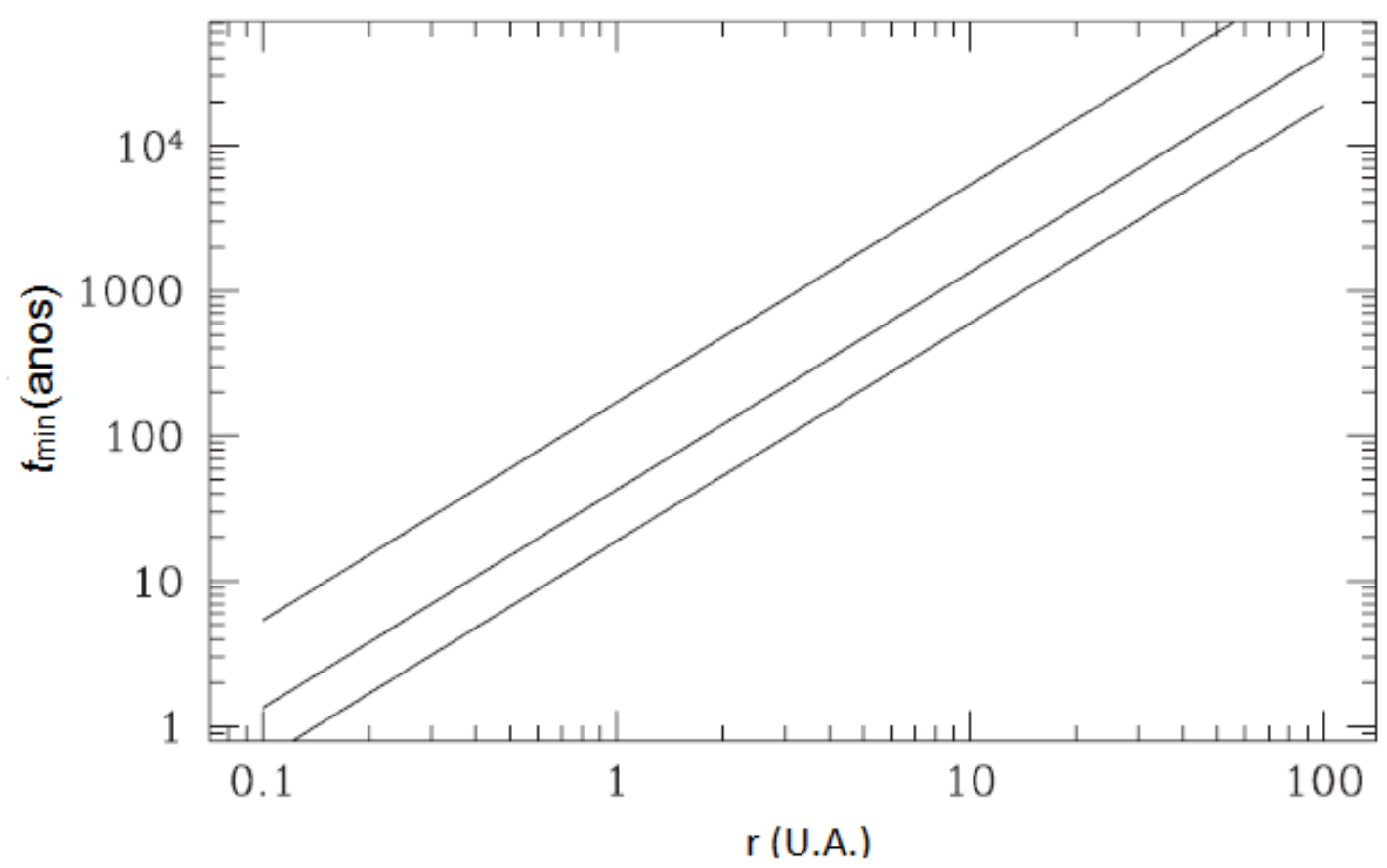

Figura 4.3: Gráfico do tempo de descolamento de uma partícula com velocidade máxima em função do raio do disco. Foi adotado $\Sigma \propto r^{-1}$ e $h / r=0.025$ (linha superior), $h / r=0.05$ (linha intermediária) e $h / r=0.075$ (linha inferior). Figura obtida em: Armitage (2010).

mesmo procedimento do deslocamento vertical, no qual todas as colisões são consideradas adesivas, obtém-se a taxa de crescimento de uma partícula de raio $s$ como

$$
\frac{d m}{d t}=\pi s^{2}\left|v_{r}\right| f \rho
$$

onde $f$ é a razão entre a densidade da partícula e do gás em $z=0$ e $\rho$ a densidade do gás no plano médio do disco $\left(\rho=\frac{1}{\sqrt{(2 \pi)}} \frac{\Sigma}{h}\right)$. No entanto, podemos comparar o tempo de crescimento $\left(t_{\text {cres }}=\frac{m}{d m / d t}\right)$ com o tempo para o deslocamento radial $\left(t_{\text {des }}=\frac{r}{\left|v_{r}\right|}\right)$, obtendo $t_{\text {cres }}<t_{\text {desl }}$ para partículas com um tamanho

$$
s<\frac{3 f}{4 \sqrt{2 \pi}}\left(\frac{h}{r}\right)^{-1} \frac{\Sigma}{\rho_{\mathrm{m}}} .
$$

Assumindo que o arranjo vertical já tenha ocorrido e usando alguns valores típicos do interior do disco $\left(f=0.1, \Sigma=10^{3} \mathrm{~g} / \mathrm{cm}^{2}, \rho_{\mathrm{m}}=3 \mathrm{~g} / \mathrm{cm}^{3}\right.$ e $\left.h / r=0.05\right)$, encontra-se $s=2 \mathrm{~m}$. Isso mostra que partículas menores caem na estrela antes mesmo de poder crescer o suficiente. 
A turbulência também pode ser um fator importante. Entretanto, estudos mostram que sua inclusão é bem menos dramática do que é para a distribuição vertical, pois ela não altera a velocidade sub-kepleriana, responsável pelo deslocamento radial (Armitage, 2010).

O modelo de coagulação que usamos permitiu colisões adesivas e o crescimento de partículas num intervalo curto de tempo. Para partículas pequenas, da ordem de mm, esse modelo parece ser razoável, todavia, é difícil de aceitar que ele funcione para partículas maiores, da ordem de metros, devido a altos valores para as velocidades relativas que poderiam fragmentar as partículas em vez de permitir a coagulação. A dificuldade de obter informações observacionais também é um problema, gerando uma brecha no nosso conhecimento sobre a formação dos planetesimais.

Além disso, foi usada uma taxa de crescimento constante para todas as partículas. Contudo, observacionalmente detectamos partículas pequenas nos discos, de modo que elas precisam sobreviver ou se regenerar via colisões erosivas. O tratamento matemático que engloba essa situação, entre outras, é a equação de coagulação desenvolvida por Smoluchowski (1916). Todavia, essas relações mais complexas fogem do escopo deste trabalho.

A conclusão mais importante é que a análise da distribuição vertical e radial de partículas, de fato, revelou que a formação dos planetesimais deve ocorrer numa escala de tempo muito menor que a da formação dos planetas terrestres.

\subsection{Formação de planetas terrestres}

A análise acima permitiu revelar que a formação planetesimal deve ocorrer de forma rápida, de modo que podemos partir diretamente para o estudo da formação de um núcleo sólido e de um planeta terrestre, que ocorre por meio da acreção desses planetesimais. Iremos considerar o caso de um protoplaneta de massa $0.01 \mathrm{M}_{\text {Terra }}$ e o limite de massa do núcleo como sendo de $10 \mathrm{M}_{\text {Terra }}$, a partir da qual a acreção de gás tem seu início.

Uma vez formados os planetesimais, a atração gravitacional mútua passa a ser o processo físico dominante. A dificuldade no estudo desse sistema reside no grande número de corpos interagindo entre si. Portanto, para as fases iniciais, costuma-se usar métodos estatísticos similares aos usados na teoria cinética dos gases. Somente quando o número de corpos diminui para uma ordem de centenas ou milhares, é que se torna possível o uso das simulações para N-corpos. 
Em geral, o tratamento estatístico envolve uma distribuição de elementos orbitais keplerianos $f(e, i)$, no qual a longitude do pericentro e a longitude do nodo ascendente são tomadas como uniformes. Utilizando conceitos análogos à distribuição de velocidades num gás e a distribuição de Rayleight para uma população de planetesimais de massa $m$ e densidade superficial local $\Sigma_{\mathrm{m}}$, obtém-se

$$
f(e, i)=4 \frac{\Sigma_{\mathrm{m}}}{m} \frac{e i}{\left\langle e^{2}\right\rangle\left\langle i^{2}\right\rangle} \exp \left[-\frac{e^{2}}{\left\langle e^{2}\right\rangle}-\frac{i^{2}}{\left\langle i^{2}\right\rangle}\right]
$$

onde $\left\langle e^{2}\right\rangle$ e $\left\langle i^{2}\right\rangle$ são, respectivamente, os valores quadráticos médios para excentricidade e inclinação. É importante destacar que a exata conversão entre os elementos orbitais e as componentes randômicas da velocidade variam de acordo com o problema em estudo.

Para o processo de captura do planetesimal, é importante introduzir o conceito de seção de choque $(\Gamma)$, definida como a área que mede a probabilidade de uma colisão (interação) entre partículas ocorrer. A atração gravitacional de um corpo massivo irá defletir a trajetória de um corpo que se move em sua direção resultando em uma seção de choque maior, numa espécie de "focalização gravitacional". Considere a Figura 4.4, na qual dois corpos de massa $m$ movem-se com velocidade relativa $\sigma$ numa trajetória cujo parâmetro de impacto, ou seja, a distância perpendicular entre o vetor velocidade do projétil e o centro do objeto do qual está se aproximando, é $b$.

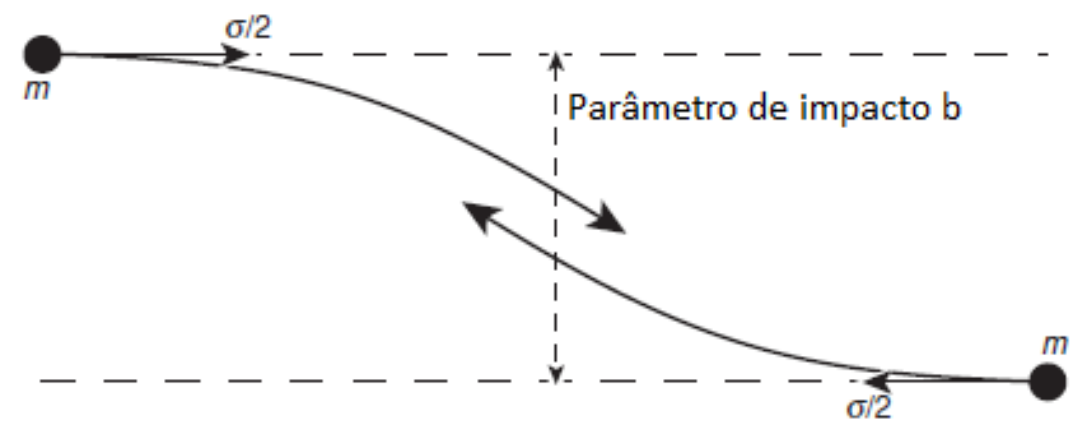

Figura 4.4: A atração gravitacional pode tornar a seção de choque maior, desde que a velocidade randômica seja menor que a velocidade de escape de sua superfície. Figura obtida em: Armitage (2010).

Definindo o momento de maior aproximação como aquele em que os corpos possuem uma separação $R_{\mathrm{c}}$ e velocidade máxima $v_{\max }$, a equação de conservação de energia, no referencial do centro de massa, fornece 


$$
\frac{1}{4} m \sigma^{2}=m v_{\max }^{2}-\frac{G m^{2}}{R_{\mathrm{c}}}
$$

Como não há componente radial no ponto de maior aproximação, a conservação do momento angular permite escrever

$$
v_{\max }=\frac{1}{2} \frac{b}{R_{\mathrm{c}}} \sigma
$$

Definindo a soma dos raios dos corpos como $R_{\mathrm{s}}$; então, se $R_{\mathrm{c}}<R_{\mathrm{s}}$, haverá uma colisão, caso contrário, não. O maior valor do parâmetro de impacto necessário à colisão ocorre quando $R_{\mathrm{c}}=R_{\mathrm{s}}$, logo

$$
b_{\max }^{2}=R_{\mathrm{s}}^{2}+\frac{4 G m R_{\mathrm{s}}}{\sigma^{2}} .
$$

Expressando em termos da velocidade de escape $v_{\mathrm{esc}}^{2}=\frac{4 G m}{R_{\mathrm{s}}}$, temos

$$
b_{\max }^{2}=R_{\mathrm{s}}^{2}\left(1+\frac{v_{\mathrm{esc}}^{2}}{\sigma^{2}}\right) .
$$

Portanto, a seção de choque é descrita por

$$
\Gamma=\pi R_{\mathrm{s}}^{2}\left(1+\frac{v_{\mathrm{esc}}^{2}}{\sigma^{2}}\right)
$$

A equação acima só levou em conta a força gravitacinal mútua entre os corpos. No entanto, a atração gravitacional da estrela também pode ser importante e, neste caso, torna-se necessário considerar o problema de três corpos. Uma estimativa para a condição no qual o tratamento para o problema de três corpos se torna importante, é obtida usando o conceito de esfera de Hill, cujo raio define uma região dentro da qual a gravidade do protoplaneta, com massa $M_{\mathrm{p}}$ e semieixo maior $a$, domina sobre o campo gravitacional da estrela de massa $M_{\star}$, sendo seu valor dado por

$$
R_{\mathrm{H}} \equiv\left(\frac{M_{\mathrm{p}}}{3 M_{\star}}\right)^{1 / 3} a .
$$

Dentro da esfera de Hill, o problema de dois corpos é uma aproximação adequada para a dinâmica dos corpos. Usando a Equação 4.30, utiliza-se uma velocidade característica, definida como a velocidade orbital ao redor do protoplaneta numa distância igual ao raio de Hill, assim 


$$
v_{\mathrm{H}} \equiv \sqrt{\frac{G M_{\mathrm{p}}}{R_{\mathrm{H}}}} .
$$

Se a velocidade relativa randômica $\sigma$ do planetesimal é maior que a velocidade de Hill $\left(\sigma>v_{\mathrm{H}}\right)$, então a taxa com que eles entram na esfera de Hill e colidem é determinada pela dinâmica de dois corpos. No entanto, se $\sigma<v_{\mathrm{H}}$, a atração gravitacional da estrela precisa ser considerada. O tratamento que utiliza a dinâmica de dois corpos falha para planetesimais em baixo regime de velocidade randômica, pois o tempo de interação com o protoplaneta deixar de ser desprezível em relação ao tempo orbital.

Inicialmente, vamos analisar cada regime separadamente, fornecendo a base para o entendimento de um modelo mais complexo, que será utilizado para a formação do núcleo sólido.

\subsubsection{Crescimento do planeta no regime de dois corpos $\left(\sigma>v_{\mathrm{H}}\right)$}

Podemos obter um resultado simples para a taxa de crescimento de um protoplaneta no domínio de dois corpos. Considere um corpo de massa $M_{\mathrm{p}}$ e raio $R_{\mathrm{s}}$, imerso em um enxame de pequenos planetesimais movendo-se com velocidade relativa $\sigma$ (Figura 4.5). A taxa de crescimento do corpo pode ser estimada através de um modelo conhecido como partícula em uma caixa, como igual ao produto da densidade do enxame de planetesimais, da velocidade relativa e da seção de choque (Equação 4.29). Logo

$$
\frac{d M_{\mathrm{p}}}{d t}=\rho_{\mathrm{enx}} \sigma \pi R_{\mathrm{s}}^{2}\left(1+\frac{v_{\mathrm{esc}}^{2}}{\sigma^{2}}\right) .
$$

Podemos obter a densidade do enxame de planetesimais através da relação

$$
\rho_{\mathrm{enx}} \approx \frac{\Sigma_{\mathrm{m}}}{2 h_{\mathrm{p}}},
$$

onde $\Sigma_{\mathrm{m}}$ é a densidade superficial de planetesimais (ou densidade superficial de sólidos) e $h_{\mathrm{p}}$ a escala de altura que pode ser aferida como

$$
\frac{h_{\mathrm{p}}}{a} \approx \frac{\sigma}{v_{\mathrm{K}}}=\frac{\sigma}{a \Omega} \Rightarrow h_{\mathrm{p}} \approx \frac{\sigma}{\Omega} .
$$

Substituindo as relações acima na Equação 4.32 , obtém-se

$$
\frac{d M_{\mathrm{p}}}{d t}=\frac{\sqrt{3}}{2} \Sigma_{\mathrm{m}} \Omega \pi R_{\mathrm{s}}^{2}\left(1+\frac{v_{\mathrm{esc}}^{2}}{\sigma^{2}}\right) .
$$




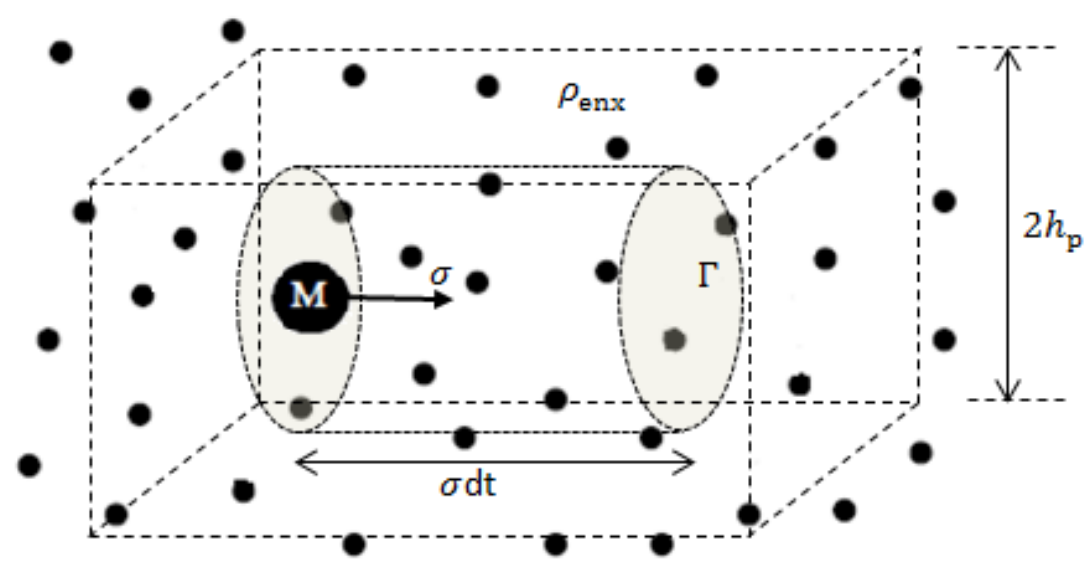

Figura 4.5: Enxame de planetesimais.

onde o pré-fator numérico $\sqrt{3}$ surge porque a velocidade relativa é considerada isotrópica (Lissauer, 1993).

É possível explorar duas soluções simples que podem nos ajudar a compreender modelos mais complexos. A primeira assume que o fator de foco gravitacional $F_{\mathrm{g}}=\left(1+\frac{v_{\mathrm{esc}}^{2}}{\sigma^{2}}\right)$ é constante e que a densidade superficial de planetesimais não muda com o tempo. Usando $M_{\mathrm{p}}=d \frac{4 \pi}{3} R_{\mathrm{p}}^{3}$, em que $d$ é a densidade do protoplaneta, a Equação 4.35 pode ser escrita na forma

$$
\frac{d R_{\mathrm{s}}}{d t}=\frac{\sqrt{3}}{8} \frac{\Sigma_{\mathrm{m}} \Omega}{d} F_{\mathrm{g}}
$$

cuja integral mostra que o raio cresce numa taxa linear $\left(R_{\mathrm{s}} \propto t\right)$, desde que a densidade do protoplaneta seja mantida constante.

A Equação 4.36 descreve um crescimento muito lento, por exemplo, um corpo de densidade $d=1 \mathrm{~g} / \mathrm{cm}^{3}$ numa distância de $5.2 \mathrm{UA}$, levaria cerca de 10 milhoes de anos para atingir um tamanho de $100 \mathrm{~km}$, tempo maior que a vida útil do disco. Concluímos, então, que a construção de corpos maiores exige maior foco gravitacional e, portanto, uma maior seção de choque.

Assim, o próximo limite a considerar é $v_{\text {esc }} \gg \sigma$, que resulta na maior seção de choque possível, a qual fornece $F_{\mathrm{g}} \approx \frac{v_{\mathrm{esc}}^{2}}{\sigma^{2}}=\frac{2 G M_{\mathrm{p}}}{\sigma^{2} R_{\mathrm{s}}}$, e a taxa de crescimento torna-se

$$
\frac{d M_{\mathrm{p}}}{d t}=\frac{\sqrt{3} \pi G \Sigma_{\mathrm{m}} \Omega}{\sigma^{2}} M_{\mathrm{p}} R_{\mathrm{s}} \simeq \frac{2.5 \pi^{2 / 3} G \Sigma_{\mathrm{m}} \Omega}{\sigma^{2} \rho_{\mathrm{m}}^{1 / 3}} M_{\mathrm{p}}^{4 / 3}=k M_{\mathrm{p}}^{4 / 3}
$$


na qual $k$ será constante desde que as propriedades do enxame de planetesimais sejam mantidas fixas, ou seja, o crescimento do protoplaneta não muda a velocidade de dispersão, nem consome uma fração significativa de planetesimais. Devido à dependência da massa na forma $M_{\mathrm{p}}^{4 / 3}$, percebemos que um corpo mais massivo cresce mais rápido que um menos massivo, fenômeno conhecido como runaway growth. Integrando a Equação 4.37, obtém-se

$$
M_{\mathrm{p}}(t)=\frac{1}{\left(M_{0}^{-1 / 3}-k^{\prime} t\right)^{3}} .
$$

Observe na equação acima que o planeta alcança uma massa infinita num tempo finito $\left(t=M_{0}^{-1 / 3} / k^{\prime}\right)$. Na realidade, a taxa de crescimento diminui pelo fato de a velocidade de dispersão dos planetesimais aumentar à medida que ocorre o crescimento, evitando assim essa singularidade.

A análise acima mostra que o foco gravitacional adequado permite a formação, dentro do regime de dois corpos, de núcleos sólidos grandes num tempo menor que o tempo de vida do disco.

\subsubsection{Crescimento do planeta no regime de três corpos $\left(\sigma<v_{\mathrm{H}}\right)$}

No regime de três corpos, a análise é mais complexa, sendo usual o tratamento aproximado com base no artigo de Greenberg et al. (1991). Vamos dividir o cálculo em duas partes: na primeira, estimamos a largura da zona na qual os planetesimais podem ser desviados para trajetórias que entram na esfera de Hill, denominada de zona de alimentação, e, na segunda, avaliamos a fração de planetesimais que entram e colidem com o protoplaneta.

Para estimar a largura da zona de alimentação, vamos considerar um planetesimal em uma órbita circular $a+\Delta a$ que, ao ser perturbado, passe próximo do protoplaneta de raio orbital a. O efeito gravitacional dominante ocorre enquanto a separação entre os dois é menor que $\Delta a$, esta condição continua durante o tempo $\delta t=\frac{2 \Delta a}{|d v|}=\frac{2 \Delta a}{\frac{1}{2} \Omega \Delta a}=\frac{4}{\Omega}$. Isso permite obter a mudança de velocidade do planetesimal em decorrência do impulso do protoplaneta. Da definição de impulso de uma força, temos

$$
m \delta v \approx F_{\text {grav }} \delta t \Rightarrow \delta v \approx \frac{4}{\Omega} \frac{G M_{\mathrm{p}}}{(\Delta a)^{2}} .
$$

A mudança de velocidade necessária para o planetesimal passar pela órbita do planeta é $\delta v \simeq \Omega \Delta a$, que substítuido na Equação 4.39 , fornece 


$$
\Delta \mathrm{a}^{3} \approx \frac{4 G M_{\mathrm{p}}}{\Omega^{2}}
$$

Usando $\Omega^{2}=\frac{G M_{\star}}{a^{3}}$, a relação acima nos dá a largura da zona de alimentação

$$
\Delta a \approx\left(\frac{4 M_{\mathrm{p}}}{M_{\star}}\right)^{1 / 3} \Rightarrow a \approx 2.3 R_{\mathrm{H}}
$$

onde $R_{\mathrm{H}}$ é o raio de Hill (Equação 4.30).

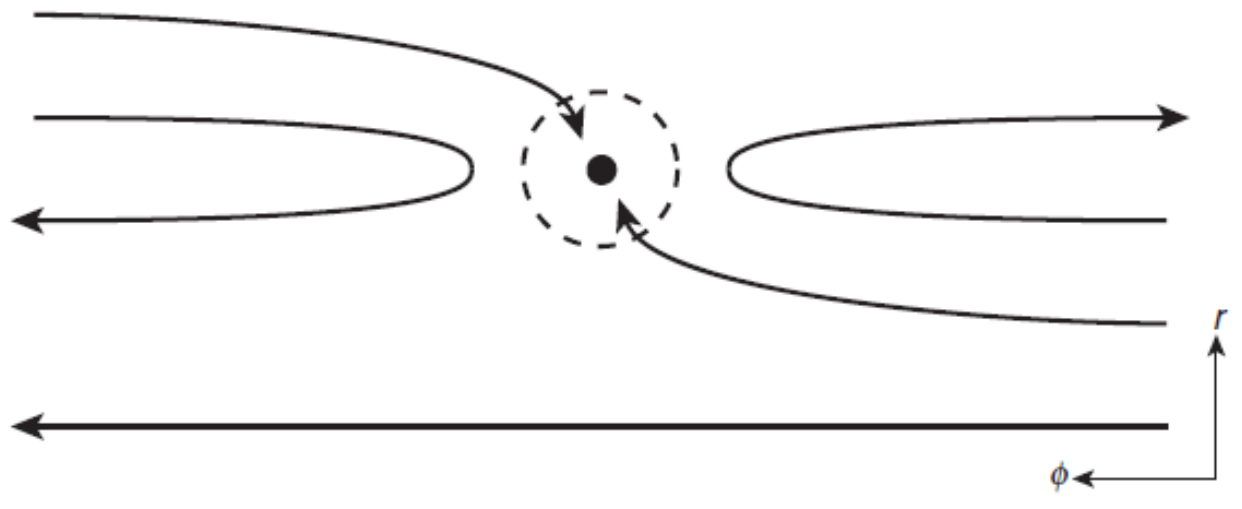

Figura 4.6: Trajetória de partículas em órbitas circulares próximas de um protoplaneta, considerando o problema de três corpos. Partículas muito próximas são desviadas em órbitas do tipo ferrradura diminuindo a zona de alimentação. Figura obtida em: Armitage (2010).

Planetesimais dentro da região $(a-\Delta a)$ e $(a+\Delta a)$ podem ser desviados para órbitas que se aproximam do protoplaneta. No entanto, as soluções do problema de ressonância 1/1 e simulações numéricas, usando as equações de Hill para uma partícula teste na vizinhaça do planeta, mostram que trajetórias muito próximas do planeta possuem formato de ferradura que nunca encontram a esfera de Hill, reduzindo a zona de alimentação (Figura 4.6). Portanto, o planetesimal que pode fazer parte da zona de alimentação está numa distância próxima de $\frac{3}{4} \Delta a$ do protoplaneta (Greenberg et al., 1991). A velocidade relativa média de aproximação $(\sigma)$ desse planetesimal, no referencial do protoplaneta, é dada por

$$
\sigma=a\left|\frac{d \Omega}{d a}\right| \frac{3}{4} \Delta a=\frac{9}{8} \Omega \Delta a .
$$

Portanto, o fluxo de planetesimais que são desviados, será 


$$
\frac{d M_{\mathrm{H}}}{d t}=\frac{9}{8} \Omega \Delta a \Sigma_{\mathrm{m}} \Delta a,
$$

que pode ser considerado, com boa aproximação, igual ao fluxo que entra na esfera de Hill ao redor do protoplaneta.

Uma vez que entram na esfera de Hill, a seção de choque com o protoplaneta pode ser obtida usando a dinâmica de dois corpos.

A geometria simples, retratada na Figura 4.7, na qual a espessura da zona de alimentação é inferida como 2ai, e $i$ é a inclinação dos planetesimais, permite estimar a fração de planetesimais que entram na esfera de Hill e terão impacto com o protoplaneta. Esta fração (adimensional) é dada por

$$
f \approx \frac{\Gamma}{\left(2 R_{\mathrm{H}}\right)(2 a i)}
$$

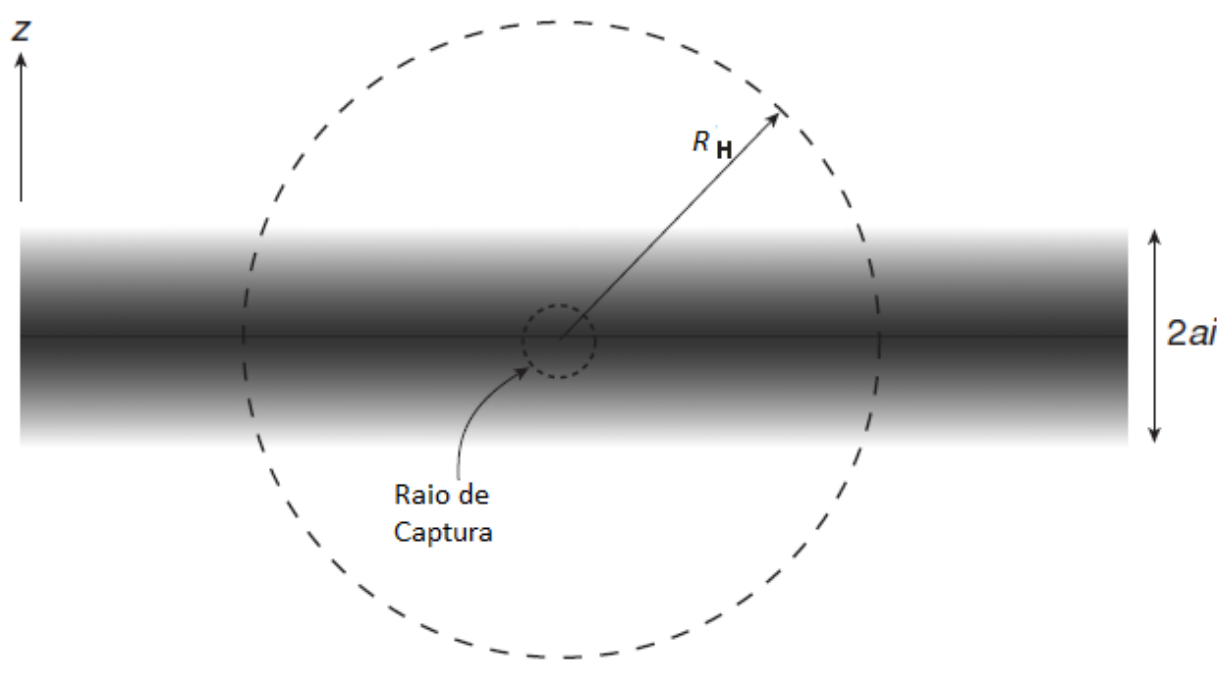

Figura 4.7: Uma visão de perfil mostrando o fluxo de planetesimais dentro da esfera de Hill do protoplaneta no regime de três corpos. Figura obtida em: Armitage (2010).

A relação acima pode ser usada desde que a espessura da zona de alimentação seja maior que o raio de captura definido por

$$
R_{\text {captura }}=R_{\mathrm{s}}\left(1+\frac{v_{\mathrm{esc}}^{2}}{v_{\mathrm{enc}}^{2}}\right)^{1 / 2},
$$

onde $v_{\text {enc }}$ é a velocidade de encontro do planetesimal com o protoplaneta. Considerando a taxa com que o protoplaneta cresce, via acreção de planetesimais, como o produto da 
fração com o fluxo de entrada de massa na esfera de Hill, obtemos

$$
\frac{d M_{\mathrm{p}}}{d t}=\frac{9}{32} \frac{(\Delta a)^{2}}{a i R_{\mathrm{H}}} \Sigma_{\mathrm{m}} \Omega \pi R_{\mathrm{s}}^{2}\left(1+\frac{v_{\mathrm{esc}}^{2}}{v_{\mathrm{enc}}^{2}}\right) .
$$

Esta expressão é similar à obtida no regime de dois corpos (Equação 4.37). No entanto, há diferenças importantes: primeiramente, no foco gravitacional não aparece a dependência da velocidade randômica dos planetesimais, mas da velocidade de escape e da velocidade de encontro, como $v_{\text {enc }}^{2} \propto R_{\mathrm{H}}^{2} \propto M_{\mathrm{p}}^{2 / 3}$, enquanto $v_{\mathrm{esc}}^{2} \propto M_{\mathrm{p}}$, ocorre um cancelamento parcial da dependência de massa no termo do foco gravitacional. Segundo, há uma dependência explicíta com a espessura vertical do enxame de planetesimais $\left(\frac{d M_{\mathrm{p}}}{d t} \propto \frac{1}{i}\right)$, caso o disco seja muito frio, pode ocorrer uma zona de alimentação muito fina necessitando de análise complementar.

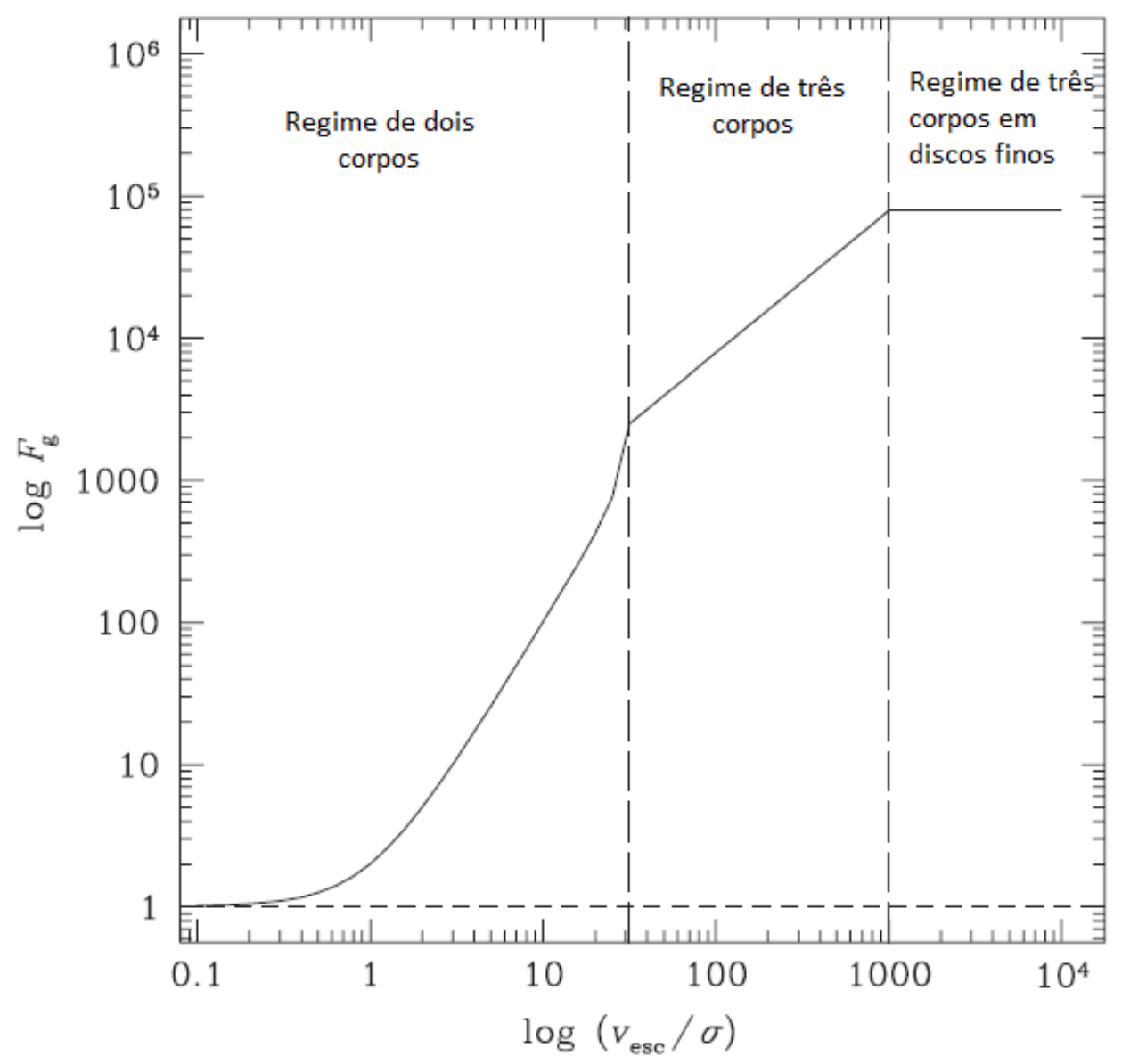

Figura 4.8: Dependência do foco gravitacional em função da razão da velocidade de escape e da velocidade de dispersão dos planetesimais. A massa do protoplaneta é fixa e varia-se a velocidade de dispersão. Figura obtida em: Armitage (2010).

Como os parâmetros que controlam a taxa de crescimento são diferentes em cada regime, 
não há uma consenso sobre as regiões de transição, além disso, os métodos computacionais mostram que a transição é muito tênue. A Figura 4.8 mostra a dependência da seção de choque com a razão $v_{\text {esc }} / \sigma$, na qual assume-se $v_{\text {esc }}$ fixo, enquanto $\sigma$ varia mantendo $e=2 i$ cosntante (Greenberg et al. 1991). Nesse caso, quatro regimes podem ser identificados: para $\frac{v_{\text {esc }}}{\sigma}<1$, o foco gravitacional é irrelevante, e o crescimento ocorre no regime de dois corpos com a seção de choque geométrica. Uma vez que $\frac{v_{\text {esc }}}{\sigma}>1$, ainda dentro do regime de dois corpos, o foco gravitacional torna-se importante e aumenta linearmente $\operatorname{com} \frac{v_{\mathrm{esc}}}{\sigma}$. Saindo do regime de dois corpos, o foco gravitacional aumenta mais lentamente. Finalmente, o disco torna-se fino o suficiente, de modo que a seção de choque torna-se constante.

\subsection{Modelo computacional para formação de um núcleo sólido}

A análise acima mostrou que a excentricidade e a inclinação dos planetesimais podem influenciar a taxa de acreção, fazendo-a oscilar entre o regime de dois ou três corpos, dependendo das condições do enxame de planetesimais e da interação destes com o gás do disco, com o protoplaneta e até mesmo com outros planetesimais.

Um modelo análitico mais acurado pode ser construído utilizando dois métodos equivalentes: o primeiro trata de um formalismo cinético baseado em adicionar um termo colisional na equação de Boltzmann, descrevendo a evolução da densidade do espaço de fase dos corpos (Hornung et al., 1985; Stewart e Wetherill, 1988); o outro modelo utiliza um formalismo baseado no tratamento de três corpos utilizando as equações de Hill (Ida, 1990). As duas aproximações podem ainda ser melhoradas com o uso da integração numérica do problema de três corpos (Stewart e Ida, 2000).

Esses modelos dependem do cálculo da excentricidade e das inclinações dos planetesimais que definem sua velocidade relativa. Nesta dissertação, iremos trabalhar com as relações obtidas para a situação mais comum, na qual a velocidade de dispersão dos planetesimais é controlada pela relação entre o impulso do protoplaneta e o arrasto do gás.

Considere um protoplaneta de massa $M_{\mathrm{p}}$ e raio $R$, numa órbita circular em torno da estrela com semieixo maior $a$ e velocidade angular $\Omega$, crescendo via acreção de planetesimais de raio $r_{\mathrm{m}}$ e massa $m$. Para descrever a transição entre o regime de dois e três corpos, é comum utilizar a excentricidade e a inclinação na forma normalizada 


$$
\tilde{e} \equiv a e / R_{\mathrm{H}}
$$

e

$$
\tilde{i} \equiv a i / R_{\mathrm{H}},
$$

no qual $R_{\mathrm{H}}$ é o raio de Hill do corpo (Equação 4.30).

Utilizando a distribuição de Rayleigh para o enxame de planetesimais, Inaba et al. (2000) mostram que o crescimento do protoplaneta é descrito pela relação

$$
\frac{d M_{\mathrm{p}}}{d t}=\left(\frac{2 \pi \Sigma_{\mathrm{m}} R_{\mathrm{H}}^{2}}{P_{\text {orbital }}}\right) P_{\text {coll }},
$$

onde $\Sigma_{\mathrm{m}}$ é a densidade superficial dos planetesimais no local onde ocorre a acreção, também denominada densidade superficial de sólidos, e $P_{\text {orbital }}$ é o período orbital do protoplaneta. A taxa de colisão $P_{\text {coll }}$ mede a probabilidade de o planetesimal ser acretado e depende da velocidade relativa entre o planetesimal e o protoplaneta, que, por sua vez, tem relação com a inclinação $(\tilde{i})$ e a excentricidades média $(\tilde{e})$ dos planetesimais. De acordo com Inaba et al. (2000), a taxa de colisão média pode ser aproximada por

$$
P_{\text {coll }}=\min \left(P_{\text {med }},\left(P_{\text {high }}^{-2}+P_{\text {low }}^{-2}\right)^{-1 / 2}\right),
$$

onde $P_{\text {med }}, P_{\text {high }}$ e $P_{\text {low }}$ são os diferentes regimes encontrados para as diferentes velocidades dos planetesimais, o que permite diferentes taxas de colisões. Esses regimes são descritos pelas equações

$$
\begin{gathered}
P_{\text {high }}=\frac{\left(R+r_{\mathrm{m}}\right)^{2}}{2 \pi R_{\mathrm{H}}^{2}}\left(I_{\mathrm{F}}(\beta)+\frac{6 R_{\mathrm{H}} I_{\mathrm{G}}(\beta)}{\left(R+r_{m}\right) \tilde{e}^{2}}\right), \\
P_{\text {med }}=\frac{\left(R+r_{\mathrm{m}}\right)^{2}}{4 \pi R_{\mathrm{H}}^{2} \tilde{i}}\left(17.3+\frac{232 R_{\mathrm{H}}}{R+r_{m}}\right)
\end{gathered}
$$

$\mathrm{e}$

$$
P_{\text {low }}=11.3\left(\frac{R+r_{m}}{R_{\mathrm{H}}}\right)^{1 / 2} .
$$

O limite para altas velocidades $\left(P_{\text {high }}\right)$ é mais apropriado para $\tilde{e}, \tilde{i}>2$, para médias velocidades $\left(P_{\text {med }}\right)$, para $0.2<\tilde{e}, \tilde{i}<2$, e baixas velocidades $\left(P_{\text {low }}\right)$, para $\tilde{e}, \tilde{i}<0.2$. O parâmetro $\beta$ é definido como $\beta \equiv \tilde{i} / \tilde{e}$, enquanto as funções $I_{\mathrm{F}}(\beta)$ e $I_{\mathrm{G}}(\beta)$ pelas relações 


$$
I_{\mathrm{F}}(\beta)=8 \int_{0}^{1} \frac{\beta^{2} \mathrm{E}(\theta)}{\left[\beta^{2}+\left(1-\beta^{2}\right) \lambda^{2}\right]^{2}} d \lambda
$$

e

$$
I_{\mathrm{F}}(\beta)=8 \int_{0}^{1} \frac{\mathrm{K}(\theta)}{\beta^{2}+\left(1-\beta^{2}\right) \lambda^{2}} d \lambda
$$

onde $\mathrm{E}(\theta)$ e $\mathrm{K}(\theta)$ são integrais elípticas, respectivamente, de primeira e segunda ordem e $\theta \equiv \frac{1}{2} \sqrt{3-3 \lambda^{2}}$. O modelo numérico, que iremos implementar no MATHEMATICA, utiliza relações aproximadas para as relações acima (Chambers, 2006), descritas por

$$
I_{\mathrm{F}}(\beta)=\frac{1+0.95925 \beta+0.7725 \beta^{2}}{\beta(0.13142+0.12295 \beta)}
$$

e

$$
I_{\mathrm{G}}(\beta)=\frac{1+0.3996 \beta}{\beta\left(0.0369+0.048333 \beta+0.00687 \beta^{2}\right)} .
$$

As relações são aparentemente complexas, mas mostram uma dependência da excentricidade e da inclinação dos planetesimais, que combina com a descrição dos regimes anteriores. No regime de altas velocidades (Equação 4.51), a velocidade de dispersão, que depende de $1 / \tilde{e}^{2}$, entra pelo termo do foco gravitational; no caso de velocidades intermediárias (Equação 4.52), a dependência com $1 / i$ é mantida de forma similar à equação para o regime de três corpos (Equação 4.46), e, finalmente, para o caso de um disco frio com velocidades baixas (Equação 4.53), não há dependência da excentricidade ou da inclinação, como era esperado.

Todavia, para facilitar os cálculos numéricos, iremos fazer algumas simplificações. Primeiramente, podemos escrever o raio de Hill (Equação 4.30) em função da densidade do protoplaneta (e.g. $d=5.5 \mathrm{~g} / \mathrm{cm}^{3}$ ) usando a relação $M_{\mathrm{p}}=d \frac{4 \pi}{3} R^{3}, \log \mathrm{o}$

$$
\frac{R_{\mathrm{H}}}{R}=c=\left(\frac{a^{3} d 4 \pi}{9 M_{\star}}\right)^{1 / 3} .
$$

Considerando a equação acima e a situação na qual $R \gg r_{\mathrm{m}}$, as probabilidades, dadas pelas Equações 4.51, 4.52 e 4.53 , podem ser escritas na forma

$$
P_{\text {high }}=\frac{1}{2 \pi c^{2}}\left(I_{\mathrm{F}}(\beta)+\frac{6 I_{\mathrm{G}}(\beta) c}{\tilde{e}^{2}}\right)
$$




$$
P_{\text {med }}=\frac{1}{4 \pi c^{2} \tilde{i}}(17.3+232 c)
$$

$\mathrm{e}$

$$
P_{\text {low }}=11.3 c^{-1 / 2} \text {. }
$$

Para o cálculo das excentricidades e inclinações dos planetesimais, foi utilizado um dos modelos apresentados por Fortier et al. (2013), no qual o impulso nos planetesimais, produzido pelo protoplaneta, é instantaneamente balanceado pelo arrasto do gás. Obtémse então uma aproximação para excentricidades na forma

$$
e_{\mathrm{eq}}=1.7 \frac{m^{1 / 15} M_{\mathrm{p}}^{1 / 3} \rho_{\mathrm{p}}^{2 / 15}}{b^{1 / 5} C_{\mathrm{D}}^{1 / 5} \rho^{1 / 5} M_{\star}^{1 / 3} a^{1 / 5}} .
$$

Usando a definição do raio de Hill, a relação acima pode ser escrita na forma

$$
e_{\mathrm{eq}}=2.45 \frac{m^{1 / 15} \rho_{\mathrm{p}}^{2 / 15}}{b^{1 / 5} C_{\mathrm{D}}^{1 / 5} \rho^{1 / 5} a^{1 / 5}}\left(\frac{R_{\mathrm{H}}}{a}\right) .
$$

Isso permite escrever a excentricidade reduzida de equilíbrio $\left(\tilde{e}_{\mathrm{eq}}=a e_{\mathrm{eq}} / R_{\mathrm{H}}\right)$ como

$$
\tilde{e}_{\mathrm{eq}}=2.45 \frac{m^{1 / 15} \rho_{p}^{2 / 15}}{b^{1 / 5} C_{\mathrm{D}}^{1 / 5} \rho^{1 / 5} a^{1 / 5}},
$$

onde $\rho_{\mathrm{p}}=5.5 \mathrm{~g} / \mathrm{cm}^{3}$ é a densidade volumétrica do bulbo de planetesimais ao redor do protoplaneta, $b=10$ é a largura do raio de captura em função do raio de Hill, $C_{\mathrm{D}}=$ 1 é o coeficiente de arrasto, $\rho$ é a densidade volumétrica do gás na região onde está o protoplaneta e depende do modelo de disco considerado, $a$ é o semieixo maior e $m$ é a massa dos planetesimais $\left(m=d_{\mathrm{pl}} \frac{4 \pi}{3} r_{m}^{3}\right)$, onde $d_{\mathrm{pl}}$ é a densidade dos planetesimais que são considerados homogêneos e sempre do mesmo tamanho. Devido à presença da linha de gelo, definida nesta dissertação como a distância na qual a temperatura permite a condensação de compostos de hidrogênio, usaremos os valores de $d_{\mathrm{pl}}=1 \mathrm{~g} / \mathrm{cm}^{3}$ para além da linha de gelo e $d_{\mathrm{pl}}=3.2 \mathrm{~g} / \mathrm{cm}^{3}$ para dentro da linha de gelo. Para a inclinação reduzida, a situação de equílibrio fornece

$$
\tilde{i}_{\mathrm{eq}}=\frac{\tilde{e}_{\mathrm{eq}}}{2},
$$

que permite escrever $\beta=0.5$ (Fortier et al., 2013). 
No entanto, não está claro se os planetesimais podem ser considerados sempre nessa condição, especialmente devido ao fato de o arrasto depender de sua massa, além disso, o disco pode ser afetado pela migração do protoplaneta e pela sua própria evolução. Todavia, os cálculos de Fortier et al. (2013) mostram que há boa concordância entre a situação de equilíbrio e modelos mais complexos, não havendo uma mudança muito brusca no tempo de formação do protoplaneta.

\subsubsection{Modelos de discos protoplanetários usados no modelo computacional da formação planetária}

Tendo em vista os pressupostos teóricos apresentados, podemos obter a taxa de acreção para a formação de um núcleo sólido de acordo com alguns parâmetros do disco protoplanetário. Para isso, usaremos os principais modelos de discos utilizados nos estudos de formação planetária, inclusive o modelo computacional para o disco de acreção obtido no Capítulo 3.

A Equação 4.49, referente à taxa de acreção, depende da densidade superficial de planetesimais $\left(\Sigma_{\mathrm{m}}\right)$ do local onde se formam. Na maioria dos trabalhos de formação planetária, essa densidade é considerada proporcional à densidade superficial do gás no plano médio do disco protoplanetário $(\Sigma)$, que, por sua vez, é obtida de um modelo para o disco ou por diferentes métodos observacionais. Nesta dissertação, a estimativa para a densidade superficial de planetesimais é descrita pela relação

$$
\Sigma_{\mathrm{m}}=f_{\mathrm{D} / \mathrm{G}} f_{\mathrm{R} / \mathrm{I}} \Sigma
$$

onde $f_{\mathrm{D} / \mathrm{G}}$ é a razão entre a quantidade de gás e de poeira no disco que, normalmente, considera-se em escala com a metalicidade da estrela, variando de 0.03 até 0.125 , sendo $f_{\mathrm{R} / \mathrm{I}}$ um fator que leva em conta o grau de condensação de elementos pesados. Seguindo Fortier et al. (2013), usaremos $f_{\mathrm{R} / \mathrm{I}}=0.25$ dentro da linha de gelo e $f_{\mathrm{R} / \mathrm{I}}=1$ para além da linha de gelo. Essa descontinuidade ocorre devido ao material do disco externo ser evaporado em regiões mais internas do disco. A localização da linha de gelo foi computada a partir do modelo para o disco de acreção descrito no Capítulo 3, através da temperatura e pressão no plano médio do disco. O valor encontrado para a distância da linha de gelo à estrela, num disco com $\alpha=7 \times 10^{-3}$, foi de 3.5 UA. Modelos mais precisos, que levem em conta a sublimação, podem utilizar um valor diferente. Além disso, vamos assumir que a 
linha de gelo não evolui com o tempo. O estudo a seguir compara três modelos diferentes para o disco.

O primeiro modelo de disco é uma lei de potência obtida para a Nebulosa Solar, que tem como base a distribuição de material do nosso Sistema Solar (Weidenschilling, 1977). Para esse disco, obtém-se um perfil de densidade superficial para os sólidos que varia com $r^{-3 / 2}$, cuja normalização é dada por Hayashi (1981). Nesse modelo, a densidade superficial de gás é descrita pela relação

$$
\Sigma=1.7 \times 10^{3}\left(\frac{r}{1 \mathrm{U} . \mathrm{A} .}\right)^{-3 / 2} \mathrm{~g} / \mathrm{cm}^{2},
$$

e a densidade superficial de sólidos por ${ }^{1}$

$$
\Sigma_{\mathrm{m}}(\text { rocha })=7.1\left(\frac{r}{1 \mathrm{UA}}\right)^{-3 / 2} \mathrm{~g} / \mathrm{cm}^{2} \text { para } r<3.5 \mathrm{UA}
$$

$\mathrm{e}$

$$
\Sigma_{\mathrm{m}}(\text { rocha/gelo })=30\left(\frac{r}{1 \mathrm{UA}}\right)^{-3 / 2} \mathrm{~g} / \mathrm{cm}^{2} \text { para } r>3.5 \mathrm{UA}
$$

Estas distribuições são mostradas na Figura 4.9. Embora haja diversas razões para suspeitar que essa distribuição não reproduz as condições iniciais que deram origem ao nosso Sistema Solar, e muito menos a de sistemas extrassolares, é uma relação costumeiramente usada nos estudos de formação e migração planetária e podemos usá-la para comparar o tempo de formação planetária entre os modelos.

O segundo modelo é baseado em medidas observacionais para o perfil de densidade superfical de gás, descrita por

$$
\Sigma=(2-\gamma) \frac{M_{\text {disco }}}{2 \pi a_{\mathrm{c}}^{2-\gamma} a_{0}^{\gamma}}\left(\frac{a}{a_{0}}\right)^{-\gamma} \exp \left[-\left(\frac{a}{a_{\mathrm{c}}}\right)^{2-\gamma}\right],
$$

onde $a_{0}$ é igual a 5.2 UA. A massa do disco $\left(M_{\text {disco }}\right)$, o raio característico $\left(a_{\mathrm{C}}\right)$ e a lei de potência $(\gamma)$ foram extraídas de Andrews et al. (2010) e seus valores estão descritos na Tabela 4.1 .

\footnotetext{
${ }^{1}$ No modelo original, a linha de gelo é colocada em 1 UA, nesta dissertação, foi usado 3.5 UA com o propósito de facilitar a comparação entre os modelos dos discos.
} 


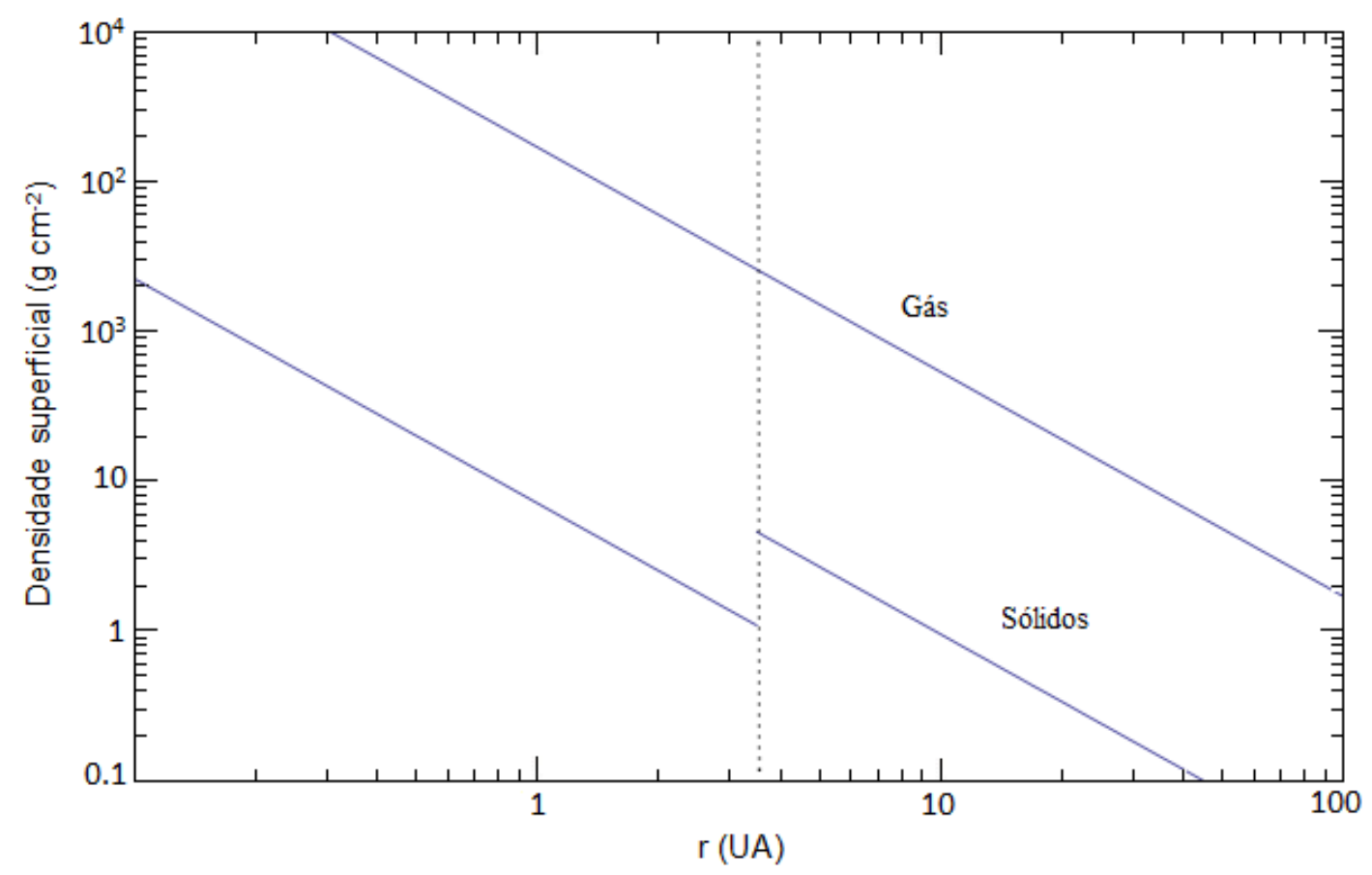

Figura 4.9: Densidade superficial do gás (linha superior) e de sólidos (linha inferior) em função do raio para Nebulosa Solar seguindo a normalização de Hayashi (1981). A linha vertical denota a localização da linha de gelo.

\begin{tabular}{ccccc} 
Tabela 4.1 Medidas observacionais de & \multicolumn{3}{l}{ Andrews et al. } \\
\hline \hline Disco & $M_{\text {disco }}\left(M_{\star}\right)$ & $a_{\mathrm{C}}(\mathrm{UA})$ & $a_{\text {int }}(\mathrm{UA})$ & $\gamma$ \\
\hline 1 & 0.029 & 46 & 0.14 & 0.9 \\
2 & 0.117 & 127 & 0.16 & 0.9 \\
3 & 0.143 & 198 & 0.10 & 0.7 \\
4 & 0.028 & 126 & 0.10 & 0.4 \\
5 & 0.136 & 80 & 0.10 & 0.9 \\
6 & 0.077 & 153 & 0.12 & 1.0 \\
7 & 0.029 & 33 & 0.10 & 0.8 \\
8 & 0.004 & 20 & 0.10 & 0.8 \\
9 & 0.012 & 26 & 0.10 & 1.0 \\
10 & 0.007 & 26 & 0.10 & 1.1 \\
11 & 0.007 & 38 & 0.10 & 1.1 \\
12 & 0.011 & 14 & 0.10 & 0.8 \\
\hline \hline
\end{tabular}


Esses perfis foram obtidos para estrelas de 0.3 até $1.3 \mathrm{M}_{\odot}$ e, portanto, assumiremos que é um perfil comum para discos presentes em estrelas similares ao Sol. O cálculo da densidade superficial de planetesimais é feito com a Equação 4.66. A Figura 4.10 mostra o perfil da densidade superficial de gás e de sólidos para os dados da primeira linha da Tabela 4.1 .

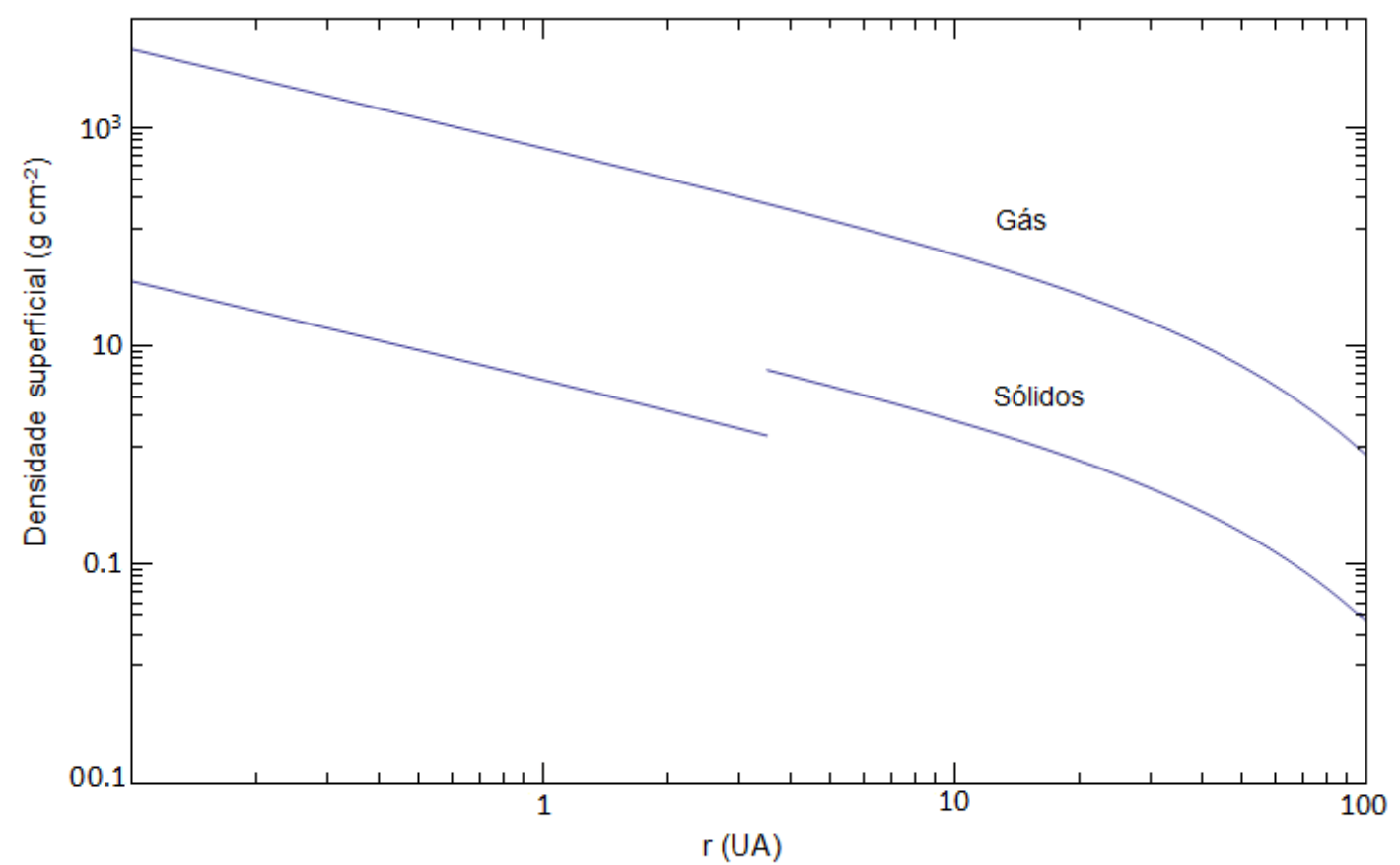

Figura 4.10: Densidade superficial do gás (linha superior) e de sólidos (linha inferior) em função do raio para as medidas observacionais de Andrews et al. (2010) utilizando os dados para o disco 1 da Tabela 4.1. A linha vertical denota a localização da linha de gelo. Foi utilizado $f_{\mathrm{D} / \mathrm{G}}=0.03$.

O terceiro modelo para o disco é o estado de equilíbrio para um disco de acreção, descrito no Capítulo 3, para $\alpha=7.5 \times 10^{-3}$. Devido ao alto custo computacional do modelo, foi feito um ajuste utilizando método dos mínimos quadrados para obter uma função que descreve a densidade superficial e volumétrica do gás no intervalo de 1 UA até $10 \mathrm{UA}^{1}$ (Figuras $4.11 \mathrm{e} 4.12$.

\footnotetext{
${ }^{1}$ Fora desse intervalo, o ajuste exponencial não será o mais adequado, necessitando de um ajuste polinomial ou em lei de potências. Para valores de $r<1$ UA as diferenças serão bastante significativas.
} 


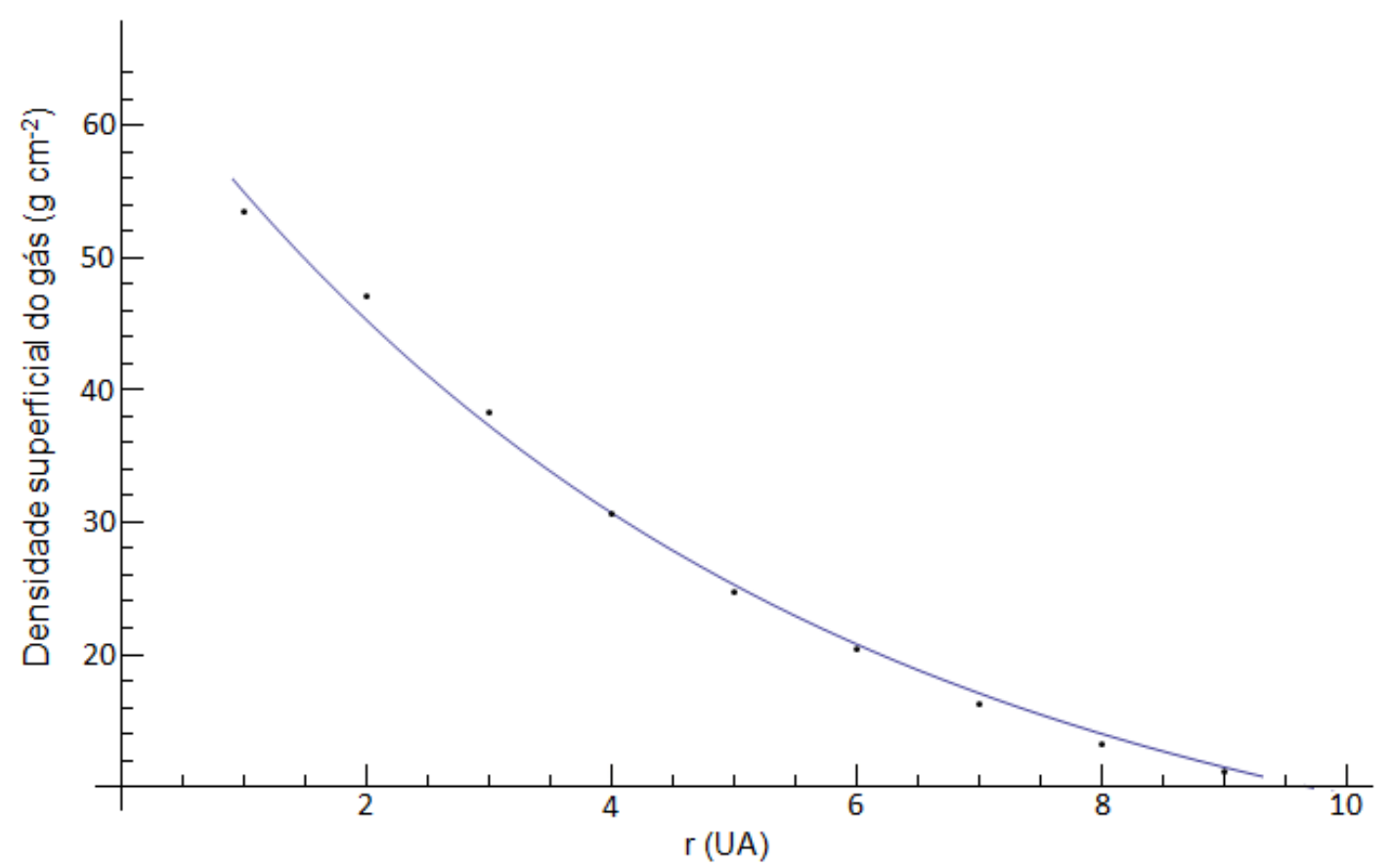

Figura 4.11: Ajuste de uma curva exponencial para a densidade superficial do gás em função do raio (1 UA até 10 UA) num disco de acreção em equilíbrio.

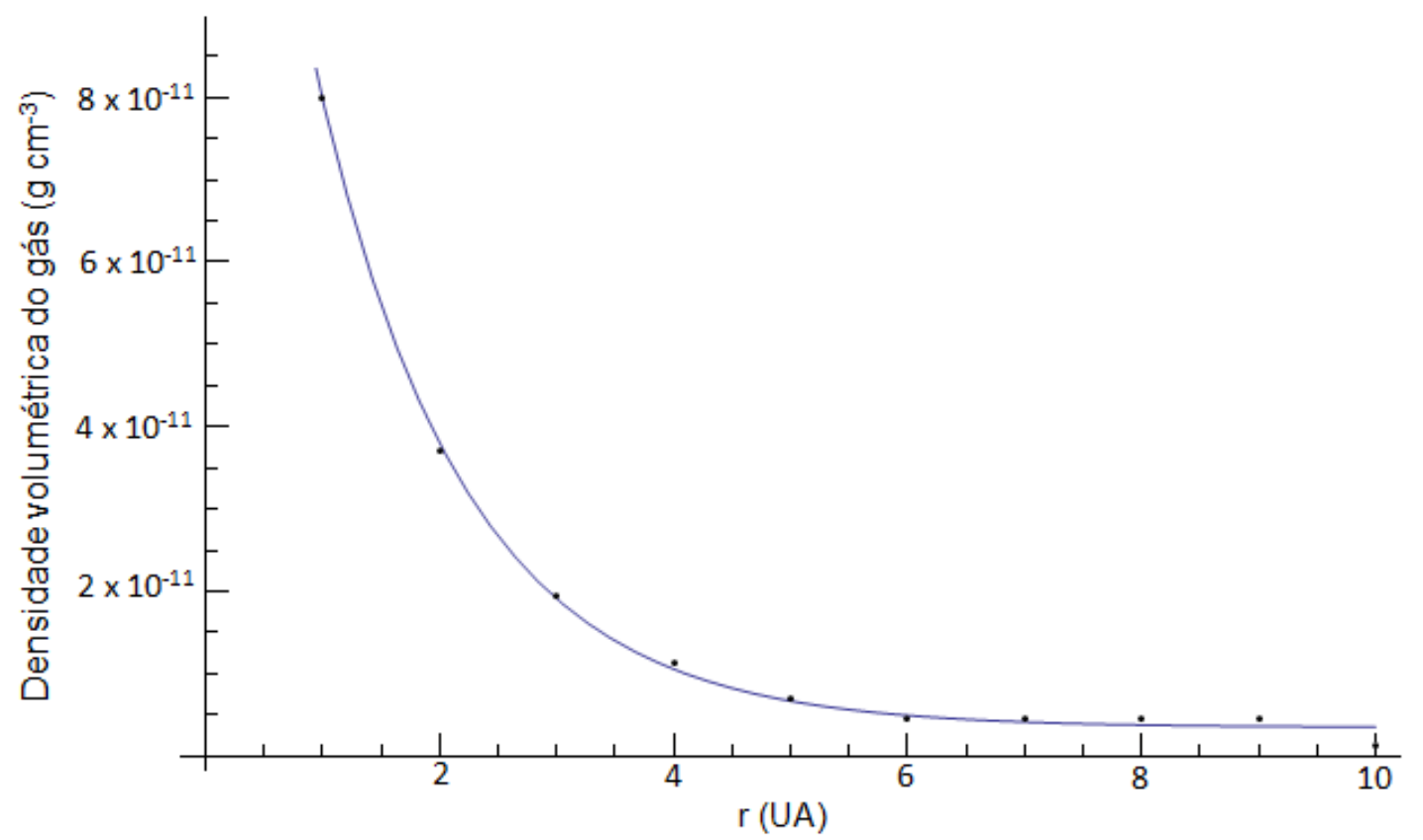

Figura 4.12: Ajuste de uma curva exponencial para a densidade volumétrica do gás em função do raio (1 UA até $10 \mathrm{UA})$ num disco de acreção em equilíbrio. 
As funções obtidas são

$$
\Sigma=-0.487939+67.1157 \exp (-0.19151 r)
$$

e

$$
\rho=3.48091 \times 10^{-12}+1.68482 \times 10^{-10} \exp (-0.792697 r)
$$

\subsubsection{Resultados obtidos}

Dada uma distância $r$, podemos, com o modelo de acreção descrito pela Equação 4.49, obter numericamente a taxa de crescimento do exoplaneta e, consequentemente, o gráfico da massa em função do tempo para cada modelo de disco apresentado.

A Tabela 4.2 resume os parâmetros encontrados para cada modelo de disco em $r=3 \mathrm{UA}$ e $r=6$ UA, que serão as regiões analisadas. No modelo da Nebulosa Solar e no modelo baseado em dados observacionais, que denominaremos híbrido, não é possível obter a densidade volumétrica do gás $\rho$, por isso, foi utilizada a relação $\rho=\frac{\Sigma}{\sqrt{2 \pi} h}$, essa relação é obtida pela integração da Equação 3.11 num disco verticalmente isotérmico, definiremos $h$ como $0.05 r$. O modelo da Nebulosa Solar já oferece uma estimativa para a densidade superficial de sólidos (Equação 4.68 e 4.69), enquanto para os outros dois modelos foi utilizada a Equação 4.66 .

\begin{tabular}{|c|c|c|c|}
\hline & $\Sigma\left(\mathrm{g} / \mathrm{cm}^{2}\right)$ & $\Sigma_{\mathrm{m}}\left(\mathrm{g} / \mathrm{cm}^{2}\right)$ & $\rho\left(\mathrm{g} / \mathrm{cm}^{3}\right)$ \\
\hline Nebulosa Solar (3 UA) & 327.2 & 1.4 & $5.8 \times 10^{-11}$ \\
\hline Nebulosa Solar (6 UA) & 115.7 & 2.1 & $1.1 \times 10^{-13}$ \\
\hline Modelo híbrido ( 3 UA) & 235.6 & 1.8 & $4.2 \times 10^{-11}$ \\
\hline Modelo híbrido ( 6 UA) & 119.3 & 3.6 & $1.1 \times 10^{-11}$ \\
\hline Disco de acreção com $\alpha$ constante (3 UA) & 37.3 & 0.27 & $1.9 \times 10^{-11}$ \\
\hline Disco de acreção com $\alpha$ constante ( 6 UA) & 20.7 & 0.62 & $4.9 \times 10^{-12}$ \\
\hline
\end{tabular}

Tabela 4.2 - Resumo de dados para cada perfil do disco 
A Figura 4.13 mostra os gráficos da massa em função do tempo para cada modelo de disco, considerando o crescimento de um protoplaneta de $0.01 \mathrm{M}_{\text {Terra }}$ até $1 \mathrm{M}_{\text {Terra }}$. A primeira característica que notamos em todos os gráficos é que o crescimento depende do tamanho dos planetesimais, sendo que o protoplaneta cresce mais rápido numa região de planetesimais menores. Isso se deve ao fato de os planetesimais maiores serem menos afetados pelo arrasto do gás, mantendo altos valores para suas inclinações e excentricidades, dificultando a acreção. Em todos os casos, o tempo para o protoplaneta alcançar $1 \mathrm{M}_{\text {Terra }}$ foi maior que o tempo típico da vida do disco, que é menor que $10 \times 10^{6}$ anos. Para a formação de um planeta rochoso, isso não é um problema, já que o tempo de vida do material sólido é extremamente maior. No entanto, para a formação de um planeta gasoso este é um ponto de dificuldade, pois não haveria gás remanescente no disco para a formação de seu envelope.

A comparação entre os modelos também fornece algumas características interessantes. No modelo para o disco de acreção (Figura 4.13C), obteve-se o maior tempo necessário para a formação de um núcleo sólido de $1 \mathrm{M}_{\text {Terra }}$ para ambas as regiões, 3 UA e 6 UA. Isso se deve ao fato de o decaimento da densidade superficial e volumétrica do gás ser exponencial (Equação 4.71 e 4.72, que influencia no arrasto sofrido pelo planetesimal. Com exceção do modelo da Nebulosa Solar, o tempo de formação em 6 UA foi menor que em 3 UA, isso se deve ao decaimento do perfil de densidade do gás ser compensado pela presença maior de material sólido $\left(f_{\mathrm{R} / \mathrm{I}}\right)$, pois, no modelo da Nebulosa Solar, a estimativa de sólidos foi feita com base nas medidas do nosso Sistema Solar (Weidenschilling, 1977), que resulta nas Equações 4.68 e 4.69 , ao passo que, nos outros modelos, a estimativa foi feita com base na Equação 4.66. De fato, as medidas referentes à quantidade de material sólido, normalmente feitas por estimativa, são um fator sensível nos modelos de formação planetária, o que torna necessários maiores vínculos observacionais ou modelos computacionais mais complexos que levem em conta a sedimentação, a aglutinação e a evolução da poeira no disco. De fato, os perfis obtidos para a densidade superficial de sólidos podem ser um fator de dificuldade para explicar a formação de planetas gigantes dentro desse cenário, visto que o tempo para a formação do núcleo pode ser bem superior ao tempo de vida do disco. 


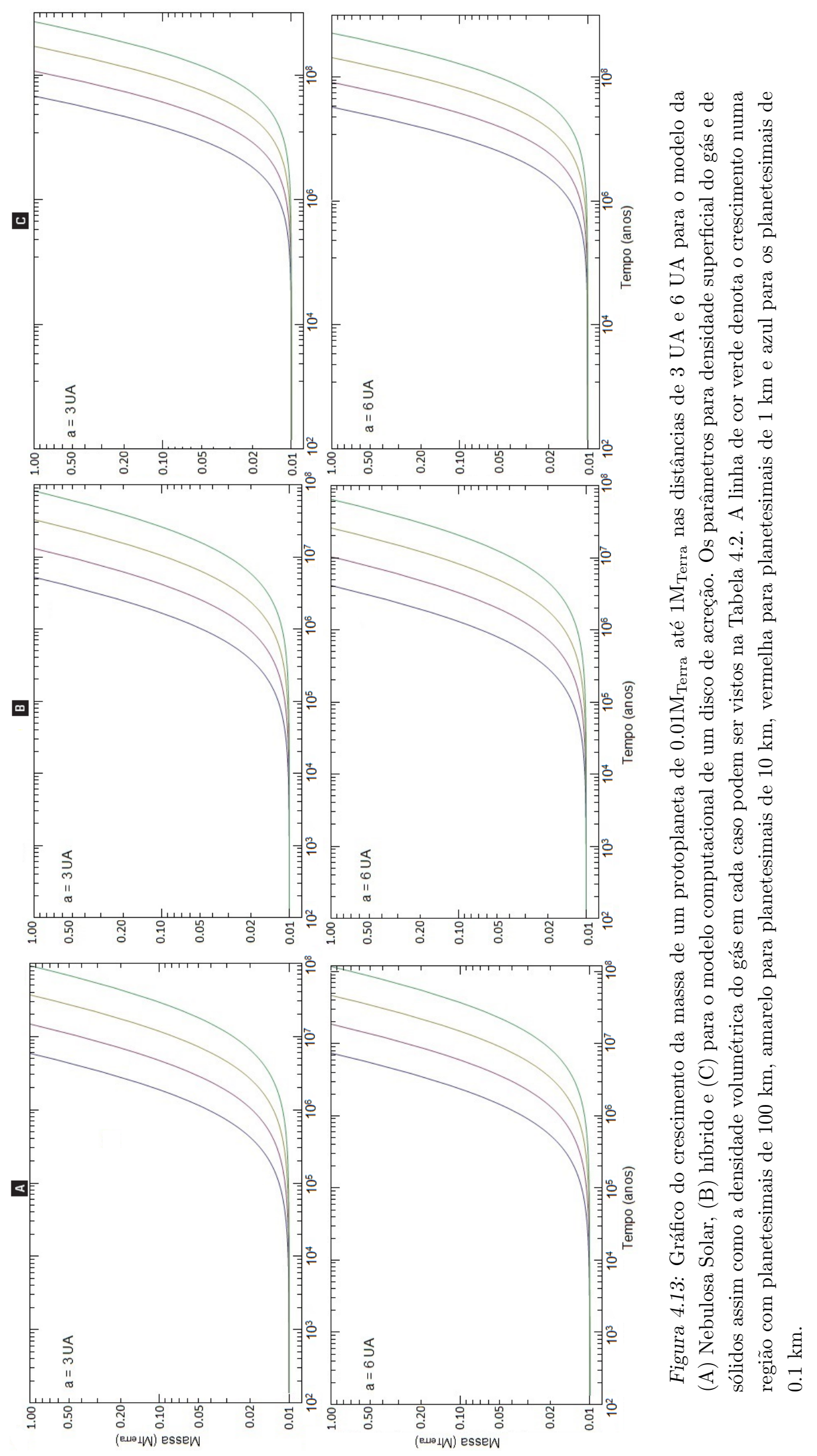


Tanto no modelo para a Nebulosa Solar, quanto no híbrido, a densidade volumétrica, obtida na relação $\rho=\frac{\Sigma}{\sqrt{2 \pi} h}$, que leva em conta a integração da densidade superficial num disco verticalmente isotérmico, além de um valor ad hoc para a razão de altura $(h=0.05 r)$, é um fator a ser melhor explorado. De fato, vínculos observacionais ou uma modelagem computacional mais completa, que leve em conta outros processos físicos, pode revelar uma mudança brusca nesse perfil de densidade volumétrica do gás.

Por fim, no modelo computacional foi utilizado $\alpha=7 \times 10^{-3}$ e uma taxa de acreção de $\dot{M}=10^{-9} \mathrm{M}_{\odot} /$ ano. Primeiramente, não há razão para acreditar que o parâmetro $\alpha$ seja constante ao longo do raio do disco, e modelos mais recentes já levam isso em consideração, ademais, a taxa de acreção pode variar sensivelmente ao longo do tempo de vida do disco. As alterações desses parâmetros e a inclusão de um modelo considere a distribuição de poeira podem alterar significativamente os valores encontrados para a densidade superficial e volumétrica do gás e até mesmo as curvas desses perfis.

A evolução da linha de gelo também pode ser um fator importante, de fato, a simples mudança da densidade dos planetesimais e da razão de poeira para regiões dentro e fora da linha de gelo foi um fator diferencial que permitiu compensar a queda na densidade superficial e volumétrica do gás. No entanto, esse excesso de material presente na região além da linha de gelo, ao que tudo indica, não é capaz de explicar, por si só, a formação de um núcleo sólido em tempo suficiente para a formação de um planeta gigante. Necessitamos, portanto, de outros mecanismos que possam acelerar esse processo, um deles pode ser a migração planetária que será explorada no próximo capítulo.

\subsection{Sumário}

A formação planetária ocorre, dentro do cenário de acreção, em três grandes fases: a formação dos planetesimais devido principalmente ao arrasto aerodinâmico, a formação de um núcleo sólido através da acreção de planetesimais e, finalmente, a acreção conjunta de gás e planetesimais que resulta na formação de um planeta gigante.

Vimos, através do cálculo do tempo de sedimentação vertical e deslocamento radial de partículas de poeira, que a formação de planetesimais precisa ocorrer de forma rápida, de modo que as partículas não caiam na estrela. Além disso, a força de arrasto também é responsável pela distribuição de material no disco. O estudo da formação dos planetesimais 
foi suficiente para detectar essas duas características, mas é incompleto no que tange à formação de planetesimais maiores, quando surge a necessidade de ferramentas mais complexas, que abrajam outros processos físicos importantes. Vale ressaltar que este ainda é um campo em estudo e que precisa ser analisado com maior profundidade, dado que observações de discos protoplanetários indicam uma concentração de poeira muito maior do que o esperado.

Com esses planetesimais formados, a força gravitacional mútua passa a ser o processo físico dominante. No entanto, devido ao grande número de planetesimais uma abordagem estatística se torna necessária e, em vez do alto custo computacional da interação N-corpos, em geral, é preferível utilizar uma distribuição de Rayleight para os parâmetros inclinação e excentricidade, uma vez que especificam a velocidade de colisão desses planetesimais com o protoplaneta.

A análise do processo de colisão resulta numa seção de choque influenciada pela gravidade do protoplaneta (regime de dois corpos) e até mesmo pela estrela (regime de três corpos). Em ambos os casos, foi possível obter uma taxa de acreção que poderia resultar na formação de um núcleo sólido. No entanto, a dificuldade de separar os dois processos que acontecem de forma diferente à medida que o protoplaneta cresce, expandindo seu raio de Hill e esvaziando a zona de alimentação dos planetesimais, levou à construção de um modelo mais sofisticado, dado pela Equação 4.49 que, com algumas simplificações, permitiu obter numericamente o aumento da massa do protoplaneta com o tempo.

Todavia, para obter o gráfico da massa em função do tempo de acreção do protoplaneta, é necessário obter o perfil de densidade superficial e volumétrica do gás, assim como o perfil de densidade dos sólidos na região na qual o protoplaneta está sendo formado. Para isso, usaram-se então três perfis diferentes para os discos protoplanetários. O primeiro perfil utilizado foi o da Nebulosa Solar, obtido por Weidenschilling (1977) através de dados do nosso Sistema Solar, e que resulta nas Equações 4.67, 4.68 e 4.69, com exceção do valor da distância da linha de gelo em que usamos 3.5 UA para facilitar a comparação com os outros modelos. O segundo modelo foi baseado nos dados observacionais de Andrews et al. (2010) e resulta na Equação 4.70 para a densidade superficial de gás. Esses dois modelos não fornecem os valores para a densidade volumétrica do gás, neste caso, foi utilizada a relação $\rho=\frac{\Sigma}{\sqrt{2 \pi} h}$ que leva em conta a integração da densidade superficial num disco verticalmente isotérmico, além de um valor ad hoc para a razão de altura que adotamos 
como 0,05r. Por fim, o último perfil utilizou os valores numéricos obtidos para um disco de acreção em equilíbrio (Capítulo 3), do qual foi possível, pelo método dos minímos quadrados, obter as Equações 4.71 e 4.72 para, respectivamente, a densidade superficial e a densidade volumétrica do gás. Para os dois últimos perfis, foi necessário estimar a densidade de sólidos, seguindo Fortier et al. (2013), usamos a Equação 4.66 para obter esse valor.

Levando em conta as considerações descritas, foi possível obter os gráficos da Figura 4.13 para o crescimento de um protoplaneta de $0.01 \mathrm{M}_{\text {Terra }}$ até $1 \mathrm{M}_{\text {Terra }}$, em 3 UA e $6 \mathrm{UA}$. A primeira característica encontrada é a dependência do tempo de formação do protoplaneta com o tamanho dos planetesimais, que pode resultar numa diferença de até duas ordens de grandeza no tempo final de formação. Além disso, levando em conta as limitações físicas de cada modelo, o excesso de material presente na região além da linha de gelo, não foi suficientemente capaz de compensar a queda brusca que ocorre na densidade superficial do gás, que é a responsável, através do arrasto, por diminuir as velocidades dos planetesimais e aumentar a taxa de acreção. Em todos os gráficos, o tempo de formação foi maior que o tempo de vida do disco, o que não configura um problema para a formação de um planeta terrestre, mas é um ponto de dificuldade para planetas gigantes, já que não haverá gás remanescente no disco protoplanetário para a formação de seus envelopes.

Vale a pena ressaltar a sensibilidade do modelo de acreção com relação à densidade de sólidos, que demanda, portanto, dados observacionais mais confiáveis ou modelos numéricos mais complexos, que tornem possível obter uma distribuição melhor desse material ao longo do disco. De fato, os modelos aqui utilizados são bem simples e desconsideram alguns processos físicos importantes como a irradiação da estrela, a condução de calor e a convecção. Modelos mais complexos, como de D'Alessio et al. (1998), indicam que a poeira muda drasticamente o cenário físico do disco, portanto, espera-se, em trabalhos futuros, o uso de modelos mais sofisticados, como o código ANDES (Akimkin et al. 2013), que é pioneiro em considerar a influência da evolução da poeira na estrutura do disco, combinando os detalhes computacionais do campo de radiação com o modelo de crescimento da poeira, fragmentação e sedimentação. Isso permitirá obter valores mais realistas para a densidade de gás, perfil de temperatura e uma melhor estimativa para a densidade superficial de sólidos. 
Capítulo 5

\section{Migração planetária devido à interação com o disco de}

$$
\text { gás }
$$

\subsection{Introdução}

O modelo de acreção indica que a formação de planetas gigantes ocorre, preferencialmente, em regiões externas do disco protoplanetário, onde há disponibilidade de material que justifique sua constituição. No entanto, a detecção de exoplanetas revela órbitas em regiões mais próximas à estrela, sendo esses exoplanetas denominados de Júpiteresquentes. Um dos mecanismos responsáveis pela evolução desses sistemas planetários é, provavelmente, a migração em razão da interação com o disco de gás, cuja descrição é o objetivo deste capítulo.

A migração devido à interação com o disco tem origem na mudança de momento angular que ocorre mediante o torque entre o planeta e o gás do disco. Nenhum torque é exercido em um disco axissimétrico, de modo que a migração só irá ocorrer pela perturbação do planeta, ou mediante outro processo, como a turbulência, que seja capaz de gerar uma estrutura não axissimétrica para o disco. O torque entre o planeta e o disco pode levar não apenas à mudança do semieixo maior, como também da excentricidade e inclinação da órbita planetária. Nesta dissertação, nos limitaremos à mudança do semieixo maior.

Considere um referencial fixo centrado na estrela, chamado heliocêntrico, no qual um elemento de fluido gira com velocidade angular $\Omega$ e o planeta com velocidade angular $\Omega_{\mathrm{p}}$, ambas descritas pela terceira lei de Kepler. Considere agora um referencial de corrotação, que consiste num sistema de coordenadas centrado na estrela que gira, com velocidade angular $\Omega_{\mathrm{p}}$, de maneira que o eixo $x$ sempre apontará para o planeta e o eixo $z$ na direção do momento angular. Nessa referência, a velocidade angular do elemento de fluido é 
$\left|\Omega-\Omega_{\mathrm{p}}\right|$, o módulo se justifica pois, em órbitas externas ao planeta, a velocidade angular do elemento de fluido é menor que a do planeta e em órbitas internas é maior. O tempo entre duas conjunções, ou período sinódico, é dado por $\frac{2 \pi}{\left|\Omega-\Omega_{\mathrm{p}}\right|}$.

O planeta perturba o elemento de fluido gerando nele uma oscilação em torno da sua órbita não perturbada, a amplitude dessa oscilação será maior nos locais em ressonância com o período sinódico. Cria-se então, uma onda espiral de densidade, fixa no referencial girante, que comprime diferentes partes do disco em diferentes momentos. Esta onda se propaga no sentido contrário ao do movimento do planeta na parte externa do disco e no mesmo sentido na parte interna (Figura 5.1). Uma descrição didática sobre a formação das ondas espirais pode ser encontrada no Capítulo 2.

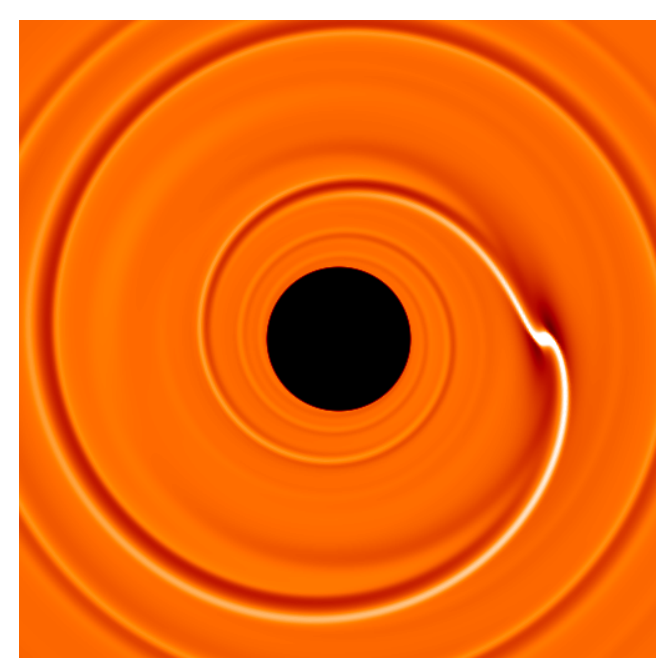

Figura 5.1: Simulação computacional obtida com o programa FARGO mostrando braços espirais gerados pela pertubação do planeta no disco protoplanetário e que leva ao cenário da migração tipo I. Figura obtida em: <http://www.maths.qmul.ac.uk/ masset/moviesmpegs.html>. Acesso em: 24 jan. 2014.

A compressão gravitacional do material do disco gera uma atração gravitacional entre o planeta e o elemento de fluido. Voltando ao sistema heliocêntrico, no disco externo, ocorre uma força na direção da rotação kepleriana (torque positivo), acelerando o disco que, consequentemente, sofre um deslocamento para longe da estrela. Da mesma forma, o torque de reação do fluido desacelera o movimento de translação do planeta (torque negativo) que, como resultado, se desloca em direção à estrela. Para o disco interno, ocorre o oposto, o planeta exerce um torque negativo que desacelera o elemento de fluido e, consequentemente, o planeta sofre um deslocamento para fora devido ao torque de reação 
positivo do disco interno que aumenta sua velocidade.

Conforme veremos neste capítulo, o efeito do disco externo no planeta é sempre maior que o do disco interno; como consequência, o torque resultante é negativo e proporcional ao quadrado da massa do planeta. Portanto, seu momento angular específico decai a uma taxa proporcional à sua massa, configurando a migração de tipo I.

O torque "empurra" o disco externo para fora e o disco interno para dentro, efeito que tende a dividir o disco. No entanto, o gás tende a ocupar essa região vazia e amenizar a queda brusca. Este dois efeitos competem até que o planeta se torne massivo o suficiente para abrir um gap ao redor de sua órbita (Figura 5.2). O planeta permanece preso a essa região e, ao contrário da migração tipo I, ele não muda seu semieixo maior. Todavia, um disco de acreção evolui devido sua viscosidade e a parte interna é acretada, enquanto a externa tende a se espalhar para fora do disco. Como a formação planetária ocorre entre 1 UA e 10 UA, que corresponde a parte mais interna do disco, estes sofrem uma migração em direção à estrela. Essa migração governada pela evolução viscosa do disco configura a migração de tipo II.

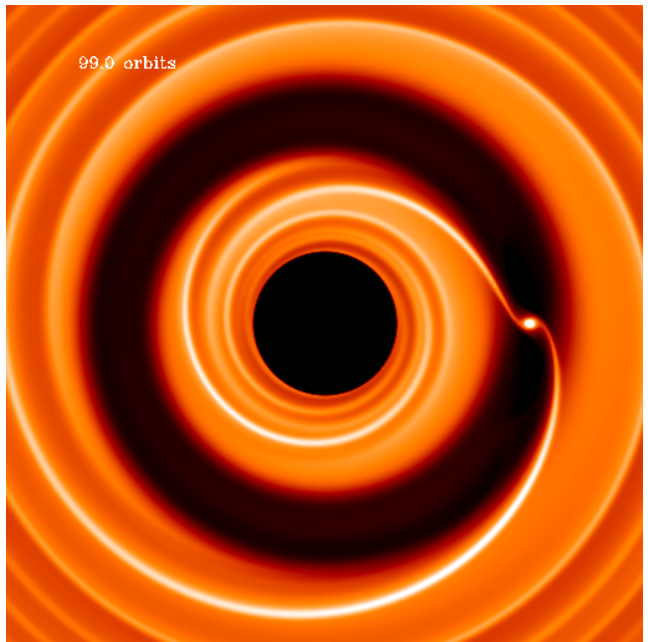

Figura 5.2: Simulação computacional obtida com o programa FARGO mostrando a abertura de um gap no disco protoplanetário e que leva ao cenário da migração tipo II. Figura obtida em: <http://www.maths.qmul.ac.uk/ masset/moviesmpegs.html>. Acesso em: 24 jan. 2014.

Caso o gap seja parcial, o disco interno e o externo são separados por uma leve depressão, que pode ser preenchida por gás. O planeta pode, ao atravessar essa região, capturar gás do disco interno e repassar para fora, transferindo seu momento angular para o gás, configurando deste modo uma migração do tipo runaway ou migração tipo III 
(Figura 5.3), que pode ser para fora ou para dentro, dependendo das condições iniciais. Neste cenário, a taxa de migração cresce exponencialmente e, apesar de ser saturada rapidamente com o tempo, permite mudanças bruscas nas órbitas planetárias (Masset e Papaloizou, 2003).

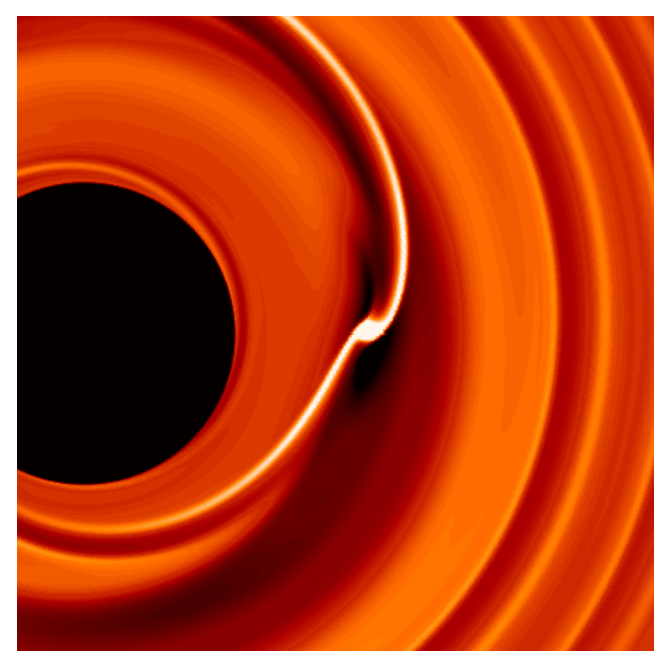

Figura 5.3: Simulação computacional obtida com o programa FARGO mostrando a abertura de um gap parcial no disco protoplanetário e que leva ao cenário da migração tipo III. Figura obtida em: <http://www.maths.qmul.ac.uk/ masset/moviesmpegs.html>. Acesso em: 24 jan. 2014.

Outros tipos de migração vêm sendo estudados, tais como a migração estocástica, que ocorre em discos turbulentos para planetas que não abrem um gap no disco Nelson. 2005). A turbulência produz flutuações na densidade e, consequentemente, no torque entre o planeta e o disco. No entanto, neste estudo, trabalhamos com o disco laminar, no qual esse tipo de migração não acontece.

O grande problema dos processos migratórios é sua conciliação com o processo de formação planetária. De fato, na migração tipo I, os planetas menos massivos migram rapidamente em direção à estrela num tempo menor que o estimado para a vida do disco. Isso implica que os embriões dos planetas gasosos cairiam na estrela antes mesmo da fase de acreção do gás. A solução usual para esse problema é introduzir fatores numéricos que diminuem a taxa de migração tipo I, e possibilitam que o planeta acrete gás até reunir massa suficiente para abrir um gap no disco, passando a sofrer uma migração de tipo II.

Os cálculos para a abertura do gap também vêm sendo alvo de pesquisas, visto que seus valores não coincidem com os resultados numéricos. Modelos que envolvem a massa planetária, a razão de altura do disco e a viscosidade possibilitam obter resultados mais 
expressivos.

As migrações tipo I e II conseguem explicar a presença de Júpiteres-quentes. No entanto, surge a questão sobre como alguns planetas gasosos gigantes se mantêm longe da estrela, como ocorre no nosso Sistema Solar. Acredita-se que, sob certas condições, esses planetas gigantes consigam dissociar sua migração tipo II da evolução do disco, diminuindo sua taxa (Crida, 2006). Questões como essas ainda permanecem nas teorias migratórias e serão exploradas neste capítulo, longe ainda de uma solução definitiva, mas abrindo um leque de opções para trabalhos futuros.

\subsection{Derivação do torque pelo método de aproximação impulsiva}

A principal ideia desse método, usado por Lin e Papaloizou (1979), é trabalhar com uma dinâmica simples de dois corpos, na qual um elemento de fluido, em órbita circular não perturbada, é defletido pela ação gravitacional do planeta. Assume-se que esse encontro seja breve o suficiente, para que possamos considerar o movimento em linha reta, desprezando a rotação ao redor da estrela.

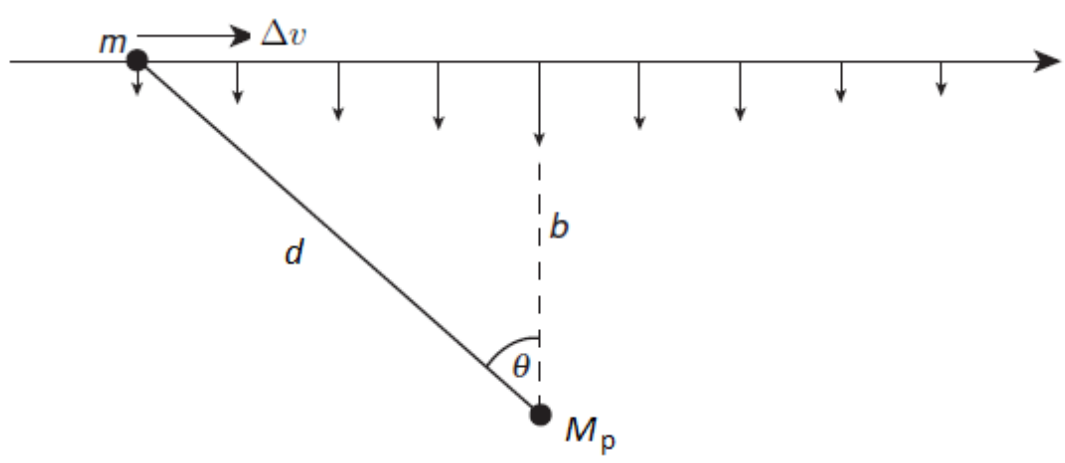

Figura 5.4: O elemento de fluido de massa $m$ passa próximo de um segundo corpo; o parâmetro de impacto é $b$ e a velocidade relativa entre os dois corpos é $\Delta v$. Considerando a interação entre os dois fraca, de modo que o ângulo de deflexão é pequeno, o impulso pode ser calculado assumindo uma trajetória não perturbada.

A força que age no elemento de fluido próximo do ponto de maior aproximação (Figura 5.4) é dada por

$$
F_{\perp}=F_{\text {grav }} \cos \theta=\frac{G M_{\mathrm{p}} m}{d^{2}} \cos \theta .
$$

Usando o teorema de Pitagoras e a definição para o cosseno, obtemos 


$$
F_{\perp}=\frac{G M_{\mathrm{p}} m b}{\left.\left[b^{2}+(\Delta v t)^{2}\right)\right]^{3 / 2}}=\frac{G M_{\mathrm{p}} m}{b^{2}}\left[1+\left(\frac{\Delta v t}{b}\right)^{2}\right]^{-3 / 2},
$$

onde $b$ é o parâmetro de impacto e $\Delta v$ é a velocidade relativa entre o elemento de fluido e o planeta, que pode ser considerada constante próximo do ponto de maior aproximação $(\theta \rightarrow 0 \Rightarrow \sin \theta \rightarrow 0)$.

Pelo teorema do Impulso, podemos obter o acréscimo na velocidade perpendicular do elemento de fluido

$$
\left|\delta v_{\perp}\right|=\int_{-\infty}^{+\infty} \frac{F_{\perp}}{m} d t=\frac{G M_{\mathrm{p}}}{b^{2}} \int_{-\infty}^{+\infty}\left[1+\left(\frac{\Delta v t}{b}\right)^{2}\right]^{-3 / 2} d t .
$$

Resolvendo a integral, obtém-se

$$
\left|\delta v_{\perp}\right|=\frac{2 G M_{\mathrm{p}}}{b \Delta v}
$$

A velocidade radial não afeta o momento angular; no entanto, da conservação de energia, o aumento da velocidade radial $\left(\delta v_{\perp}\right)$ leva a uma diminuição da velocidade tangencial da partícula $\left(\delta v_{\|}\right)$, alterando seu momento angular. Equacionando a energia cinética antes e depois da interação, obtemos

$$
(\Delta v)^{2}=\left(\delta v_{\perp}\right)^{2}+\left(\Delta v-\delta v_{\|}\right)^{2}
$$

Usando a Equação 5.4 e desprezando termos de $2^{\circ}$ ordem, temos

$$
\delta v_{\|} \approx \frac{1}{2 \Delta v}\left(\frac{2 G M_{\mathrm{p}}}{b \Delta v}\right)^{2}
$$

Assim, a mudança de seu momento angular específico será

$$
\delta j=\delta v_{\|} r \approx\left(\frac{2 G^{2} M_{\mathrm{p}}^{2}}{b^{2} \Delta v^{3}}\right) r,
$$

onde $r$ é o raio da órbita do elemento de fluido ao redor da estrela $\left(r=r_{\mathrm{p}}+b\right)$.

Considerando que, nesse intervalo de tempo, o planeta teve um movimento aproximadamente linear, podemos escrever

$$
\Delta v=r\left(\Omega-\Omega_{\mathrm{p}}\right)
$$

Portanto, a Equação 5.7 pode ser escrita na forma 


$$
\delta j \approx \frac{2 G^{2} M_{\mathrm{p}}^{2}}{r^{2} b^{2}\left(\Omega-\Omega_{\mathrm{p}}\right)^{3}} .
$$

Como o gás exterior possui velocidade menor que a do planeta, o decréscimo da componente paralela da velocidade relativa corresponde a um aumento do momento angular do gás exterior, aumentando sua velocidade em relação ao planeta. Da Equação 5.9 concluimos que:

- A interação entre o planeta e o gás exterior aumenta o momento angular do gás e diminui o do planeta, logo o planeta migra para dentro e o gás acaba se deslocando para fora.

- A interação com o gás interior decresce o momento angular do gás e aumenta o do planeta, logo o planeta migra para fora e o gás passa a se deslocar para dentro.

A Equação 5.9 fornece a perda do momento angular a cada encontro com o planeta, e que ocorre a cada período sinódico. Logo, a taxa de perda do momento angular específico é dada por

$$
\frac{\delta j}{\delta t}=\frac{\delta j}{2 \pi /\left|\Omega-\Omega_{\mathrm{p}}\right|} \approx \frac{G^{2} M_{\mathrm{p}}^{2}}{\pi r^{2} b^{2}\left(\Omega-\Omega_{\mathrm{p}}\right)^{2}} .
$$

O torque resultante irá, portanto, depender do efeito total entre a interação do planeta com o gás exterior e interior.

O torque total é obtido integrando a Equação 5.10 para todo o restante do disco. Para isso, Lin e Papaloizou (1979) fazem uma expansão em série de Taylor para $\Omega$, assim

$$
\Omega-\Omega_{\mathrm{p}} \approx \frac{d \Omega}{d r} b \approx-\frac{3}{2} \frac{\Omega_{\mathrm{p}}}{r_{\mathrm{p}}} b .
$$

Dessa expansão no qual se considera $b \ll r_{\mathrm{p}}$, obtém-se o torque total $(\mathrm{T})$ integrando, em coordenadas polares, de $r=r_{\mathrm{p}}+\Delta$ até o infinito, para qualquer $\Delta>0$. Logo

$$
\begin{gathered}
\mathrm{T}=\int_{\Delta}^{\infty} \int_{0}^{2 \pi} \frac{\delta j}{\delta t} \Sigma r_{\mathrm{p}} d \theta d b= \\
=\int_{\Delta}^{\infty} 2 \pi \frac{\delta j}{\delta t} \Sigma r_{\mathrm{p}} d b= \\
=\int_{\Delta}^{\infty} \frac{2 \pi \Sigma r_{\mathrm{p}} G^{2} M_{\mathrm{p}}^{2}}{\pi r_{\mathrm{p}}^{2} b^{4}\left(-\frac{3}{2} \frac{\Omega_{\mathrm{p}}}{r_{\mathrm{p}}}\right)^{2}} d b=
\end{gathered}
$$




$$
\begin{aligned}
& =\frac{8}{9} \Sigma r_{\mathrm{p}} \frac{G^{2} M_{\mathrm{p}}^{2}}{\Omega_{\mathrm{p}}^{2}} \int_{\Delta}^{\infty} \frac{d b}{b^{4}}= \\
= & \frac{8}{27} \Sigma r_{\mathrm{p}}^{4}\left(\frac{M_{\mathrm{p}}}{M_{\star}}\right)^{2} \frac{G M_{\star}}{r_{\mathrm{p}}^{3}} \frac{r_{\mathrm{p}}^{3}}{\Delta^{3}},
\end{aligned}
$$

onde $\Sigma$ é a densidade superficial do gás.

A relação acima pode ser reescrita como

$$
\mathrm{T}=\frac{8}{27}\left(\frac{M_{\mathrm{p}}}{M_{\star}}\right)^{2} \Sigma r_{\mathrm{p}}^{4} \Omega_{\mathrm{p}}^{2} \frac{r_{\mathrm{p}}^{3}}{\Delta^{3}} .
$$

É importante perceber que o torque tende ao infinito quando $r_{\mathrm{p}}$ tende ao infinito; porém essa singularidade é evitada, pois $b^{-4}$ tende a zero nessa situação. Para o torque do disco interno (de $r_{\mathrm{p}}$ até 0 ) basta inverter o sinal da relação acima.

A Equação 5.12 deixa de ser válida no caso de aproximações muito lentas, portanto, não vale para todo $\Delta$. De fato, se a velocidade relativa for menor do que a velocidade do som, a influência do planeta ocorre antes do encontro, por causa dos efeitos de pressão. Assim, Lin e Papaloizou (1979) estimam a distância mínima, com um fator de correção, como aquela para a qual a velocidade relativa é igual à velocidade do som, portanto, $\Delta_{\min }=\frac{c_{\mathrm{s}}}{r}|d \Omega / d r|^{-1}$, onde $c_{\mathrm{s}}=h \Omega$ (seção 3.5), logo $\Delta_{\min }=\frac{2}{3} h$. Isso resulta num torque devido à parte externa do disco, dado por

$$
\mathrm{T} \approx 0.23\left(\frac{M_{\mathrm{p}}}{M_{\star}}\right)^{2} \Sigma r_{\mathrm{p}}^{4} \Omega_{\mathrm{p}}^{2} \frac{r_{\mathrm{p}}^{3}}{h^{3}}
$$

\subsection{Derivação do torque via ressonâncias de Lindblad}

O disco pode ser entendido como o equivalente a uma rede contínua de osciladores harmônicos, alguns dos quais são ressonantes com o planeta. Nessas frequências, ocorrem as maiores amplitudes de oscilação. Efeitos ressonantes entre o disco e o planeta orbitando a estrela mudam a estrutura e a evolução do disco. Esses efeitos são encontrados em diversos mecanismos como no disco galáctico (Lynden-Bell e Kalnajs, 1972), discos de acreção em binárias (Lin e Papaloizou, 1979), anéis perturbados por satélites (Goldreich e Tremaine, 1980), entre outros.

Nesta dissertação, iremos obter o torque que levará à mudança de momento angular num caso típico, chamado ressonância de Lindblad, que ocorre quando os movimentos 
médios das partículas do disco (frequência epiciclíca) e o planeta estão na razão $\frac{m}{m \pm 1}$, onde $m$ é um número natural. Seguiremos a mesma estrutura de cálculo realizada por Meyer-Vernet e Sicardy (1987).

Vamos considerar um disco fino bidimensional, sem pressão e sem viscosidade, cuja evolução é descrita pela equação de Euler (Seção 2.2.2) e de continuidade (Seção 2.2.1). Portanto

$$
\frac{\delta \vec{u}}{\delta t}+\vec{u} \cdot \vec{\nabla} \vec{u}=-\vec{\nabla}\left(\Phi_{\star}+\Phi_{\mathrm{p}}\right)
$$

$\mathrm{e}$

$$
\frac{\delta \Sigma}{\delta t}+\vec{\nabla} \cdot(\Sigma \vec{u})=0
$$

onde $\vec{u}(r, \theta, t)$ é a velocidade do fluido no ponto $(r, \theta, 0)$ no tempo $t, \Sigma(r, \theta, 0)$ é a densidade superficial do gás no disco e $\Phi_{\star}$ e $\Phi_{\mathrm{p}}$ são, respectivamente, o potencial da estrela central e do planeta.

O potencial do planeta, assumido perfeitamente esférico, é dado por

$$
\Phi_{\mathrm{p}}=-\frac{G M_{\mathrm{p}}}{r}
$$

Esse potencial pode ser escrito em termos de uma série de Fourier (Seção 2.3), como

$$
\Phi_{\mathrm{p}}(r, \theta, t)=\operatorname{Re} \sum_{m=-\infty}^{m=+\infty} \Phi_{m}(t) e^{i m\left(\theta-\omega_{\mathrm{p}} t\right)}
$$

onde

$$
\omega=\left(\frac{M_{\mathrm{p}} G}{r_{\mathrm{p}}^{3}}\right)^{1 / 2}
$$

é a frequência orbital, e

$$
\Phi_{m}(r)=-\left(\frac{G M_{\mathrm{p}}}{2 r_{\mathrm{p}}}\right) b_{1 / 2}^{(m)}\left(\frac{r}{r_{\mathrm{p}}}\right)
$$

em que $M_{\mathrm{p}}$ é a massa do protoplaneta, $r_{\mathrm{p}}$ é o raio orbital e $b_{1 / 2}^{(m)}$ é o coeficiente clássico de Laplace, dado por

$$
b_{\gamma}^{(m)}=\frac{2}{\pi} \int_{\pi}^{0} \frac{\cos (m \theta)}{\left(1+\beta^{2}-2 \beta \cos \theta\right)^{\gamma}} d \theta
$$


A influência do achatamento do planeta, a inclinação e a excentricidae afetam a ressonância de Lindblad. No entanto, nesse estudo estamos mais interessados num estudo inicial e nas consequências físicas desse processo.

Para começar, é importante linearizar as Equações diferenciais 5.14 e 5.15 usando a teoria de pequenas perturbações. Isso implica considerar qualquer uma das funções que aparecem nas equações (densidade, velocidade e potencial) como a soma de uma função conhecida mais uma pequena perturbação. Por exemplo, a densidade superficial do gás no disco pode ser considerada como $\Sigma_{0}+\Sigma_{1}$, em que $\Sigma_{0}$ é o termo de ordem zero, ou seja, a densidade que existe sem perturbação e $\Sigma_{1}$ é uma perturbação variável no tempo, muito menor que $\Sigma_{0}$. Como a situação sem perturbação tem solução conhecida, é possível reduzir o sistema eliminando os termos de ordem zero. Além disso, podemos desprezar o produto entre quantidades pequenas, obtendo então um sistema de equações diferenciais linearizado na forma

$$
\frac{\delta \overrightarrow{u_{1}}}{\delta t}+\left(\overrightarrow{u_{0}} \cdot \vec{\nabla}\right) \overrightarrow{u_{1}}+\left(\overrightarrow{u_{1}} \cdot \vec{\nabla}\right) u_{0}=-\vec{\nabla} \Phi_{\mathrm{p}}
$$

e

$$
\begin{array}{r}
\frac{\delta \Sigma_{1}}{\delta t}+\vec{\nabla} \cdot\left(\Sigma_{0} \overrightarrow{u_{1}}\right)+\vec{\nabla} \cdot\left(\Sigma_{1} \overrightarrow{u_{0}}\right)=0 . \\
\text { Como } \Omega=\left(\frac{G M}{r^{3}}\right)^{3 / 2} \text { e } u_{0}=\Omega r \hat{\theta}, \text { encontramos } \\
\frac{\delta u_{1 r}}{\delta t}+\Omega \frac{\delta u_{1 r}}{\delta \theta}-2 \Omega u_{1 \theta}=-\frac{\delta \Phi_{\mathrm{p}}}{\delta r}, \\
\frac{\delta u_{1 \theta}}{\delta t}+\Omega \frac{\delta u_{1 \theta}}{\delta \theta}+\frac{\Omega}{2} u_{1 r}=-\frac{1}{r} \frac{\delta \Phi_{\mathrm{p}}}{\delta \theta}
\end{array}
$$

$\mathrm{e}$

$$
\frac{\delta \Sigma_{1}}{\delta t}+\Omega \frac{\delta \Sigma_{1}}{\delta \theta}=-\frac{\Sigma_{0}}{r}\left[\frac{\delta\left(r u_{1 r}\right)}{\delta r}+\frac{\delta u_{1 \theta}}{\delta \theta}\right] .
$$

Podemos apresentar uma "solução tentativa" tendo como base a perturbação do planeta, propondo, para o caso estacionário, que as perturbações também são periódicas na forma 


$$
\begin{aligned}
& u_{1 r}=\sum_{m=-\infty}^{m=+\infty} u_{1 r m} e^{i m\left(\theta-\omega_{\mathrm{p}} t\right)}, \\
& u_{1 \theta}=\sum_{m=-\infty}^{m=+\infty} u_{1 \theta m} e^{i m\left(\theta-\omega_{\mathrm{p}} t\right)}
\end{aligned}
$$

$\mathrm{e}$

$$
\Sigma_{1}=\sum_{m=-\infty}^{m=+\infty} \Sigma_{1 m} e^{i m\left(\theta-\omega_{\mathrm{p}} t\right)}
$$

Como $\frac{\delta}{\delta t}=-i m \omega_{\mathrm{p}}$ e $\frac{\delta}{\delta \theta}=i m$, isolando as variáveis perturbadas, temos

$$
\begin{aligned}
& u_{1 r m}=-\frac{i m}{r D}\left[\left(\Omega-\omega_{\mathrm{p}}\right) r \frac{d \Phi_{m}}{d r}+2 \Omega \Phi_{m}\right], \\
& u_{1 \theta m}=\frac{1}{2 r D}\left[\Omega r \frac{d \Phi_{m}}{d r}+2 m^{2}\left(\Omega-\omega_{p}\right) \Phi_{m}\right]
\end{aligned}
$$

e

$$
\Sigma_{1 m}=-\frac{\Sigma_{0}}{i m r\left(\Omega-\omega_{p}\right)}\left[\frac{d\left(r u_{1 r m}\right)}{d r}+i m u_{1 \theta m}\right],
$$

onde $D=\Omega^{2}-m^{2}\left(\Omega-\omega_{\mathrm{p}}\right)^{2}$, que igualado a zero, define a ressonância de Lindblad na forma

$$
\Omega_{m}=\left(\frac{m}{m \pm 1}\right) \omega_{\mathrm{p}}
$$

Portanto, na ressonância, a frequência perturbada sentida pelo elemento de fluido $(\Omega-$ $\left.\omega_{\mathrm{p}}\right)$ é um submúltiplo da frequência natural $\Omega$ do elemento. O comportamento do disco, próximo da ressonância de Lindblad, é similar ao movimento forçado de um oscilador harmônico próximo da condição ressonante.

O próximo passo é o cálculo do torque, que pode ser obtido pela relação

$$
\overrightarrow{\mathrm{T}}=-\iint d^{2} \vec{r}\left(\vec{r} \times \nabla \Phi_{\mathrm{p}}\right) \Sigma .
$$

Podemos linearizar o torque da mesma forma que fizemos com as equações da hidrodinâmica, logo 


$$
\overrightarrow{\mathrm{T}}_{1}=-\iint d^{2} \vec{r}\left(\vec{r} \times \nabla \Phi_{\mathrm{p}}\right) \Sigma_{1}
$$

Desenvolvendo a equação acima, obtemos apenas uma componente $\hat{k}$, dada por

$$
\mathrm{T}_{1}=-\iint d^{2} r \frac{\delta \Phi_{\mathrm{p}}}{\delta \theta} \Sigma_{1}
$$

Substituindo as variáveis perturbadas, ficamos com

$$
\mathrm{T}_{1}=-\int_{0}^{\infty} \int_{0}^{2 \pi} r d r d \theta \sum_{m=-\infty}^{m=+\infty} i m \Phi_{m} e^{i m\left(\theta-\omega_{p} t\right)} \sum_{m=-\infty}^{m=+\infty} \Sigma_{1 m} e^{i m\left(\theta-\omega_{p} t\right)} .
$$

A última integral pode ser resolvida com o uso do teorema de Parseval, logo

$$
\mathrm{T}_{m}=-4 \pi m \operatorname{Im}\left(\int_{0}^{\infty} d r r \Sigma_{1 m} \Phi_{m}\right),
$$

na qual o torque total foi denotado por $\mathrm{T}=\sum_{m=1}^{m=\infty} \mathrm{T}_{m}$.

Queremos obter o torque gerado próximo da situação de ressonância, para isso, vamos isolar a Equação 5.32 na forma

$$
\Omega_{m}-\omega_{\mathrm{p}}= \pm \frac{\Omega_{m}}{m}
$$

e substituir essa relação nas Equações 5.29 e 5.30. Obtém-se então a forma degenerada

$$
u_{1 r m} \sim-\frac{i \Omega_{m} A}{r_{m} D}
$$

$\mathrm{e}$

$$
u_{1 \theta m} \sim \pm \frac{i u_{1 r m}}{2}
$$

onde $A=2 m \Phi_{m} \pm r_{m} \frac{d \Phi_{m}}{d r}$.

Substituindo a relação 5.40 na Equação 5.31, encontra-se

$$
\Sigma_{1 m}=-\frac{\Sigma_{0}}{i m r\left(\Omega-\omega_{\mathrm{p}}\right)}\left[\frac{d\left(r u_{1 r m}\right)}{d r} \pm \frac{m u_{1 r m}}{2}\right]
$$

Portanto, o torque próximo da ressonância é dado por

$$
\mathrm{T}_{m}=4 \pi \Sigma_{0} \operatorname{Re}\left(\int_{0}^{\infty} \frac{\Phi_{m}}{\Omega-\omega_{\mathrm{p}}} \frac{d\left(r u_{1 r m}\right)}{d r} d r \pm \int_{0}^{\infty} \frac{m u_{1 r m} \Phi_{m}}{2\left(\Omega-\omega_{\mathrm{p}}\right)} d r\right)
$$


Integrando a primeira integral por partes, temos

$$
\int_{0}^{\infty} \frac{\Phi_{m}}{\Omega-\omega_{\mathrm{p}}} \frac{d\left(r u_{1 r m}\right)}{d r} d r=\left(\frac{r u_{1 r m} \Phi_{m}}{\Omega-\omega_{\mathrm{p}}}\right)_{0}^{\infty}-\int_{0}^{\infty} r u_{1 r m} \frac{d}{d r}\left(\frac{\Phi_{m}}{\Omega-\omega_{\mathrm{p}}}\right) d r
$$

que substituído na Equação 5.42 gera

$$
\mathrm{T}_{m}=4 \pi \Sigma_{0} \operatorname{Re}\left(\int_{0}^{\infty} d r\left[-r \frac{d}{d r}\left(\frac{\Phi_{m}}{\Omega-\omega_{\mathrm{p}}}\right) \pm \frac{m \Phi_{m}}{2\left(\Omega-\omega_{\mathrm{p}}\right)}\right] u_{1 r m}\right) .
$$

Assumindo que $u_{1 r m}$ varie suficientemente rápido próximo da ressonância $\left(\Omega \sim \Omega_{m}\right)$, o termo entre colchetes pode ser colocado fora da integral e calculado em $r=r_{m}$, ficamos então com

$$
\mathrm{T}_{m}=4 \pi \Sigma_{0}\left[-r \frac{d}{d r}\left(\frac{\Phi_{m}}{\Omega_{m}-\omega_{\mathrm{p}}}\right) \pm \frac{m \Phi_{m}}{2\left(\Omega_{m}-\omega_{\mathrm{p}}\right)}\right] \operatorname{Re} \int_{0}^{\infty} d r u_{1 r m}
$$

que, com o uso da Equação 5.32 , pode ser escrita na forma

$$
\mathrm{T}_{m}=\frac{4 \pi \Sigma_{0} m A}{\Omega_{m}} \operatorname{Re} \int_{0}^{\infty} d r u_{1 r m}
$$

Substituindo na relação acima a Equação 5.39 , obtém-se

$$
\mathrm{T}_{m}=\frac{4 \pi \Sigma_{0} m A^{2}}{r_{m}} \operatorname{Im} \int_{0}^{\infty} \frac{d r}{D}
$$

Fazendo uma mudança de variável, de forma que $x=\frac{r-r_{m}}{r_{m}} \Rightarrow r=r_{m}-r_{m} x$ e expandindo $D$ em torno de $x$, encontramos

$$
D\left(r_{m}\right)=\frac{G M}{\left(r_{m}+r_{m} x\right)^{3}}-\Omega_{m}^{2} \simeq \frac{d D\left(r_{m}\right)}{d x} x
$$

Como $d x=\frac{d r}{r_{m}}$, ficamos com

$$
D\left(r_{m}\right) \simeq r_{m} \frac{d D\left(r_{m}\right)}{d r} x
$$

Portanto, a Equação 5.47 pode ser escrita como

$$
\mathrm{T}_{m}=\frac{4 \pi \Sigma_{0} m A^{2}}{r_{m} \mathcal{D}} \operatorname{Im} \int_{-1}^{\infty} \frac{d x}{x}
$$

onde $\mathcal{D}=\frac{d D}{d r}$. 
Para eliminar a singularidade da integral, assumimos uma pequena perturbação na parte imaginária de $\omega_{\mathrm{p}}$, de forma que $\omega_{\mathrm{p}}^{c}=\omega_{\mathrm{p}}\left(1+i \alpha^{\prime}\right)$, logo

$$
\omega_{\mathrm{p}}+i \alpha^{\prime}=\omega_{\mathrm{p}}+\delta r \frac{d \omega_{\mathrm{p}}}{d r} \Rightarrow \delta r=-\frac{2}{3} i \alpha^{\prime} r_{m}
$$

Consequentemente, para a primeira ordem, em que $\alpha=\frac{2}{3} \alpha^{\prime}$, substituimos $x$ por $x^{c}=$ $x+i \alpha$, temos então

$$
\operatorname{Im} \int_{-1}^{\infty} \frac{d x}{x}=-\int_{-1}^{\infty} \frac{\alpha}{x^{2}+\alpha^{2}} d x=-\frac{\pi}{2}+\arctan \left(-\alpha^{-1}\right) .
$$

Assumindo $\alpha \ll 1$, obtém-se

$$
\operatorname{Im} \int_{-1}^{\infty} \frac{d x}{x}=-\pi \operatorname{sgn}(\alpha)
$$

A introdução dessa pequena perturbação imaginária permitiu evitar a singularidade na ressonância em $x=0$, pois a área total sobre a curva em forma de sino é independente de $\alpha$, como mostra a Figura 5.5 .

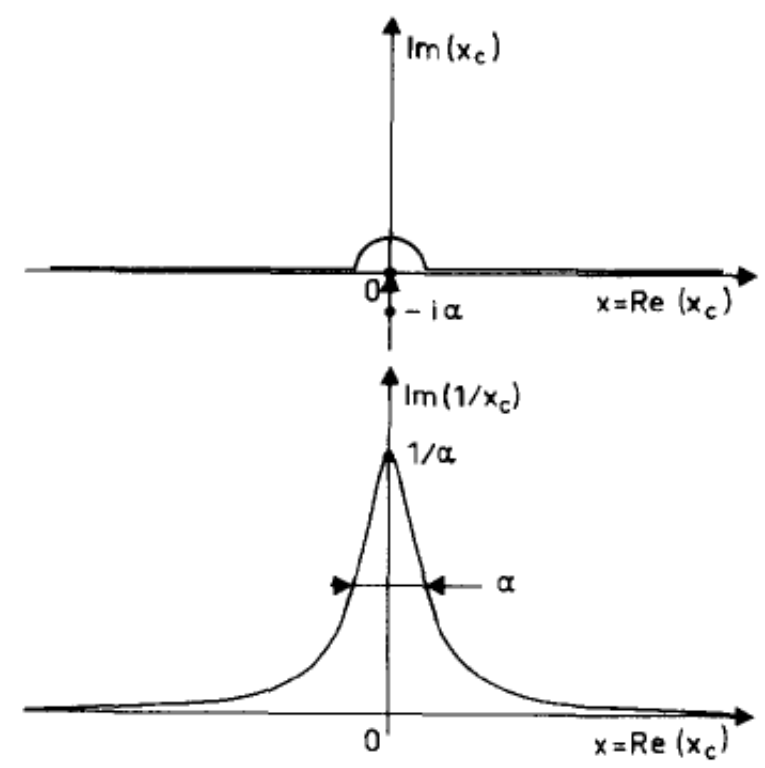

Figura 5.5: Uma pequena parte imaginária $\alpha$ na frequência do satélite desloca a ressonância para fora do eixo real, de modo a evitar a singularidade na integração. A densidade do torque, proporcional a $\operatorname{Im}\left(1 / x_{c}\right)$ é bem definida, com uma janela $\Delta x \sim \alpha$ e uma altura proporcional a $1 / \alpha$, de maneira que a área total (o toque) é independente de $\alpha$. Isto funciona para o caso em que a altura e a janela são grandezas pequenas. Figura obtida em: Meyer-Vernet e Sicardy (1987).

Portanto, a Equação 5.50 fica na forma 


$$
\mathrm{T}_{m}=\frac{4 \pi^{2} \Sigma_{0} m A^{2}}{r_{\mathrm{p}} \mathcal{D}} \operatorname{sgn}(\alpha)
$$

Para um disco kepleriano, temos $\Omega \propto r^{-3 / 2}$, assim, da definição de $D(r)=\Omega^{2}-m^{2}(\Omega-$ $\left.\omega_{\mathrm{p}}\right)^{2}$, obtém-se

$$
\frac{d \mathcal{D}}{d r}=-\frac{3}{2} \Omega^{2}\left(1-m^{2}\right)-\frac{3}{2} m^{2} \Omega \omega_{\mathrm{p}}
$$

Logo

$$
\mathcal{D}=\frac{d D}{d r}=\frac{3}{r_{p}} \Omega_{m}\left[\Omega_{m}\left(1-m^{2}\right)+m^{2} \omega_{p}\right],
$$

que, com a Equação 5.32 , pode ser escrita como

$$
\mathcal{D}= \pm \frac{3 m}{r_{p}} \Omega_{m} \omega_{\mathrm{p}}
$$

Obtemos, finalmente, substituindo a Equação 5.57 na Equação 5.54, a fórmula final para o torque

$$
\mathrm{T}_{m}= \pm \frac{4 \pi^{2} \Sigma_{0} A^{2}}{3 \Omega_{m} \omega_{p}} \operatorname{sgn}(\alpha)
$$

Expressão idêntica à obtida por Goldreich e Tremaine (1980) para um torque exercido por um satélite num anel.

A magnitude de $\mathrm{T}_{m}$ para diferentes $m$ é mostrada na Figura 5.6. Inicialmente, $\mathrm{T}_{m}$ aumenta com o valor de $m$, todavia, depois de um certo valor de $m$, começa a decrescer. Esse pico, tradicionalmente conhecido como torque cutoff, ocorre devido a $r_{m}$ não tender mais a $r_{\mathrm{p}}$, mas, sim, a $r_{\mathrm{p}}+\frac{2}{3} h$.

Assumindo que o torque dado pela Equação 5.58 seja aplicado na vizinhança de $r_{\mathrm{p}}$, a soma desses torques pode ser considerada uma função suave de $r$, cuja densidade é dada por Goldreich e Tremaine (1980), na forma

$$
\frac{d}{d r}\left(\sum_{m} \mathrm{~T}_{m}\right)=\frac{32}{81} \tilde{K} \operatorname{sgn}\left(r-r_{\mathrm{p}}\right)\left(\frac{M_{\mathrm{p}}}{M_{\star}}\right)^{2} \Sigma r^{3} \Omega^{2}\left(\frac{r}{\Delta}\right)^{4},
$$

onde $\tilde{K}=\left[2 K_{0}(2 / 3)+2 K_{1}(2 / 3)\right]^{2}=6.35\left(K_{0}\right.$ e $K_{1}$ são funções modificadas de Bessel), mesmo resultado obtido usando o método de aproximações impulsivas, exceto por um fator numérico de 2.83 . 


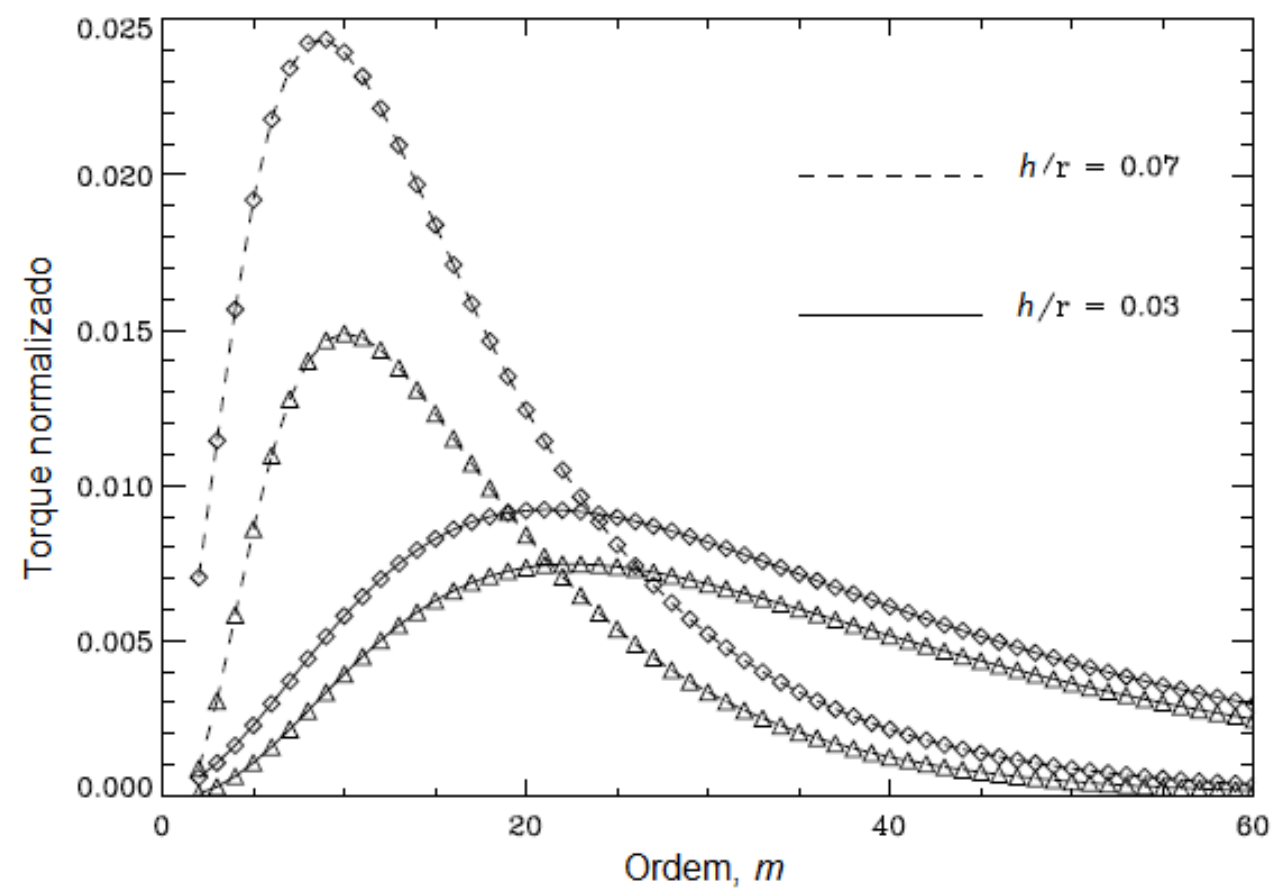

Figura 5.6: Torque $\mathrm{T}_{m}$, normalizado para $\mathrm{T}_{0}=\pi q \Sigma r_{\mathrm{p}}^{4} \Omega_{\mathrm{p}}^{2}(h / r)^{3}$, para duas diferentes razões de altura do disco. Os triângulos são usados para designar o torque interno e os diamantes para os torques externos. Figura obtida em: Papaloizou et al. (2007).

Portanto, o torque total é a integral da densidade do torque sobre todo o plano externo e interno do disco. Dado que o torque, em cada ressonância, é nulo entre $r_{\mathrm{p}}$ e $r_{\mathrm{m}}$, e que $r_{\mathrm{m}}$ se acumula em $r=r_{\mathrm{p}}+2 / 3 h$ para $m \rightarrow \infty$, a Equação 5.60 deve ser integrada de $\Delta=\frac{2}{3} h$ até $\infty$. Isto permite escrever

$$
\mathrm{T}=\frac{4}{27} \tilde{K} \operatorname{sgn}\left(r-r_{\mathrm{p}}\right)\left(\frac{M_{\mathrm{p}}}{M_{\star}}\right)^{2} \Sigma r^{3} \Omega_{\mathrm{p}}^{2}\left(\frac{r}{\Delta}\right)^{3} .
$$

A Figura 5.6 também mostra que o torque, na ressonância de Lindblad, no disco interno, não é exatamente o oposto ao disco externo, sendo o torque da parte externa do disco, maior, em módulo, ao valor da parte interna. Esse diferença gera um torque diferencial, chamado de torque diferencial de Lindblad, que é proporcional a $(h / r)^{2}$.

Uma análise mais completa, que inclui a ressonância de corrotação e um disco tridimensional, é descrita por Tanaka et al. (2002), que obteve a fórmula analítica para o torque entre o planeta e o disco, usada nesta dissertação, e cuja a forma é dada por

$$
\mathrm{T}_{\text {total }}=-(1.364+0.541 q)\left(\frac{M_{\mathrm{p}}}{M_{\star}}\right)^{2}\left(\frac{h}{r}\right)^{-2} \Sigma r_{\mathrm{p}}^{4} \Omega_{\mathrm{p}}^{2}
$$


no qual $h / r$ é a escala de altura e $q$ é o parâmetro usado para definir o perfil de densidade superficial de gás no disco $\left(\Sigma=\Sigma_{0} r^{-q}\right)$.

O torque total obtido depende da massa do planeta, portanto, o próximo passo é a adaptação de um modelo computacional que combine a formação planetária com o processo migratório, para que possamos estudar como esses processos podem, juntos, explicar a formação de um núcleo sólido num tempo coerente com a estimativa do tempo de vida do disco.

\subsection{Modelo computacional para formação planetária com a migração devido à interação com o disco}

Usando a Equação 5.61, podemos analisar o efeito da migração sobre a formação planetária e vice-versa. Como o torque total tem sinal negativo, a velocidade da migração radial $\dot{r}_{\mathrm{p}}$, é dada por

$$
\dot{r}_{\mathrm{p}}=\dot{L}_{\mathrm{p}}\left(\frac{d L_{\mathrm{p}}}{d r_{\mathrm{p}}}\right)^{-1}=-2 r_{\mathrm{p}} \frac{\mathrm{T}_{\text {total }}}{L_{\mathrm{p}}},
$$

onde o momento angular do planeta $L_{\mathrm{p}}$ é $M_{\mathrm{p}}\left(G M_{\star} r_{\mathrm{p}}\right)^{1 / 2}$. Substituindo a Equação 5.61 . obtém-se a expressão

$$
\dot{r}_{\mathrm{p}}=-\frac{2.7+1.1 q}{(h / r)^{2}} \frac{M_{\mathrm{p}}}{M_{\star}} \sqrt{G} \Sigma_{0} r^{1.5-q},
$$

onde $G$ é a constante gravitacional, $h / r$ é a razão de altura (usaremos $h=0.05 r$ ) e $q$ e $\Sigma_{0}$ são os parâmetros usados para definir o perfil de densidade superficial do gás $\left(\Sigma=\Sigma_{0} r^{-q}\right)$. O modelo de disco baseado na Nebulosa Solar já possui esses parâmetros (Equação 4.67). No entanto, precisamos ajustar os melhores parâmetros possíveis, usando o método dos minímos quadrados para o perfil de densidade superficial do gás do disco híbrido e do disco de acreção, discutidos no Capítulo 4. Os valores obtidos para cada tipo de disco do modelo híbrido (Tabela 4.1) são mostrados na Tabela 5.1 .

Como era de se esperar, o ajuste $q$ é próximo de $\gamma$. Para o disco de acreção $\left(\alpha=7 \times 10^{-3}\right.$ e $\dot{M}_{\text {st }}=10^{-9} M_{\odot} /$ ano), obteve-se $\Sigma_{0}=59.3$ e $q=0.58$. Vale destacar que, devido a curva de melhor ajuste para a densidade superficial do gás desse modelo ser a exponencial, os parâmetros obtidos fornecem um ajuste bastante aproximado. 
Tabela 5.1 - Ajuste do modelo híbrido

\begin{tabular}{lcccccc}
\hline \hline Disco & $M_{\text {disco }}\left(M_{\star}\right)$ & $a_{\mathrm{C}}(\mathrm{UA})$ & $a_{\text {int }}(\mathrm{UA})$ & $\gamma$ & $\Sigma_{0}\left(\mathrm{~g} \mathrm{~cm}^{-2}\right)$ & $q$ \\
\hline 1 & 0.029 & 46 & 0.14 & 0.9 & 657.5 & 0.94 \\
2 & 0.117 & 127 & 0.16 & 0.9 & 876.7 & 0.92 \\
3 & 0.143 & 198 & 0.10 & 0.7 & 271.2 & 0.70 \\
4 & 0.028 & 126 & 0.10 & 0.4 & 27.6 & 0.41 \\
5 & 0.136 & 80 & 0.10 & 0.9 & 1692.4 & 0.92 \\
6 & 0.077 & 153 & 0.12 & 1.0 & 706.1 & 1.02 \\
7 & 0.029 & 33 & 0.10 & 0.8 & 728.1 & 0.86 \\
8 & 0.004 & 20 & 0.10 & 0.8 & 182.8 & 0.91 \\
9 & 0.012 & 26 & 0.10 & 1.0 & 629.5 & 1.10 \\
10 & 0.007 & 26 & 0.10 & 1.1 & 450.5 & 1.20 \\
11 & 0.007 & 38 & 0.10 & 1.1 & 324.8 & 1.18 \\
12 & 0.011 & 14 & 0.10 & 0.8 & 764.6 & 0.97 \\
\hline \hline
\end{tabular}

Resolvendo numericamente a Equação 4.49 com a 5.63 , é possível analisar a formação planetária com a migração em decorrência da interação com o disco de gás. A Figura 5.7 mostra o gráfico da massa do protoplaneta, inicialmente com $0.01 \mathrm{M}_{\text {Terra }}$ em $6 \mathrm{UA}$, e seu semieixo maior em função do tempo para cada perfil de disco. A simulação é interrompida quando o núcleo sólido atinge $10 \mathrm{M}_{\text {Terra }}$ ou migre até $r=0.5 \mathrm{UA}$. Acima de $10 \mathrm{M}_{\text {Terra }}$ o núcleo começa a acretar gás e o modelo de formação utilizado deixa de ser válido, enquanto os núcleos que atingem $r=0.5$ UA serão considerados, devido à rápida migração, perdidos no envelope estelar.

A primeira característica que se nota em todos os modelos de disco é que o planeta migra rapidamente quando entra no regime de crescimento de tipo runaway, o que pode ser explicado pela dependência da massa na Equação 5.63. Isso é confirmado quando compara-se a migração dos planetas que crescem com planetesimais menores, que ganham massa rapidamente, com os que crescem com planetesimais maiores, que demoram mais para ganhar massa. 

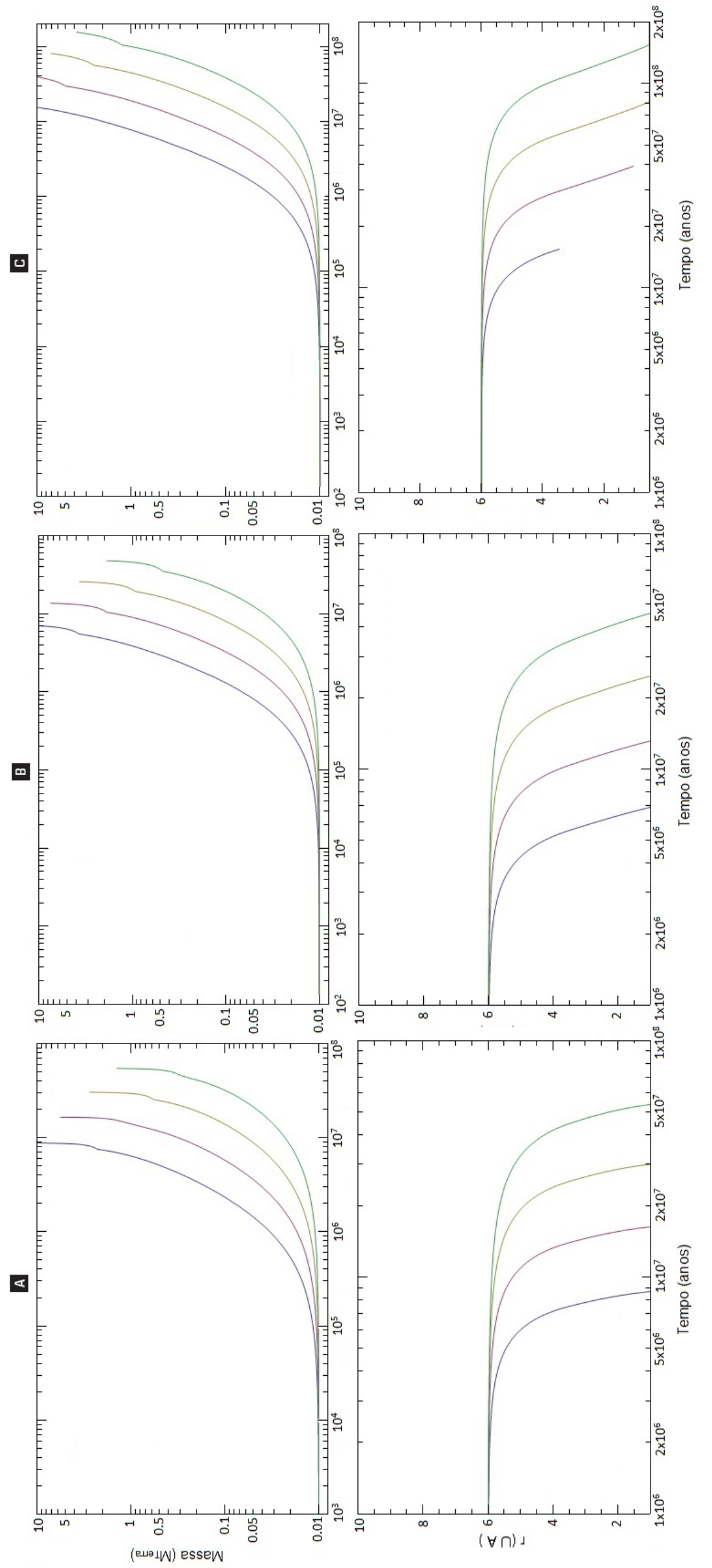

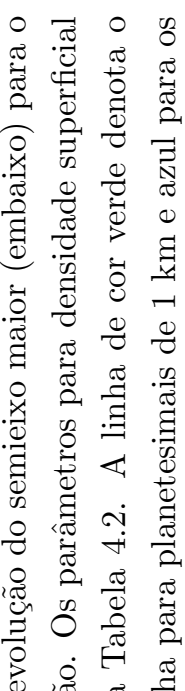


O leve desvio, presente em algumas curvas, ocorre quando o planeta atravessa a linha de gelo, onde há uma diferenciação da densidade dos planetesimais e na densidade superficial de planetesimais (Equação 4.66).

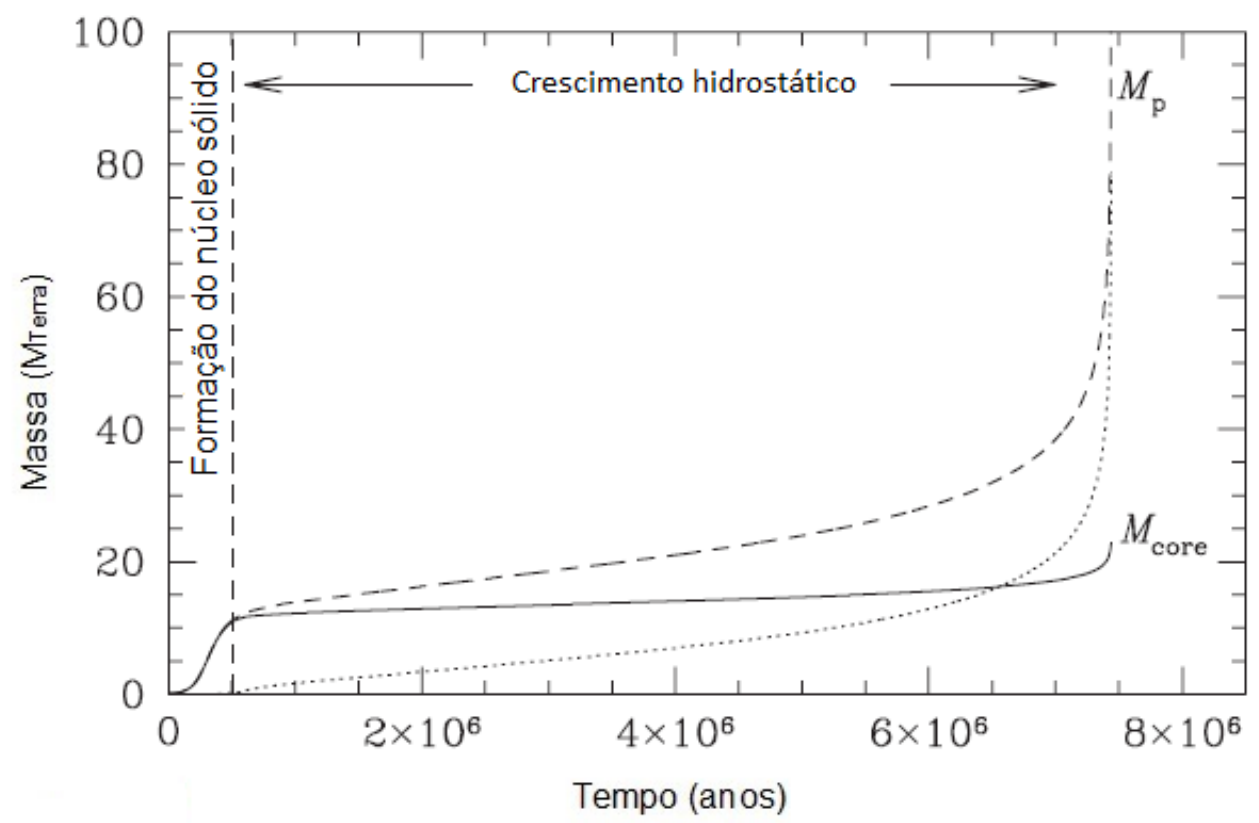

Figura 5.8: Evolução da massa do núcleo sólido (linha sólida), envelope do gás (linha pontilhada) e massa total (linha tracejada) em função do tempo. Neste modelo, um núcleo sólido cresce em um raio fixo de $5.2 \mathrm{UA}$ em um disco com densidade superficial de sólidos de 10 $\mathrm{g} \mathrm{cm}^{-2}$ e densidade superficial de gás de $7 \times 10^{2} \mathrm{~g} \mathrm{~cm}^{-2}$. Com esses parâmetros, é obtido um tempo curto para a formação do núcleo sólido. A divergência da linha tracejada é evitada na prática devido ao esgotamento de material do disco. Figura obtida em: Armitage (2010).

Nessas figuras, consideramos o tempo de vida do disco bem alto, da ordem de $10^{8}$ anos. A ideia é verificar o valor da massa atingida nesse tempo e se os núcleos sobreviveriam, antes de cair no envelope estelar. Em geral, como indica a Figura 5.8 obtida por Pollack et al. (1996), o núcleo sólido atinje um tamanho de $10 \mathrm{M}_{\text {Terra }}$ num período de, aproximadamente, $0.5 \times 10^{6}$ anos. No entanto, esse tempo é obtido sob determinadas circunstâncias que aceleram esse processo. De fato, Pollack et al. (1996) consideram que a inclinação dos planetesimais depende apenas da interação com outros planetesimais, de forma que a inclinação normalizada foi prescrita como $\tilde{i}=\frac{v_{\text {esc }}}{\sqrt{3} \Omega R_{\mathrm{H}}}$, o que implica uma inclinação constante e independente da massa do protoplaneta. Já as excentricidades são controladas pela interação entre os planetesimais e o protoplaneta e variam entre $\tilde{e}=(2 \tilde{i}, 2)$. Portanto, se $\tilde{e}=2 \tilde{i}$, o protoplaneta cresce num regime de runaway, pois a excentricidade e a inclinação não dependem da massa do planeta. Essas condições fazem com que o crescimento do 
núcleo sólido seja bem mais rápido do que o modelo usado nesta dissertação.

Percebe-se, para o modelo de Nebulosa Solar (Figura 5.7A), que os planetas, inicialmente em 6 UA e $0.01 \mathrm{M}_{\text {Terra }}$ são engolidos pela estrela num período entre $10^{7}-5 \times 10^{7}$ anos e, dificilmente, atingiriam a massa de $10 \mathrm{M}_{\text {Terra }}$ antes de caírem no envelope estelar. Para distâncias iniciais maiores para o protoplaneta, mais tempo demora o processo de formação, pois o menor valor para a densidade do gás implica um menor arrasto dos planetesimais, o que, consequentemente, dificulta a acreção. Isso mostra que, para o modelo de acreção utilizado, o perfil do modelo de Nebulosa Solar Mínima, com essas condições iniciais, não permite a formação de planetas gigantes, já que eles não conseguem atingir a massa crítica antes do tempo de vida do disco, da ordem de $10^{7}$ anos.

O modelo híbrido (Figura 5.7B) apresentou características similares ao da Nebulosa Solar. O crescimento para planetesimais da ordem de 0.1 e $1 \mathrm{~km}$ foi um pouco mais rápido, mas ainda insuficiente para permitir a formação de núcleos massivos num período de tempo adequado.

Por fim, com o modelo de acreção (Figura $5.7 \mathrm{C}$ ), foi possível obter um núcleo de 10 $\mathrm{M}_{\text {Terra }}$ sofrendo uma migração de 6 até $3.5 \mathrm{UA}$, para planetesimais de $0.1 \mathrm{~km}$, num tempo próximo de $1.5 \times 10^{7}$ anos. Entretanto, esse ainda é um tempo muito grande, não havendo mais gás remanescente no disco.

Todavia, os gráficos da Figura 5.7 foram obtidos usando certos parâmetros para o disco (Tabela 4.2), o que nos leva a questionar como estes podem influenciar os resultados. Vamos então explorar a variação dos parâmetros inicias e analisar a massa e o semieixo final do planeta para quatro tempos distintos em cada perfil de disco. Os parâmetros serão variados da seguinte forma: os raios dos planetesimais $(r)$ serão variados de 0.1 , $0.2, \ldots, 0.9,1,2, \ldots, 9,10,20, \ldots, 90,100 \mathrm{~km}$; a razão entre a quantidade de gás e de poeira $\left(f_{\mathrm{D} / \mathrm{G}}\right)$ de 0.03 até 0.125 variando de 0.005 ; a densidade volumétrica do bulbo de planetesimais $\left(\rho_{\mathrm{p}}\right)$ será 3 ou $6 \mathrm{~g} \mathrm{~cm}^{-3}$; o coeficiente de arrasto será 0.5 ou 1, a densidade do protoplaneta (d) será 4 ou $6 \mathrm{~g} \mathrm{~cm}^{-3}$ e a largura do raio de captura (b) 5 ou 10. Os gráficos a seguir representam, portanto, a situação final do planeta (massa e semieixo maior) para cada combinação desses valores iniciais com distâncias inicias de 3, 6 e 10 UA em cada perfil de disco. Foi escolhida uma maior variação para o raio do planetesimal e para a razão de quantidade de gás e poeira devido serem os fatores mais sensíveis do modelo. Vale lembrar que o perfil da Nebulosa Solar não varia com $f_{\mathrm{D} / \mathrm{G}}$; de qualquer forma, os outros 
parâmetros foram mantidos com a mesma variação.

A Figura 5.9A mostra as possibilidades obtidas para o modelo da Nebulosa Solar para um protoplaneta inicialmente em 3 UA. Observa-se que o protoplaneta poderia atingir uma massa de, no máximo, $0.12 \mathrm{M}_{\text {Terra }}$ em um tempo de $2 \times 10^{6}$ anos, e sua migração seria muito tênue, indo de 3 UA para 2.9 UA. Aumentando o tempo para $4 \times 10^{6}$ anos, seria possível encontrar um planeta de $0.6 \mathrm{M}_{\text {Terra }}$ em 2.5 UA. Tempos maiores cobrem um grande espectro de massas e poderiam, para certos parâmetros, resultar na queda do planeta na estrela. Vale ressaltar que a obtenção de massas da ordem de $1 \mathrm{M}_{\text {Terra }}$ só seria possível para tempos de vida maiores que $4 \times 10^{6}$ anos. Outra característica interessante é a rápida migração, que impossibilita a formação de planetas maiores que $5 \mathrm{M}_{\text {Terra }}$ entre 1 e 3 UA.

Para um protoplaneta começando em 6 UA (Figura $5.9 \mathrm{~B}$ ), nota-se que um tempo de $2 \times 10^{6}$ anos não é suficiente para formar núcleos muito massivos, obtendo-se no máximo a formação de um núcleo de $0.09 \mathrm{M}_{\text {Terra }}$ em, aproximadamente, $5.9 \mathrm{UA}$. Um tempo de formação de $4 \times 10^{6}$ anos não melhora esse cenário, obtendo-se, no máximo, um planeta de $0.3 \mathrm{M}_{\text {Terra }}$ em 5.7 UA. Tempos maiores, da ordem de $8 \times 10^{6}$ anos, permitem, sob a condição de melhores parâmetros, a formação de um planeta de até $3 \mathrm{M}_{\text {Terra }}$ em 2 UA. De fato, esse é um forte indicativo que mostra que para o perfil da Nebulosa Solar, a migração é muito mais rápida que a taxa de acreção do modelo considerado. Isso é um problema, já que torna impossível a formação de um núcleo, massivo o suficiente, num tempo hábil para a formação de um planeta gigante.

Em 10 UA o cenário é mais drástico, já que o tempo de vida de $8 \times 10^{6}$ anos permitiu, para as melhores condições iniciais, a formação de planetas de, no máximo, $0.1 \mathrm{M}_{\text {Terra }}$, isso se deve principalmente à baixa densidade do gás que não cria arrasto suficiente para facilitar a acreção de sólidos.

No entanto, devemos ressaltar algumas características que não foram usadas nesta dissertação e que podem favorecer a formação planetária. A primeira delas se refere à atmosfera planetária, de fato, se considerarmos um protoplaneta capturando uma parte do gás quando próximo de $0.5 \mathrm{M}_{\text {Terra }}$, essa atmosfera poderia favorecer uma maior captura de planetesimais, levando a um processo de acreção mais rápido. A segunda trata da imposição dos planetesimais numa situação de equilíbrio entre o arrasto e o impulso do protoplaneta (Equação 4.63), situações fora desse equilíbrio, principalmente para planetesimais menores, podem prover uma acreção mais rápida para o protoplaneta (Fortier et al., 2013). 

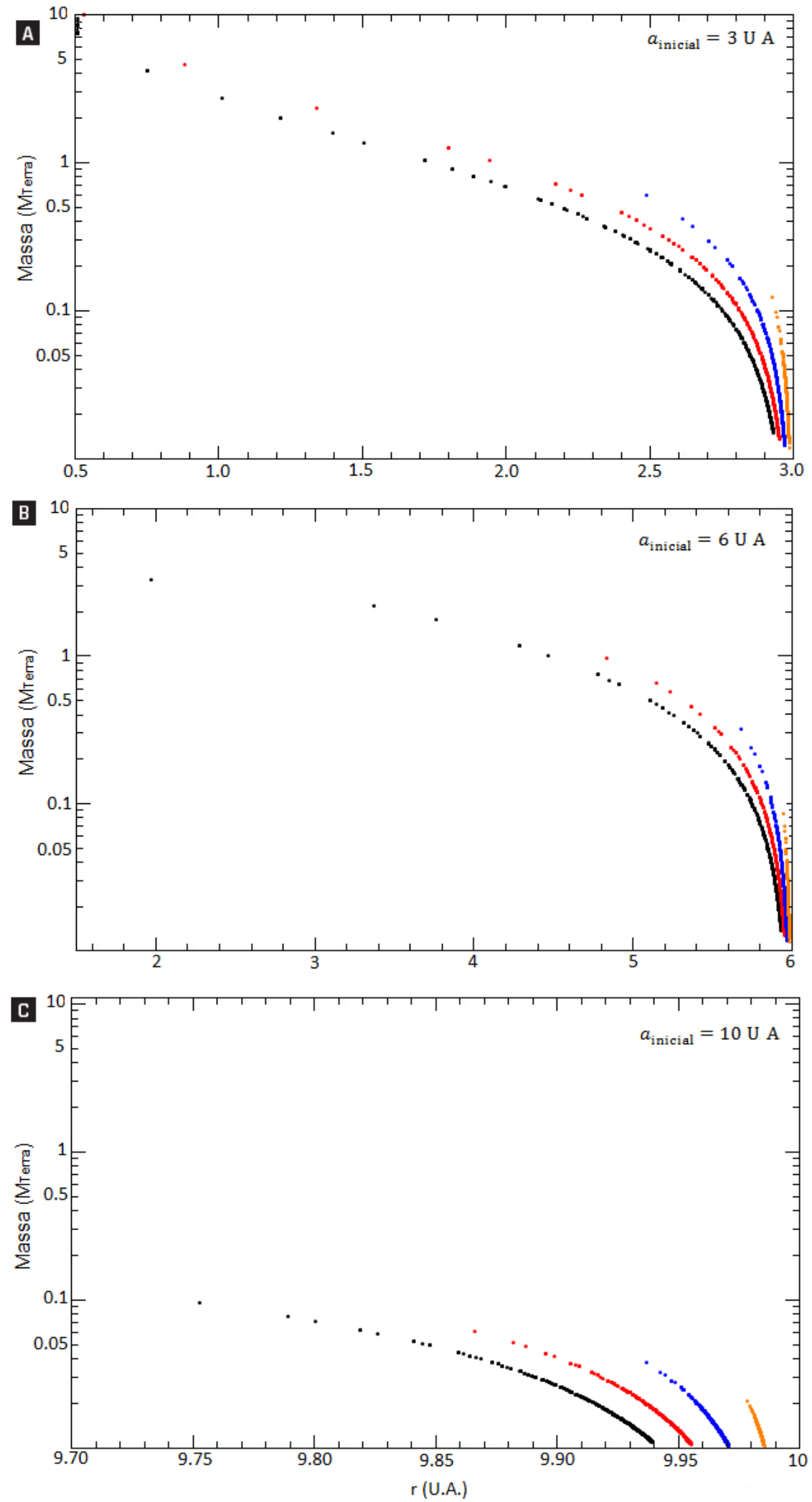

Figura 5.9: Possíveis valores para a configuração final do planeta (ou núcleo sólido) para o modelo da Nebulosa Solar. Os pontos laranjas são obtidos para um tempo de $2 \times 10^{6}$ anos, os pontos azuis para um tempo de $4 \times 10^{6}$ anos, os pontos vermelhos para um tempo de $6 \times 10^{6}$ anos e os pontos pretos para um tempo de $8 \times 10^{6}$. As distâncias iniciais do protoplaneta são (A) 3 UA, (B) 6 UA e (C) 10 UA. 
Analisando agora a variação dos parâmetros para o modelo híbrido (disco de tipo 1 da Tabela 4.70, obtemos a Figura 5.10. Notamos que esse perfil de disco permite a formação planetária numa ampla faixa de massas e semieixos, mesmo para um tempo de $2 \times 10^{6}$ anos e um protoplaneta inicialmente em 10 UA (Figura 5.10C). Foi possível encontrar, para a melhor condição dos parâmetros, um núcleo sólido de até $0.6 \mathrm{M}_{\text {Terra }}$, e de, aproximadamente, $10 \mathrm{M}_{\text {Terra }}$ para distâncias iniciais de 6 UA (Figura 5.10B). É interessante destacar que o protoplaneta é capaz de crescer mais rápido em 6 UA do que em 3 UA, em consequência da diferenciação da densidade dos planetesimais e da fração de sólidos que ocorre devido a linha de gelo (Equação 4.66). Assim, numa distância inicial de 3 UA foi obtida, para a melhor condição dos parâmetros, uma massa de $5.5 \mathrm{M}_{\text {Terra }}$, num tempo de $2 \times 10^{6}$ anos.

Esse amplo aspecto obtido para esse modelo se deve principalmente à variação da razão entre gás e poeira $\left(f_{\mathrm{D} / \mathrm{G}}\right)$. De fato, com uma maior metalicidade do disco, a formação planetária consegue ser mais rápida do que para o modelo da Nebulosa Solar, no qual a quantidade de sólidos possui uma equação com parâmetros fixos (Equação 4.68 e 4.69).

Para um protoplaneta, inicialmente em $3 \mathrm{UA}$, é possível obter num tempo de $4 \times 10^{6}$ anos, usando a melhor condição de parâmetros possível, um núcleo planetário de $10 \mathrm{M}_{\text {Terra }}$ em 1 UA. Para uma distância inicial de 6 UA, no mesmo tempo e nas melhores condições, obtém-se a mesma massa numa distância, aproximada, de 1.5 UA. E se, inicialmente em 10 UA, uma massa de $4.6 \mathrm{M}_{\text {Terra }}$ em 6.7 UA.

Os pontos na linha horizontal de $10 \mathrm{M}_{\text {Terra }}$ de todos os gráficos devem ser analisados com mais cuidado, pois a simulação é interrompida quando o núcleo atinge essa massa. Logo, o ponto azul em $10 \mathrm{M}_{\text {Terra }}$ indica que o núcleo atingiu essa massa entre $2 \times 10^{6}$ e $4 \times 10^{6}$ anos, pois não sabemos o momento exato em que a simulação foi interrompida.

Percebe-se então que a grande vantagem desse modelo foi a possibilidade de usar metalicidades diferentes para o disco, de modo a tornar possível uma acreção mais rápida de que o processo de migração tipo I, como podemos verificar em todos os gráficos, nenhum núcleo planetário caiu na estrela antes de atingir $10 \mathrm{M}_{\text {Terra. }}$. No entanto, essa acreção não foi tão rápida quanto no modelo de Pollack et al. (1996), que trabalha com uma faixa de $0.5 \times 10^{6}$ anos para obtenção de massas dessa ordem (Figura 5.8.

No modelo de disco em equilíbrio (Figura 5.11), o cenário não é tão promissor quanto é no híbrido. De fato, com um tempo da ordem de $8 \times 10^{6}$ anos, sob a melhor condição de parâmetros, foi possível obter apenas um núcleo planetário de $0.55 \mathrm{M}_{\text {Terra }}$ para uma 

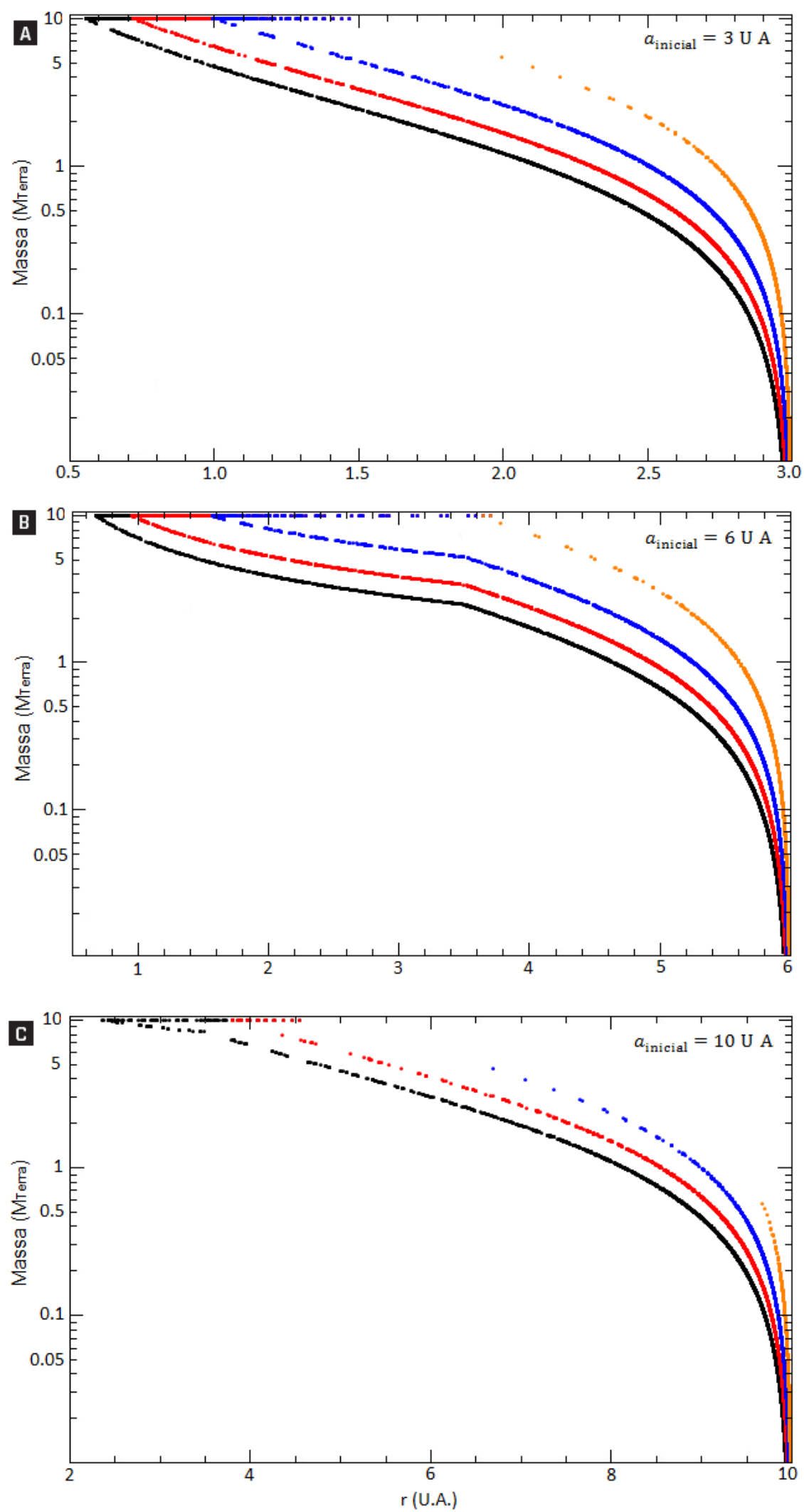

Figura 5.10: Possíveis valores para a configuração final do planeta (ou núcleo sólido) para o modelo da híbrido. Os pontos laranjas são obtidos para um tempo de $2 \times 10^{6}$ anos, os pontos azuis para um tempo de $4 \times 10^{6}$ anos, os pontos vermelhos para um tempo de $6 \times 10^{6}$ anos e os pontos pretos para um tempo de $8 \times 10^{6}$. As distâncias iniciais do protoplaneta são (A) 3 UA, (B) 6 UA e (C) 10 UA. 
distância inicial de 3 UA (Figura 5.11A), 1.2M Terra para uma distância inicial de 6 UA (Figura $5.11 \mathrm{~B}$ ) e $0.15 \mathrm{M}_{\text {Terra }}$ para uma distância inicial de 10 UA (Figura $5.11 \mathrm{C}$ ), todos com migrações bem baixas. Para este perfil, as taxas de acreção foram muito baixas, de modo que, mesmo para tempos altos, não foi possível que o planeta entrasse no regime de runaway, isso se deve, principalmente, ao decaimento exponencial da densidade superficial do gás.

Entretanto, esse perfil não pode ser descartado, pois diversas condições do disco podem mudar esse cenário. Primeiramente, trabalhamos com um disco de acreção com $\alpha$ constante $\left(\alpha=7 \times 10^{-3}\right)$, e, de fato, nada leva a crer que isso realmente ocorra. Além disso, foram desconsiderados a radiação da estrela e os mecanismos de aquecimento devido à poeira do disco, que podem mudar radicalmente esse cenário. A taxa de acreção que utilizamos também foi constante $\left(\dot{M}_{\text {st }}=10^{-9} \mathrm{M}_{\odot} /\right.$ ano $)$, e medidas observacionais mostram que essa taxa evolui com o tempo de vida do disco.

Vale destacar que muitos estudos de formação e migração planetária trabalham com uma massa inicial maior para o protoplaneta, da ordem de $0.1 \mathrm{M}_{\text {Terra }}$. Massas dessa ordem, obviamente, são capazes de acretar mais planetesimais e alcançar o regime de runaway mais rapidamente, permitindo a formação de núcleos sólidos de $10 \mathrm{M}_{\text {Terra }}$ em tempos menores que $2 \times 10^{6}$ anos. A falta de conhecimento, ou de modelos melhores, para a formação de planetesimais é um ponto que precisa ser melhor explorado para justificar massas dessa ordem. De fato, a escolha de uma massa inicial de $0.01 \mathrm{M}_{\text {Terra }}$, usada nesta dissertação, tomou como base o trabalho de Fortier et al. (2013), todavia, não há uma razão física que possa ser usada para descartar massas menores ou maiores.

Os perfis dos discos utilizados neste estudo, mostram como o cenário de formação planetária é sensível aos parâmetros livres do problema. Muitos autores justificam o uso de um fator númerico na taxa de migração entre 0.1 e 0.01, com o intuito de obter, principalmente para o perfil da Nebulosa Solar, uma taxa de migração menor que a taxa de acreção, o que torna possível a formação de núcleos sólidos maiores. Contudo, não há nenhuma razão física para essa adaptação. Principalmente, se levarmos em conta a possibilidade do uso de modelos de acreção mais complexos que possam mudar esse cenário.

De fato, o modelo híbrido mostra ser o perfil mais adequado, ou pelo menos, o que possui melhor ajuste de parâmetros capazes de explicar a evolução de sistemas planetários. Surge então a necessidade de maiores vínculos experimentais ou modelos computacionais 

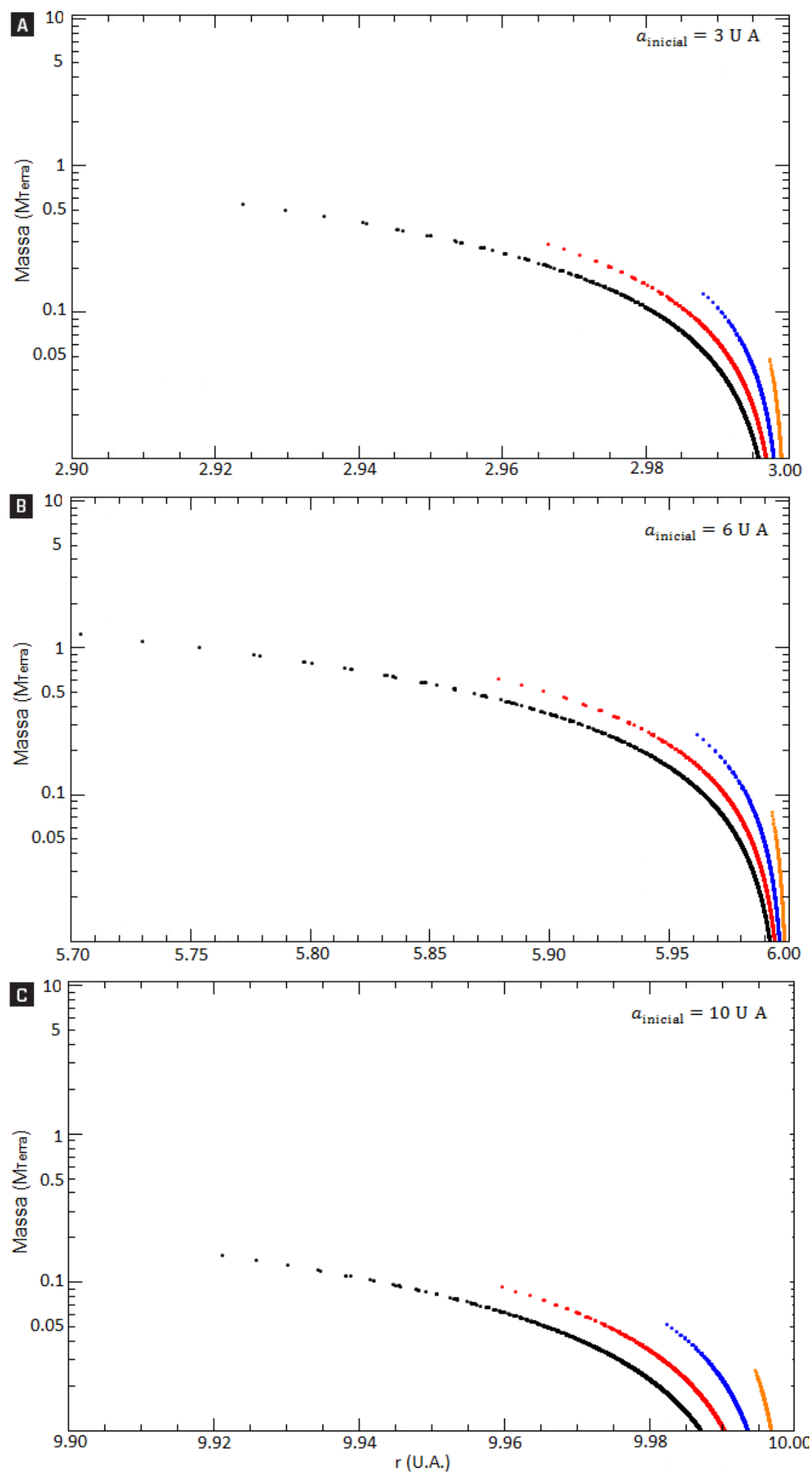

Figura 5.11: Possíveis valores para a configuração final do planeta (ou núcleo sólido) para o modelo de disco de acreção em equilíbrio. Os pontos laranjas são obtidos para um tempo de $2 \times 10^{6}$ anos, os pontos azuis para um tempo de $4 \times 10^{6}$ anos, os pontos vermelhos para um tempo de $6 \times 10^{6}$ anos e os pontos pretos para um tempo de $8 \times 10^{6}$. As distâncias iniciais do protoplaneta são (A) 3 UA, (B) 6 UA e (C) 10 UA. 
mais complexos, para obtenção de discos protoplanetários que sejam capazes de fornecer condições mais propícias para a formação do núcleo sólido num tempo adequado.

\subsection{Sumário}

Primeiramente, foi feita uma descrição dos principais tipos de migração em razão da interação do exoplaneta com o disco de gás. Entre elas, temos a migração tipo I, que ocorre por causa da perturbação que o planeta gera no disco protoplanetário, criando uma onda espiral de densidade responsável por torques entre o planeta e o disco de gás. Esse torque provoca mudanças dos parâmetros orbitais do planeta como, por exemplo, seu semieixo maior.

O torque produzido pelo planeta tende a abrir um gap no disco. No entanto, o gás tende a ocupar essa região vazia e a amenizar a queda brusca. Estes dois efeitos competem até que o planeta se torne massivo o suficiente, de modo que a formação do gap seja inevitável e o planeta entre na migração tipo II. Nesse tipo de migração, o planeta fica sujeito apenas às condições de evolução do disco, portanto, configura-se uma migração mais lenta.

Caso o gap seja parcial, o disco interno e o externo são separados por uma leve depressão que pode ser preenchida por gás, nesse caso, o planeta é capaz de transferir seu momento angular enviando o gás do disco interno para o disco externo, configurando uma migração runaway, chamada migração tipo III. Essa migração apresenta uma taxa que varia exponencialmente, todavia, num tempo de duração muito curto (Masset e Papaloizou, 2003).

Nesta dissertação, trabalha-se com a migração tipo I, para planetas com massas menores que $10 \mathrm{M}_{\text {Terra. }}$. Apresentamos então uma dedução usando o método de aproximações sucessivas e, em seguida, uma dedução usando as ressonâncias de Lindblad. Essas deduções não representam o cenário completo, mas fornecem as ideias iniciais para a compreensão de métodos mais avançados, como o encontrado em Tanaka et al. (2002).

Com a dedução do torque entre o disco de gás e o planeta, foi possível obter a taxa de migração e estudar como esta afeta a formação planetária e vice-versa. Para isso, usamos novamente os perfis de discos discutidos no Capítulo 4, são eles: Nebulosa Solar, híbrido e o modelo de disco de acreção do Capítulo 3.

Usando as mesmas condições iniciais do Capítulo 4 e um tempo de $10^{8}$ anos, obteve-se 
a Figura 5.7, que mostra a impossibilidade de se formar um núcleo sólido de $10 \mathrm{M}_{\text {Terra }}$ num tempo menor que o tempo de vida costumeiramente adotado para o disco, que é da ordem de $10 \times 10^{6}$ anos. No entanto, surge a questão sobre como a variação dos parâmetros iniciais poderiam influenciar esse cenário.

As Figuras 5.9, 5.10 e 5.11 são, justamente, a massa e o semieixo final do núcleo sólido, que poderiam ser obtidos através da variação dos parâmetros iniciais (descritos no capítulo) para o perfil da Nebulosa Solar, híbrido e para o disco de acreção do Capítulo 3, em quatro intervalos de tempo diferentes.

A análise revelou, que o modelo híbrido possui o perfil mais propício à formação de núcleos sólidos de $10 \mathrm{M}_{\text {Terra }}$, num tempo suficiente para que possa ocorrer a formação de um planeta gigante. De fato, foi possível obter núcleos planetários dessa ordem de massa num tempo de $2 \times 10^{6}$ anos em diferentes distâncias iniciais. Entretando, esse tempo ainda é maior do que o sugerido por Pollack et al. (1996), que utilizaram uma situação específica para excentricidades e inclinações dos planetesimais, permitindo alcançar um cenário de runaway num tempo mais curto.

Além disso, a análise mostra que é possível, através de maiores vínculos observacionais ou modelos computacionais mais complexos, favorecer o cenário de acreção de planetesimais, evitando fatores numéricos nas taxas de migração que aparecem sem uma justificativa física plausível nos modelos migratórios. 


\section{Capítulo 6}

\section{Conclusão e perspectivas}

A análise realizada nesta dissertação mostrou que a compreensão de um cenário global, que envolve desde o disco protoplanetário até a acreção de sólidos pelo protoplaneta, é essencial para um melhor entendimento da formação planetária de núcleos sólidos e dos processos de migração.

As mudanças nos perfis de densidade do gás e dos sólidos, obtidas com cada modelo de disco, mostraram a importância desses parâmetros no modelo de formação com migração planetária, indicando a necessidade de observações ou modelos mais complexos para o disco protoplanetário.

De fato, usando uma massa inicial de $0.01 \mathrm{M}_{\text {Terra }}$, o perfil de densidade para Nebulosa Solar, que varia com $r^{-3 / 2}$, que é costumeiramente usado nos estudos de formação e migração planetária, não foi possível, com o modelo de acreção adotado, obter núcleos massivos da ordem de $10 \mathrm{M}_{\text {Terra }}$ em tempo hábil para a formação de planetas gigantes. Isso ocorreu devido à rápida migração de tipo I, que faz com que esses núcleos caiam na estrela antes de conseguirem obter massa suficiente para entrar na fase de acreção de gás.

O modelo de Papaloizou e Terquem (1999) para o disco de acreção, descrito no Capítulo 3, não melhorou esse cenário. A obtenção de um perfil para densidade volumétrica de gás que decai de forma exponencial não permitiu a entrada no regime de crescimento de runaway num tempo adequado. No entanto, vimos que se trata de um modelo muito simples que desconsidera alguns processos físicos importantes tais como a irradiação da estrela, a condução de calor e a convecção, além disso, ele trata apenas do aquecimento devido ao gás e utiliza valores tabelados para opacidade que precisam ser atualizados. Modelos mais complexos, como o de D'Alessio et al. (1998), indicam que a poeira muda drasticamente o cenário físico do disco e, inclusive, reproduz melhor as medidas observacionais. 
Com o modelo híbrido, que utiliza dados observacionais para a densidade superficial de gás e uma estimativa para a densidade volumétrica do gás, foi possível, com a mudança dos parâmetros livres, obter núcleos de $10 \mathrm{M}_{\text {Terra }}$ num tempo da ordem de $2 \times 10^{6}$ anos, em distâncias de 3.5 UA. Isso mostra que é possível obter núcleos sólidos, massivos o suficiente para iniciar acreção de gás, sem que sejam engolidos pelo envelope estelar e sem necessidade de acrescentar fatores numéricos, ad hoc, no modelo de migração de tipo I.

Todavia, isso provoca novas questões: será a acreção de gás rápida o suficiente, de modo que o modelo permita que esse núcleo sólido se torne um planeta gigante sem que caia na estrela? Quais as condições necessárias para esse núcleo, com atmosfera, adentrar na migração de tipo II? Quanto tempo levará para abrir o gap? Após sofrer a migração de tipo II, esta será lenta o suficiente para que o planeta não caia na estrela? Essas questões serão exploradas num trabalho futuro, no qual a terceira fase, a acreção de gás, será acrescentada ao modelo.

Além disso, alguns parâmetros do modelo de acreção precisam ser melhor explorados. A fração entre a poeira e o gás, por exemplo, é feita com base numa estimativa baseada na metalicidade da estrela (Equação 4.66), e necessita de um embasamento físico mais aprofundadado, principalmente no que se refere à condensação dos elementos para além da linha de gelo. A própria evolução da linha de gelo pode ser um fator importante. Espera-se, num trabalho futuro, o uso de um disco protoplanetário mais complexo, tendo como ferramenta o código ANDES (Akimkin et al., 2013), que é pioneiro em considerar a influência da evolução da poeira na estrutura do disco, combinando os detalhes computacionais do campo de radiação com o modelo de crescimento da poeira, em conjunto com a fragmentação e sedimentação. Isso permitirá obter valores mais realistas para a densidade de gás e de poeira, assim como para a distribuição de temperatura.

Os dados observacionais, obtidos com Atacama Large Millimeter Array (ALMA), podem fornecer vínculos importantes para os modelos de formação planetária e, portanto, perspectivas para trabalhos científicos cooperativos. De fato, a detecção de exoplanetas em discos protoplanetários através da interferometria infravermelha e submilimétrica abre um enorme leque de possibilidades como, por exemplo, o estudo da abertura do gap na migração tipo II e a perspectiva de obtenção de perfis mais detalhados para densidade superficial e volumétrica do gás, parâmetros, que como vimos, são essenciais para uma modelagem mais completa da formação e migração planetária. Como exemplo das poten- 
cialidades do ALMA podemos citar o estudo de Fukagawa et al. (2013).

O tamanho dos planetesimais também se mostrou um parâmetro de importância para o tempo de formação do núcleo sólido, no modelo não há uma diferenciação de tamanho e essa situação precisa ser explorada.

O modelo utilizado nesta dissertação representa a situação de equilíbrio entre a interação com o protoplaneta e o arrasto do gás, o próximo passo é sair dessa condição e utilizar equações diferenciais que descrevam o arrasto devido ao gás, a interação do planetesimal com o protoplaneta e a interação entre os planetesimais.

Com o modelo computacional completo, será possível testar suas limitações e comparar os tempos de formação planetária com o tempo de vida do disco protoplanetário.

Além disso, o uso de diversas condições iniciais permitirá comparar os resultados do modelo com as principais medidas observacionais encontradas para os exoplanetas.

Outro ponto interessante será a análise da importância dos processos migratórios no cenário da formação planetária e a obtenção de vínculos que indiquem características importantes para a compreensão do nosso Sistema Solar. 


\section{Referências Bibliográficas}

Adams F. C., Lada C. J., Shu F. H., Spectral evolution of young stellar objects, ApJ, 1987, vol. 312 , p. 788

Agol E., Steffen J., Sari R., Clarkson W., On detecting terrestrial planets with timing of giant planet transits, MNRAS, 2005, vol. 359, p. 567

Akimkin V., Zhukovska S., Wiebe D., Semenov D., Pavlyuchenkov Y., Vasyunin A., Birnstiel T., Henning T., Protoplanetary Disk Structure with Grain Evolution: The ANDES Model, ApJ, 2013, vol. 766, p. 8

Amaral L. H., Lepine J. R. D., A self-consistent model of the spiral structure of the Galaxy, MNRAS, 1997, vol. 286, p. 885

Andre P., Montmerle T., From T Tauri stars to protostars: Circumstellar material and young stellar objects in the rho Ophiuchi cloud, ApJ, 1994, vol. 420, p. 837

Andrews S. M., Williams J. P., Circumstellar Dust Disks in Taurus-Auriga: The Submillimeter Perspective, ApJ, 2005, vol. 631, p. 1134

Andrews S. M., Wilner D. J., Hughes A. M., Qi C., Dullemond C. P., Protoplanetary Disk Structures in Ophiuchus. II. Extension to Fainter Sources, ApJ, 2010, vol. 723, p. 1241

Armitage P. J., Astrophysics of Planet Formation, 2010

Armitage P. J., Bonnell I. A., The brown dwarf desert as a consequence of orbital migration, MNRAS, 2002, vol. 330, p. L11

Beaugé C., Nesvorný D., Multiple-planet Scattering and the Origin of Hot Jupiters, ApJ, 2012, vol. 751, p. 119 
Bell K. R., Cassen P. M., Klahr H. H., Henning T., The Structure and Appearance of Protostellar Accretion Disks: Limits on Disk Flaring, ApJ, 1997, vol. 486, p. 372

Benítez-Llambay P., Masset F., Beaugé C., The mass-period distribution of close-in exoplanets, A\&A, 2011, vol. 528, p. A2

Boss A. P., Giant planet formation by gravitational instability., Science, 1997, vol. 276, p. 1836

Buchhave L. A., Latham D. W., Johansen A., Bizzarro An abundance of small exoplanets around stars with a wide range of metallicities, Nature, 2012, vol. 486, p. 375

Campbell B., Walker G. A. H., Yang S., A search for substellar companions to solar-type stars, ApJ, 1988a, vol. 331, p. 902

Campbell B., Walker G. A. H., Yang S., A search for substellar companions to solar-type stars, ApJ, 1988b, vol. 331, p. 902

Cattani M., Elementos de mecânica dos fluídos. São Paulo, Edgard Blücher, 1990

Chambers J., A semi-analytic model for oligarchic growth, Icarus, 2006, vol. 180, p. 496

Cochran W. D., Hatzes A. P., Hancock T. J., Constraints on the companion object to HD 114762, ApJ, 1991, vol. 380, p. L35

Crida A., Planetary Migration in Solar System Formation, Université de Nice SophiaAntipolis, 2006, Phd thesis

Crida A., Morbidelli A., Masset F., Type II Migration and Cavity Opening in Protoplanetary Disks. In AAS/Division for Planetary Sciences Meeting Abstracts \#38, vol. 38 of Bulletin of the American Astronomical Society, 2006, p. 611

D’Alessio P., Canto J., Calvet N., Lizano S., Accretion Disks around Young Objects. I. The Detailed Vertical Structure, ApJ, 1998, vol. 500, p. 411

Davis T. A., Wheatley P. J., Evidence for a lost population of close-in exoplanets, MNRAS, 2009, vol. 396, p. 1012

Fortier A., Alibert Y., Carron F., Benz W., Dittkrist K.-M., Planet formation models: the interplay with the planetesimal disc, A\&A, 2013, vol. 549, p. A44 
Fukagawa M., Tsukagoshi T., Momose M., Saigo K., Ohashi N., Kitamura Y., Inutsuka S.i., Muto T., Nomura H., Takeuchi T., Kobayashi H., Hanawa T., Akiyama E., Honda M., Fujiwara H., Kataoka A., Takahashi S. Z., Shibai H., Local Enhancement of the Surface Density in the Protoplanetary Ring Surrounding HD 142527, PASJ, 2013, vol. 65, p. L14

Furlan E., Hartmann L., Calvet N., D’Alessio P., Franco-Hernández R., Forrest W. J., Watson D. M., Uchida K. I., Sargent B., Green J. D., Keller L. D., Herter T. L., A Survey and Analysis of Spitzer Infrared Spectrograph Spectra of T Tauri Stars in Taurus, ApJS, 2006, vol. 165, p. 568

Giannini E., Lunine J. I., Microlensing detection of extrasolar planets, Reports on Progress in Physics, 2013, vol. 76, p. 056901

Goldreich P., Tremaine S., Disk-satellite interactions, ApJ, 1980, vol. 241, p. 425

Goodman A. A., Benson P. J., Fuller G. A., Myers P. C., Dense cores in dark clouds. VIII - Velocity gradients, ApJ, 1993, vol. 406, p. 528

Greenberg R., Bottke W. F., Carusi A., Valsecchi G. B., Planetary accretion rates - Analytical derivation, Icarus, 1991, vol. 94, p. 98

Grether D., Lineweaver C. H., How Dry is the Brown Dwarf Desert? Quantifying the Relative Number of Planets, Brown Dwarfs, and Stellar Companions around Nearby Sun-like Stars, ApJ, 2006, vol. 640, p. 1051

Hartmann L., Calvet N., Gullbring E., D'Alessio P., Accretion and the Evolution of T Tauri Disks, ApJ, 1998, vol. 495, p. 385

Hatzes A. P., Cochran W. D., Endl M., McArthur B., Paulson D. B., Walker G. A. H., Campbell B., Yang S., A Planetary Companion to $\gamma$ Cephei A, ApJ, 2003, vol. 599, p. 1383

Hayashi C., Structure of the Solar Nebula, Growth and Decay of Magnetic Fields and Effects of Magnetic and Turbulent Viscosities on the Nebula, Progress of Theoretical Physics Supplement, 1981, vol. 70, p. 35 
Henon M., Petit J.-M., Series expansion for encounter-type solutions of Hill's problem, Celestial Mechanics, 1986, vol. 38, p. 67

Hornung P., Pellat R., Barge P., Thermal velocity equilibrium in the protoplanetary cloud, Icarus, 1985, vol. 64, p. 295

Ida S., Stirring and dynamical friction rates of planetesimals in the solar gravitational field, Icarus, 1990, vol. 88, p. 129

Inaba S., Wetherill G. W., Tanaka H., Nakazawa K., A New Statistical Simulation of Planetary Accretion. In Lunar and Planetary Institute Science Conference Abstracts , vol. 31 of Lunar and Planetary Institute Science Conference Abstracts, 2000, p. 1048

Johnson J. A., Aller K. M., Howard A. W., Crepp J. R., Giant Planet Occurrence in the Stellar Mass-Metallicity Plane, PASP, 2010, vol. 122, p. 905

Kalas P., Graham J. R., Chiang E., Fitzgerald M. P., Clampin M., Kite E. S., Stapelfeldt K., Marois C., Krist J., Optical Images of an Exosolar Planet 25 Light-Years from Earth, Science, 2008, vol. 322, p. 1345

Kenyon S. J., Hartmann L., Spectral energy distributions of T Tauri stars - Disk flaring and limits on accretion, ApJ, 1987, vol. 323, p. 714

Kepler S., Astromomia e astrofísica. São Paulo, Editora Livraria da Física, 2 Edição, 2004

Lada C. J., Wilking B. A., The nature of the embedded population in the Rho Ophiuchi dark cloud - Mid-infrared observations, ApJ, 1984, vol. 287, p. 610

Latham D. W., Stefanik R. P., Mazeh T., Mayor M., Burki G., The unseen companion of HD114762 - A probable brown dwarf, Nature, 1989, vol. 339, p. 38

Lépine J., A Via Láctea, Nossa Ilha no Universo. EDUSP, 2008

Lequeux J., The Interstellar Medium, 2005

Lin D. N. C., Papaloizou J., Tidal torques on accretion discs in binary systems with extreme mass ratios, MNRAS, 1979, vol. 186, p. 799

Lissauer J. J., Planet formation, ARA\&A, 1993, vol. 31, p. 129 
Lynden-Bell D., Kalnajs A. J., On the generating mechanism of spiral structure, MNRAS, 1972, vol. 157 , p. 1

Ma B., Ge J., Statistical Properties of Brown Dwarf Companions: Implications for Different Formation Mechanisms, ArXiv e-prints, 2013

Maciel W. J., Hidrodinâmica de ventos estelares: uma introdução. São Paulo, EDUSP, 2003

Marcy G. W., Benitz K. J., A search for substellar companions to low-mass stars, ApJ, 1989, vol. 344 , p. 441

Masset F. S., Papaloizou J. C. B., Runaway Migration and the Formation of Hot Jupiters, ApJ, 2003, vol. 588, p. 494

Mayor M., Queloz D., A Jupiter-mass companion to a solar-type star, Nature, 1995, vol. 378 , p. 355

McKee C. F., Ostriker E. C., Theory of Star Formation, ARA\&A, 2007, vol. 45, p. 565

Meyer-Vernet N., Sicardy B., On the physics of resonant disk-satellite interaction, Icarus, 1987, vol. 69, p. 157

Murray C. D., Dermott S. F., Solar system dynamics, 1999

Nelson R. P., On the orbital evolution of low mass protoplanets in turbulent, magnetised disks, A\&A, 2005, vol. 443, p. 1067

Olliver M., Encrenaz T., Roques F., Selsis F., Casoli F., Planetary System - Detection, Formation and Habitability of Extrasolar Planets. Springer, 2009

Papaloizou J. C. B., Nelson R. P., Kley W., Masset F. S., Artymowicz P., Disk-Planet Interactions During Planet Formation, Protostars and Planets V, 2007, pp 655-668

Papaloizou J. C. B., Terquem C., Critical Protoplanetary Core Masses in Protoplanetary Disks and the Formation of Short-Period Giant Planets, ApJ, 1999, vol. 521, p. 823

Perryman M., The exoplanet handbook. Cambrige University Press, 2011 
Pollack J. B., Hubickyj O., Bodenheimer P., Lissauer J. J., Podolak M., Greenzweig Y., Formation of the Giant Planets by Concurrent Accretion of Solids and Gas, Icarus, 1996, vol. 124 , p. 62

Pringle J. E., Accretion discs in astrophysics, ARA\&A, 1981, vol. 19, p. 137

Raghavan D., McAlister H. A., Henry T. J., Latham D. W., Marcy G. W., Mason B. D., Gies D. R., White R. J., ten Brummelaar T. A., A Survey of Stellar Families: Multiplicity of Solar-type Stars, ApJS, 2010, vol. 190, p. 1

Rossiter R. A., On the detection of an effect of rotation during eclipse in the velocity of the brigher component of beta Lyrae, and on the constancy of velocity of this system., ApJ, 1924, vol. 60, p. 15

Safronov V. S., Evolution of the protoplanetary cloud and formation of the earth and planets., 1972

Santos N. C., Israelian G., Mayor M., Rebolo R., Udry S., Statistical properties of exoplanets. II. Metallicity, orbital parameters, and space velocities, A\&A, 2003, vol. 398, p. 363

Santos N. C., Mayor M., Queloz D., Udry S., Extra-solar planets, The Messenger, 2002, vol. 110, p. 32

Shakura N. I., Sunyaev R. A., Black holes in binary systems. Observational appearance., A\&A, 1973, vol. 24, p. 337

Shu F. H., Waves in planetary rings. In IAU Colloq. 75: Planetary Rings , 1984, p. 513

Smoluchowski M. V., Drei Vortrage uber Diffusion, Brownsche Bewegung und Koagulation von Kolloidteilchen, Zeitschrift fur Physik, 1916, vol. 17, p. 557

Souza F. D. M., Algoritmos genéticos aplicados á estimativa de parâmetros na resolução de equações diferenciais de discos protoplanetários, UESC, Universidade Estadual de Santa Cruz, Ilhéus-BA, 2008, Mestrado

Stewart G. R., Ida S., Velocity Evolution of Planetesimals: Unified Analytical Formulas and Comparisons with N-Body Simulations, Icarus, 2000, vol. 143, p. 28 
Stewart G. R., Wetherill G. W., Evolution of planetesimal velocities, Icarus, 1988, vol. 74, p. 542

Takeuchi T., Lin D. N. C., Radial Flow of Dust Particles in Accretion Disks, ApJ, 2002, vol. 581, p. 1344

Tanaka H., Takeuchi T., Ward W. R., Three-Dimensional Interaction between a Planet and an Isothermal Gaseous Disk. I. Corotation and Lindblad Torques and Planet Migration, ApJ, 2002, vol. 565, p. 1257

Udry S., Mayor M., Santos N. C., Statistical properties of exoplanets. I. The period distribution: Constraints for the migration scenario, A\&A, 2003, vol. 407, p. 369

Weidenschilling S. J., The distribution of mass in the planetary system and solar nebula, Ap\&SS, 1977, vol. 51, p. 153

Wolszczan A., Frail D. A., A planetary system around the millisecond pulsar PSR1257 + 12, Nature, 1992, vol. 355, p. 145

Wright J. T., Fakhouri O., Marcy G. W., Han E., Feng Y., Johnson J. A., Howard A. W., Fischer D. A., Valenti J. A., Anderson J., Piskunov N., The Exoplanet Orbit Database, PASP, 2011, vol. 123, p. 412

Zucker S., Mazeh T., On the Mass-Period Correlation of the Extrasolar Planets, ApJ, 2002, vol. 568, p. L113 
Apêndice 



\section{Apêndice A}

\section{Dedução dos parâmetros de Oorst's}

Em 1920, Bertil Lindblad e Jan Oort, estudando a rotação do disco Galáctico, descobriam que as estrelas movem-se, com relação ao Sol, sistematicamente em função da longitude galáctica, introduzindo os valores $A$ e $B$ para parametrizar o campo de velocidade local. Iremos usar o mesmo processo para estudar o campo de velocidade ao redor de uma estrela.

Imaginemos um referencial inercial $O$ localizado numa distância $R_{0}$ da estrela $S$ e um elemento massivo orbitando-a numa distância $r$. A velocidade tangencial da estrela em relação ao ponto $O$ é $V\left(R_{0}\right) \equiv V_{0}$ e a do elemento é $V(R)$ (Fig. A.1).

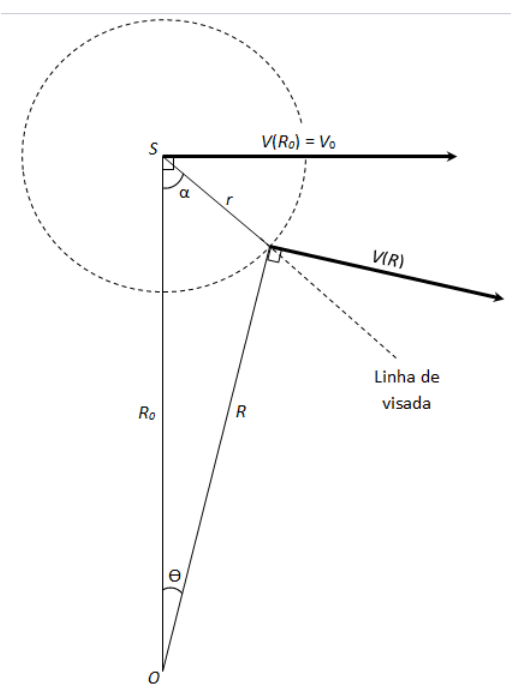

Figura A.1: Em relação ao observador $O$, a estrela possui velocidade tangencial $V_{0}$ e o elemento que a orbita possui velocidade $V(R)$.

Da Figura A.1, obtemos: $\Delta R \simeq R_{0}-R \simeq r \cos \alpha$ e $\theta \simeq \frac{r \sin \alpha}{R_{0}}$.

Para obter a velocidade relativa do elemento em relação à estrela, subtraímos vetorialmente suas velocidades, como mostra a Figura A.2. 


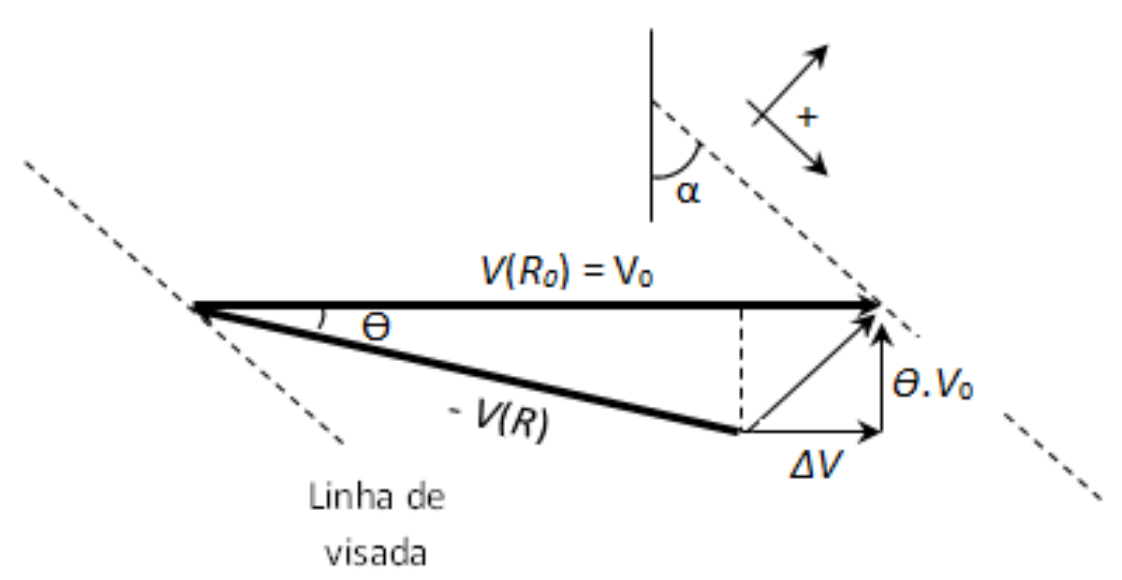

Figura A.2: Velocidade relativa do elemento em relação à estrela.

A diferença vetorial de velocidade pode ser expressa em termos de duas componentes, cujo módulo tem um valor aproximado de $\triangle V$ e $\theta V_{0}$. Decompondo essas componentes na direção radial e tangencial à linha de visada, verificamos que seus módulos são respectivamente

$$
V_{r}=-\theta V_{0} \cos \alpha+\triangle V \sin \alpha
$$

e

$$
V_{t}=\theta V_{0} \sin \alpha+\triangle V \cos \alpha
$$

onde

$$
\triangle V=V\left(R_{0}\right)-V(R) \simeq \triangle R \frac{d V}{d R} \simeq r \cos \alpha \frac{d V}{d R} .
$$

Das equações A.1 e A.3 usando $\theta \simeq \frac{r \sin \alpha}{R_{0}}$, obtemos

$$
\begin{gathered}
V_{r}=-\frac{V_{0}}{R_{0}} r \sin \alpha \cos \alpha+\frac{d V}{d R} r \sin \alpha \cos \alpha \Rightarrow \\
\Rightarrow V_{r}=r \sin \alpha \cos \alpha\left(\frac{d V}{d R}-\frac{V_{0}}{R_{0}}\right) \Rightarrow \\
\Rightarrow V_{r}=A R \sin 2 \alpha
\end{gathered}
$$

em que

$$
A=\frac{1}{2}\left(\frac{d V}{d R}-\frac{V_{0}}{R_{0}}\right)_{R_{0}}
$$


que é o primeiro parâmetro de Oort relacionado com o campo de velocidade radial.

Agora, considerando as equações A.2 e A.3 e usando $\theta \simeq \frac{r \sin \alpha}{R_{0}}$, obtemos

$$
\begin{gathered}
V_{t}=\frac{V_{0}}{R_{0}} r \sin ^{2} \alpha+\frac{d V}{d R} r \cos ^{2} \alpha \Rightarrow \\
\Rightarrow V_{t}=\frac{1}{2}\left(\frac{d V}{d R}+\frac{V_{0}}{R_{0}}\right) r\left(\cos ^{2} \alpha+\sin ^{2} \alpha\right)+\frac{1}{2}\left(\frac{d V}{d R}-\frac{V_{0}}{R_{0}}\right) r\left(\cos ^{2} \alpha-\sin ^{2} \alpha\right) \Rightarrow \\
\Rightarrow V_{t}=\frac{1}{2}\left(\frac{d V}{d R}+\frac{V_{0}}{R_{0}}\right) r+\frac{1}{2}\left(\frac{d V}{d R}-\frac{V_{0}}{R_{0}}\right) r \cos 2 \alpha \Rightarrow \\
\Rightarrow V_{t}=B r+A r \cos 2 \alpha,
\end{gathered}
$$

em que

$$
B=\frac{1}{2}\left(\frac{d V}{d R}+\frac{V_{0}}{R_{0}}\right)_{R}
$$

é o segundo parâmetro de Oort e está relacionado com a rotação local ou vorticidade do campo de velocidade. 


\section{Apêndice B}

\section{Condições de fronteira para a estrutura vertical do disco protoplanetário}

Deduziremos aqui as condições de contorno usadas para o modelo computacional de um disco de acreção 3.7.1.

Usando a densidade óptica $\tau(z)=\int_{0}^{z} \rho \kappa z d z$, obtemos $\frac{d \tau}{d z}=\rho \kappa$, assim, podemos reescrever a Equação 3.30 na forma

$$
\frac{1}{\rho} \frac{d P}{d \tau} \rho \kappa=-\Omega^{2} z \Rightarrow \frac{d P}{d \tau}=-\frac{\Omega^{2} z}{\kappa} .
$$

Integrando a equação, acima da superfície, até o infinito, no qual $P=0$, obtemos

$$
P_{\mathrm{s}}=\int_{\tau(h)}^{\tau(\infty)} \frac{\Omega^{2} z}{\kappa} d \tau .
$$

Para um disco com atmosfera aproximadamente isotérmica, a principal contribuição da integral vem dos valores de $z$ um pouco acima da superfície do disco, da ordem de $c_{\mathrm{s}} / \Omega$, que é bem menor que $h$. Isso permite tomar $\Omega^{2} z$ e $\kappa$ como aproximadamente constantes e iguais a seus valores na superfície. Assim

$$
P_{\mathrm{s}}=\frac{\Omega^{2} h \tau_{\mathrm{AB}}}{\kappa_{\mathrm{s}}},
$$

onde $\tau_{\mathrm{AB}}=\int_{h}^{\infty} d \tau$ é a densidade óptica do disco. Como consideramos a atmosfera acima do disco isotérmica, tomamos $\tau_{\mathrm{AB}} \ll 1$. Satisfeita essa condição, os resultados não dependerão do valor de $\tau_{\mathrm{AB}}$.

A outra condição de contorno é obtida integrando a Equação 3.31 entre $h$ e $-h, \log o$

$$
\int_{F_{\mathrm{s}, \text { acima }}}^{F_{\mathrm{s}, \text { abaixo }}} \delta F=\int_{-h}^{h} \frac{9}{4} \rho \nu \Omega^{2} \delta z
$$


Como se trata de um disco simétrico no qual o fluxo no plano médio é nulo, obtemos

$$
2 F_{\mathrm{s}}=\frac{9}{4} \Omega^{2} \int_{-h}^{h} \rho \nu \delta z
$$

Usando a definição de viscosidade média $\langle\nu\rangle=\int_{-h}^{h} \frac{\rho \nu}{\Sigma} \delta z$, podemos escrever

$$
2 F_{\mathrm{s}}=\frac{9}{4} \Omega^{2} \Sigma\langle\nu\rangle
$$

Como $\dot{M}=3 \pi \Sigma\langle\nu\rangle$, ficamos com

$$
F_{\mathrm{s}}=\frac{3 \dot{M} \Omega^{2}}{8 \pi}
$$

Por fim, a última condição de contorno é uma expressão para a temperatura na superfície. O fluxo radioativo na superfície pode ser escrito na forma

$$
F_{\mathrm{s}}=F_{+}-F_{-}
$$

em que o sinal negativo denota a orientação do fluxo de acordo com o eixo $z$, que está orientado para cima.

Sendo a temperatura de fundo denotada por $T_{\mathrm{b}}$, podemos escrever $F_{-}=\sigma T_{\mathrm{b}}^{4}$. Logo, da Equação B.7, temos

$$
F_{+}=\frac{3 \dot{M} \Omega^{2}}{8 \pi}+\sigma T_{\mathrm{b}}^{4}
$$

Outra expressão para $F_{+}$pode ser obtida usando a densidade de energia dada por

$$
E_{\mathrm{s}}=\frac{2 F}{c}=\frac{2\left(F_{+}+F_{-}\right)}{c}
$$

junto com a equação de energia

$$
\nabla \cdot \vec{F}=\rho \kappa c\left(a T^{4}-E\right)
$$

onde $F$ é o vetor que representa o fluxo de energia, $E$ é a densidade de energia, $c$ é a velocidade da luz e $a=\frac{4 \sigma}{c}$ é a constante de radiação.

Em um disco fino, o gradiente de temperatura vertical é muito maior que o horizontal, de modo que 


$$
\nabla \cdot \vec{F}=\frac{\delta F}{\delta z}=\frac{9}{4} \rho \nu \Omega^{2}
$$

Substituindo a relação acima e a B.10 na B.11, obtém-se

$$
F_{+}=2 \sigma T_{\mathrm{s}}^{4}-\sigma T_{\mathrm{b}}^{4}-\frac{9 \alpha c_{\mathrm{s}}^{2} \Omega}{8 \kappa_{\mathrm{s}}}
$$

onde $\nu$ foi expresso em termos de $\alpha$ através da relação 3.34. Igualando as duas expressões obtidas para $F_{+}$, obtemos a terceira e última condição de contorno

$$
2 \sigma\left(T_{\mathrm{s}}^{4}-T_{b}^{4}\right)-\frac{9 \alpha k T_{s} \Omega}{8 \mu m_{H} \kappa_{s}}-\frac{3}{8 \pi} \dot{M}_{\mathrm{st}} \Omega^{2}=0 .
$$

